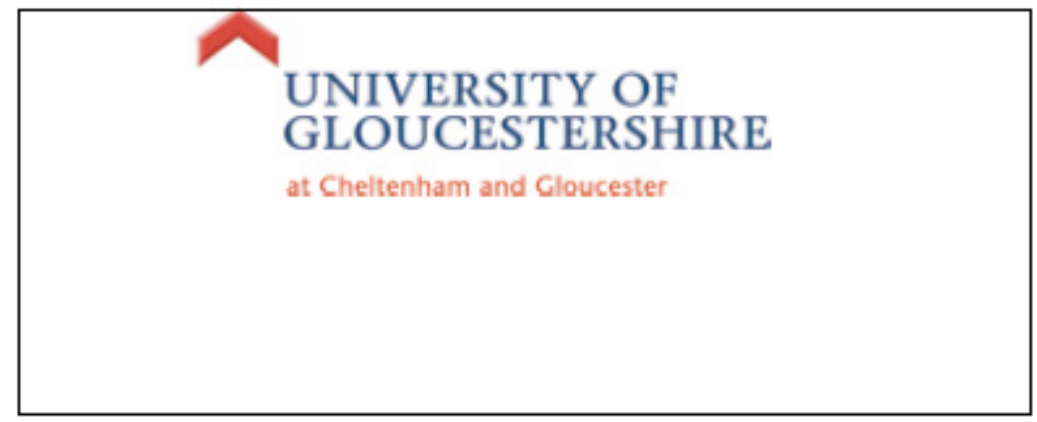

DBA Thesis

University of Gloucestershire

at Cheltenham and Gloucester

\title{
Doctorate in Business Administration
}

Ayse Yilmaz

\section{Change management and cultural factors:}

A study of German and Chinese middle-managers'

behaviour in a Sino-German automobile joint ventures

First advisor: Professor Dr Marc Helmold

Second advisor: Dr Sue Williams

A thesis submitted to the University of Gloucestershire in accordance with the requirements of the degree Doctor in Business Administration (DBA) in the Faculty of Business, Education and Professional Studies.

February 2020 


\section{Abstract}

Purpose and objective: The study sought to establish a conceptual framework model (Figure 12, p. 104) for, and to make recommendations for automobile producing companies involved in a Sino-German joint venture based in China. The objective of this thesis was to understand the perspectives of German and Chinese middle managers working in a cross-cultural environment to enhance their collaborative work. My aim was to add to knowledge of decision-making processes in this context and to assist middle managers with understanding cultural differences in order to reduce staff resistance to change.

Design and methodology: The study follows a constructivist philosophy and was conducted according to a descriptive qualitative method, using semi-structured interviews with German and Chinese middle managers working together in the same department in Beijing. The key literature that underpinned the study was based on Albach et al. (2015), Wooldridge et al. (2008) and Ghemawat and Reiche’s (2011) research and concepts. The data obtained were clustered using the Zwicky Box method (Table 5, p. 87; Zwicky, 1969) and a decision matrix (Table 4, p. 86; Lorenz, 2010) to discover the main topics to process as the findings and recommendations. The interview method assisted with the ethical obligation to maintain anonymity, which was essential as the interview partners were sources of in-depth information required to develop the practice-based framework for middle managers.

Findings: My findings concern matters such as cultural differences, language issues, hierarchical structures, compliance, relationship-building, technical improvements, good management skills, and corporate culture in joint ventures. The need to improve communication and information flow for middle managers by means of a communication model (Figure 12, p. 104) is a significant finding, as are improving cross-cultural qualifications and instituting appropriate hiring practices.

Contribution to knowledge and practice: My findings make a significant contribution to the topic of complex cross-cultural collaboration in joint ventures. The research presents an appropriate communication model and establishes a conceptual framework.

Research limitations and implications: The implementation of the model in other industries should be the subject of further research, as it has not yet been implemented. 


\section{Author's declaration}

I declare that the work in this thesis was carried out in accordance with the regulations of the University of Gloucestershire and is original except where indicated by specific reference in the text. No part of the thesis has been submitted as part of any other academic award. The thesis has not been presented to any other education institution in the United Kingdom or overseas. Any views expressed in the thesis are those of the author and in no way represent those of the University.

Signed Date

2903.2019 
For

Asya Irem Yilmaz,

Emir Yilmaz, and

Noah Mikail Keklik 


\section{毛里之行，始於足下}

(cin lei zi hang, ci jyu zuk haa)

A journey of a thousand miles begins with a single step.

(Chinese Proverb: Laozi, in the Tao Te Ching, Chapter 64) 


\section{Acknowledgements}

First, I would like to say that many people supported and travelled the path of my research journey with me. It is very important for me to say thank you to all of the people who supported me and gave me direction and the strength to move forward. I would like to thank all of you very much for providing me with guidance, valuable support, and trust during my research.

I would like to thank Professor Dr Marc Helmold of the International University of Applied Sciences Bad Honnef. You are very special person to me and I hope that our paths cross again in future. Before I move on to the next journey in my life, I would like to take a moment to extend my deepest and sincerest thanks to you. I also want to thank Dr Sue Williams, lecturer at the University of Gloucestershire at Cheltenham and Gloucester. I truly appreciate that I have had this wonderful opportunity to work with you and to learn from you. You have so much experience to share. All of the support and feedback I received from you to improve my work to a level of excellence was amazing. I also want to mention the great support I have received from staff of the University of Gloucestershire, to Dr Philippa Ward, Dr Keith Donne and Charley Sercombe, for their great support with all kinds of issues I had during the three-year research path. Dr Philippa Ward especially was always a great support for me. Her experience and guidance always helped me to advance my work.

Management research always depends on the offerings of organisations. I want to say thank you to Beijing Automobile Consulting Firm (BACF). This is the pseudonym given by me - as the author of this Doctorate in Business Administration (DBA) thesis - to an organisation which wishes to remain anonymous. The department that is key to this study was part of their production line. BACF gave me their trust and the opportunity to obtain their support for this analysis. Thank you for your friendliness, openness, and honesty. In particular, many thanks to all of the participants in the interviews that are a central component of this study. Your input was essential to my work and has contributed extensively to science and research in the field of culture and change management. This work adds knowledge to management practice.

Finally, thank you to my family who supported and always motivated me to move forward, and to take the time to finalise my doctorate within the planned timeframe. 
Table of contents

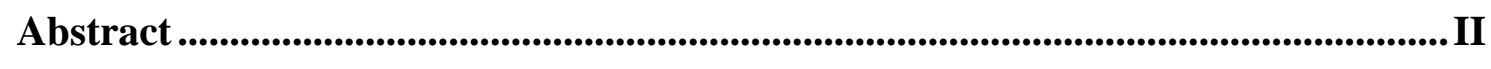

Acknowledgements.................................................................................................................

Table of contents............................................................................................................ 4

List of tables and figures....................................................................................................... 7

List of abbreviations and acronyms ............................................................................. 8

Chapter 1: Research Background .............................................................................9

1.1 Introduction: Industrial Automotive Manufacturing Companies....................... 9

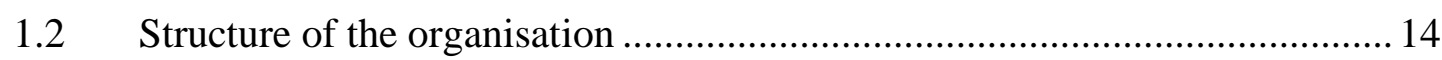

1.2.1 The concept of process management ............................................................. 15

1.2.2 The concept of cultural differences ............................................................... 17

1.2.3 The concept of relationship-building ............................................................. 19

1.3 The Standing of the Research........................................................................... 20

$1.4 \quad$ Research Questions and Objectives .................................................................25

1.5 Summary and Interim Conclusion................................................................. 27

Chapter 2: Definition of Terms and the Impact of Cultural Influences on Middle

Managers in a Joint Venture........................................................................................... 30

2.1 Key Concepts and Discussions of the Definitions of Terms............................. 30

$2.2 \quad$ National and Corporate Culture ........................................................................ 45

2.3 Conceptual Framework, Summary, and Interim Conclusion ........................... 54

Chapter 3: Methodology and Methods.......................................................................56

$3.1 \quad$ The Case-Study Organisation........................................................................ 57

3.2 The Research Case Study ……………………………………………..... 59

3.2.1 Systematic literature review ........................................................................ 59

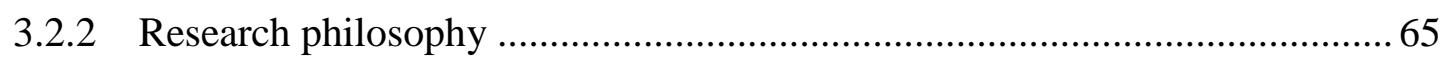

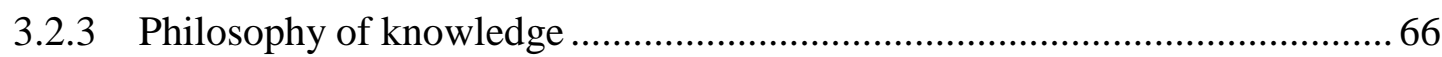

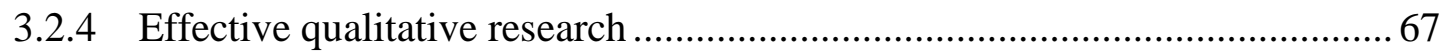

3.3 Collection Technique Used in the Interviews and Data Collection Process .. 69

3.3.1 Introductory meeting .............................................................................. 70

3.3.2 Pilot interviews with the 2 lean manufacturing experts ................................. 73

3.3.3 Sample participants ................................................................................... 76

3.3.4 Conducting the interviews.......................................................................... 77

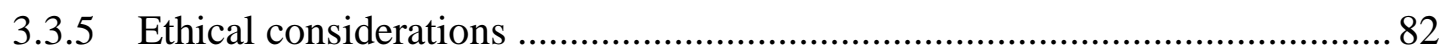


3.4 Analysis and Presentation of the Collected Data .......................................... 83

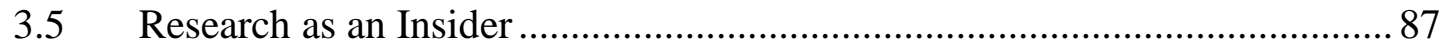

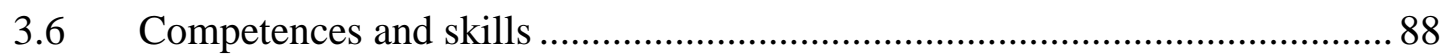

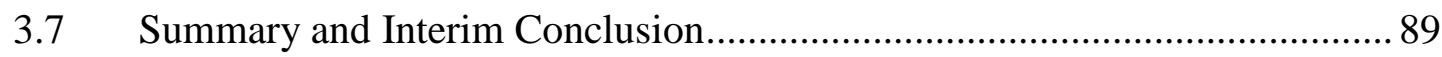

Chapter 4: Findings, analysis of the data, and observations by the researcher ..... 92

4.1 Findings from the pilot interviews ............................................................ 92

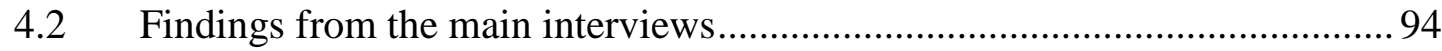

4.2.1 Communication, information flow, and collaboration ................................97

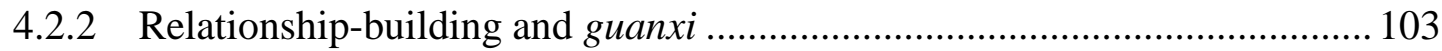

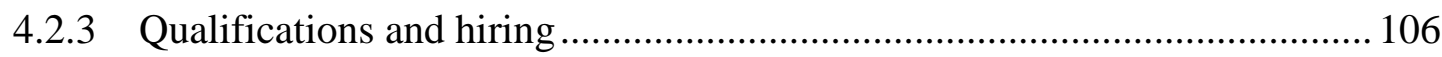

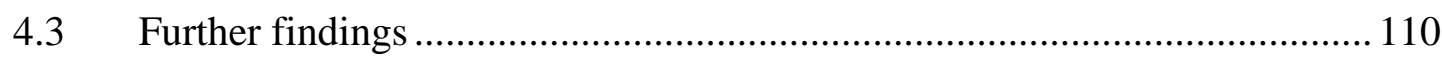

4.3.1 Change management practice................................................................ 110

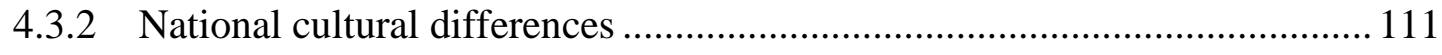

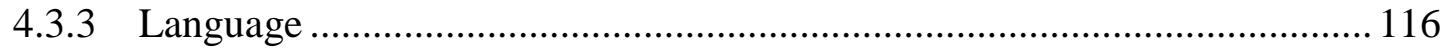

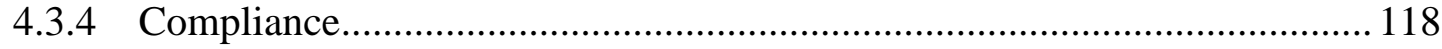

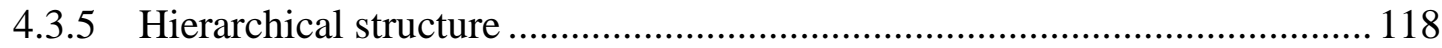

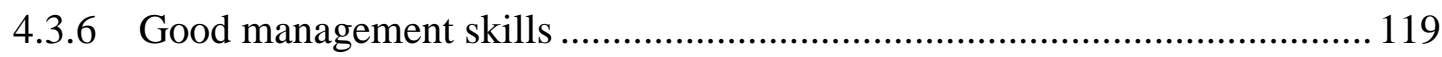

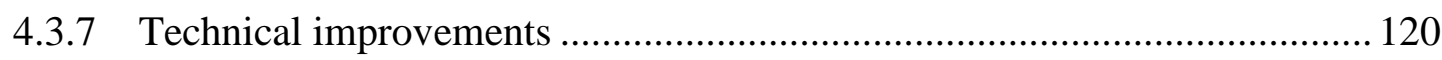

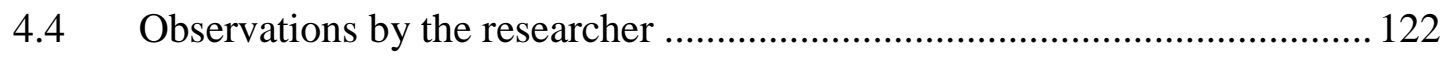

4.5 The working atmosphere in the joint venture.............................................. 126

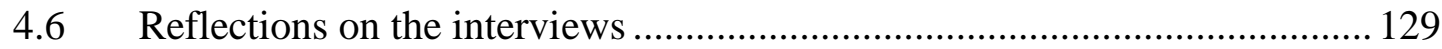

4.7 Summary and interim conclusion.............................................................. 132

Chapter 5: Achieving the Aims and Objectives of the Study............................. 134

$5.1 \quad$ Achieving the aim of this study.............................................................. 135

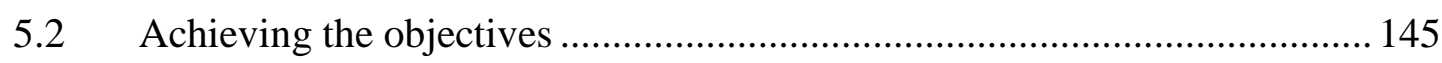

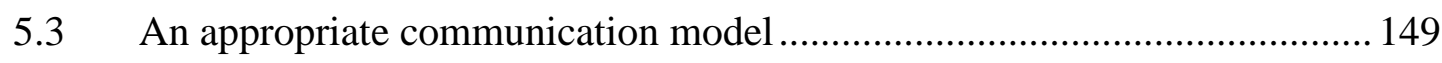

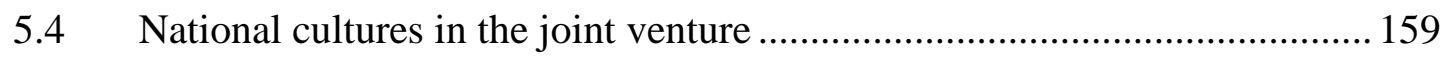

$5.5 \quad$ Summary and interim conclusion.............................................................. 159

Chapter 6: Contribution to Knowledge and Practice ............................................ 161

6.1 Conclusion: research gap and research conclusion .................................... 161

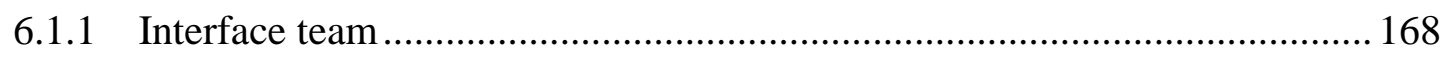

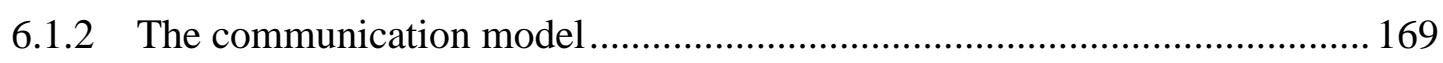

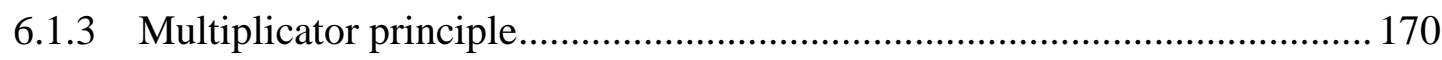

6.1.4 Understanding national culture ............................................................... 171 
6.1.5 Combining national culture and change management .............................. 172

6.1.6 The corporate culture of automotive joint ventures ................................. 172

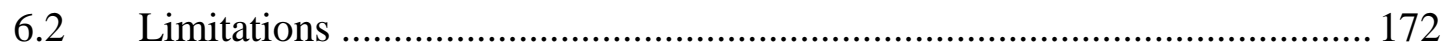

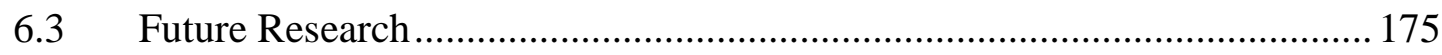

Chapter 7: Reflection............................................................................ 177

7.1 Research Journey and Professional Development....................................... 177

7.2 Research Choice and Philosophical Attitude .............................................. 180

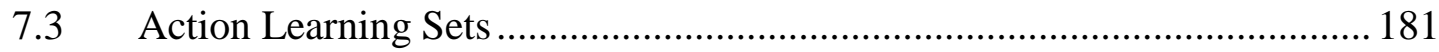

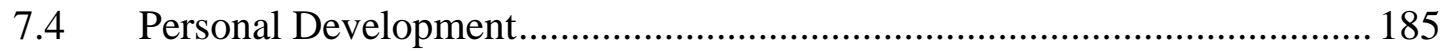

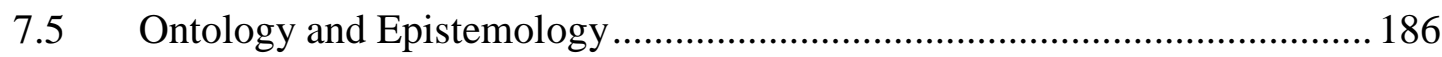

7.6 Impact on Research Questions and Interview Method................................ 188

7.7 Reflective Professional Development: The Future ..................................... 190

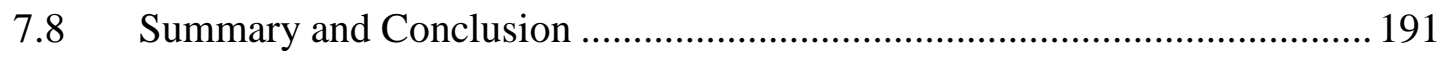

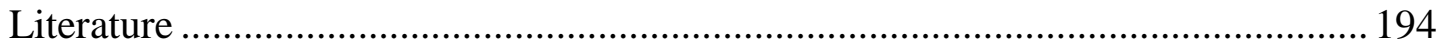

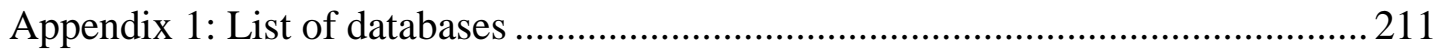

Appendix 2: Meta-analysis of the systematic literature review .............................. 212

Appendix 3: Comparison of approaches in relation to research questions .............. 214

Appendix 4: Questionnaire for the Pilot................................................................. 222

Appendix 5: Interviews with the middle managers .............................................. 224

Appendix 6: Morphological box for building a concept of collaboration

in joint venture and enhance a culture of learning due to change management.......239

Appendix 7: DB8004: Research methods assignment and Analysis DB8004 ......... 251 


\section{List of tables and figures}

Figure 1: The change spectrum 36

Figure 2: Sender-receiver model 43

Figure 3: The three dimensions of professional competence $\quad 44$

Figure 4: Schein’s organisational culture model $\quad 50$

Figure 5: Conceptual framework

Figure 6: The focus of the literature review 60

$\begin{array}{ll}\text { Figure 7: Steps to writing a literature review } & 61\end{array}$

Table 1: Inclusion and exclusion criteria $\quad 64$

Figure 8: Semi-structured interview sequence: preparation, main, and closing phases $\quad 70$

Figure 9: The list of questions for the interviews $\quad 75$

Table 2: Information relating to the middle managers $\quad 76$

Table 3: The interview participants $\quad 77$

Table 4: The decision matrix $\quad 85$

Table 5: The Zwicky box $\quad 86$

Figure 10: The researcher's ontological viewpoint $\quad 91$

Figure 11: The revised conceptual framework 95

Table 6: Morphological box showing the communication concept 99

Figure 12: Communication model middle managers 102

$\begin{array}{ll}\text { Figure 13: Future Plan } & 191\end{array}$ 


\section{List of abbreviations and acronyms}

BACF: Beijing Automobile Company Firm

DBA: Doctorate in Business Administration

DHBW: Duale Hochschule Baden-Wuerttemberg

TROPICS: Time Scales, Resources, Objectives, Perceptions, Interest, Control, and Sources 


\section{Chapter 1: Research Background}

This doctoral study addresses the issue of change management in an intercultural environment in the automotive sector, specifically, the influence of Chinese and German cultures in a joint venture. The focus is on middle managers and their relationships with employees. The literature review (Section 3.2.1, p. 58 ff.) highlights a wide range of aspects pertaining to such relationships and provides a number of diverse supporting factors of methods how to support employee level (Ala \& Cordeiro, 1999; Albach, Meffert, Pinkwart \& Reichwald, 2015; Beer, Eisenstat \& Spector 1990; Berner, 2012; Wooldridge et al., 2008). However, there is very limited information on how middle managers manage change and communicate it to employees, especially regarding collaboration in a joint venture between Germany and China (SpeierWerner, 2006; Thommen \& Grösser, 2012). The objective of this thesis is therefore to understand the perspectives of managers in a cross-cultural environment and to develop a conceptual framework with recommendations for enhancing current working collaboration by considering the main findings of semi-structured interviews with members of the relevant department, the production department in the joint venture in Beijing.

In Chapter 1, I introduce the research background of my thesis divided into five sections. Section 1.1 provides an introduction to the automotive segment of the observed company which is described in terms of its historical development and the immense growth of the automotive industry, especially in China, where the research and analysis was conducted. The cooperation between the two companies is introduced. Germany is home to the central headquarters and China to the joint venture. Section 1.2 is divided in three sub-sections which describe the concept of process management, cultural differences, and the concept of relationship-building. In the literature review, these form significant components of my conceptual framework. In Section 1.3, the standing of the research and its significance is explained. In Section 1.4, the research questions and objectives are defined. And in last section, Section 1.5 summarises the chapter by means of an interim conclusion. Similar interim conclusions form last section of each chapter throughout the whole thesis.

\subsection{Introduction: Industrial Automotive Manufacturing Companies}

The automotive industry was established in the early 1890s when cars began to replace horsedrawn carriages (Rost, 2014; Bakos, Miller, Packham, Pickernell \& Brychan, 2016). The automotive industry offers some of the highest returns on investment of any industry (Nieswandt, 2015). In 2009, China became the world leader in automotive production, with 
13.8 million units produced (Chin, 2010). Chin (2010) explains the importance of Chinese production for the world, noting that such an increase in production and the success of Chinese firms were once unthinkable. Business alliances are now being formed and will continue to be in coming years. As Chin (2010) states, China's automotive industry began in the mid-1990s, much later than those of Europe and elsewhere. A boom in the market at the time meant that manufacturers quickly arrived in China and commenced producing vehicles.

Continual adaptation is important because corporations operate in constantly changing economic, social, political, and cultural conditions. Worldwide synergistic effects and valueadded processes, as well as general social transformation, make it necessary to manage integral, all-encompassing, and long-term change projects (Krulis-Randa \& Ergenzinger, 1998). The Chinese production sector must gain a foothold in automobile production, and European companies require partners in China to develop local production plants and effortless deliveries to customers.

This study focuses on cultural change management, particularly on middle managers and their experience of intercultural frameworks in which organisations from two countries work together in a joint venture collaboration (Chapter 2, p. 29 ff.). Ghemawat and Reiche (2011) are one of the main academic sources used here as regards change management, culture, and management behaviour in cross-cultural cooperation (Chapter 2). I selected a vehicle production company with its central headquarters in Germany and an international joint venture that is in operation in China for comparison and analysis. This was a matter of convenience due to as I work for the same company; as an insider researcher (Section 3.5, p. $85 \mathrm{f}$.) and I had the double function of working for the company and writing my thesis same time - with a view to proposing improvements in international cooperation and collaboration. The German plant and its experienced employees provide the standards and process knowhow. China hosts the joint venture company, which has its plant in Beijing and retains 51\% of the revenue from the products sold. The plant in Beijing principally employs local staff, though there is a clear rule regarding how many managers should be placed there by the German plant. Some positions related to planning and engineering are staffed only by Germans in order to build a bridge to the headquarters and keep the joint venture updated by means of a strong network. This also ensures that the same standards are applied in all plants around the world that produce the same brand for the central headquarter based in Germany. These standards include the instructions for the process of assembling the car and IT systems Section 1.2.1, p. 15 ff.), which are centrally organised and controlled. 
The central headquarters in Germany has automobile producing plants across the world. It is due to internationalisation and the better fulfilment of market demands, as well as cost savings, that 'low-cost plants abroad' have been opened. Some have a similar joint venture structure (Section 2.1, p. 29 f.), with other companies as the cooperative partner that builds the cars for the central German automobile brand, while others are sub-companies. The joint venture in China produces for the local market, as well as China-specific cars which are not produced and sold in other plants. The plant in China is the largest foreign production plant of the headquarters and produces the most vehicles globally for this brand. It also has many middle managers from Germany on-site which makes it of interest for my study as I was able to write my thesis in China after interviewing a variety of middle managers who are the focus group of my work. The production plant in China also manufactures electric cars for this automobile brand. This Chinese plant is a low-cost plant abroad which focuses on planning, with the main aim of producing low-cost production vehicles. German and Chinese employees and managers work together and communicate in English. This third language brings along another challenge for the collaboration; this was a finding from the interview sessions (Section 4.3.3, p. 114 ff.). On the production lines, the operators do not speak English; rather they communicate with their direct group-leaders in Chinese. The managers, engineers, and planners have to be able to speak English well in order to communicate with one another and with other plants across the world in order to share information and conduct exchange meetings on-site or via video or telephone conference calls. English proficiency is thus a criterion for hiring local employees and for the on-boarding of experts and managers from other plants, especially from the central headquarters in Germany.

The firm selected for this study produces a popular brand of vehicle and has expanded its car production worldwide. It is referred to here as 'Beijing Automotive Company Future' (BACF). The company considers Germany the competence centre since the contract and cooperation with China began at the central plant there. Furthermore, the German plant, as the brand centre of the automobile produced in China, has a considerable number of personnel with substantial experience and has developed processes (Section 1.2.1, p. 15 f.). Managers refer to the production plant as the 'lead plant', while a 'competence centre' is any site where employees with an array of competences and a deep knowledge of the relevant processes are found. These terms are used synonymously in this study. Production of this brand of vehicle takes place under the general management of the lead plant in Germany, which is thus the competence centre. For BACF, this plant plays a supporting role in responding to technological and quality management issues for each new start-up location that results from 
the business cooperation. The lead company in the joint venture collaboration provides customers with a guarantee of high standards in all production plants. In this case, the German plant takes the lead function and sets the standards for production. For the purposes of the research observations here, as an expert, I travelled and mid of 2017 later moved to the plant in Beijing to conduct on-site interviews with production department middle managers from both countries. At the time, the German managers were working in China as expatriates, while the local Chinese middle managers were on-site in Beijing to oversee demands and processes. Middle managers (Section 2.1, p. 30), the focus group for my study, are the managers who have strategic function between the upper-level management and the staff level. They are the fulcrum between these two levels (Wooldridge et al., 2008). Wooldridge et al. (2008, p. 3) are referring to the 'middle management perspective'. I focus on the question of whether those middle managers working in the joint venture collaboration need to adapt culturally to changing situations in national and corporate culture when they work with staff from different cultures (Section 1.2.3, p. 19). The staff is mixed in the sense that local employees from China are hired to work here and German expatriates are taken over from the central headquarters to support the local staff. The expatriates are responsible for disseminating the standards and knowledge from the central headquarters and for teaching the local employees. Middle managers require support in dealing with a cooperative global business and with changing working conditions and processes, especially in joint ventures with foreign firms. In this context, the goal of the managers is to provide an effective, efficient, and structured organisational framework to give their subordinates confidence regarding forthcoming changes (Ali \& Ivanov, 2015). For the middle managers from aboard, it is of course not possible to remain in that position for a lengthy period, as is for local middle managers. The time period for the German middle managers working aboard in the same place is limited due to tax regulations, which limit it to five years, and company regulations, which limit it to seven years. This is highlighted in the analysis of the interview results (Chapter 4, p. $90 \mathrm{ff}$.). The choice of methodology for this thesis was based upon the need to gauge the perspectives of all the middle managers in one department, namely the vehicle production department. Qualitative research allows for the evaluation of standpoints, feelings, and ways of thinking (Bryman \& Bell, 2007). Kotter (1996) presents a guideline for managers of change projects, though others assert that every project has a unique character and must be dealt with individually (Mullins, 2006; McGurk, 2011). I have used qualitative research methods (Section 3.2.4, p. 65 f.) for the project, interviewing middle managers and analysing the 
findings according to their unique character, as described by Kotter (1996), and their special situations and specific times. The results are analysed according to the situation in the market in 2017 and 2018 and in line with ongoing topics and problems in the production department and assembly processes, as these were reflected in the responses of the middle managers (Section 4.6, p. $127 \mathrm{ff}$.). These focus on their current working situations and on reports of problems and their daily business in the production department. My own situation, as an insider researcher in the joint venture (Section 3.5, p. 85 f.), with know-how and experience of the company, is one of the unique factors which adds value to the interview sessions and the subsequent analyses, notably when creating and developing the conceptual framework (Figure 5, p. 53; Figure 12, p. 100) for my thesis with the title:

'Change management and cultural factors: A study of German and Chinese middlemanagers' behaviour in a Sino-German automobile joint ventures’

I also wish to highlight the limitations of my conceptual framework as the model has not yet been implemented. Its adaptation and application for use in other companies or industries should be the subject of further research.

This thesis examines the national and organisational cultural factors (Section 1.2.2, p. $17 \mathrm{f}$.) that may influence the decision-making processes of middle managers in the high-pressure context of complex global markets. I focus additionally on the behaviour of middle managers when they collaborate between the staff level and the upper management level within the joint venture (Wooldridge et al., 2008). It uses the example of a Sino-German joint venture in the automotive industry as the basis for a comparison of German and Han Chinese cultures of organisational restructuring in China. My aim is to add to our knowledge of decision-making in a cross-cultural context and to assist middle managers responding to cultural differences in Sino-German joint production ventures to reduce staff resistance to change. Middle managers confront many problems in such situations, though this is often not their focus when they deal with daily issues arising in production firms. Restructuring, in terms of organisational changes or due to standardisation in relation to partner plants, changes due to technological improvements in the market and the development of industry 4.0, and digitalisation of the production processes in companies, is becoming increasingly important in the automobile market. These factors bring additional challenges to the middle management level (Wooldridge et al., 2008; Chapter 2, p. 29 ff.). Improvements in digitalisation are becoming indispensable. These are all factors which may influence an employee's way of thinking. Such matters are being implemented in the daily tasks of engineers and planners and are discussed 
in the analysis Chapter (Chapter 4, p. 90 ff.).

Continual adaptation is important because corporations are constantly in the midst of changing economic, social, political and cultural conditions (Chapter 2, p. 29 ff.). Worldwide synergistic effects and value-added processes as well as a general social transformation have made it necessary to deal with integral, all-encompassing, and long-term change projects (Krulis-Randa \& Ergenzinger, 1998).

\subsection{Structure of the organisation}

I work in a company that has its headquarters in Germany and that produces a famous brand of automobile. Based on my expertise and knowledge, I had the opportunity to go oversees as an expatriate and join the joint venture between our company and a Chinese company based in Beijing. My study began in October 2015 within the DBA programme at the University of Gloucestershire. In the course of my studies, in July 2017, I decided to relocate to Beijing. This fit perfectly with my thesis and was a perfect timing. The joint venture comprises $70 \%$ local employees and managers and 30\% expatriates. For staffing at the management level, there is an exact rule for staffing particular positions from each cooperation partner. For this thesis, I focused on the production department; I conducted interviews with twelve middle managers from this department, six from German side and six from Chinese side. I selected this department because of this mix of middle managers and the opportunity to have middle managers with a mix of staff level behind. This department is structurally unique in the company and fit very well with both my analysis and interview questions for the purpose of answering my research questions (Section 1.4, p. 25).

First, I focused on reviewing the existing literature on the middle management level, change management, and cultural differences (Section 1.2.2, p. 17 f.) in national and corporate culture. These are important for me and especially for the joint venture collaboration between the Chinese and German companies. The next step after the systematic literature review and research (Section 3.2.1, p. 58 ff.) was to summarise the findings from literature into a conceptual framework (Figure 5, p. 53). Therefore, based on the literature, in Sections 1.2.1 to 1.2.3, I introduce the main three concepts middle management should focus on, and I link these to the journey of my thesis within the company and connect them to my findings from the interview sessions, which were conducted following a pilot study (Section 3.3.2, p. $71 \mathrm{ff}$.) with two lean manufacturing consultants in the same company. For my method, I selected an uncommon one that has nevertheless been used many times in literature, the Zwicky method combined with morphological boxes (Section 3.4, p. 81), in order to obtain the greatest 
amount of information from the interview sessions in a structured manner by reducing the complexity of the content provided by the middle managers. My findings have helped me to answer the research questions and set the focus on the research objectives so that I could formulate a new conceptual framework (Figure 11, p. 93) as a contribution to knowledge and practice, along with additional findings that I discuss in Chapter 4 (p. $90 \mathrm{ff}$.). In the reflection chapter of my thesis (Chapter 7, p. 175 ff.), I summarise all my experiences and compare these with the reflections of the middle managers obtained from the interview sessions to get additional insights into the existing literature based on the practical know-how of the middle managers interviewed.

In next Section, the concept of process management is described. This concerns knowledge of the important decision-making process of middle managers and foregrounds one of the three concepts, based on the existing literature, that is mentioned in the conceptual framework (Figure 5, p. 53). In 1.2.1, based on literature review, I introduce one of the three main findings that are important for middle managers - and on which they should focus - and for international collaboration and which can be found in the conceptual framework (Figure 5, p. 53).

\subsubsection{The concept of process management}

The implementation of change processes in an intercultural environment, such as organisational changes, for example, the restructuring of departments or processes, is very complex and therefore requires a stronger focus from managers, especially from the middle managers who are the fulcrum between upper management and staff. Complexity here refers to making necessary decisions in the context of restructuring. This is one of the causes of organisational changes and requires change management. Each process change or decision generates a risk which depends on whether decisions by the middle managers are made knowingly or unknowingly. This process change is the primary challenge in working in crossfunctional dimensions and with cross-functional communication in the joint venture (Section 2.1, p. 29 f.) automobile production company. Communication is even more complex if one considers the shop-floor level at which operators assemble the cars and need to know or learn the standards of the headquarters which are first translated into English and thereafter into Chinese. The existence of language gaps in the observed company is one of the findings which represents an additional challenge for all employees (Section 4.3.3, p. 114 f.), not merely for the middle management level, and which requires additional focus and support from those middle managers in their function as the fulcrum between the staff and 
management level of the company. Therefore, the focus is the middle management level and the gap discovered in the literature as it concerns collaboration in a joint venture based in China with a German partner. There is a gap in research concerning how managers especially at the middle management level (Wooldridge et al., 2008) - communicate change to employees and manage change (Speier-Werner, 2006; Thommen \& Grösser, 2012). My aim is to bridge this gap and contribute to knowledge of middle management and their staff. In my thesis, I focus on finding solutions and recommendations for middle managers regarding how they can manage such a complex situation in a collaborative joint venture. Collaboration is rarely mentioned in the literature. Generally, it does not concern the middle management level in a joint venture or cooperation between companies from two countries. I wish to support middle managers to positively handle staff fears regarding organisational and national cultural differences and changes.

Management positions and changing market demands and requirements make this challenging for managers. Employees and middle managers must have knowledge of departmental processes (Section 1.2.1, p. 15 f.). Employees should be able to deep dive and should have more detailed knowledge than their managers regarding process management. Departments usually have process descriptions, such as manuals or handbooks; in the production area, processes are standardised and working instructions for a job are made available, as described in the literature review (Section 3.2.1, p. 58 ff.); however, there remain challenges regarding translations of those process descriptions in the different workplaces. The descriptions for the observed company are provided by the central headquarters and are referred to as standards; however, even standards need to be adapted to the situation in the plant overseas and to the situation of the joint venture collaboration model described in Chapter 2 (p. 29 ff.). Since middle managers are the interface between staff and upper management, I wish to ascertain whether these processes and tasks have an impact on the processes of change and whether there is a relationship between the tasks of middle managers completed according to the processes described in the standard provided by central headquarters.

For me, the operational task and the operator assembling the car are an important focus, especially as, in order to determine how collaboration with their operators and employees is working, I conducted my interviews with people from the department of the company where they deal with such issues and problems in their job descriptions and with daily tasks at the middle management level. When changing processes, problems and misunderstandings may arise that lead to problems in communication and collaboration. Based on my findings, I have 
developed a communication and collaboration model (Figure 12, p. 100). Even for organisational changes in the department or company, processes of change should be considered. How the local staff and the experts from Germany deal with these kinds of change processes? How do the German experts manage the production processes they bring from Germany to China, with its different cultural background and language, while working together with local staff in a third language? Are there any issues understanding one another (Section 1.2.3, p. 19 f.)? Processes are translated from German into English, and then into Chinese. Is anything omitted or changed during the long translation process? Is any aspect of the sense lost in the first translation into English, or in the second translation into Chinese? Does the translated version of the processes retain the same meaning as is described in the first German version? Is key content regarding the processes lost, resulting in significant differences between the translations? In the literature review (Chapter 2, p. 29 ff. and Section 3.2.1, p. 58 ff.), I focus on the existing literature to find answers for the questions posed. I also focus on the work of useful authors such as Wooldridge et al. (2008) in relation to middle management level and Ghemawat and Reiche (2011) in relation to culture and change management. This helped me to develop the first conceptual framework (Figure 5, p. 53) and to formulate the questions for the interviews.

The German experts can easily observe whether the employees are implementing the processes as they are implemented at the German headquarters. This is perhaps one reason why the presence of the German middle managers on-site is important for the processes of the production department processes. How can middle managers ensure understanding of these processes and maintenance of the standards implementing in other plants producing the same cars?

In the next section, I explain the importance of the second concept in the conceptual framework that was initially developed, that of cultural difference. In the new conceptual framework model (Figure 11, p. 93), corporate culture is identified as a major influence, as reflected in the research questions. The importance of the content of 1.2.2 is stressed in the literature review (Chapter 2, p. 29 ff. and Section 3.2.1, p. 58 ff.) in relation to collaboration models for working in a joint venture. For this reason, it is important for me to introduce in Chapter 1 the concept of cultural differences before introducing the literature Chapter and the definitions in Chapter 2 and the systematic literature research in Section 3.2.1.

\subsubsection{The concept of cultural differences}

The understanding of national and corporate cultures is the focus of the model shown in 
Figure 5 (p. 53) and is part of the conceptual framework adapted and developed from the literature research (Chapter 2, p. 29 ff. and Section 3.2.1, p. 58 ff.). The appropriate handling of national culture is one of the most important and demanding challenges in people's professional and private lives. Today, managers often desire to understand national cultures and to actively share that culture with their staff. This is especially the case when different national cultures are present in the daily working context. In the company that is the focus of my thesis, this is especially important because it is joint venture (Section 2.1, p. 29) in which two corporate cultures work together. There is in addition a third corporate culture that is common to the joint venture, as described and analysed in the interview sessions (Section 4.5, p. 124). For both Chinese and German middle managers, these two corporate cultures are a challenge, a fact which is highlighted in the interviews (see the example in Appendix 5, p. 222). National cultural differences are highlighted in systematic literature review (Section 3.2.1, p. 58 ff.) as often being mentioned by many authors (Ghemawat \& Reiche, 2011; Hofstede, 2005; Bates, 1997; Wooldridge et al., 2008). In my findings, I also found a link to my research questions (Section 1.3, p. 20) as regards national cultural differences (Chapter 4.3.2, p. 109 f.).

The combination of different national cultures and change management, the first (Section 1.2.1, p. 15 f.) and second (Section 1.2.2, p. 17 f.) concepts in the initial model of the conceptual framework, can be difficult and frustrating, as Bate (1997) describes in his work and as cited by Geertz (Section 2.3, p. 52 ff.). The significance of differences between national cultures and organisational cultural differences and change is the focus of my research and is thus highlighted in the interview sessions and in the analysis Chapter (Chapter 4, p. 90 ff.). I also present new insights in contributing to knowledge and practice with my findings which I cluster in Chapter 6 (p. 159 ff.).

For the analysis and evaluation of the interview results, I develop a model which begins with the basic model of Ghemawat and Reiche (2011) and combines this with national culture and corporate culture, as reflected in Schein (2010), with the main focus on middle management level in the literature (Wooldridge et al., 2008).

In Section 1.2.3, I introduce the final concept of the first conceptual framework: relationshipbuilding, which is one of the concepts discovered in the literature review (Section 3.2.1, p. 58 ff.). As described in Sections 1.2.1 and 1.2.2, this is an important factor and I include it in the conceptual framework in Figure 5, p. 53. Following the analytical component of my thesis, I adapted this framework to generate the new conceptual framework in Figure 11, p. 96. 
Relationship-building is highlighted as important for middle managers in collaborative crosscultural joint venture working models, a matter which was confirmed in the interviews with the middle managers and is highlighted in the updated conceptual framework in Figure 11, p. 93. Relationship-building is one of the three main findings of my thesis which is described and reflected on in detail in Section 4.2.3, p. $104 \mathrm{ff}$.

\subsubsection{The concept of relationship-building}

In the conceptual framework, relationship-building is integral for working in China, for collaboration between middle managers and employees, and for leadership. The importance of relationship-building is introduced in Section 1.2.3 (p. 19 f.) in relation to cultural change and the cultures observed in the research. In the literature research, I focus more on the findings of Ghemawat and Reiche (2011) as these are more within the focus of my thesis in relation to relationship-building skills and why they are required for good collaboration and success in a joint venture, especially for middle managers’ cross-cultural work (Section 2.1, p. 29 ff.). In their work, Pappas and Wooldridge (2007) additionally highlight the middle management level and the importance of collaboration, which I also focus on throughout my whole work (Section 2.1, p. 29 ff.). Schein (2010) discusses corporate culture which I add in my thesis in relation to Ghemawat and Reiche (2011). Cross-cultural management and communication are important in the observed company and have great significance for my research (Pappas \& Wooldridge, 2007; Wooldridge et al., 2008; Ghemawat \& Reiche, 2011). This is highlighted in the summarised conceptual framework (Figure 11, p. 93).

International companies host employees and managers with different experiences and different cultural and social backgrounds. The middle managers observed in my thesis are affected by their own work environments, experiences, and socialisation as described in the literature research (Section 3.2.1, p. 58 ff.). National and corporate culture can affect the abilities of managers and can shape their experiences (Guirdham, 2005). The role of the middle manager is important for employees because the leader shapes and influences the employees and their collaborations and relationship-building measures (Adler, 2002). Hofstede (2002) reiterates Adler’s (2002) view that the 'leader is a hero’ (Hofstede, 2005, p. 268). All employee and middle manager expectations are influenced by culture and national cultural backgrounds (Wooldridge et al., 2008). Again, this is related to the second concept presented in Section 1.2.2 (p. 17).

In Section 1.3, I explain my background, why I selected this research topic, and the basis of my interest in closing the identified research gap. The standing of the research is an important 
component of the introductory chapter and explains the methodology selected and provides an excerpt of the construct of my work as a whole.

\subsection{The Standing of the Research}

Teamwork is indispensable for business. We live in a permanent state of change, influenced by the environment, national and international economic policy, and factors associated with culture, the implementation of processes, and varying levels of expert knowledge. Companies must be ready to adapt to changing conditions. Modern automotive manufacturers often cooperate through joint ventures. The complexity and dynamism of global markets and rapid changes in economic and business life have led to the formation of striking new types of corporations. To prepare for global competition, firms must adapt to changing situations and respond appropriately.

Semi-structured interviews were selected as the most appropriate data collection method for answering the research questions, and constructivism as the research philosophy (Section 3.2.2, p. 63 f.). Qualitative research - of which semi-structured interviews are a component - allows for a deeper understanding of social reality. It is ideally placed to explore the interaction of middle managers who work together through dialogue, as well as real situations and the emotions involved in such experiences.

Change management and cultural differences in corporate culture - the environment in which middle managers and their employees work - is a soft topic that should not be analysed using a structured interview. Semi-structured in-depth interviews are typically used in qualitative research. Semi-structured interviews allow for more in-depth topics to be explored, as well as encouraging interviewees to express their feelings (Sims, 1993). It was important not merely to establish the viewpoint of the interviewee, but also the reasons for these views. By means of this interview method, I not only collected information and expertise, but also gained new insights. The interviews were used as a type of network meeting for the exchange of information and thoughts. Thus, the semi-structured questionnaire was deemed most suitable. My interest in this research topic generally, and my desire to close the gap identified in the literature review, is owing to my operational business work and professional experience which focuses on middle management and supporting middle managers in dealing in changing situations in a joint venture in China. As a result of my background, I am connected to the topic of change management and affected by various cultural factors; as an employee and part of the observed company, I add contributions to practice and knowledge to my thesis as a result of 
being an inside researcher (Section 3.5, p. 85 f.). I began my professional career in the automotive sector, with various well-known firms. The professional know-how and experience I gained through these years contributes to the current work, allowing me to make recommendations that reflect the daily issues and problems middle managers face in managing process changes requested by the competence centre, as well as matters relating to national and corporate cultures. The work in which I was involved included jobs in different departments and at different levels, from junior consult to senior consultant, assistant project team leader, manager, and engineer. I eventually became a supervisor working in an environment in which I was always thinking about change management. My professional background has always been international, presenting me with opportunities to work abroad (Phoenix, Chicago, Prague, and Beijing) and in various forms of cooperation, including joint ventures.

Today, I work for a company that produces a popular automobile brand in international production facilities. Specifically, I work at one of the joint venture partner's production locations in China as an expatriate and supervisor of a local team with Chinese employees in a production assembly environment. I could recognise some of the points raised in the interviews, could compare these with my experience, and sometimes agreed with the statements made. On other occasions, as a result of my experience in the joint venture and my having begun a reflection journey (Chapter 7, p. 175 ff.) and observing in a different way during my working time in the joint venture partner onsite, I could not agree. However, important for me was the reflection of those middle managers (Section 4.6, p. $127 \mathrm{ff}$.) and the contribution to knowledge and practice in order to answer my research questions (Chapter 6, p. 159 ff.) and for future research (Section 6.3, p. 173 f.).

My aim was to add to knowledge of decision-making processes in this context and to assist middle managers with understanding cultural differences in order to reduce staff resistance to change. Based on literature research (Section 1.2.1, p. 16) there is a gap in research concerning how managers - especially at the middle management level (Wooldridge et al., 2008) - communicate change to employees and manage change (Speier-Werner, 2006; Thommen \& Grösser, 2012). My aim is to bridge this gap and contribute to knowledge of middle management and their staff.

Co-operative work in joint ventures is increasingly prevalent. Working for different automobile companies, I have seen how differently managers react to processes of organisational change, including how they help their personnel to cope with changes in international working environments in which there is daily contact with people from other 
countries. I recognise that middle managers, in particular, need more assistance as they are the fulcrum between upper management and the workforce. In moving from a position in an automobile production company to parts supplier management, and then to a middle management position with a supplier and working in collaboration with a customer in Karlsruhe, Germany, I have come to understand the importance of communication (Section 4.2.1, p. $98 \mathrm{ff}$.) which is one of the main three findings from the landscape of findings that were generated from the interview sessions. For international cooperation, communication skills are indispensable, as is an understanding of corporate culture and the cultural aspects of global cooperation (Section 3.2.1, p. 58 f.).

Living in China and studying the language opened my eyes to rapid cultural change, made me more digitally aware, and enhanced my understanding of Chinese culture and the differences and commonalities with my own background, my Turkish mother culture and the culture of Germany, in which I was born and raised. Furthermore, I realised how difficult it can be to communicate in a third language for both German and Chinese middle managers and staff. For the joint venture firm that is the subject of this study, it is questionable whether cultural aspects have substantial importance in the daily working life of the employees. This is despite the presence of two national cultures and two corporate cultures, with a third language (Section 4.3.3, p. 114 f.) used for company communication and collaboration. Language seems to be really an issue in the company which is the subject to my study. Many firms do not appreciate the meaning of culture in the daily processes of change, and this challenge must be managed carefully, especially in a joint venture, with consideration for both national and corporate cultures. Change management is essential when changing strategical views or leadership functions, and in, for example, a rotation of the leadership team. In addition, however, consideration is required for the management of new projects and the changing of daily processes for production line staff and operators due to technical and digital improvements.

Regarding the aim and research objectives of my thesis, I summarise the key points I focus on in my research in the following chapters. My aim was to add to knowledge of decisionmaking processes in this context and to assist middle managers with understanding cultural differences in order to reduce staff resistance to change. Change management may be an organisational issue or a function of daily work; however, it is a considerable task for middle managers and needs to be further considered and revised in a joint venture and in international collaborative working model. However, change management and culture concerns more than 
the points described: Change management must also include cultural features, which should have a central role in leaders' thinking about daily business. It should not be considered in change management alone.

I started to keep a diary and recorded based on my experiences and what I have learned during my DBA journey monthly one time and this diary also helped during the whole reflection (Chapter 7) of my research and the reflection of the interviewees during the interview sessions and my observations.

The insights into intercultural cooperation at the joint Sino-German production plant that were generated from the interviews help to define middle managers' current thinking regarding solutions to staff fears concerning organisational change as production is increasingly outsourced to low-cost plants outside Germany. At this economic juncture, low personnel costs, low material and start-up costs, as well as the market and customers are important. China is making substantial progress in automobile production and is becoming more important for the global industry as a whole (Helmold, 2013; Section 1.1, p. 9 ff.).

The first objective is to determine how middle managers in a Sino-German joint venture recognise and cope with factors associated with organisational change and national change that might inhibit or promote their awareness of the effects of cultural differences on the organisation.

The second objective is to identify how cultural differences affect middle managers' change management behaviour in relation to organisational issues in a German-Chinese joint venture and how middle managers support their employees in changing situations. I want to conduct an analysis of the needs of middle managers and want to consider how they can adapt to work more effectively in the changing environment of the joint venture (Lewin, 2014), as described in detail in Section 2.1 (p. 29 ff.).

The third objective of this research is to formulate an appropriate conceptual framework (Figure 11, p. 93) of culturally based change management factors for middle managers working in cross-cultural joint ventures. This will help to enhance communication and collaboration in a changing environment, especially within a corporate culture, as this relates to the behaviour of Chinese and German employees and managers engaged in collaborative work (Albach et al., 2015). The positive and negative impact of staff on colleagues who manage change processes is especially important and is analysed by means of the semistructured interviews with employees (Albach et al., 2015).

This research process covered a four-month period, excluding preparation time, during which 
interviews (Section 3.3.4, p. 75 ff.) were used to gather data from middle managers. The managers work for the same company. Their teams comprise engineers, planners, and nonadministrative staff directly involved in automobile production lines.

My own personal development has been supported by reading the literature, by discussions with colleagues and tutors in Frankfurt and Cologne, and by my position as inside researcher in the company (Section 3.5, p. 85 f.).

Change is a major process that is influenced by one's private, personal, and business life, as noted by authors such as Ghemawat and Reiche (2011), Wooldridge (2008), Lewin (2014), Bate (2012), and Berner (2012). I began my DBA research as an interventionist with a desire to be active, to act on my own initiative and to engage in conversation with others, including my research subjects. For me, this methodology is extremely interesting; the initial interventionist desire was to create a dialogue, an ongoing process of conversation, rather than merely using a questionnaire sent by mail. I intended to be involved as a moderator and as a principal supporter of the approach (Bryman \& Bell, 2007).

Regarding the systematic study of people and cultures, I tend to observe society from the point of view of the subject of the study, which constitutes a link to ethnographic studies. In these kinds of studies, researchers deal with consistent structures and observe continuous processes and people enacting or working within those processes. What is important is that, through language, one can reach others by telling stories and describing one's experiences and thoughts. In the course of my research journey, I made a difficult transition from my ontological viewpoint as an interventionist. This is described in Chapter 3 (Section 3.2.2, p. 63 f.).

This research focuses on the perceptions of employees and middle managers and the problems they face, in this case in a joint venture in China, where English is used for business communication. Therefore, collaboration, communication, and understanding and accepting the other culture are indispensable. As many companies now operate in intercultural and international environments, change management has become fundamental. It is thus in need of further analysis, especially those cases of collaboration in different countries. The point is not merely to realise that 'change management' and 'culture' exist, but rather to accept that these involve all employees, regardless of their position in the hierarchy. It is also important to communicate change processes to staff (McGurk, 2011).

As noted above, this ethnographic study concerns individuals' approaches and thinking and combines these approaches in the research activities such as the literature research or, for example, setting up a learning group (Farrimond, 2012; Crotty, 2015). The insights of an 
insider, such as an employee of a company speaking from his or her own experience, would be ideal for this type of research. This is what Pike (1967) describes as the 'etic' approach or seeing the world from one's own perspective. The qualitative tools of semi-structured interviews and questionnaires would therefore be most valuable in this regard.

To summarise the processes involved in what follows, I approached and discussed my action learning set sessions with colleagues from my DBA class, who came into being in a learning group during the class sessions of the DBA (Section 7.3, p. 179 ff.). My personal development - combining theory, a practical perspective, and influences from my environment, family, work, and contacts - as well as my experience of being a mother while working full-time at the company and completing doctoral research, are addressed in Chapter 6 (Section 7.4, p. 183, f.). I reflect on my academic, philosophical, educational, and professional development during the time from my enrolment for the DBA in October 2015 up to the present, August 2019. I indicate why I changed my perspective from being an interventionist to being a constructivist and explain my choice of semi-structured interviews as a qualitative research tool.

This study is a valuable exploration of how change can be managed in one's personal life or elsewhere, especially with the focus on middle management. Each development can be different, and the impact of each on one's understanding can vary strongly. This is why it is interesting to understand how ideas and individual considerations can be affected by reflection (Chapter 7, p. 175 ff.).

In the next section, I discuss the research questions and the objectives of my thesis. I formulated these during the literature review, with a goal of closing the research gap and developing a conceptual framework (Figure 11, p. 93) for middle managers' leadership behaviour based on the conceptual framework (Figure 5, p. 53) which was defined based on systematic literature research (Section 3.2.1, p. 58).

\subsection{Research Questions and Objectives}

In the process of formulating appropriate research questions to meet the objectives of this thesis, the literature review and finding the gap in existing literature was the main phase. There is a gap in research concerning how managers - especially at the middle management level (Wooldridge et al., 2008) - communicate change to employees and manage change (Speier-Werner, 2006; Thommen \& Grösser, 2012). My aim is to bridge this gap and contribute to knowledge of middle management and their staff. I want to add to knowledge of decision-making processes in this context and to assist middle managers with understanding 
cultural differences in order to reduce staff resistance to change. Change management may be an organisational issue or a function of daily work; however, it is a considerable task for middle managers and needs to be further considered and revised in a joint venture and in international collaborative working model.

The aim of the systematic literature review is to explore how middle managers in the automobile sector deal with 'change projects', especially in an international cultural context, and how they are able to support their staff in handling changes by reducing apprehension and resistance (Nieswandt, 2015). Bryman and Bell (2003) set some priorities for literature research, describing it as a process of reviewing the identified literature from sources such as articles, e-journals, and databases in order to ascertain information.

The objective of this thesis is to identify, based on the findings arising from the interview sessions with the middle managers in the department of concern, how German and Chinese middle managers working together in a joint venture in the automotive industry make decisions, communicate instructions to staff, and handle process changes, despite their different cultural backgrounds.

In the three years before commencing this research in October 2015, I had been gathering information on the topic of middle managers in the context of culture and managing change. The literature mostly referred to managers generally, though not all of them operate at the boundary between guiding executive management and the working level. The working level operationalises the strategic decisions, visions, and prospects of upper management. Sackmann (2004) and Schein (2003) speak very generally about managers and do not distinguish between levels of management. Wooldridge et al. (2008) provide much deeper insights into the middle management level and also talk about their reflections and needs in international collaboration; however, I was still missing the link to the joint venture and the observations regarding Chinese and German middle managers in the form of a comparison to determine the differences and what was missing and could be added to the existing literature in the form of a contribution to knowledge and practice.

How do German and Chinese middle managers in a cooperative joint venture in the automotive sector in China cope with organisational change and national cultural differences? Two principal questions came to mind as I commenced my research journey:

1) How can German and Chinese middle managers working in a joint venture learn about organisational change and national cultural differences? Is this necessary for working 
in a joint venture, especially in a collaborative one between German and Chinese cultures?

2) How can middle managers adapt their skills to the culture of the joint venture partner, especially the relationship-building skills required in situations of change?

Based on these research questions, the following research objectives were developed for the research:

1) To determine how middle managers in a Sino-German joint venture recognise and cope with factors associated with organisational change and national change that might inhibit or promote their awareness of the effects of cultural differences on the organisation.

2) To identify how cultural differences affect middle managers' change management behaviour in relation to organisational issues in a German-Chinese joint venture and how middle managers support their employees in changing situations.

3) To formulate an appropriate conceptual framework of culturally based change management factors for middle managers working in cross-cultural joint ventures.

The particular thinking of each individual constitutes the collective reality. Change management reflects the enormous influence of culture (Bates, 1997; Ghemawat \& Reiche, 2011). Various social aspects and the relationships they involve led me to adopt a constructivist epistemology. Using this method of interpretation, I considered the social context and social outcomes of different cultural viewpoints as these are quite different for the countries under consideration and affect the challenges and the pressure to produce cars within short production ramp-up times. The thesis covers the major aspects of the two cultures in the same industrial sector. The semi-structured interview method assists with the ethical practice of maintaining anonymity, which is important as the interview partners provided indepth information that supported the development of a practice-based framework for middle managers.

In Section 1.5, I summarise the main conclusions from each section of Chapter 1 and briefly introduce shortly the chapters that follow.

\subsection{Summary and Interim Conclusion}

Chapter 1 of this study presents the primary objective of my thesis as being the exploration of how middle managers deal with organisational changes and national cultural differences in 
conditions of extremely short product ramp-up times in a cooperative joint venture in the automotive sector in China and Germany. I explain that my research focuses on employees and middle managers' perceptions of the problems they face in special cases such as this joint venture cooperation in China, where the English language is used for communication and where employees work together with others from other cultures.

A descriptive qualitative research method based on semi-structured interviews is used in this study. The aim is to fill the gap in the literature and to contribute to knowledge of middle managers and how they support their staff with new insights into practice and knowledge.

The first chapter presents the research background and introduces the topic of the automotive sector, along with its historical background, and introduces the aim and the gap in the research. The research questions and objectives are also introduced. These are aligned with the study's research paradigm. Their practical importance of the research questions for the behaviour of German and Chinese middle managers working in a Sino-German joint venture in the automotive industry in times of production pressures and in the context of change management is highlighted, as is the importance of cultural factors.

In Chapter 2, I explain important terms and definitions, such as 'culture', 'change management', 'national and corporate culture', and 'culture change' and closes the chapter with the conceptual framework based on literature research.

In the third Chapter, the methodology used in the research is described. This begins with the research methodology and proceeds to that of the literature research. After considering my research philosophy, I discuss the use of constructivism in the work. I explain the ethical considerations and my positioning as an insider in the company. The conducting of the interviews, data collection, and methods of analysis are described.

In Chapter 4, the findings and the main aspects of the data analysis are described in Sections on communication, information flow and collaboration, relationship-building and guanxi, and qualifications and hiring. Further findings are grouped in Section 4.3. The chapter closes with my observations, the working atmosphere in joint venture and the reflections on the interviews of the middle managers.

Chapter 5 is the main chapter with answering the aims and objectives based on the analysis chapter (Chapter 4).

Chapter 6 deals with the contribution to knowledge and practice and offers recommendations. It also presents an appropriate communication concept for enhancing collaboration and 
exchange between staff and middle managers from different cultures who depend on a third language for communication and collaboration.

Chapter 7 describes the whole journey and my professional development, along with the decisions regarding the choice of research, my philosophical attitude, and the importance of reflection. The action learning sets, which impact on the research questions and the interview method, aid understanding of the philosophical attitude.

In the chapters that follow, I identify the principal methods of obtaining data, as well as the type of data obtained. I discuss the selection of the most suitable method for the study and present and analyse the data, including the theoretical framework that pertains to them. 


\section{Chapter 2: Definition of Terms and the Impact of Cultural Influences on Middle Managers in a Joint Venture}

In this Chapter, I explain the terms that are frequently used in my thesis, including national culture, corporate culture, communication, joint venture, middle managers, change management, guanxi, relationship, competence centre, and cultural change. I distinguish between the national culture and corporate culture (Section 2.2, p. 44) of the observed country and company, respectively, as these underline this thesis and are further analysed in the discussion on findings of the interviews. Chapter 2 introduces the literature research and is followed by the methodology and methods in Chapter 3 (p. 55 ff.) where I discuss the research philosophy and qualitative research aspects of my work.

In this Chapter, I underpin the concepts and models I have selected from the existing research in order to explain the gap (Section 1.4, p. 25) identified. I base my research questions on the concepts and ideas of the key authors in the field.

After defining and discussing the main terms in Section 2.1 (p. 29 f.) and introducing the automotive trade to provide background on the joint venture across the two cultures, I discuss the most important definitions: middle managers, joint ventures, and culture. Then I review the background terms that are frequently used in this thesis as well as change management in relation to successful change factors.

I provide some detail on the background of corporate and national culture in Section 2.2 (p. $44 \mathrm{f}$.). Before providing the summary and interim conclusion, I explain the importance of cultural change in the company which is the basis for my research.

\subsection{Key Concepts and Discussions of the Definitions of Terms}

The complex dynamics of global and international markets require the constant development of business models and challenges to them (Aula \& Heinonen, 2016; Becker, Kunz \& Mayer, 2009; Kugler, Sinn-Behrend, Bruder, Baumann, Hodek \& Niehaus, 2016). Companies may recognise that their business strategies are not suited to expanding into international collaboration in today's market and, furthermore, are not aligned with the models of cooperation used by other firms around the world today (Tidd, Bessant \& Pavitt, 2001; Becker et al., 2009). Companies can only remain competitive when they strengthen and expand their core competences (Luo, 2010). They must support their core processes as effectively and efficiently as possible by providing support services and by developing global partnerships to reduce costs and expand business operations (Kahn, Hatch, Fitzmaurice \& 
Desroches, 2010). This broadens the horizons of corporate culture and brings to light further challenges that may be faced when managing change (Aula \& Heinonen, 2016; Kugler et al., 2016). The changing environment and growing internationality - with vehicles now produced in locations with a variety of cultural backgrounds - necessitate strategy changes and farreaching, dramatic shifts in structures and processes (Dubina, Ramos \& Ramos, 2016). Strategic reorientation and the reorganisation of establishments must proceed in tandem in times of internationalisation (Becker et al., 2009; Kugler et al., 2016).

Von Rosenstiel and Lanz (1997) state that, in times of global competition, firms must quickly and continually adapt to change and associated processes (Section 1.2.1, p. 15 ff.). This no longer merely requires the implementation of business management methods that provide a company with a competitive edge over others. Rather, the focus is increasingly on corporate culture (Section 2.2, p. 44 ff.) to the extent that this affects the prosperity of the firm. The quality of the corporate culture affects the optimisation of the business processes that determine the firm's success (Sadri \& Lees, 2001). Effective change management in corporate cultures should lead to a high level of innovation readiness, a stronger customer orientation, and fluid interaction among a firm's operations. Current studies, including those introduced in the literature review (Section 3.2.1, p. 58 ff.), illustrate the importance of corporate culture and change management for yielding better organisational pay-offs (Leitl \& Sackmann, 2009). In Section 4.6 (p. 127 f.), corporate culture is presented as one of the main drivers of the working environment in the joint venture collaboration studied here. Change management is not only important for the organisation: rather, it has a significant impact on mergers and cooperation, as is the case in the joint venture described in Section 1.2 (p. 14).

Today, many firms are able to optimise their processes. Indeed, most processes and structures have already been optimised (Booth, 2015). However, as Berner (2012) points out, corporate culture and change management represent the areas in which it is most important that firms improve in order to increase their productivity in a market that is characterised by collaboration and cooperation. This is a matter of more than mere internationalisation; rather, it refers to different kinds of collaboration. In this thesis, the collaboration involves a joint venture company. Internationalisation and increasing product variety and complexity in the automotive market create new conditions, including changes to processes that middle managers must communicate to their subordinates (Glaser, Fourne \& Elfring, 2015). Some authors write of a new era in the automotive industry, following those of Ford's mass production and Toyota's lean production (Jacobides, MacDuffie \& Tae, 2015). Cooperation 
with outsourcers and increasing production of automobiles following the 2008 financial crisis has ushered in a period of change in the industry (Bellmann \& Gerner, 2012).

Middle managers are those managers who are in strategic position between the upper level management and the staff level, that its, are in an intermediate position in the organization (Wooldridge et al., 2008; Andersen, 2004). In their work, Wooldridge et al. (2008, p. 3) highlight the so-called 'middle management perspective'. They discuss the fact that, in many companies, the middle management level plays a much greater role than the upper management level in the development of capabilities (Wooldridge et al., 2008). This statement underlines the importance of my study and is confirmed in the analysis of the interviews. Pappas and Wooldridge (2007) indicate in their work that middle managers can influence changes in processes to a greater extent than others in the organisation. In a study involving the reflections of 89 middle managers sourced from interviews, the analyse how important relationships are for middle managers, especially when considering strategic decision-making processes. This point of view is one of the findings from my analysis of the results of the interview sessions; I focus specifically on relationship-building and guanxi. Mintzberg $(1978,2018)$ adds importance to middle management level with the perspective of the strategic view and expresses how important learning and adaptation to changing processes are for this management level.

Importance of upper management (Hitt et al., 2007) is analysed in Section 4.3 .5 (p. 116) and a communication model in Section 6.1.2 (p. 167) helps understand the importance.

Floyd and Wooldridge (1999) and Hitt et al. (2007) describe the three different roles of middle managers as identifying opportunities, developing initiatives, and renewing organisational capabilities; however, in my findings, I found no hint of this point of view. Wooldridge et al. (2008) note in their study that there is some literature on the behaviour of middle management; however, a large gap (Section 1.2.1, p. 15) can nevertheless be observed and that further research on this subject is required. There is a gap in research concerning how managers - especially at the middle management level (Wooldridge et al., 2008) communicate change to employees and manage change (Speier-Werner, 2006; Thommen \& Grösser, 2012). My aim is to bridge this gap and contribute to knowledge of middle management and their staff. This study aims to add fruitful findings to the existing literature.

In a joint venture, the foreign company owns more than $25 \%$ of the shares. A joint venture is a company that is jointly established by at least two companies which retain their distinct 
identities. The most significant characteristic of a joint venture is shared ownership, returns, and risks. In the case of the observed joint venture company, the German company holds $49 \%$ of the shares. A joint venture is not a merger (Devonshire-Ellis et al., 2011). Rather, it is a new entity owned by both of the cooperating parties. According to the Chamber of Foreign Trade in China and the business climate index, since 2001, 68\% of all German companies working in China have been 'Wholly Foreign Owned Enterprises' (WFOEs) rather than joint ventures (Schreiter, 2015, p. 22). There are various options for doing business in foreign countries; however, the main reason for entering into a joint venture cooperation is to share the risks associated with major investments. Other reasons include accessing the skills and capabilities of the partner company, gaining scale efficiencies, and easily accessing a new market. The latter is the case in the observed company. Another reason is that, in some countries, a joint venture is the only option for entering the new market (Devonshire-Ellis et al., 2011).

However, these companies face the substantial problem of hiring good, experienced local employees in the Chinese market. I also wish to distinguish between the two types of joint venture that exist in China: the Equity Joint Venture and the Cooperative Joint Venture. The latter is the contractual form applicable in this work as it offers entry into the Chinese market and into the industrial sector. Furthermore, in China there is the government restriction which requires a Chinese company as a participant in order to have some control over some sectors in the Chinese market (Devonshire-Ellis et al., 2011). The cooperative joint venture of relevance here, a Sino-German automotive joint venture, was established in Beijing in accordance with the principles of fair and mutual benefit. Many expatriates work in the joint venture so that their expertise is available on-site. Special expert know-how is mandatory for moving forward with the project, for the standards that need to be implemented, and for the work content. In this thesis, I focus on the middle management level and do not distinguish between the middle managers. Another aspect that is highlighted in existing literature is the effect of cultural differences. This point of view was also partly observable in my findings. Nevertheless, in critically engaging with the existing literature, it is noticeable that aspects such as a third language for communication and information relating to hiring and qualifications of local employees as on-site middle managers is lacking.

Implementing change management projects is extremely difficult for managers (Bate, 1997; Schein, 1985; Andersen, 2004; Hitt et al., 2007). The complexity of intercultural issues and the process-optimised structural framework of organisations present major obstacles. Furthermore, there are the complex needs of the market and the desire of the customers to access more and 
different types of products. Outside influences such as the environment, historical circumstances, and cultural traits affect corporate culture and the change project. Thus, it is essential that real communication takes place and that all employees are informed about upcoming changes and plans. In the literature, this is frequently described as a particularly important aspect. This is cross-referenced in the findings and analysis in Chapter 4 (Section 4.2.2, p. $101 \mathrm{f}$.$) .$

Change management projects are essential in today's business world (Siegfried, 2015; SpeierWerner, 2016). We live in a permanent state of flux and are influenced by environmental and cultural factors, such as employee habits, varying levels of employee education, and collaborative working structures, including joint venture cooperation (Speier-Werner, 2016). Companies must be ready to adapt to such changing conditions (Smith, 2015).

Dievernich, Tokarsky, and Gong (2015) define change management as core business management. For this reason, these authors consider all business management to be change management. Change management and how it should be implemented is a consideration in the present study. One might say that change is a never-ending story (Berner, 2010). Having gained experience in this field as a practitioner, I propose that change management is a part of life for everyone and a component of everyday life, rather than being merely work-related. At the core of this research, change management is regarded as the role of the interaction between employees and management (Berner, 2010). This means that change management is not simply a process undertaken by upper management - middle managers must also involve their employees in it (Praxenthaler, 2018). This can be seen in the findings from the interviews in Section 4.2 (p. 92 ff.) and Section 4.3 (p. 108 ff.). It is also the fifth step and factor of Paton and McCalman (2008) which I describe in the following.

Below, I discuss the work of Paton and McCalman (2008) as it later forms a foundation for the analysis of the findings in Chapters 4 and 5. I also identify which steps are helpful. The combination of the models of Paton and McCalman (2008) and Hofstede (2005), with an updated view of Hofstede's model by Beugelsdijk et al. (2016), the views of Schein (1999) on corporate culture, and the work of Kotter and Cohen (2002) highlight the importance of my findings.

Paton and McCalman (2008) identify six key factors for successful change management in the course of change projects. Though it is not the most important, this model was selected because I found cross-references to it in my interviews in the course of my analysis of them and especially because of the description of the change spectrum in the second key factor 
which shows the complexity of change management when interaction between people increases, as well as the greater complexity of change management as the complexity of the changes themselves increases. One of the points middle managers really needs to understand. Based on the interview results I could recognise that reflection was existing but the reflection regarding the complexity of the changes themselves and change spectrum was missing. The first factor concerns the person leading the change project; this is described as 'the role and selection of the problem owner' (McCalman, Paton \& Siebert, 2016, p. 86). Such persons, such as the middle managers considered here, are the centre of the event and must be involved in all change processes. As they are the interface between upper management and staff, they must be able to implement change in an effective and efficient manner to ensure success for the company (McGurk, 2011). Every problem that emerges during the change project must be solved by the person in charge. This person is referred to as the 'owner' in the work of Paton and McCalman (2008), and elsewhere variously as a 'change agent', 'facilitator', 'project manager', and 'team leader' (Glaser et al., 2015). In my work, I describe this function as the 'middle manager' as this is my focus group.

The second key factor is the location of the change (McCalman, 2008), described as 'locating change on the change spectrum' (McCalman, Paton, Siebert, 2016, p. 88). In the view of McCalman (2008), changes may emerge organically. There might be a change in organisational structure or a process-based change; the most difficult obstacle for the manager is usually the people he or she works with (McGurk, 2011). This key factor relates to my work since organisational structural change and process-based change (Section 1.2.1, p. 15 f.) and collaboration between middle managers and employees are in focus in my interviews with the middle managers. Figure 1 below shows the complexity of change management when interaction between people increases, as well as the greater complexity of change management as the complexity of the changes themselves increases. According to the change spectrum depicted in Figure 1, changing situations, processes, and organisational requirements are complex in a joint venture and therefore, according to the model of McCalman (2008), require the soft systems methodologies depicted in Figure 1. I explore Figure 1 as describing the change spectrum in McCalman's work in relation to my research and present the findings in Chapter 4 (p. 90 ff.). 


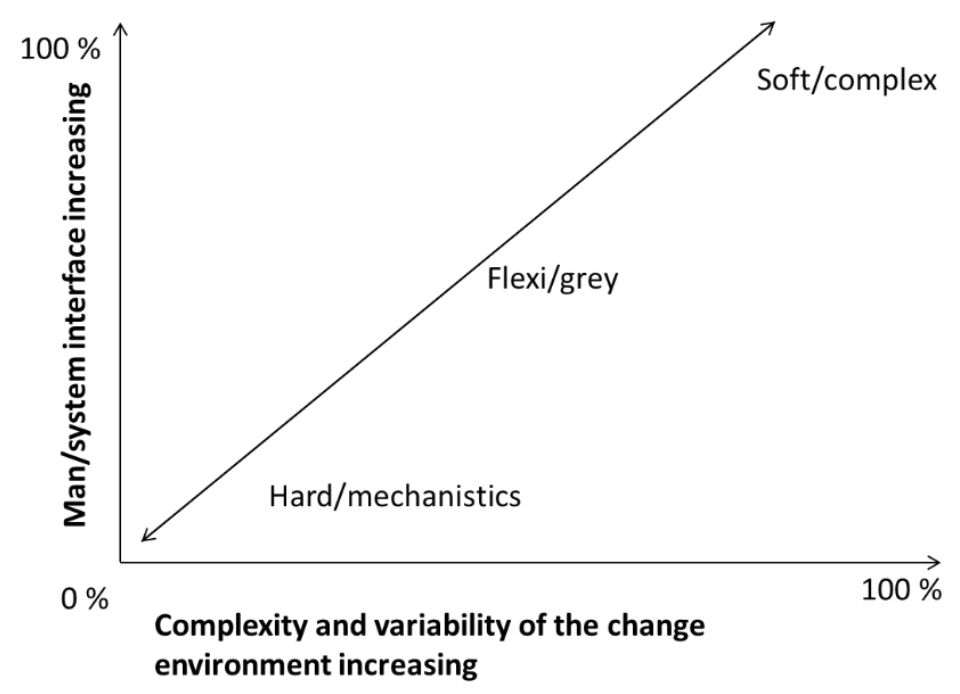

Figure 1: The change spectrum

Source: McCalman, 2008, p. 89

The third key factor proposed by Paton and McCalman (2008) is referred to as the TROPICS test for assessing time scales, resources, objectives, perceptions, interest, control, and source. Using this test, the authors developed a set of guidelines for change managers and their teams. The implementation of the TROPICS test is the first step in the methodology (McCalman, 2008). The test has not yet been used in the automotive sector, although it has been employed by organisations such as IBM, Philips, and the British Airport Authority (Paton \& McCalman, 2008). I do not implement the TROPICS test since I do did not merely want to focus on change involving time scales and resources during the interview sessions for this research; rather, as analysed in Chapter 4 (p. 90 ff.), a guideline or support such as a communication matrix seems to be very helpful for middle managers working in the joint venture as well as reflecting as 'problem owner' and the 'change spectrum'.

But this TROPICS test using as a guide to find a way to determine the change in comparing the terms of hard and soft facts for example as shown in Rees and Hall (p. 10, 2013) can be a useful reference to understand different parameters facing change, but it is very roughly determined for middle managers to let them understand the whole picture when being involved in change scenarios based on a TROPICS test or a change spectrum (Rees and Hall, 2013). To support the decision taking process of middle managers McCalman's model (2008) can be a helpful source but it is limited and doesn't support to see the whole picture, therefore it is mandatory for me to focus on establishing a conceptual framework for middle managers. 
The next key factor is the force-field analysis. As noted above, knowing the origin of the problem is helpful for deeper analysis of the situation of change. Force-field analysis distinguishes between changes that are generated externally and those that are generated internally. The employee's structure-centred view and the middle manager's view are influenced by the origin of the change. Interview question 6 concerns the force-field analysis of McCalman (Appendix 5, p. 222 ff.) though it is an indirect question that does not ask about the origin of the change. However, the answers the question produced were very helpful and allowed the formulation of recommendations for middle managers.

The fifth key factor described by the authors is that of the 'success guarantors'. As Paton and McCalman (2008) write, a fundamental step in achieving successful change is achieving a shared perception among those affected of the issues and implications associated with the change. This shows how important it is to consider the perspectives of the entire group of employees in order to develop a common perception. This fifth step was the one I focused on during the interview sessions the most out of McCalman's model. In the course of analysis, when clustering the findings (Chapter 5, 132 ff.), I saw from the middle managers' responses how important it is for them to involve employees. Without this involvement in the change process, it is difficult for an organisation to drive the process itself, especially one that involves two national cultures and corporate cultures in a joint venture.

How can changing processes, structures, and even organisations be managed successfully, and how should middle managers deal with these situations? According to Makumbe (2016) McCalman's model describes stages for an effective change management to help managers to improve the understanding of change management on staff level. The value of this model for my work is mostly in the fifth step, which promotes the inclusion of all employee perspectives, especially those of the middle manager level, as middle managers act as the link between upper management and staff. This view, alongside that of McCalman (2008), can be seen in the recommendations formulated on the basis of the interview outcomes in Chapter 4 (p. 90 ff.) and Chapter 5 (p. 132 ff.). But according to Makumbe (2016) organizational change without an appropriate management, employee engagement and motivation, as well as the right communication can't be successful and these points are not considered in McCalman's model (2008). Another aspect related with the model of McCalman (2008) is to have six key factors but it is not in a relation to each other and not in a framework (Todnem, 2005). Therefore McCalman's model can just reflect parts of the given answers from the middle 
managers but for my work a conceptual framework is needed.

'Managing triggers' is the last factor described by Paton and McCalman (2008). Managing change, with all its associated triggers and network structures, forms the crux of this element. The authors explain that it is akin to a web: if you do not handle it carefully, it might break. In the analysis of the findings in Section 4.2 (p. 92 ff.), I interpret 'network' as a collaboration in the form of information flow and communication. This was frequently highlighted by the Chinese and German middle managers during the discussions. Therefore, I stress the importance of this key factor identified by Paton and McCalman (2008).

In their model of the processes of transformation, Paton and McCalman (2008) note that certain triggers are necessary for the implementation of a new process. This is true for processes of change in changing organisations with changing structures, especially in times of difficulty and pressure, such as in the automotive sector, which has very brief product rampup times. These researchers also emphasise the importance of communication: by sharing ideas regarding implementation and what follows it, middle managers can forestall fears and reach out to subordinates (McGurk, 2011).

Hofstede's (2005) model plays a role in my thesis; however, I give more consideration to works which are more up to date and add content to Hofstede's basic model, such as that of Beugelsdijk et al. (2016), Apetrei et al. (2015), Eisend (2016), and Ghemawat and Reiche (2011) which I discuss in the analysis chapter (Chapter 4, p. 90 ff.), as along with Paton and McCalman (2008) and the Schein’s (1999) view of corporate culture. For change management to occur during the implementation of a project or in the course of organisational change, employees must be supported by their managers so that they may adapt to the new situations in their daily operational working lives. Through better collaboration, the team can begin to learn (Sackmann, 2004). Gattermayer and Al-Ani (2001) define change as the steering of processes, with all employees involved in the initiation, arrangement, and implementation of the changes. Managing change in the long-term is aided by proactive change management, such as planning and preparing for these situations in the intercultural framework. If a change emerges, the manager must take the lead to prepare with employees the process flow and must initiate, arrange, and push the implementation of the process (Bate, 1997).

Bate (1997) discusses the importance of national culture, which has been considered in management leadership and training sessions since 1980. As it is not directly part of the day- 
to-day work in the production department, it is important that managers are concerned with and focus on culture-specific topics, especially in the case of working collaborations between people from different countries in joint ventures who rely on a third language for communication.

It is for this reason that I conducted the interviews with middle managers. It should be noted, however, that the interviews provide the views of the middle managers in the production department in the observed joint venture company and not the views of other departments, staff levels, or upper management.

The next important factor in my work that is relevant for the analysis of the interviews is the work of Kotter and Cohen (2002). They interviewed 400 employees from different kinds of institutions and identified how change management projects commonly fail. The focus of the interviews was Asia. The guidelines generated from the sample are intended to support survival of change management reversals. The authors note that the failure of change projects is often due to the behaviour of employees, especially the actions of managers in relation to the right time for communication or to the content of the communication, lack of structured management, and the absence of a suitable team. The views of the managers and the failure of change projects due to the behaviour of those middle managers are important factors in my thesis. Kotter and Cohen's (2002) guidelines comprise nine processual items: creating urgency, guiding the team, using strategies, communicating visions and strategies, empowerment, short-terms wins, consolidating change, nurturing the new culture, and making change stick. These items are important from my perspective, and I considered them in my interview questions, although I did not use precisely the same terminology.

One of the focal points of this study is the manner in which middle managers in the automotive sector deal with 'change projects' in an international cultural context and how they support their staff in handling changes by reducing fear and resistance (Nieswandt, 2015). The strategic focus of this research is the perspective of the managers (Nieswandt, 2015), particularly their cognitive processes (Bakos et al., 2016; Nieswandt, 2015), as they are the most significant practitioners of change. Of particular interest for me when I was preparing the interviews and analysing the responses were the existing methods used by middle managers and the kinds of assistance they currently accept (Evans, 2015). The primary objective here is to explore how middle managers deal with organisational changes in conditions of extremely short product ramp-up times. Product ramp-up in a manufacturing company refers to the period from the start of production to the point when the number of units produced reaches the upper limit. The focus 
here is the individual middle manager: not the senior-level manager, but rather the mid-level team leader (Albach et al., 2015). Middle managers are often foregrounded in research due to their connection with staff members who perform the work processes. Albach et al. (2015) write that in order to execute engagements and attain project targets, the change process must begin at the level of employees, and it thus affects the organisation as a whole. Here, I refer to two types of middle managers and examine two different groups: middle managers in the joint venture who have a Chinese cultural background and middle managers from the headquarters in Germany who have a German cultural background and are working in China. Even within the same company, a difference is observed: the company operates under different names at the central German plant and in the joint venture company in China; in this work, I focus on the middle managers who are defined as such at the Chinese plant.

The present study reviews established knowledge of the features of corporations as these relate to change management and culture (Schein, 1985). The corporate culture of a firm can be a barrier for staff and managers. Cultural differences may lead to the failure to achieve goals (Homma \& Bauschke, 2010). Cultural differences - especially those concerning the leadership behaviour of managers and their decision-making practices - may lead to failure (Vlasic \& Stertz, 2001).

For the purpose of this study, change management is taken to mean the active co-ordination of procedures, employees, and information technology in order to ensure that employees, middle managers, and company management are willing and able to adapt to the required new mode of behaviour and its goals (Berner, 2010). If the corporate culture can achieve this, and all the desired and appropriate changes are implemented, a process of internalisation begins and all newly defined aims become integral to the corporate culture (Beer, Eisenstat \& Spector, 1990). Understanding both corporate culture and national culture are important for success in business (Berner, 2010). Many studies using Hofstede’s culture definitions and understanding have shown that Eastern and Western countries have different values and therefore different cultural understandings (Kim et al., 2016). However, in relation to the work of Beugelsdijk et al. (2016) and the findings that were derived from the interview sessions, Hofstede's work was one of the first findings in the literature on a model developed in relation to national cultural and the different cultural dimensions. However, in the context of further understanding of development and change from a practical point of view, Hofstede’s work can be criticised; therefore, I consider it as basic model and add additional literature, such as the work of Beugelsdijk et al. (2016), Ghemawat and Reiche (2011), Yin (2014) and Paton 
and McCalman's model (2008).

Cultural change is a conscious, controlled process that aims to alter an existing, strategic corporate culture. In the context of managerial economics, it can be defined as change in the corporate culture (Deal \& Kennedy, 1982; Sackmann, 2009). Deal and Kennedy (1982) argue that long, protracted, and expensive culture change can lead to resistance and excessive demands. Some middle managers face resistance from their subordinates (Sackmann, 2009). The aim of any upcoming changes in processes and change in the corporate culture falls under the umbrella of change management (McGurk, 2011), which is described in Section 2.1, p. 29. In Section 2.2 (p. 44 ff.), the key characteristics of the two cultures in terms of business behaviour are described. This is the challenge in the observed joint venture company. To ensure successful collaboration between the cultures, the employees need broad professional competence. In the literature, this is described as an important point to consider for enhancing communication in relation to the linguistic, applied geographical, and intercultural levels of competence described in Section 2.2, p. 42, and Figure 3, p. 42.

People from other countries do not understand local markets and customer satisfaction in the same way as locals do, as is emphasised by Berner (2012). Numerous studies of international cooperation and cultural change (Ala \& Cordeiro, 1999; Ali \& Ivanov, 2015; Bendt, 2000; Chin, 2010; Dellner, 2009; Dubina \& Ramos, 2016), as well as current articles on the automotive market (Shaw, 2016; Aula \& Heinon, 2016; Garcia, 2015; Beech \& Macintosh, 2012; Booth, 2015) and discussions that I had with colleagues - both at the company at which I currently work and in other firms in the automotive market - have illuminated issues of Chinese culture and cooperation for me.

My study of the Chinese language has taught me much about the country's culture: even the pictorial representations in the ideograms used for writing have meaning. A major assumption of this work is that differences between the people of China and Germany should be identified and accepted. Personal relationships should be supported in order to build trust and define the rules for cooperation and the procedures for implementing change management projects.

According to Tan and Chow (2009), when people emigrate, as in the specific case of German workers moving to China, it is interesting to note the languages that the immigrants speak, the cultures they teach their children, and whether they choose to reshape or maintain the values and ethics they have brought from their own countries. According to Aycan et al. (2000), it is 
expected that organisational culture and its decisions will be affected by the managers. Aycan et al (2000) says that the national cultural values of managers affect an organisation's corporate culture. This includes the nations in which the managers have lived, worked, or studied. This has relevance for my interviews because, although the middle managers are Chinese and German, some of the Chinese managers have previously worked or studied aboard in Western countries. The German middle managers have worked in Germany and now live and work in China which also affects their decision-taking culture and the values they bring to the joint venture. Regarding cultural change or cultural fit, the Chinese staff have brought to management decisions and practices values from both Chinese culture and the cultures of various other countries (Kim et al, 2016). Kim et al. (2016) state that those companies that cooperate with foreign-owned companies use Western work experience and practice in their daily life to a greater. This is a point of view I discuss further in the analysis chapter (Chapter 4, p. 90 ff.), highlighting whether this outcome of Kim et al.'s (2016) work is applicable or whether it can be refused in this case and in the points of view expressed in the findings of my work. Kim et al. (2016) discuss the idea that Chinese employees show more Westernised thinking in their working styles and decision-making processes. However, they also recommend cultural values and suggest that one should not assume that Chinese people, employees, and managers share Western values, or even Eastern values or those of their own society.

As Ogbonna and Harris (2002) state, there is a gap between academic theories of cultural change and the practical perspectives of organisations. They base their discussion on insights from a cross-national comparison of the hospitality industry. However, regardless of which industry is observed, the observations are sourced human beings and their interactions with different people from different national cultures. Especially interesting is the view of the German middle managers who work and live as expatriates in China. How do their viewpoints change? Continuous improvements in processes and organisational structures are special and need to be taken care of according to Ogbonna (1993). Middle managers should therefore be integrated into a process of continuous improvement. Cultural changes and related change processes should be controlled centrally by managers and not directly by staff.

Why is communication important for change management and changing processes? Communication is defined as receiving a message from a sender (Umstaetter, 2000). The sender and recipient must use the same character set for the information transfer. An interaction takes 
place between two or more people who may be affected by a common action. Umstaetter (2000) refers to information transfer, while managers talk about more efficient communication. Though many people would say that it is easy to talk to others, communication involves more than this. It is a complex process which includes emotions, acceptance, an aptitude for learning, one's own attitude and cognition, as well as the distribution of power. The sender-receiver model in Figure 2 shows the key aspects of communication (Franken, 2010).

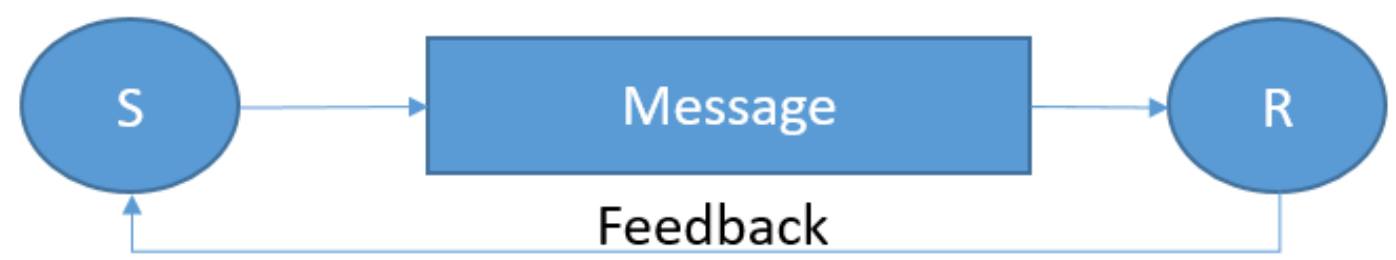

\section{Figure 2: Sender-receiver model}

Source: Franken (2010, p. 17), adapted by Ayse Yilmaz

The sender sends a message that is transliterated through a special filter. Subsequently, the messages are transported through a channel and decoded by the receiver using a filter. The model in Figure 2 was translated from German into English and Franken (2010) explains in his work that the message is dependent on the filter and the transfer, and thus can be changed by the receiver. Feedback is important in this sender-receiver model: this is the purpose of the communication. The reaction of the receiver to the message is the focus of the sender, and feedback can reveal how the message has been received (Franken, 2010). Communication takes place between different people in the company. Intra-company communication describes information and knowledge transfer within the company, and company external communication occurs with all the players the company stays in touch, such has suppliers, customer, and the public (Franken, 2010). Intra-company communication has the aim of information, activation, and commitment as external effects.

Communication is important during processes of change and in relation to culture. Barmeyer (1996) describes the three dimensions of professional competence in relation to communication (Figure 3). 


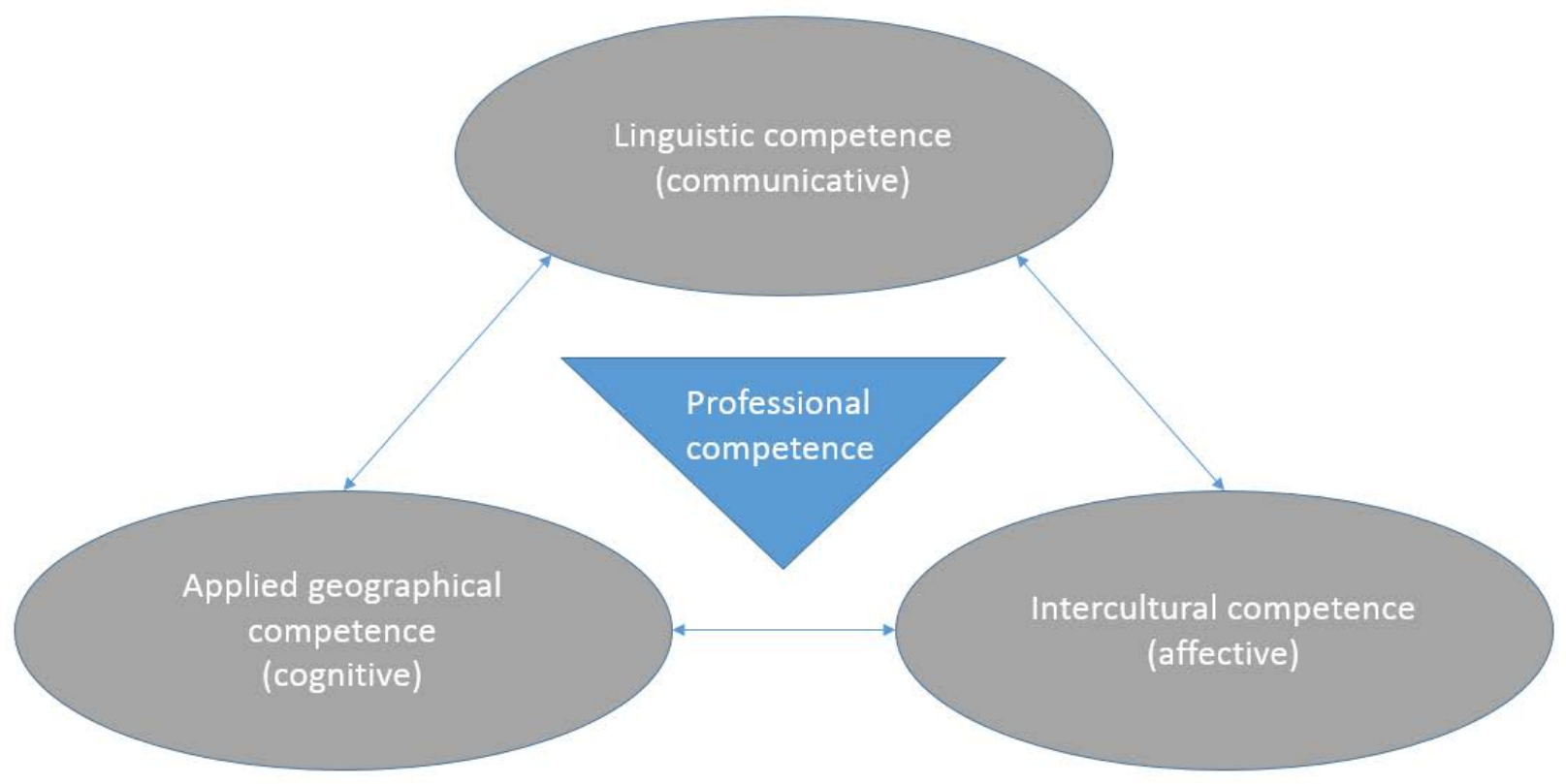

Figure 3: The three dimensions of professional competence

Source: Barmeyer (1996, p.12), adapted by Ayse Yilmaz

The first dimension is linguistic competence and refers to the fact that a person can actively engage in conversation (Barmeyer, 1996). In intercultural cooperation, there is usually a lingua franca which is the language of a larger multilingual space. The second dimension is applied geographical competence, which exists at a cognitive level. Here, the focus is on defining or conveying geographical know-how, mentalities, and forms of communication. The dimension of intercultural competence has the largest impact. This occurs at the affective level and is tightly connected to the other two competences.

The term competence centre is important in the context as it refers to the central headquarters of the company in Germany. This is the partner of the joint venture company set up in China which owns the automobile brand. A central function of a competence centre is to regulate the processes of training and qualifying employees through the transfer of know-how to the production departments of the other production facilities. The competence centre disseminates the skills of the employees, including expert knowledge and substantial working experience of the processes required for producing cars. The new production plants in foreign countries (such as BACF in China) are constructed to support production at the central plant in Germany and to more easily and effectively serve the markets in the localities where they 
have been established. The German plant cannot meet the company's entire production needs since it does not have the space to expand. Many companies seek cheaper solutions by building new plants in foreign countries or by launching cooperative ventures with other companies. The German plant in particular benefits from these effects as it profits from the expertise and experience of the Chinese staff at the newly established locations or the joint venture plants. Moreover, the synergistic effects of collaboration can be utilised and can emphasise the uniformity of standards and processes as well as efficiency. This is why it is important today to have a centre of competence. In this case, the German plant is co-operating with a Chinese firm as a joint venture partner, having built a new plant in China to better cope with issues in the automotive industry when transferring know-how from Europe to China while maintaining the standards of the centre of competence. The question arises as to how qualifications and training, transfer of know-how to new production plants abroad, and the ramp-up of new series of vehicles can be easily implemented. Since the venture is located in China, almost $50 \%$ of the management is appointed by the central German plant, as described in the joint venture contract. Some on-site engineering and planning positions in China are filled locally to support the local Chinese staff with professional know-how of the standards and processes of the German plants. In China, everything is dynamic and fast-growing (Kim et al., 2016). The German employees bring benefits to China as well as learning from Chinese staff about how to implement and improve new projects or organisational changes.

\subsection{National and Corporate Culture}

Change management and culture are terms of intercultural relevance for managers coping with cultural differences between countries and with employees implementing associated processes (Section 1.2.2, p. 17 f.). For German companies entering the Chinese market, sociocultural factors need to be taken into consideration (Praxenthaler, 2018). Communication, relationships, and - for the Chinese in particular - guanxi and social reputation are very important (Praxenthaler, 2018; Luo, 2007; Jing, 2006; and Gesteland and Seyk, 2002), as was observed during the interview sessions. In this section, I explain the background and meaning of national culture and corporate culture. Economic success can be achieved if there is careful handling of cultural differences (Hofstede, 2005). I compare the cultural differences of Chinese and German middle managers, using the literature of Ghemawat and Reiche (2011) regarding the business implications of national cultural differences.

As national culture, culture is by definition important and has a local value (Sackmann, 2009; Eisend et al. 2016). The culture is collective and there is strong group consciousness. 
According to Yin (2014), Chinese culture is not principle-oriented in the manner that German culture is. This means that after each step and each change of situation, the Chinese person begins with a new thought about the next step to take and moves forward one step at a time, whereas European people act according to a plan they have developed (Kim et al., 2016). This characteristic of national culture can affect group thinking in the course of collaborative work. Hogan and Coote (2014) and Schein (2019) especially express the importance of close relationships to generate openness and trust. The authors also refer to the culture in the organisation and national culture as being connected to leadership and management; in this regard, I come closer to the gap I am intending to close at least somewhat: do middle managers need to improve communicate change to employees in a better way in a joint venture. Therefore, for Westerners, the behaviour of Chinese people can be difficult to predict. Chinese people avoid open and controversial discussions. It is difficult to find conflict or argument within the Chinese culture. Direct and confrontational negotiations do not lead to successful results (Preyer, 2009). This is very different to German culture. Chinese people tend to employ a strategy of avoiding conflict as harmony is of the utmost importance (Praxenthaler, 2018). Chinese people are very humorous (Preyer, 2009). Similarly, for Chinese employees, cooperation with German people is often difficult. For those working at Chinese production sites, given that the time zones of Europe and Asia are far apart, daily business communication is only possible at specific times of the day (Yin, 2014). With the great distances, different time zones, and cooperation and communication limited to certain time slots each day, short time periods are available in which to achieve the desired results. There are also different holidays in the two countries. For example, Chinese New Year is celebrated according to the lunar calendar in January or February and plants are closed for the week preceding it.

Kluckhohn (1951, p. 52) defines culture as a conglomerate of 'patterns of thoughts, feelings' and actions acquired characteristically in groups and pictured in artefacts. However, in order to critically consider the theories of Andersen (2014), Apetrei et al. (2015), Bate (1997), Beugelsdijk (2016), Eisend et al. (2016), Floyd and Wooldridge (1999), Ghemawat and Reiche (2011), Hitt et al. (2007), Hoogan and Coote (2014), Kluckhohn (1951), Macharzina (2005), Sadri and Lees (2002), Sackmann (2004), Schein (1985), Waisfisz (2019), and Yin (2014), it remains insufficient to place these theories in an intercultural framework that comprises Asia and Germany. None of these works discuss international collaboration and the cultural differences between Germany and China, in particular those relating to business culture. One must look beyond mere feelings and actions, given that culture is more than these (Mantere, 
2008). Furthermore, none of the abovementioned authors describes culture in the context of a joint venture. The authors refer to a model of culture and change management, though none mention a link between a model of internationality, working with people from different cultures, or working in a joint venture. It is on this basis that I have identified a gap in the literature which this thesis seeks to fill.

The reasons for an establishment improving its culture are varied. Schneier and Beatty (1994) distinguish between internal and external triggers. An internal trigger may involve the ineffectiveness and inefficiency of corporate structures, as well as a serious mismatch between corporate strategies, organisational structures, and the existing corporate culture. Wide-ranging changes should be implemented using the key processes and structures of organisations (Beugelsdijk, 2016). Other internal factors include rapid inorganic growth and the collapse of sales or profits (Gomez \& Müller-Stewens, 1994). Internal triggers may include changes in integration or the merging of corporate departments (Apetrei et al., 2014). Denison, Hooijberg, Lane, and Lief (2012) state that managers often ignore changes and focus on, for example, cash flows and purchases for upcoming projects. As Gerstner (2002) notes, culture is not a single aspect of the organisation, and the organisation must create the value together with its employees. Schein (1999), the father of the concept of organisational culture, says that culture must be managed, otherwise everything is managed by culture. However, Ogbonna (1993) asks whether either national or corporate culture are really manageable. This question is critical to this investigation of change management and cultural factors.

Hofstede (2005) refers to his five-dimension model as one of cultural dimensions and national cultures. The conceptual framework I initially developed, which was in line with Hofstede, Ghemawat and Reiche (2011), and McCalman and Paton (2008) indicates that national cultures must be properly considered and well reflected as they are key concepts in daily business life. Ghemawat and Reiche (2011) explain in their work how national cultures in an inter-cultural environment, if they reflect the business behaviour of managers, can be supported based on a pattern of trust. This is also reflected in my analysis of the interview material. Four types of flows can be distinguished when studying an international working environment and inter-cultural business behaviour. These are information, people, products, and capital. Information flow is shown in Figure 5, p. 53 by means of the arrows. The people in my study are the middle managers, while the product in the observed company are the vehicles which have been produced, the observed company itself and the production department and capital I don't consider in my work.

Since middle managers are the focus group of my work, an understanding of leadership styles 
in cross-cultural and intra-cultural management and the effects of this on employees is important. Adler (2002) explains that an effective leader is one who motivates his or her employees and those working with them and who knows what ideas and visions are important for improving the organisation. Since leadership is no longer limited to national work collaborations, international and cross-cultural communication increasingly influences modern business success and communication. This is relationship-building. As Hofstede (2005) explains, leaders must understand the societies in which they live and work and must understand the behaviours of these groups. As Adler (2002, p. 136) points out, 'styles of leading, motivating, communicating, decision-making, planning, organizing, and staffing vary among countries the world'.

Hofstede's work (Section 2.2, p. 44 ff.) is especially useful for understanding cross-cultural dimensions and cultural communication (Smith, 2015; Ghemawat \& Reiche, 2011). For Hofstede (2001), people think, feel, and act differently, but there remains a structure which he describes as the 'structure of mind' (Hofstede, 2005, p. 2). This 'mental program' (Hofstede, 2005, p. 2) means that each human being is in a social environment. Mental programming begins in infancy, with many factors forming the human being, including family, friendships, employment, and the social milieu to which one belongs. This is the personal culture of each individual person living in a national or organisational culture. Therefore, culture is the collective programming of the mind of the individual, and can be distinguished from that of other groups, nations, and organisations (Hofstede, 2005). Though each person learns collective programming in early infancy, it is also formed by the culture in which one lives and the organisation in which one works (Beugelsdijk et al., 2016). Ghemawat and Reiche (2011) point out that information flow between people is as important as the so-called 'mental program' of Hofstede's model. Ghemawat and Reiche (2011) too point out that language is an important factor; I can confirm this as I found it in my analysis too. In the observed organisation, the middle managers refer to the use of a third language as sometimes being difficult for both cultures, and as leading to misunderstandings between the groups of German and Chinese employees or middle managers. The adaptation of the management level and its importance are also highlighted in Ghemawat and Reiche's (2011) findings, though they do not focus on middle management or on a special joint venture between companies from China and Germany as I do in this study, in which I add additional findings to contribute to knowledge and research.

Hofstede (1990) developed another model of culture. His study of 20 case studies demonstrates how national cultures influence organisational culture. Hofstede's model is very close to that of Schein (1985). Hofstede refers to cultural characteristics that can manifest at 
different levels and in different locations of socialisation. He takes an onion as an example: the exterior represents symbols such as images that have meaning for the organisational culture. Beneath this level is what he calls 'heroes', or persons of importance in the organisation. The next level is that of rites, or values, paralleling Schein's model. This third level is the most complex as it describes invisible values. Here again, we note the connection to Schein's iceberg model which is introduced in Section 2.2 (p. 44).

The term corporate culture (Section 2.2, p. 44 ff.) originates in the concept of culture (Sadri \& Lees, 2002). Macharzina (2005) writes that the cultural features of an establishment are drawn from the cultural features of its society, with the universal term 'culture' being transferred from the latter to the former. Schein (1985) was one of the first authors to define corporate culture, referring to it as a pattern of basic assumptions (as introduced in Section 2.2, p. $44 \mathrm{f}$. with the iceberg model) invented, discovered, or developed by a group as it learns to cope with problems of external adaptation and internal integration. Corporate culture is one that has worked sufficiently well to be considered valid and thus to be taught to new members as the correct way to perceive, think, and feel in relation to those problems. In this section, I further discuss Schein's organisational culture model (Figure 4, p. 49) and explain the connection between Schein and Hofstede (Waisfisz, 2019) and their importance for my work.

When I began this research, I considered using Hofstede's model with the addition of Apetrei et al. (2015), Beugelsdijk et al. (2016), Eisend (2016), Ghemawat and Reiche (2011), Waisfisz (2019) and their organisational cultural perspectives. However, having explored the model in depth, I determined that there must be more to culture than it proposes, as Waisfisz (2019) also analyses and describes. I subsequently discovered Schein’s model, which, although is close to Hofstede's, reflects the dynamic situation of markets and is thus a good foundation for this study. In relation to Schein's model, I also take into consideration Apetrei et al.'s (2015) point of view and the discussion of how culture shapes international business. The authors highlight the importance of adaptation and standardisation, which is crucial for my work and which I considered in analysing the interview sessions in order to generate appropriate recommendations from up-to-date data. Schein (1985) refers to three levels of organisational culture: artefacts, espoused beliefs and values, and basic underlying assumptions (Figure 4, p. 49). He defines artefacts as visible organisational structures and their processes, which, for him, are difficult to decode. Espoused beliefs and values are the goals and philosophies, as well as strategies that are forms of justifications. The most difficult 
level is that of underlying assumptions, which encompass feelings and thoughts. For Schein (1985), these three levels affect one another. I adopt Schein's model based upon my work I share Schein's definition of the dynamic process. I decided to combine different models from the literature, as described in Section 2.1 (p. 29 ff.), in order to analyse the findings and their limitations.

Schein (1984) writes about the terms and definitions of culture, corporate culture, and transculturation. He considers an establishment to be a clearly defined social group when it has social patterns. The group should be able to solve problems that emerge both externally and internally (Schein, 1996). The adoption of these patterns is obligatory for the new employees of a corporation (Schein, 1984). All employees should integrate themselves - along with their thoughts, senses, and feelings - into this pattern (Schein, 1996). This basic pattern manifests itself in organisations in a certain set of moral concepts, standards, and norms for behaviour that are then represented in artefacts and symbols (Schein, 1984). Beugelsdijk et al. (2016) suggest distinguishing between country and cultural effects, which is not a feature of Schein and Hofstede's work. Hence, there must be differences when examining different countries, here China and Germany. Nevertheless, Schein's thinking may not be always perfect and it arises from a particular point of view and perspective (Apetrei et al., 2015). In the conclusion to this work, I combine various models and authors' points of view in order to close the research gap, while also adding my own findings to the existing literature.

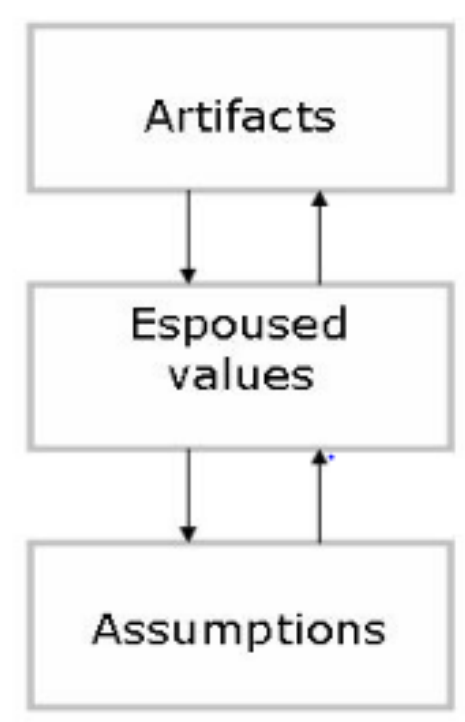

Figure 4: Schein's organisational culture model (Schein, 2003, p. 36)

Source: Organisational culture and leadership

http://www.businessmate.org, p. 36 
The alteration of corporate culture by means of selective change management often reveals both open and previously hidden resistance, both of which can lead to failure. The literature often terms these 'soft factors' (Kotter \& Heskett, 1992). Intra-corporate resistance is mentioned in the literature as the main cause of the total breakdown of an establishment (Grochla, 1995). Hence, the literature clarifies that intra-corporate resistance is the main obstacle to successful change management. Organisational changes are most often handled quickly, though it is still ultimately human beings who lead the firm and execute the changes. This study also examines the resistance of employees to change projects and in Chapter 5 (Section 5.3, p. $147 \mathrm{ff}$.) discusses possible ways of counteracting this. The key limitation of my work is that the research questions and objectives focus on the viewpoint of middle managers. The perspectives of employees are not been analysed in this thesis.

The difficulty and complexity of culture is that there may be many different perspectives and levels that, however, do not provide a comprehensive picture. There are many disciplines that examine culture, such as ethnology, philosophy, sociology, psychology, anthropology, and cultural studies (Neubauer, 2003). Each of these views the concept of culture in different ways and has different aims. Thus, they all belong to different 'schools' and no single meaning is attached to culture.

In the course of the literature research, while searching for a definition of culture, I discovered a metaphor used to describe the character of organisational culture. Bate quotes Clifford Geertz's account to show how culture is fraught with many difficulties and expresses frustration when working with a concept of culture:

This story is about an Englishman who, having been told that the world rested on a platform which rested on the back of an elephant which rested in turn on the back of a turtle, asked ... what did the turtle rest on? Another turtle. And that turtle? 'Ah sahib, after that it is turtles all the way down' (Geertz, as cited in Bate, 1997, p. 3).

First of all, it is important to be familiar with the local conditions. In this case, China and the Chinese local company are the host, and the German middle managers are the foreigners. Regardless of which country is the host, correct behaviour and collaboration is very important. Both guanxi and mianzi, meaning the need to maintain face, are very important in China. For Chinese people, this shows honour and one’s individual dignity (Dallas, 2008). Guanxi comprises two words: guan and xi. Guan means door. Xi means to do someone a favour, which is a very important concept in Chinese national culture, or to have a 
relationship with someone. Guanxi refers to personal relationships with people (Luo, 2007). Lihua (2013) notes that traditional cultural values such as harmony (和谐), wisdom (智慧), courtesy (礼貌), honesty (诚信为本), and loyalty (忠诚) are fundamental to the Chinese cultural psyche. These values have been extremely important in this study, particularly in the course of developing the interview questions and analysing various aspects of the culture in the joint venture. Ala and Cordeiro (1999) discuss the Japanese decision-making process of ringiseido - a trial that provides an opportunity for ranking both managers and employees. This process underpins Japanese culture and further confirms the desire for harmony in the Asian workplace.

Asian people in business are, due to national culture, more relationship-oriented, while German people tend to be deal-oriented (Luo, 2007). Chinese people prefer to deal with colleagues or people who they trust and know well (Luo, 2007). German people, who are more deal-oriented (Gesteland \& Seyk, 2002), conduct business more easily with strangers. Therefore, for middle managers arriving from Germany, awareness of guanxi is key to successfully doing business in China and ensuring good collaborations on the basis of trust and personal relationships (Praxenthaler, 2018).

For Jing (2006), living and working in China without guanxi feelings or relationships with local people is not impossible, but would be very difficult. Anybody coming to China, especially from a European country, should first consider guanxi. Described as the most powerful asset or strength of Chinese culture, guanxi (Yin, 2014) refers to relationshipbuilding between two parties. If one person has guanxi in relation to another, this means that it is easier to do favours for them and support them with necessary and optional tasks.

Chinese people seek harmony in business relationships, in contrast to German people who tend to focus on facts and Figures (Preyer, 2009). Western expatriates in China may struggle to adjust to Chinese Confucianism, which assigns substantial importance to relationships such as guanxi, or working in harmony (Yin, 2014). Western countries tend to focus on personal performance and being more direct and individualist, as opposed to prioritising group thinking and maintaining balance by working in harmony with business partners (Kim et al., 2016). Mianzi means face (Jing, 2006). Jing (2006) states that, in Chinese national culture, mianzi is important in both business and personal life. The public appearance of a person is mianzi, referring to how a person performs in his or her social role (Praxenthaler, 2018), and how this performance affects their reputation in the organisation. Therefore, mianzi can be part of the guanxi a person has with many other persons. 
One middle manager mentioned mianzi in terms of how important it is not to lose face in Chinese national culture, noting that he himself must consider this as a German middle manager working in the joint venture (Section 4.6, p. 127 ff.). Having a good reputation should be seen as an aim when working in China (Praxenthaler, 2018). If a person threatens the 'face' of a colleague or employee, or even his boss, this person automatically threatens his or her own mianzi. My work is limited to a focus on middle managers and their views of their relationships with employees, without consideration of their relationships with managers or, indeed, their employees' views of their relationships with them.

German middle managers can benefit from social networking and collaborating by helping Chinese employees to maintain their reputation and face (Jing, 2006). The German national culture tends to be open and direct, with people criticising their employees in front of others in their business lives and personal lives (Schein, 1985). While this is expected by German people, in China it could lead to a loss of reputation and poor guanxi (Praxenthaler, 2018). Individuals should be mindful of this on the German side and should consider it during business collaborations to ensure harmony. The German culture is individualistic, with personal independence and independent working being highly prized (Praxenthaler, 2018). Germans have a direct style of communication and speak clearly and directly about the things that are important to them. Germans act directly and with principle (Praxenthaler, 2018). The future is planned for the long term. Humour often rests on concrete allusions, settings, and ironic commentary (Preyer, 2009).

For Schein (2003), culture is like an iceberg: there is a part which can be seen easily and another part below the surface. Likewise, in organisational culture, there are parts of the culture which are not visible - such as traditions, attitudes, values, and beliefs which can be heavily challenged. Many companies have failed due to an inability to grasp the nature of this iceberg model (Dallas, 1996). People should first understand their own culture before they can understand those of others. Cultural insights, observation, and self-reflection are important, and face-to-face experiences are essential.

The Chinese and German cultures differ as regards directness and individualism (Dallas, 1996), as described above. For more effective communication, a better understanding of cultural differences is required. Day-to-day learning and reflection support progress, as does consideration of how culture shapes colleagues' behaviour in daily working life, as reflected in the analysis of the interviews. To establish trust, people should show acceptance and 
knowledge of the other's culture. Regular exchanges are therefore of great importance, as is training in cross-cultural communication for management and employees.

In Section 2.3, I discuss the findings from the literature review in combination with a conceptual framework and then provide an interim conclusion and summary for Chapter 2 as a whole. Corporate culture is one of the largest influences on collaborations between middle managers and their staff as they face the challenges of change management.

\subsection{Conceptual Framework, Summary, and Interim Conclusion}

The role of middle management has been enhanced in recent years, though evidently there are no studies dealing explicitly with middle managers’ perspectives on intercultural change in the automotive sector or on the transfer of knowledge to new production sites in other countries in the form of joint ventures. There is thus a gap in research concerning how managers - especially at the middle management level - communicate change to employees and manage change (Speier-Werner, 2006; Thommen \& Grösser, 2012; Wooldridge et al., 2008). My aim is to bridge this gap and to contribute to knowledge of middle management and their staff. The following conceptual framework summarises the key points from the literature review. The gaps that I address with my study are highlighted in the outcomes and updated conceptual framework presented in Figure 11, p. 93.

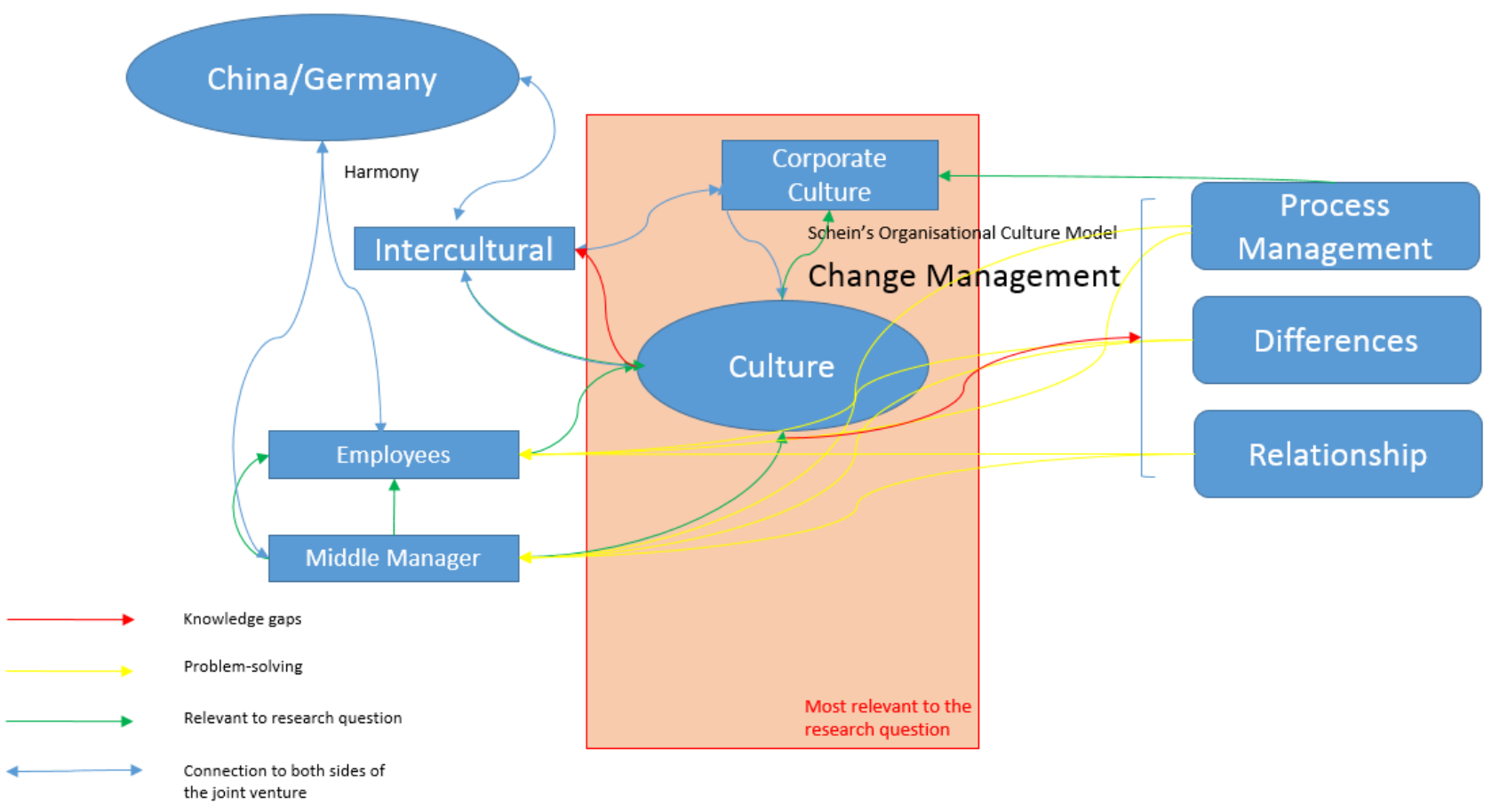


This study takes the example of a joint venture between a German company and a Chinese company in the automotive sector. The right side of Figure 5 above depicts the first conceptual framework I developed in the course of the literature review in order to consider the research questions and research objectives and to introduce the concept of process management (Section 1.2.1, p. 15 f.). Process management considers changes in decision-making about current processes in the production department and refers to the first objective of this research, which is described in Section 1.4 (p. 25). In the literature, 'process management' is shown to be indispensable to organisations in order for them to achieve the most appropriate culture for implementing required change process. Before discussing cultural differences, organisational changes must be considered (Schein, 2010; Beugelsdijk, 2016). The second concept introduced in the figure is 'coping with cultural differences' (Section 1.2.2, p. 17 f.). This relates to the second research objective and involves analysing behaviour. In the literature on joint venture organisations, there is little discussion or analysis of middle management behaviour, although the studies I consulted consider it to be an influence that may require in-depth analysis. The last objective concerns 'relationship-building' (Section 1.2.3, p. 19 f.). This directly influences the employees and middle managers in the conceptual framework presented in Figure 5 (p. 53). This is a particularly important issue in collaboration between different countries.

After a brief introduction to Chapter 2, I began Section 2.1 with definitions of the key and frequently used terms in my work. In Chapter 2, I have focused on the main concepts in the literature on national and corporate culture (Section 2.2, p. $44 \mathrm{ff}$.). The gap in the literature is described to pinpoint the value of my own work. I captured the main findings from the literature, including existing interviews, to identify the kinds of firms and companies examined so far, the kinds of questions asked and of whom, how change management and culture were embedded in the interviews, and the kinds of findings that already exist.

Kim et al. (2016) stress the importance of state-owned companies and their managers understanding what informs their employees' cultural values and national cultural behaviour. These are very complex and thus management - especially change management - should be conducted with consideration of this complexity. Managers must therefore carefully set targets and the cultural orientation of the organisation. Kim et al. (2016) highlight that the potential for further research concerning joint venture cooperation between Chinese and non-Chinese middle 
managers. I wish to take up this option and contribute to closing the gap in the literature with my own findings.

In Chapter 3, I discuss the methodology of the systematic literature review. I discuss how I conducted the interviews in the three phases of piloting, preparation, and conducting and provide an introduction to the philosophy of knowledge.

\section{Chapter 3: Methodology and Methods}

This chapter discusses the methodology used in this work. First, I introduce the organisation under study which was the source of the personnel with whom my discussions and interview sessions took place, then I present the general methodology and justify the selected research paradigm. I also describe the systematic literature review and identify the limitations of the research, most prominently the research philosophy of constructivism that was selected for this study. In this chapter, I additionally discuss important factors, such as ethical considerations and my perspective as an insider in the organisation (Section 3.5, p. 85) as this played a role in the data collection and analysis.

This chapter concerns how I conducted the interviews, including the preparation phase, the introductory meeting with the main participants, the piloting of the interviews with two lean manufacturing experts, and the sample participants. The chapter presents the storyline of the preparation and the approach to the interviews, as well as how I dealt with the various questions that arose.

For the purpose of analysis, I selected the Zwicky method in combination with a morphological box in order to cluster the findings and make the findings as transparent as 
possible by deriving a rating with the help of the morphological boxes. I show how one finding can be further analysed in detail and how I can support the middle managers in the joint venture to adapt themselves to changing situations in the given corporate culture and in relation to both national cultures.

\subsection{The Case-Study Organisation}

This research was conducted at a company in Beijing which is here referred to by the pseudonym Beijing Automobile Consulting Firm (BACF) in order to conceal its identity. The company, which produces cars, was founded more than 30 years ago. The Chinese co-owner has remained the same over this time, but the foreign co-owner - the joint venture partner (Section 1.2, p. 15) - has changed several times, with different foreign co-owners having taken over the partnership and cooperation. The current German company began its cooperation as partner of BACF 14 years ago. The Joint Venture company grew incredibly

quickly throughout the $20^{\text {th }}$ century, and new production sites were built and new departments established. Furthermore, new production halls were built in response to changing market requirements for battery production, and real estate was bought to expand production. As departments grow, change management of processes and structures remains particularly important. On-going and regular training of employees takes place. Increasing the number of cars produced is the focus of middle management.

On the Chinese side, management has not fluctuated, having remained stable for many years, although not with the same number of staff. Here, fluctuation is very high, as the strong Beijing market allows employees to easily find new opportunities. Many different car types and brands are being produced in China, and the market is growing very quickly. At the management level, over the last 10 years an increasing number of new employees have been promoted. On the German side, the human resources department has extended the benefits for engineers and management to include housing, school fees for employees' children to attend private international schools, and higher salaries. These conditions were offered to the German expatriates to make a living in Beijing more attractive as many were unwilling to relocate to the city due to its poor air quality and smog.

I started work with the joint venture partner as a supervisor in the summer of 2017 to train and support local staff (Section 1.2, p. 15). The fast-growing vehicle production volumes in China were very exciting and interesting to me, as was the corporate culture of the joint venture, and I enjoyed the opportunity to bring my ideas, knowledge, and expertise to the middle management level. At this time, I had begun my doctorate, and at the time of my on-boarding, 
I had submitted my RD1 for approval in order for me to write my thesis. Since I was working at the middle management level as an insider (Section 3.5, p. 85) for the company, though not in the same department, I sought approval from the general manager of the production department to interview his middle managers. I had good connections with the interviewees, as I knew each of them personally and understood the topics they were talking about and dealing with. However, the responses to the interview questions were new for me. I focused on the production department, where the product was produced by the workers, to ensure a practical and operational point of view for my research. I contacted all the middle managers in this department (Table 2, p. 74). It was clear to me that I should involve those working in the same company and in the same or a similar department to obtain a better understanding of different and common perspectives. I wanted the middle managers for the interview sessions for their knowledge and know-how. I decided to use my own knowledge and expertise and to focus on those working with me so that it would be easier for me to ask the right questions and give the middle managers hints and examples of projects ongoing at the time. It is actually not easy in this company to get the permission due to the internal program supporting doctorates and an existing cooperation with a German university. But due to a good network and a good relationship with my supervisors I could arrange the interview group after I took the decision to change into an assignment to the plant in China. Having chosen to rely on one department, I was not able to select for gender, age, or education. I wanted to exclude those departments that did not work together or have interfaces with one another in order to keep the sample small. This was because, first, it would have taken a long time to confirm the appointments with them, second, I was not familiar with all the departments and their middle managers or their tasks and daily business and, third, that this is an outcome from choosing a qualitative design which I wanted in order to get details, the underpinning issues of Chinese and German working and change. In China trust is important and is related to culture and if you want to do business well in China, relationships are important. With a relationship based on trust, people can talk openly, which is what I was looking for. Thus, it was a simple decision to select the production department as I was familiar with both the Chinese and German middle managers and trust had already been established in the course of collaborative work.

I knew that some of the interviews would not be easy because, as an insider (Section 3.5, p. 85), I would have more sympathy for one participant than another. However, to the extent that it was possible, I put these thoughts aside and did my best to gather a mixture of answers positive and negative - to obtain the best results for the study. In the following section, I 
introduce the case study in my research.

\subsection{The Research Case Study}

The issue of the management of change processes in production departments in the automotive sector in an intercultural environment is not prominent in studies focusing on middle management (Glaser et al., 2015; Section 3.2.1, p. 58 ff.). A qualitative research model appeared to be the most suitable for answering the research questions (Denzin \& Lincoln, 2000). Such a model does not describe things statistically, but rather uses case studies (Yin, 2014) to empirically support the research assumptions. As Yin (2014) states, a case study and the results thereof can be generalised even if the participant sample is small in size and just one department has been selected for a study to find appropriate results for the research; these results can then be transmitted to the company as a whole. In addition, approval from the company had only been provided for the selected department. Qualitative research can generate the information needed to describe the experiences of middle managers and allows this information to be applied to the research questions and research objectives. Improvements in automotive production using digital or industry 4.0 solutions and battery cars are becoming increasingly important, as is enhancing corporate strategy to place a greater focus on change management. It is important to analyse and research the middle management level as it is the link between staff and upper management and is the bridge between the Chinese company and its partner, the German competence centre (Section 2.1, p. 29 f.). In the following, I introduce the systematic literature review and the limitations for my research.

\subsubsection{Systematic literature review}

For the literature research, keywords were used to search, identify, and sort e-journals, articles, books, magazines, newspapers, and even unpublished grey literature. A focus on authors did not prove helpful for finding the required research content. Instead, the following keywords were used to delimit the range of the literature: change management, knowledge management, social change, cultural change, employee habits, project management, service level agreement, corporate culture, process optimisation, organisational change, middle management, communication, cross-cultural collaboration, changes, joint ventures, clustering employees, reasons for restructuring processes, and motivation for improving change management. These keywords were based upon a consideration of the activity spheres presented in Figure 6, p. 58. 


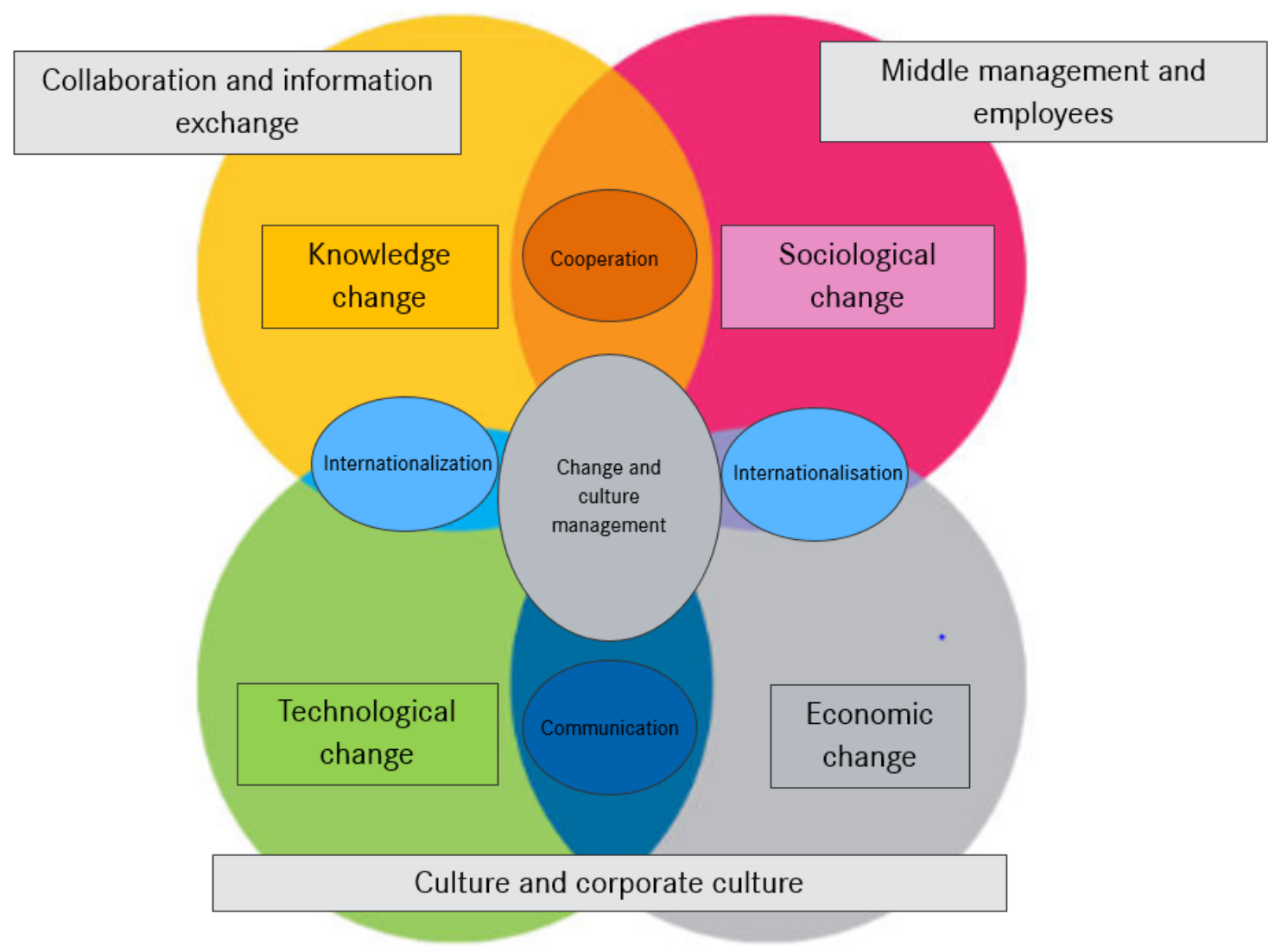

Figure 6: The focus of the literature review

Source: Ayse Yilmaz (August, 2019)

This use of keywords to search for literature that would assist in answering the research questions was important for this research. There is limited literature that can assist managers in handling their teams, provide advice on reducing staff resistance, and motivating staff to accept changes in their work life (Vahs \& Weiand, 2013; Pappas \& Wooldridge, 2007). Some key authors and concepts were found (Chapter 2, p. 29 f.) and these formed the basis of my research. I was able to link these concepts with the research questions and research objectives, the responses to the interviews, and the analysis of my findings. Of course, with the limitations described in Chapter 2, it would be not possible to close the gap in the literature entirely, though I was able to contribute interesting solutions and recommendations to the literature and make suggestions for possible future research.

I used EndNote to organise and structure the findings generated by the literature research. A large number of results is necessary to limit bias when critically analysing and evaluating the literature, as indicated in Step 5 of Hillman's process for producing a literature review (Figure 7, p. 59). This process reflects the approach of the author in the form of a seven-step model (Hillman, 2012). 


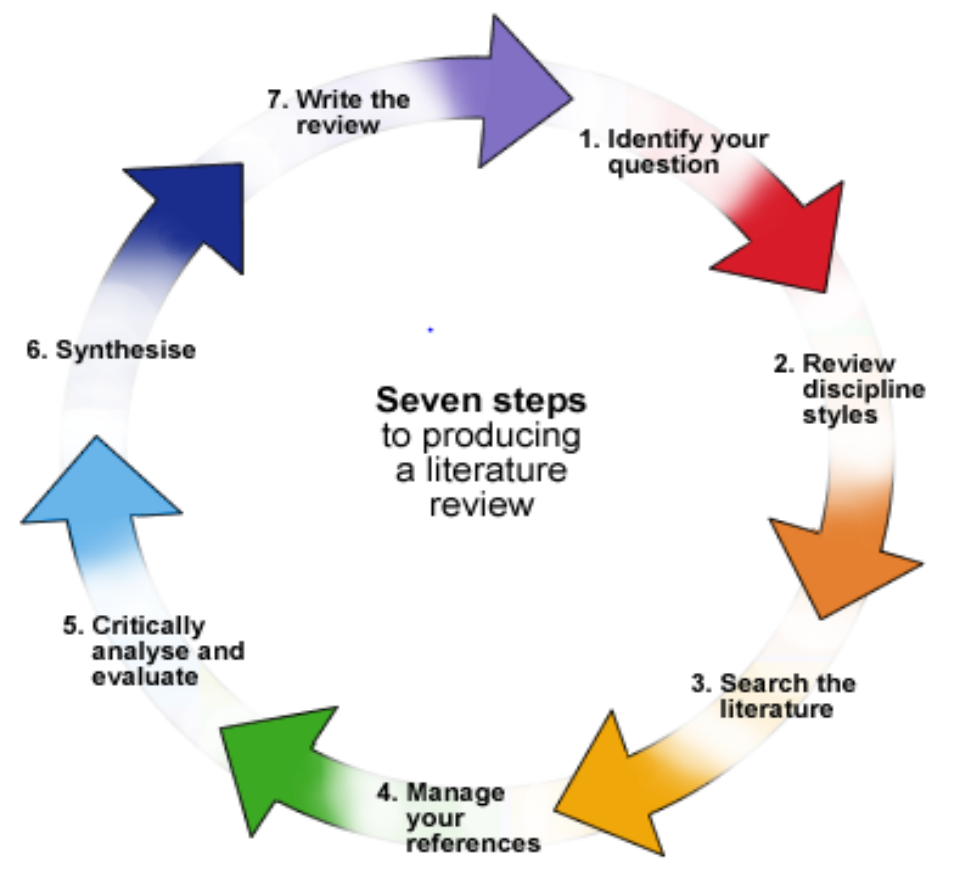

Figure 7: Steps to writing a literature review (Hillman, 2012, p. 54)

Source: 'Course guide for COM-205 Research Methods'

http://www.librarydevelopment.group.shef.ac.uk/showcase/tutorials/lit_review/intro.html 10 March 2016 (accession date by Ayse Yilmaz).

The literature review began with a review protocol that was used to record all of the results from the searches I conducted. All relevant research databases were included in the search process. In Appendix 1 (p. 209), the table displays the databases. Google Scholar delivered the most extensive results, with 4,280,000 studies of 'change management' as at 2 December 2015. To reduce this large number of results, I refined the search terms to 'change management in automobile market', which covered 1,040,000 studies. The title of this thesis ('Change management and cultural factors: A study of German and Chinese middle managers' behaviour in Sino-German automobile joint ventures') yielded 107,480 articles. During the period of the DBA, until October 2019, I regularly checked the literature and I updated my work with the new findings to identify whether the research gap could be closed by the literature that had been produced during this period of 4 years.

The literature search delivered not only practically-oriented literature from that time (e.g. Sackmann, 2004) but also theoretical projections (e.g. Bates, 1997). Many of the studies are based on a theoretical framework, although only a very small range of the literature empirically analyses middle management (Glaser et al., 2015). I integrated some literature on the point of view of upper management regarding change management or culture. 
The meta-analysis in Appendix 2 (p. 210 f.) uses a filled-in circle (O) to indicate a contribution to this thesis's research questions, and an open circle $(O)$ to indicate no relation to the thesis and research questions. The table lists articles, papers, books, journals, studies, and other findings. I synthesised the evidence from these into four categories: author, year of publication, type of paper, and research questions.

The present study focuses on middle managers but also explores various theoretical aspects relating to employee attitudes and habits. A goal of this investigation is to locate these themes within an organisational and intercultural framework so that middle managers can find a suitable strategy and method of execution to achieve their goals. Certain key factors that I identified during the interview sessions and later analysed assisted in contextualising change and culture management (Chapter 4, p. 90 ff., and Chapter 5, p. 132 ff.).

Before writing the review, I synthesised the data. Two of the methods identified in the literature review were meta-synthesis and meta-analysis (Tranfield, Denyer \& Smart, 2003). With meta-analysis, it is possible to discover patterns by comparing relevant studies; thus, such a study combines the findings of numerous scientific studies (Cooper \& Hedges, 1994). Meta-synthesis is a term from qualitative research; it is a popular method for analysing facts and a means of formulating a conclusion based upon different findings the researcher brings together. It is a more qualitative approach which fits my overall philosophy and the approach of social constructivism rather than being one which aggregates the findings of different kinds of studies.

This study focuses on the automotive sector and demonstrates how middle managers in the same department of the same company - and partaking in the same work processes - differ in their levels of knowledge and experience due to cultural differences. Human beings derive experience from their surroundings and environment. In terms of this methodology, I was an 'insider’ (Section 3.5, p. 85 ff.). Constructivism is a research philosophy (Section 3.2.2., p. 63 ff.) in which the social aspect plays a significant role. The aim of this methodology should thus be to discover something new, namely a practical intervention, and to develop theory in research (Easterby-Smith et al., 2008).

The qualitative method can be useful for researching change management. Qualitative analysis offers the ability to examine how changing processes can be explained (Easterby-Smith et al., 2008). Thus, this methodology makes it easier to contribute to finding new theories naturally rather than by means of simulation, as is the case with the methodologies of realism and interventionism.

The interpretation and analysis of a constructivist perspective make sense as the procedure is 
based upon conversation, and people think about meanings while talking with one another. It also fits well with the topic of change management.

In summary, for my research philosophy, I worked with the methodology of constructivism approach.

Table 1 (p. 62) shows the inclusion and exclusion criteria that I used during the literature review phase. First, the language parameter defined the area in which the study was conducted and published. Three languages were selected for the inclusion criteria because I wanted to explore different perspectives from different cultures. My first languages are Turkish and German. My parents are from Turkey, I was born and grew up in Germany, and I work and study using English. I am able to read academic documents in all of these languages. I included Turkish here because, while none of the interview participants are from Turkey, for me, this is the country that bridges the Asian and European continents. The city of Istanbul is divided into two, one part of which is in Asia and the other in Europe. The second criterion in Table 1 is the timeframe, which specifies when the literature was published. I chose to focus on recent literature as collaborative joint ventures are not common in the older literature. The period from 1980 to the present day was selected as the inclusion criterion.

The third criterion in Table 1 is the study criterion and the next, the type of study. The final criterion is geography. Here, I selected Asia, Europe, America, Australia, and New Zealand. 


\begin{tabular}{|c|c|c|c|}
\hline 1)Type & 2) Inclusion criteria & 3) Exclusion criteria & 4) Implementation \\
\hline $\begin{array}{l}\text { A) } \\
\text { Language }\end{array}$ & $\begin{array}{l}\text { English, German, and } \\
\text { Turkish. }\end{array}$ & Other languages & $\begin{array}{l}\text { Studies published in one of } \\
\text { these languages. }\end{array}$ \\
\hline $\begin{array}{l}\text { B) } \\
\text { Timeframe }\end{array}$ & $\begin{array}{l}\text { Literature published until } \\
1979 .\end{array}$ & $\begin{array}{l}\text { Literature published until } \\
1900 .\end{array}$ & \\
\hline $\begin{array}{l}\text { C) } \\
\text { Sample }\end{array}$ & $\begin{array}{l}\text { - Studies focusing on } \\
\text { culture and change } \\
\text { management } \\
\text { internationally in the } \\
\text { automotive sector, with the } \\
\text { integration of middle } \\
\text { managers' attitudes. } \\
\text { - Studies focussing on joint } \\
\text { venture collaboration. } \\
\text { - Studies focussing on } \\
\text { international cooperation. }\end{array}$ & $\begin{array}{l}\text { Literature not focused on } \\
\text { middle managers and } \\
\text { studies not focused on } \\
\text { social aspects of culture and } \\
\text { change management. }\end{array}$ & $\begin{array}{l}\text { - Integrated approach to } \\
\text { corporate culture undergoing } \\
\text { change, cultural aspects of } \\
\text { China and Germany. } \\
\text { - Perspectives of middle } \\
\text { managers. } \\
\text { - Joint Ventures. } \\
\text { - Cross-cultural } \\
\text { communication. }\end{array}$ \\
\hline $\begin{array}{l}\text { D) } \\
\text { Study type }\end{array}$ & Qualitative & Quantitative & Focus on qualitative research. \\
\hline $\begin{array}{l}\text { E) } \\
\text { Location }\end{array}$ & $\begin{array}{l}\text { Europe, America, Asia, } \\
\text { Australia and New Zealand. }\end{array}$ & Areas outside these regions. & Focus on inclusion criteria. \\
\hline
\end{tabular}

\section{Table 1: Inclusion and exclusion criteria}

Source: Ayse Yilmaz (August, 2019)

The literature review identified a number of models for describing change management and culture by means of the use of specific search keywords. However, from an intercultural standpoint and with a focus on the pragmatic handling of change processes (Kanter et al., 1992), only one article addressed how middle managers deal with these processes (Lewin, 2014) and one other with how staff show fear and resistance (Albach et al., 2015). Articles were found that address the topics of middle managers and upper managers and their tasks and challenges; however, these did not include analyses of the relationships to their employees and staff (Pappas \& Wooldridge, 2007). There was no discussion on reducing resistance or on which factors influence workers' fears as they cope with processes of change in a company within an intercultural framework.

In Emerald, ABI/INFORM, and Journalseek, a number of articles described the internationalisation of companies by means of joint ventures and the ensuing processual problems. However, taking a critical stance, there was no connection to employees and their habits or to how managers can adapt to these new working conditions and resolve the challenges 
of how and when to communicate with staff (Bakos et al., 2016).

\subsubsection{Research philosophy}

Brumer (1986) examines how logical and mental perspectives in cognitive science show how human beings act. In this research, I show, from an insider's perspective, how important it is to analyse the experiences and occurrences of daily life. To achieve this, socialising and observing this behaviour are fundamental (Ali \& Ivanov, 2014); this can be seen in the analysis and findings in Chapter 4 and Chapter 5.

Ahmadin and Lincoln (2001) state that qualitative approaches take into consideration social context and human interactions, reflecting the social environment and changes in everyday life. Ahmadin and Lincoln's (2001) statements underlined the selection of the qualitative approach for the purpose of considering and deciding to conduct the interviews and to prepare the questionnaire. Similarly, Easterby-Smith et al. (2008) and Anney (2014) indicate that such approaches enable a researcher to gain an understanding of the lived experience of the participant group. Qualitative methodologies are more flexible than quantitative, and the findings obtained often differ as concerns behaviour, thinking, and observation on the basis of insider knowledge and perspectives (Denzin \& Lincoln, 2000; Golafshani, 2003). A qualitative approach followed by an in-depth analysis of a small sample group - as recommended by Saunders et al. (2012) and Van de Ven (2007) - was deemed the best practice for eliciting the information required.

The selection of this research approach and the chosen research paradigm were analysed and discussed with the tutors and my supervisors over a long period within the DBA programme. This occurred in order to reach the best paradigm and approach for my special case and my situation in the observed company as an inside researcher and, at the same time, analyst and interviewer. The number of participants in my interview sample and the context of my research opened the way for a qualitative approach linked to a constructivist viewpoint in order to set the focus on my research questions and objectives (Golafshani, 2003). Patton (2001, p. 39) holds that research should occur in a 'real world setting where the researcher does not attempt to manipulate the phenomenon of interest'; in this vein, my research also needed to occur in a real world setting.

I took a constructivist ontological stance since individual viewpoints and social constructs constitute the basis of my research and analysis, especially in terms of observing behaviour in the context of intercultural collaboration. 
The results of the semi-structured interviews (Section 4.2, p. 92 ff.), provide an in-depth understanding of the workings of daily business life in the production department. They account both for both managers under stress make decisions relating to their staff members and the kinds of problems that managers face in their decision-making processes. The interviews, questions, and interactive discussion revealed the influence of factors (including cultural differences) that prompt managers to act differently in different situations when implementing change projects. I further discuss the choice of the ontological stance of constructivism in the next section.

\subsubsection{Philosophy of knowledge}

Ontology and epistemology are important in the context of my work and, indeed, in any other research study, and therefore I considered them as part of the philosophy of knowledge. An epistemological perspective is a way of posing a problem, including the knowledge and specific understanding of it (Crotty, 2015). Thus, one can say that epistemology deals with 'the nature of knowledge, its possibility, scope and general basis' (Hamlyn, 1995). In contrast, ontology is the study of being and focuses on the nature of existence (Moses \& Knutsen, 2012). Thus, ontology describes how something is and the understanding of what it is, while epistemology describes the understanding of what it would mean and why it is important to know this.

Bryman and Bell (2007) describe epistemology in social sciences from the interpretivist perspective. This is helpful for the current research as it does not employ natural theories. This thesis analyses the social impacts, habits, thoughts, meanings, and feelings relating to change management from an intercultural perspective. Bryman and Bell (2007) describe the ontological aspect as it relates to a constructivist approach. Here, the relations between human beings are described as instrumental for analysing intercultural relationships and behaviour. Quantitative research explores relationships between hypotheses and theories that have been tested using numerical data, presenting the observer with a deductive view of the relationship between research and theory (Bryman \& Bell, 2007). Researchers in the natural sciences with a positivist bent tend use the quantitative method. Quantitative researchers acknowledge that change management and cultural differences between Chinese and German middle managers in corporate culture are usually measured by numerical key performance indicators (Chin, 2010). In such a methodology, the researcher constructs a hypothesis and tests it using data collected by means of a questionnaire distributed among the research population (Crotty, 2015). It would have been insufficient to interview six middle managers from Germany and 
six from China working in the production department in China. Twelve managers would not be sufficient for the quantitative research method. For the purpose of this study, I wanted to learn during the discussions and to have the flexibility to ask questions that had not been prepared beforehand. Furthermore, I wanted to be able to explain any questions the interviewees did not understand.

Qualitative research emphasizes words rather than quantification in the collection and analysis of data.

\subsubsection{Effective qualitative research}

External reliability is defined as the possibility of replicating a study (Le Compte \& Goetz, 1982; Patton, 2002; Golafshani, 2003; Tracy, 2010; Anney, 2014). Le Compte and Goetz (1982) note that a social state of affairs cannot remain unchanged. They state that the qualitative researcher must come from a similar position in order to understand and reproduce the information and discussion in an interview. Internal reliability is more concerned with examining views that are beyond the scope of this thesis. The current study used the externalreliability paradigm. This means that the paradigm refers to the extent that its measures can vary and does not have to be consistent in results when observing the use of reliability during the interview sessions.

With qualitative research, one has the opportunity to observe, describe, and interpret phenomena. I shared my transcripts with the interviewees and asked others, including my DBA action learning set colleagues and my supervisors, to review my analyses. As Lincoln and Guba (1985) advise, I collected the data in order to ensure a good contribution to practice, and they were used in an interpretative manner.

Regarding the reliability of the interview findings, each middle manager knew at the time of interview that I was an insider with knowledge of ongoing projects, tasks, and their functions in the system. Thus, it was not difficult for me to ask the right questions and to quickly observe the direction in which the answers of the participants were going.

Due to my position as inside researcher (Section 3.5, p. 85 f.), I had a personal connection with the middle managers. I sought to discover how managers coped with the problems of their employees, which methods they already knew, what they were willing to do, and, if they did not want to do anything, why not. These kinds of questions were helpful for finding answers for the middle managers, as well as for enabling them to make life easier for their employees and themselves in an ever-changing technical, social, and organisational work environment. Technical changes were particularly important, since the employees worked in 
the automotive production industry and were confronted with technical issues every day. After deciding on the qualitative approach, I needed to select the most suitable interview strategy. As Silverman (2014) describes, there are different types of interviews a researcher can choose from, including the structured interview, the semi-structured interview, the openended interview, and the focus group. Focus groups are used when the researcher wants to stand back from the answers and act informally and neutrally. This was the basis of my rejection of this type, as neutrality was not possible for me due to my position as inside researcher.

Easterby-Smith et al. (2008) provide a similar classification of interviews: highly structured, semi-structured, and unstructured interviews. However, what do the views of Silverman (2014) and Easterby-Smith et al. (2008) mean in the context of my work? For a structured interview, total neutrality is required from the researcher, with no prompting or support for the interviewees and no improvisation. This was unrealistic again due to my being an insider researcher (Section 3.5, p. 85 f.) - as the middle managers knew me from our daily working lives, they were likely to ask me questions during the sessions. Neutrality and the lack of improvisation therefore made structured interviews impossible.

Unstructured interviews require flexibility. The researcher can gather information by asking questions and receiving answers (Silverman, 2014). The researcher usually begins with some basic questions, since the observer or interviewer typically does not know their participants or their backgrounds. The interviews are open-ended because the interviewer cannot predict the answers of the interviewee. These factors made the method unsuitable for my situation because, as I knew the participants very well and had been working with them on projects and daily tasks in a partner department, I was able to predict some of their answers to my questions. Equally, there was no requirement to ask questions about basic facts, such as their gender or age, since I already had this information. Six middle managers were Chinese and six with German nationality. Table 2 (p. 74) provides an overview of the interviewees’ ages, genders, work experience, internationalization and assignments.

I selected all the middle managers from one department for better comparability and for a better mix of German and Chinese interviewees. To my mind, this was a unique selling point for the department I selected. Usually, for the purpose of asking questions and evaluating the results, the mix of six middle managers from Germany and six from China is unlikely to occur. For this reason, I also rejected this interview method. Rather, I selected the semistructured interview type in the preparation phase and focused on preparing an adequate 
interview questionnaire in order to undertake a good pilot beforehand in order to obtain the best possible results in the free discussions during the interview sessions. Of course, there is always a limitation to this as the interviewed person can discuss with greater freedom any kind of project from the past or one that the middle managers are currently dealing with; this makes the analysis far more complex for the researcher.

In the Section 3.3. I introduce the collection technique used in the interviews and explain the methods of data collection used for my work.

\subsection{Collection Technique Used in the Interviews and Data Collection Process}

The research framework and style were adapted to the research questions of this thesis. The focal point of the research was the practical knowledge and experience of middle management. Having initially considered a written questionnaire which I had rejected due to the chance being an inside researcher in the same company and rather using a qualitative research with gaining more deeper knowledge and information about personal experience with the chance to ask additional questions in between, I decided instead to prepare personal interviews. This enabled me to guide the interviewees and explain the content of the questions by means of examples (Section 3.3, p. $67 \mathrm{ff}$.) as well as add additional information based on my own observation (Section 4.1, p. 90 ff.). Interviews were a suitable way of encouraging respondents to talk about the topics, and thus for discovering more in-depth information about their experiences, their ways of thinking, and their emotions. I could observe as researcher based on the given answers, the reactions to additional questions not listed in the interview schedule and the eye-contact additional input for my research.

The outcomes of this thesis reflect the typical workday of middle managers and their employees in terms of their daily problems and confrontations of change, thereby illustrating the viewpoints of the participants and enabling a critical evaluation of these. These viewpoints are presented in the analysis and the conclusion, while the main body of the thesis provides information and analysis.

The qualitative approach and the empirical research were divided into three phases, as shown in Figure 8 (p. 68). The research questions are affirmed and the objectives depicted. As described in my objectives (Section 1.4, p. 25), by means of interviews and a systematic literature review, I sought to determine how middle managers cope with change management despite the cultural differences in the joint venture. I then identified how cultural differences affect middle managers' behaviour in relation to organisational change, analysing the interview sessions based upon the relevant literature. The central objective was to formulate a 
conceptual framework of culturally based change management factors for middle managers. Based on this framework, I formulated recommendations to support middle managers and their personnel to achieve better communication and to accept organisational or project-based changes with corporate and national culture in mind.
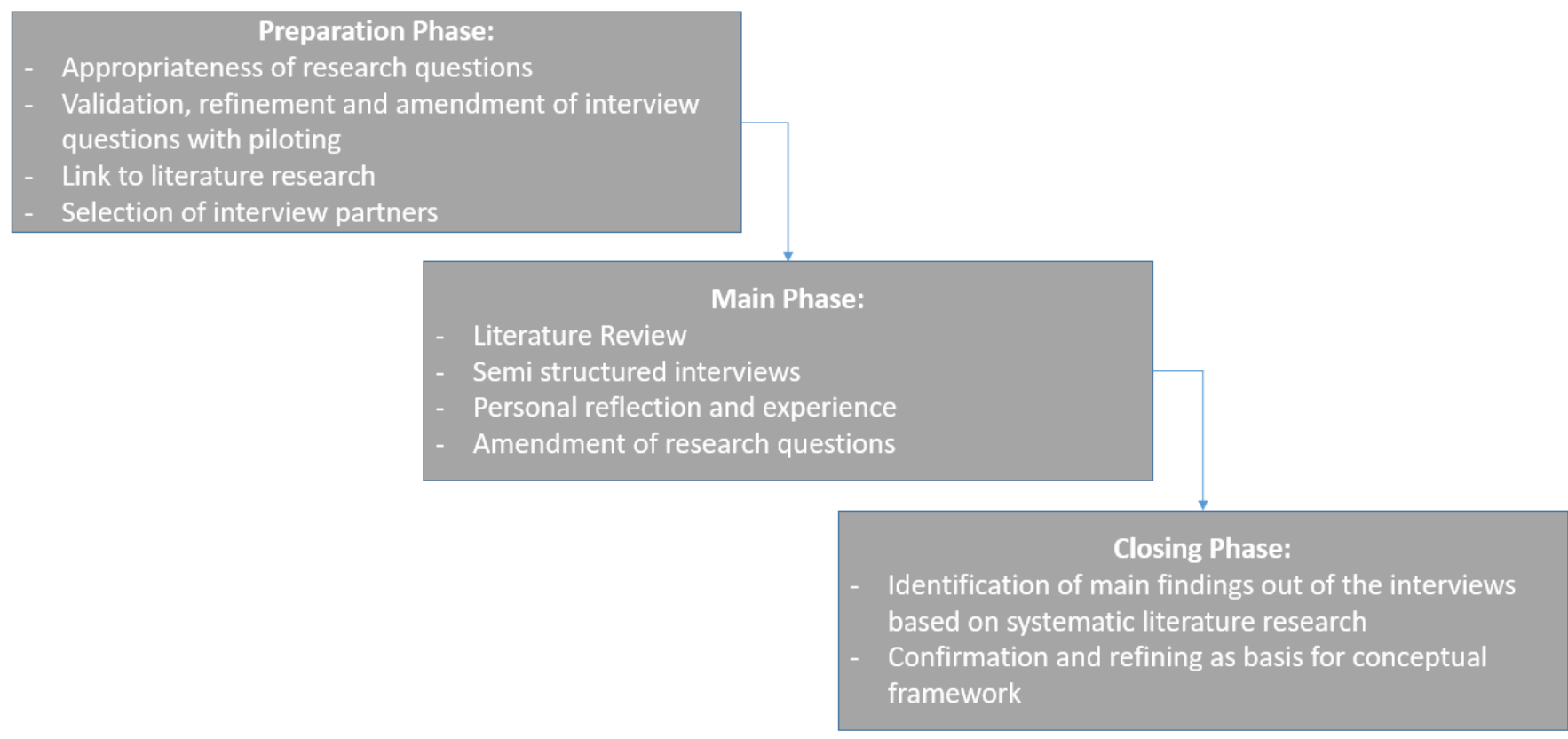

Figure 8: Semi-structured interview sequence: preparation, main, and closing phases

Source: Ayse Yilmaz (July, 2018)

Twelve interviewees - six German expatriates living in China and working in a Sino-German joint venture company, and six Chinese middle managers from the same department of the company (Table 2, p. 74) - were approached to be interviewed. The interview schedule had a total 17 questions (Figure 9, p. 73).

In Section 3.3.1, I note the introductory meeting with the main interview participants which occurred before the pilot interviews with two experts in lean manufacturing experts in January 2018. This was important as I needed to convince them that their participation would be very useful for their work and collaboration. The introductory meeting with the main participants in October 2017 was their first involvement and was required to ascertain the suitable questions for the interview schedule and was a pre-part of the preparation phase (Figure 8 above).

\subsubsection{Introductory meeting}

After selecting the participants, the next step was to obtain their agreement to be interviewed. 
For this purpose, I invited the middle managers to attend a two-hour introductory meeting to talk about my intentions. I promised to share the analysed results with them. I explained in this meeting why I was conducting the research and how I had begun it in order to get their attention and trust. I read out part of a research methods assignment and Analysis DB8004 (Appendix 7, p. 249), which was the research method and analysis theme of the DBA programme. I also invited the two lean manufacturing experts who I had selected for the pilot interviews. All those contacted chose to participate. This was fortunate, since it is usually the case that if one invites 12 people, with two additional for the pilot, some will be unable to participate. As an insider, I found it more convenient to make phone calls than to send out email invitations. Usually, in the joint venture, I experienced that it is much more convenient for the middle managers to talk face to face or via phone call. This was the case when discussing with them the intention of my work and was why I wanted to talk with the middle managers I had selected from the specific department. As the middle managers who regularly work under high pressure usually receive many emails on urgent topics from upper management as well as on regular topics which need to be acted on quickly, an email request for an interview would not have appeared as urgent as other topics in their inboxes. If all those contacted fully understood the invitation, the process would be much simpler.

To introduce the topic of my research, I first called each middle manager to invite them to the introductory meeting and discuss the purpose of my work. I obtained the approval of their general manager and of the company to begin the research and cooperate with the managers in the interview sessions. This had a significant impact on the pre-phase of the interviews since obtaining, first, the approval of the middle managers for the interviews and, second, some hints in the course of the phone calls about how to structure and formulate the questions was crucial to getting them involved in the project.

Six months before the planned interview session, in October 2017, I held the introductory meeting with the middle managers from the production department. I introduced the plan and the current status of the research. The main goal for me was to obtain their agreement to participate in the interview sessions and to share their knowledge, know-how, and experience. The meeting took place in a meeting room at the training centre in Beijing. I introduced the research questions (Figure 9, p. 73) based on the interview guide I had prepared and the research objectives, and presented them using a projector. I explained briefly that I wanted to gather information from the interviews and that this information could support them afterwards. The introductory meeting was useful as they provided me with an opportunity to explain to participants the purpose of the work and that I intended to support them by sharing my findings. 
After asking some questions about the research in the introductory meeting, the German middle managers expressed an interest in participating. The Chinese middle managers then also began asking questions. As I knew these middle managers as a result of my daily work, trust had already been established and I was able to respond to their queries. After agreeing that the thesis would not include the names of the people interviewed or the name of the department or company and that all key information would remain anonymous, all those present at the meeting agreed to participate. I was struck by how strong their interest in the results was - all attendees asking me to provide a copy of the findings which I have done in December 2018 before I have submitted my DBA in final version.

After this successful introductory meeting, I began to put the interview questions together and prepared a trial with the two lean manufacturing consultants. I selected these two individuals because I had a good working relationship with them and had worked with them on other projects. I wanted to have one Chinese lean manufacturing expert and one German. I began by sending out the interview questions to the action learning set group and my colleagues preparing for their DBAs. I also sent them to Professor Dr Marc Helmold and Dr Sue Williams to obtain their input in order to improve the questions.

I attended the interviews in daily working clothes, and the participants were able to dress as they pleased.

Following the introductory meeting, I was thinking, as an insider, about supportive tools in order to be able to choose the participants' ideas as (Section 3.5, p. 85) I already knew a great deal about their jobs and current tasks. Much of the information in my mind was a result of working with the interviewees. Certain ideas that were the result of my experience as being an inside researcher (Section 3.5, p. 85) were helpful in providing examples and hints that would help the participants to formulate in their own minds the ideas they wanted to talk about. Rather than being divided into sections, the interview questions began with general matters, proceeding from a general overview to deeper and more particular considerations, and ultimately reached the personal level after I had gained more trust during the interview sessions. The design of the question list (Figure 9, p. 73) was the result of ongoing literature research and ongoing projects during the pilot phase that concerned changes in the company at the time that this thesis was being written (Fink, 2010).

An expert interview is a systematic, theory-based data collection technique that involves interviewing individuals with specialist knowledge (Bogner et al., 2014). The pilot interviews with the consultants represent the expert interviews in this thesis. An expert is usually an employee with specific know-how (Kaiser, 2014). Within the framework of academic 
research, expert interviews are common. Following the interviews, all the participants were granted an appointment to see the results. Every interviewee was thus informed about the recommendations arising from this study. No problems were raised regarding understanding of the questions. Since both the topic and the aim had already been introduced, the interviews began with an acknowledgment and a short introduction. After the interviewees had received the appointment details, a promise of attendance was required. The interviews were recorded and the interviewees remained anonymous.

At the beginning of 2018, I held the two appointments with the lean manufacturing consultants (Section 3.3.2, p. 71) in order to refine my interview questions and confirmed the interviews with the interview partners. The pilot interview sessions were very helpful for me to get an affirmation for the main phase of the semi-structured interviews.

\subsubsection{Pilot interviews with the 2 lean manufacturing experts}

An important step before conducting the interviews were the pilot interviews which was when I could amend the entire process according to my method. To conduct good pilot interviews before starting the main interviews with the twelve selected middle managers, I decided to select experts who have both good know-how of the processes in production and who know and are familiar with selected middle managers and their employees in the department. To this end, I selected lean manufacturing experts who do work that is similar to that of those who were selected for the interviews. This means that they work together in the same team and form and optimise processes for the production department, including the middle managers and their employees.

The decision to run a pilot was undertaken as recommended by Remenyi et al. (2003).

Remenyi et al. (2003) mention how important it is to conduct a pilot before starting the main phase of the interview sessions with the main interviewees. First, it provides direction for what follows and, second, it confirms the appropriateness of the questions that will be posed. Even feedback to the effect that some of the questions were inappropriate helps to further improve matters (Remenyi et al., 2003). The aim of pre-testing the interview questions was to assess their appropriateness and obtain confirmation of practices within BACF (Yin, 2014). The experts were contacted by telephone and, after an introduction to the topic and the research questions, they agreed to participate in the pilot interviews in January 2018.

The German lean manufacturing consultant was an expatriate who had been living in Beijing for four years and working with this team to support and train supervisors and middle managers to integrate lean manufacturing processes. He had had significant experience with 
the 12 middle managers selected for the main interview session and he knew them well. Furthermore, he had experience with the German central plant and had worked there in the same position for more than 15 years, gaining in-depth experience of international collaboration. The Chinese lean manufacturing consultant had been working in the SinoGerman joint venture for eight years in Beijing, similarly providing support for supervisors and middle managers.

The first interviewee was from the lean manufacturing consulting office. The interview took place on 17 January 2018, in the same location in Beijing as the 12 middle manager interviews; namely, the training centre. The interviewee, a lean manufacturing consultant, was from the German side. He was an expatriate who had been working in Beijing for four years, based on this team with a function of supporting and training supervisors and middle managers to integrate lean manufacturing processes. Furthermore, he had experience of working in other international companies, having previously worked for a British cooperation. The confirmation or lack of confirmation of the research questions by the lean manufacturing consultants seemed mostly suitable, though adjustments were required. On the basis of their feedback, I adapted questions 5, 8, and 11 for the main interviews (Appendix 4, p. 220). The pilot interviews helped me to define the focal point of the research objectives. I was guided by the experts to ask different questions or to explain those I had prepared. The feedback from the lean manufacturing experts provided the opportunity to use them as consultants. Indeed, this is their daily work - to support the production department in generating its processes and to support them in relation to the daily challenges of manufacturing. With the feedback of the two experts, I gained another point of view for my research and for structuring the main interviews. After I had confirmed the appropriateness of the questions for these interviews, I conducted no further interview sessions in the pilot prephase, though I did practice with my action learning set group (Section 7.3, p. 179 ff.) in preparation for the interview sessions. Overall, 17 questions were asked, based on existing literature (Ala \& Cordeiro, 1999; Aula \& Heinon, 2016; Bogner et al., 2014). The recommendations in Bogner et al. (2014) especially supported my formulation of the questions in sequence, and before I conducted the pilot interviews I received advice from my colleagues in the action learning set group. They supported my preparation for the DBA as concerns situations that could arise during the interviews and posing probing questions when there was an opportunity. We had four sessions together. I asked questions and they gave me different responses, such as replying with a question or not at all. 
with adjustments made during the interview sessions so that I could explain something or ask a question in a different manner when necessary. Questions 5, 8, and 11 were answered by the experts, but did not seem to be acceptable and suitable for my research questions. Question 16 was formulated for the middle managers only; thus, the experts did not answer it during the pilot.

\subsubsection{Sample participants}

The intention of the research questions was to confirm their appropriateness and their contribution to knowledge and practice. First, I decided what kind of people I needed to interview. For several weeks, I investigated who would be feasible to approach. I wanted to have the same number of German and Chinese middle managers. In June 2017, I contacted the general manager of the production department for approval to contact the middle managers and begin preparing the interviews. The middle managers selected as potential interview candidates were a mix of newly-promoted candidates (Table 2, p. 74): one Chinese manager had been promoted seven months previously, and one German manager 12 months before. Four had been in a management position for between four and six years, while six of the middle managers had been in a management position for more than 12 years, with experience of different production departments in the same company.

\begin{tabular}{|c|c|c|c|c|c|c|c|c|c|c|c|}
\hline & $\begin{array}{l}\text { No middle } \\
\text { manager }\end{array}$ & Position \& Role & \begin{tabular}{|l} 
between \\
$45-50$ \\
years old
\end{tabular} & $\begin{array}{l}\text { under } 35 \\
\text { years old }\end{array}$ & gender & \begin{tabular}{|l} 
more than 10 \\
years \\
work experience
\end{tabular} & $\begin{array}{l}\text { Work for other } \\
\text { companies }\end{array}$ & $\begin{array}{l}\text { Internationali- } \\
\text { zation }\end{array}$ & \begin{tabular}{|l|} 
promotion \\
being \\
middle \\
manager 1 \\
year< \\
\end{tabular} & \begin{tabular}{|l} 
in middle \\
management \\
position 4-6 \\
years \\
\end{tabular} & $\begin{array}{l}>8 \text { years in middle } \\
\text { management } \\
\text { position }\end{array}$ \\
\hline \multirow{6}{*}{ 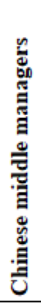 } & 1 & $\begin{array}{c}\text { Change } \\
\text { management }\end{array}$ & $x$ & & female & & $x$ & & & & $x$ \\
\hline & 2 & Assembly hall 1 & & $x$ & female & & $x$ & $x$ & & & $x$ \\
\hline & 3 & Assembly hall 2 & & $\mathrm{x}$ & female & & & & & $x$ & \\
\hline & 4 & New Type projects & & $x$ & male & & & $\mathrm{x}$ & & $x$ & \\
\hline & 5 & Assembly hall 3 & & $x$ & male & & & & & $x$ & \\
\hline & 6 & Torque & & $\mathrm{x}$ & male & & & $\mathrm{x}$ & $x$ & & \\
\hline \multirow{6}{*}{ 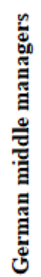 } & 1 & Equipment & $x$ & & male & $x$ & $\mathrm{x}$ & $x$ & & & $x$ \\
\hline & 2 & Marriage & $x$ & & male & $x$ & $\mathrm{x}$ & $x$ & & $x$ & \\
\hline & 3 & Engine & $x$ & & male & $\mathrm{x}$ & $x$ & & & $x$ & \\
\hline & 4 & Chassis & $x$ & & female & $\mathrm{x}$ & $x$ & $x$ & & $\mathrm{x}$ & \\
\hline & 5 & Assembly hall 4 & $x$ & & male & $x$ & $\mathrm{x}$ & & & $x$ & \\
\hline & 6 & Finish & & $x$ & male & & & & $x$ & & \\
\hline
\end{tabular}

Table 2: Information relating to the middle managers

Source: Ayse Yilmaz (May, 2018)

The German middle managers had worked for the company for more than 10 years, and five of them had previously worked for another company in Germany. All were working as 
expatriates in China. All of the participants who had attended the introductory meeting also attended the main interview sessions. The six Chinese middle managers were based locally and working on-site. Two of them had worked for other companies beforehand. The other four had come directly to BACF from university and none had more than eight years’ work experience. Two had been working for the company for more than 10 years and had more than five years' experience as middle managers.

\begin{tabular}{|c|l|l|l|}
\hline No & \multicolumn{1}{|c|}{ Position } & \multicolumn{1}{c|}{ Middle manager } & Date of interview \\
\hline 1 & Change management & Chinese middle manager & $2018 / 002 / 028$ \\
\hline 2 & Hall 1 & Chinese middle manager & $2018 / 003 / 001$ \\
\hline 3 & Hall 2 & Chinese middle manager & $2018 / 003 / 006$ \\
\hline 4 & New type projects & Chinese middle manager & $2018 / 003 / 012$ \\
\hline 5 & Hall 3 & Chinese middle manager & $2018 / 003 / 012$ \\
\hline 6 & Torque & Chinese middle manager & $2018 / 003 / 019$ \\
\hline 7 & Equipment & German middle manager & $2018 / 003 / 019$ \\
\hline 8 & Marriage & German middle manager & $2018 / 003 / 021$ \\
\hline 9 & Engine & German middle manager & $2018 / 004 / 010$ \\
\hline 10 & Chassis & German middle manager & $2018 / 004 / 010$ \\
\hline 11 & Hall 4 & German middle manager & $2018 / 004 / 010$ \\
\hline 12 & Finish & German middle manager & $2018 / 004 / 010$ \\
\hline
\end{tabular}

Table 3: The interview participants

Source: Ayse Yilmaz (April, 2018)

\subsubsection{Conducting the interviews}

A few months after the introduction meeting, I began planning the interview appointments.

Understanding how to conduct the sessions was important therefore I selected the training centre close to the company but not in the working area of the middle managers.

One month after the pilot interviews, in January 2018, I began conducting the interviews, which took until the end of April 2018. In addition to the findings for this study, I learned about the problems the managers' face in their operational working lives, which also helped me to improve my own daily business collaboration in the partner department. I did not interrupt them when they were talking in the interviews as this allowed time for more ideas to arise. Though I gave examples, guiding them through the semi-structured questions was not easy: it required spontaneity and guesswork. However, I had a deep understanding of the topic due to my position as an inside researcher (Section 3.5, p. 85). As I was listening to the interviewees, I 
was also considering my own place and position. Sometimes the questions were not answered in the way that I had anticipated; these I then needed to take into consideration and use as a springboard for further questions. When I found aspects that were different to my understanding or different to what I had found in the literature, I asked additional questions, and I highlighted those I needed to check further in the literature, for example, the matter of the challenge of a third spoken language, English, in the joint venture. As an insider in the context, it was easy for me to listen to the interviewees explain their situations and recount their experiences. I recorded the interviews and took notes.

As English is the language used in company, the interviews were conducted in English. I invited all of the middle managers to a meeting seven days before the interviews commenced, after the introductory meeting and pilot meeting (Section 3.3.2, p. 71), for me to personally hand over the interview schedule (Figure 9, p. 73) and to detail the questions I planned to ask in the interviews (Helmold, 2013) as in the course of the initial phone calls some of the middle managers had asked for the questions in advance to give them time to think about their responses. Their foreknowledge of the questions would mean that we could use the planned 90-minute sessions as well as possible and that there would be no surprises in store for them. Drever (2003), discussing prompts and probes, suggests that if the respondent does not understand the question, the interviewer should repeat the question in other words, giving hints and examples to aid understanding.

In the interviews, I sought to maintain eye contact with the people I was talking to. I posed the questions, looking directly at the candidate, and provided them with hints when needed. If an interviewee was German, he would occasionally answer in German. To avoid being rude, I would then explain again in German. These responses were translated by me and doublechecked by the managers after the interview sessions. The interviews included a 15-minute introduction. The participants described the current, ongoing topics in which they were involved in their daily business lives. The compliance aspects and the ethical considerations were reiterated before the interview sessions began, and I assured the interviewees that I would avoid bias during the analysis the data and that the information given during the interviews would be reported honestly. The first interviewees appeared very relaxed in the interview sessions. I explained to them in great detail what the questions concerned, even though they had received the list of questions to prepare themselves before Chinese New Year. The first interviewee had received it one week before the interview started.

Timing was another important factor: I tried not to interrupt the interviewees whilst they were talking. However, if I saw that an answer was going in another direction or had the sense that 
the interviewee did not understand the question, I asked it again after a few seconds or I tried to support the participant by asking the question differently or explaining the idea using examples from daily business. This was simple for me as an inside researcher, as I knew their current daily tasks. I spoke at normal volume and in a normal tone of voice. Everything the participants said seemed important to them, and I used responses such as 'good', 'okay', and 'yes' to show that I understood what they were saying and that it was interesting and important to me too. Indeed, it was genuinely very interesting to hear their views. Some questions went unanswered by the interviewees, but, rather than emphasise them, I skipped them as I wanted to avoid creating pressure and making the participant feel uncomfortable.

Bogner et al. (2014) highlight the need for a logical structure to the questions, with a logical beginning and structured closing of the interview sessions. In my case, there was no need to introduce myself by name, but I provided the interviewees with more background about myself and the research topic. I worked with the middle managers, but they were not all familiar with my private life, including my part-time DBA or my being a mother of two children. According to Drever (2003) and Bogner et al. (2014), thanking the interviewees for participating in the interview sessions encourages them. Thanking the interviewees before the interviews, and again at the end for sharing their expertise, encourages them to take pride in their contribution. If the participant gave answers quickly and wanted to continue, it was not always possible to prompt, but it was important for me to note the correct moment to prompt. This was always the moment when the middle manager was still thinking and had not yet moved on to the next question. Since I had shared the questions in advance and some had brought the document to the interview session, I explained that I would ask each question in turn, so they should not imagine that it was their responsibility to move forward to the next question themselves. I did not want them to be looking at the paper, but this worked better than I had expected: they followed my instructions and moved to the next question when I asked them to. This also provided me with the opportunity to ask further helpful questions, if appropriate. The final questions alluded to the participants' personal lives and attitudes. The structure of the interviews allowed me to gain the interviewees' trust throughout the session, motivating them to talk more and to provide me with inside information about their work and daily operational working lives.

The goals of their work were deemed important by the participants. I explained that I was looking for a way to help middle managers reduce the fears of their staff and to formulate recommendations that the managers could implement in their daily operational work in production plants to manage changes in the organisation. 
Some answers were aligned with my personal experience, while others were not. Sometimes the interviewees asked questions such as, 'Don't you also think so?' or 'You experienced the same as me, right?' To maintain the flow of the answers and the atmosphere of the conversation, I allowed small discussions to develop or even responded with short anecdotes about my own experience.

I, the researcher, and the interviewee were the only people present for an interview session. The interview questions were asked one-by-one. I sometimes changed the order of the questions in order to follow the interviewee's line of thinking, which made it easier for them to answer. The sessions were intended to last 90 minutes each, but actually lasted 110 minutes on average, as I gave the interviewees time to think through their responses and to answer the questions as they liked. When they chose not to answer a question, I did not push them for an answer. Rather, I tried to ensure harmony during the interviews, making them feel comfortable and encouraging them to trust me. After transcribing the interviews, as indicated above, I shared the documents with the participants so that they could check that everything was written as it had been spoken and without any interpretation. The question list that I used is shown in Figure 9 (p. 73) and transcriptions of example interviews are presented in Appendix 5 (p. 222).

All of the participants had concerns about being recorded. When I asked the reasons for this, they said they wanted to talk truthfully but wanted to ensure that none of their managers would have access to the information. It was agreed that I would record the 12 interviewees, but not the two lean manufacturing experts since they insisted on not being recorded and I really wanted them to support me with their answers based on their experience and consultative abilities. Had I insisted on recording those interviews, they would not have agreed to participate.

Most of the interviewees made notes during the interview sessions. Some brought the question lists along with handwritten notes. The German middle managers had notes about how they wanted to answer the questions; what was in the notes was exactly what they said. The Chinese middle managers had written their notes in Chinese, which I could not read, though they stated that the notes were merely about how they wanted to answer the questions. This was interesting to me, as those without handwritten notes asked more questions and did not reply to all of my questions.

Some answers and hints were provided after the recording had ended, notably by the Chinese middle managers who did not want everything recorded. I recognised, due to my insider position, that the answers and examples provided were true. Of exceptional interest to me was 
their thinking and feeling about the topics, projects, and changing processes. I was happy to speak after the recording, as I wanted simply to have the questions answered honestly in order to generate answers to my research questions and derive recommendations. I wrote down these answers as well as possible. After the interview sessions, I double-checked them against the recordings and finished writing down the text of answers which I could not write down fully during the interview sessions when an interviewee was speaking too fast.

Since all of the middle managers were managing projects concerning digitalisation and daily operational tasks and were looking to move forward in their daily technical working tasks, they were very interested in the topic of change management and changing processes. They were particularly keen to find ways of bringing the new ideas to their staff and to gain employees' acceptance of the implementation of the outstanding topics. They informed me that the topic was timely and that this thesis would be a great support for their responsibilities as practitioners.

Finding an appropriate way to articulate fair and good recommendations embedded in conceptual framework of this study is the goal of the research thesis. Having received the list of interview questions, the interviewees developed in their minds a story to tell me about themselves and their specific situation in the company. They developed for themselves a correct order for the facets of these stories. I occasionally had to return to a question and ask it again but in another way this time to make it as easy as possible and comfortable for my interview partner.

Language played an important role, since sometimes in meetings a Chinese middle manager may quickly switch to Chinese to explain to another partner in the meeting the meaning and ideas being discussed. For the German middle managers, this was not a problem as they were able to switch to German to explain their intended meaning. I did not want to interrupt the flow of the conversation, as it was much more important for me to obtain answers to my questions than to judge my interview partner's language skills. However, for the Chinese middle managers, I could not offer to speak in Chinese since my current level of Chinese is B1. As the company language is English, it should not be a problem to communicate in English. Therefore, in the evaluation of my deliverables from the interviews, this linguistic imbalance was considered. The interview partners were all university graduates, working as middle managers after being promoted to these positions in the company.

During the interview sessions, I noted that the German middle managers opened up very quickly, from the first question, and were happy to speak directly. With the Chinese middle 
managers, however, the responses to the first three or four questions were very cautious - as I had learned they might be during collaboration on-site (Section 3.2.1, p. 58). Chinese people first need to build up trust, even though I was a familiar and well-known person, in order to understand what is behind the questions and why I was asking all those kind of questions in the first place. After the first few questions, the Chinese interviewees also opened up. I think this was because I was well-known in the company and the department. The middle managers were familiar with me and I was asking about situations that we could discuss easily. It was this that allowed them to open up and encouraged them to engage in a conversation rather than in a question and answer session.

In Section 7.6, p. $186 \mathrm{f}$., I will reflect on the impact of the research questions and the interview method.

The final part of each interview included the summing up and acknowledgements, as well as a note to the effect that the appointment for reporting the results would be made by August 2018. In closing the interview, each participant received a thank you gift and a light snack of either sandwiches and drinks or cake and coffee. None of the appointments were postponed by the middle managers. Each appointment took place as confirmed, with the exception of one. In this one case, after we had begun the interview, the middle manager received notification of a family emergency. The manager left immediately but returned an hour later and finished the last few questions. This showed me that he was strongly interested in the results and genuinely wanted to answer the questions, which may reflect a belief among the participants that to have been chosen for the project was a distinction. BACF has many middle managers at its Beijing plant. It was therefore an honour for the middle managers to be selected to take part in the interviews for my study.

\subsubsection{Ethical considerations}

The interviewees were informed during the introductory session that the information they would provide would be protected and that confidentiality would be preserved by the use pseudonyms, the securing of information, and the signing of the confidentiality agreement. All data are due to be disposed of upon completion of the research. All bias related to conflicting interests was to be avoided so that no stakeholders associated with this study could influence the results due to other interests of theirs. This was an entirely self-financed work. Everything was reported honestly, nothing was added to the interviewees' responses, and no data were falsified.

Due to the duality of the role of the researcher, there were ethical issues to be considered (Holian \& Coghlan, 2012). The ethical issues concerning the duality of my role differ from those that 
might emerge as a result of other factors. My role duality involved holding an ongoing work role and power associated with this in the company while conducting my research. This active research role may have influenced my choices regarding alternatives to decisions or any kind of effect of the input and outcomes of the research. The selection of the participants was one aspect that could have raised ethical issues for the university's institutional review committee to consider.

None of the candidates refused the appointments. During the meeting, none of the potential interviewees indicated that they were not interested. Had anyone refused, I would have sought a replacement candidate. As the author of this study, I guaranteed confidentiality and stressed that the participation of the interview candidates was voluntary. It was clearly communicated that the interviews would receive the results before the thesis was submitted to the committee of the University of Gloucestershire for a doctoral degree. Furthermore, it was explained that the research was conducted according to the guidelines of the University of Gloucestershire's 'Handbook of Research Ethics' (2008), and every participant received a hardcopy of of the handbook.

\subsection{Analysis and Presentation of the Collected Data}

For the purpose of the analysis and presentation of the data, I used a Zwicky box for a general morphological analysis (Zwicky, 1969) since I found nine different findings which I clustered after the interview sessions as the most common outcomes and most important feedback. The combination of the decision matrix and the Zwicky box - a systematic, creative, and heuristic method of examining a complex situation or problem in order to find an objective solution was developed by Zwicky (1969), a Swiss astrophysicist and aerospace scientist. I had read valuable research (Moore, 2015; Strasser \& Albayrak, 2016) that used the Zwicky box and this provided me with a suitably structured method. I wanted to find a way to effect viable clustering of the different nine findings and to be able afterwards to extract the most benefit from the interviews using the Zwicky box method. As this study used the qualitative method of semistructured interviews for data-gathering, a general morphological analysis using a Zwicky box supports the study trajectory and aids the analysis of the results. The explanations of the middle managers were evaluated in stages. The basis of the Zwicky box is a multi-dimensional matrix which offers the possibility of clustering different outcomes as different solution possibilities to ascertain the most frequent use of the selected attributes for the selected department or company (Olfert, 2009). With this methodology, different iterations and creative solutions can be created and presented in a transparent manner. I decided to combine the Zwicky box solution 
with a decision matrix to make the findings encountered transparent and easier to cluster. Since the middle managers gave a lot of different aspects and viewpoints based on their own experience it was easier for the clustering to have a decision matrix additionally to the Zwicky box solution. There are many kinds of data-gathering techniques and tools available in research. This method helped me to select the most important key words that had been used by the interviewees. Based on these key words, such as 'language' and 'communication', I was able to start creating the morphological boxes with characteristics and attributes in order to set the focus on what had been said, to add to the information based on my knowledge of the company as an inside researcher, and to add additional attributes derived from the literature research. This eventually helped me to formulate good recommendations for the middle managers in terms of what is important, what exists, what is missing, and what needs more focus and needs to be improved by them.

First, I clustered the main findings of my analysis into qualifications and hiring, communication, information flow and collaboration, and relationship building and guanxi (Section 4.2, p. 92), based on the words used most frequently in the answers of the middle managers. This was Step 1 of my sequence of analysis. The second step was to select one overall concept for the follow-up analysis in order to limit the dimension of the analysis. I selected the concept of collaboration, and for the second step I selected the attributes of occasion, centrality, direction, formalisation grade, and media and channels (Appendix 6, p. 237 ff.). This rating of the different attributes could take place via the decision matrix (Table 4, p. 83) in Step 3 of the analysis. Table 4 (p. 83, derived from Lorenz, 2010) presents non-compliance as a minus sign and compliance as a plus sign. Compliance means that the selected attribute fits the selected characteristics.

This method also has disadvantages for formulating recommendations. In the course of analysis of the interview responses, I found different types of answers which I have clustered in Section 4.2 (p. 92 ff.). However, for in-depth analysis, I used the Zwicky box with one overall finding rather than the findings I had clustered to give an example for the middle managers how to work or adapt based on my findings and recommendation in the joint venture collaboration to improve. If compliance was limited, the matrix shows the zero sign. The most suitable alternative could be determined using this matrix: in this case, it would be alternative C (Lorenz, 2010). On one side, the morphological box shows the criteria and on the other, the alternatives to be rated in a matrix form. For the rating, the plus sign is used if the alternatives and the selected criteria selected fit with one another. The minus sign is used when the criteria do not match the alternative, as shown in Table 4 (p. 83) for D. Zero is selected if there is no connection 
at all between the criteria and the alternative. Using this method with a rating in the form of plus signs, it is clear and transparent what is possible for the middle managers to consider to further their existing collaboration in the joint venture. This rating also helps the middle managers to have transparency about what is occurring in the company and what is yet possible and exists in the literature already as attributes.

Using this method, the criteria were rated and compared with the results. As Zwicky (1969) states, a morphological analysis is a means of looking at things in an uncomplicated manner in order to explain them.

\begin{tabular}{|c|c|c|}
\hline \multirow{2}{*}{} & \multicolumn{2}{|c|}{ alternatives } \\
\cline { 2 - 3 } criteria & C \\
\hline A & + & D \\
\hline B & + & - \\
\hline
\end{tabular}

Table 4: The decision matrix

Source: Lorenz, H. (2010). Das Unternehmerhandbuch: Entscheidungsmethoden - Komplexität reduzieren, Klarheit schaffen.

http://Das-Unternehmerhandbuch.de/2010/10/18/Entscheidungsmethoden-Komplexität-Reduzieren-KlarheitSchaffen/20 October 2016 (accession date by Ayse Yilmaz).

This method identified all the variations of potential solutions. The aim of this technique is to seek new combinations of answers in the context of a specific culture. When analysing complex organisational fields for future relationships in firms and complex joint ventures with many methodological problems, many of the factors involved are non-quantifiable. This means that strong social dimensions and conscious self-reference among the actors are necessary to analyse the issues. Accordingly, traditional quantitative methods and causal models are inappropriate. Even the uncertainties in such problems are generally irreducible and often cannot be described. Ritchey (2011) states that between 1998 and 2011 more than 100 qualitative research projects were conducted using this method to analyse organisational and stakeholder structures, such as complex problems in firms, structure complex policy and planning issues, and develop scenarios and strategies in laboratories. To find a way to interpret the complex answers I received in the interview sessions, I decided on the Zwicky box methodology. 
The Zwicky box is a method of indicating new ideas and result variations that are not easy to arrive at using other methods (Zwicky, 1996). Following the interviews, I created a Zwicky box, and the different results and possibilities for the possible values were generated. For this reason, I rated one of the alternatives to assess how well it fit the criteria (Lorenz, 2010; see Appendix 6, p. $237 \mathrm{ff}$., for an example of collaboration). With the help of the different boxes and cells in the box, ideas can be created, identified, processes described and easily presented, and a model can be created for the findings. The different boxes and the cells in the morphological box were determined based on the findings that arose from the interview sessions. As an inside researcher, I provided additional input to obtain a clearer picture of what already exists in the company (Appendix 6, p. 237 ff.). For example, in relation to communication channels, what kinds of meeting or communication possibilities exist?

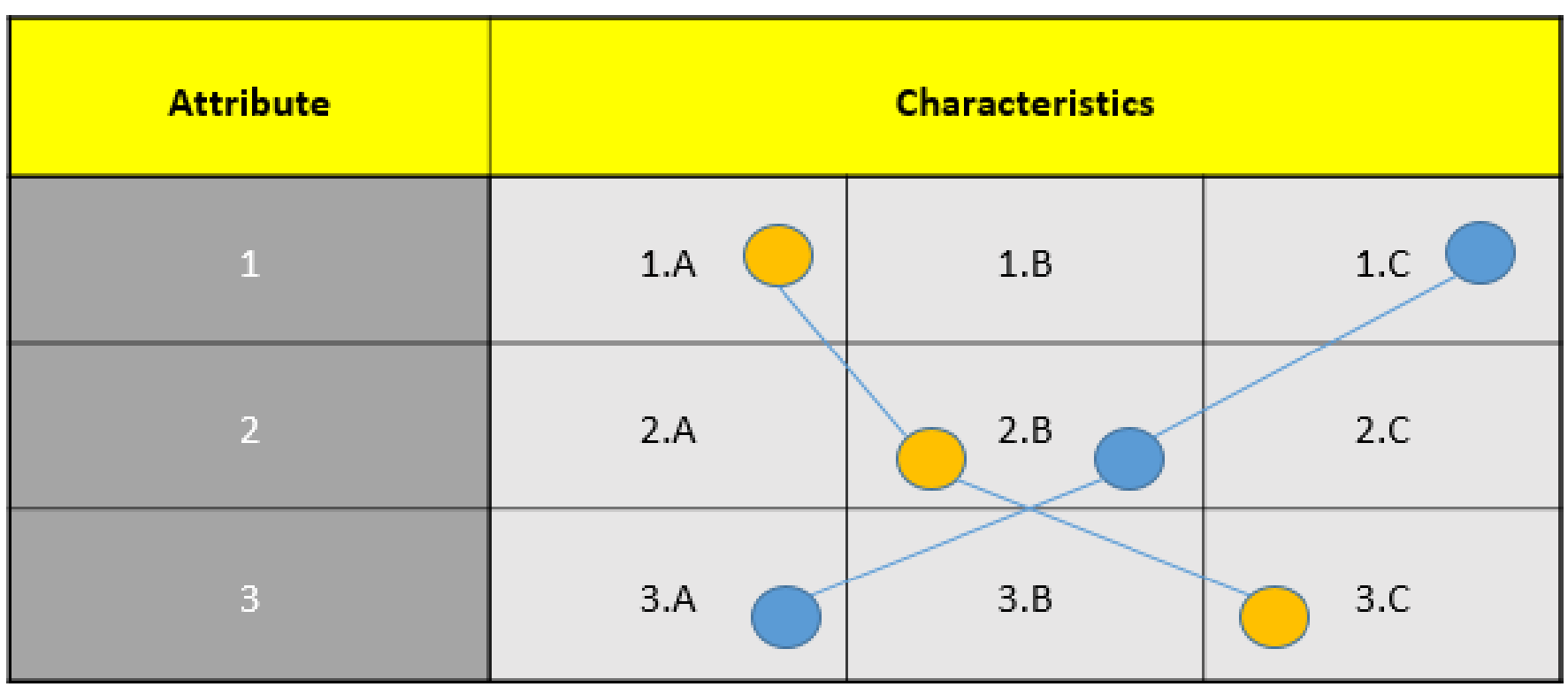

Table 5: The Zwicky box

Source: IBIM. Morphologischer Kasten

http://Das- http://www.ibim.de/techniken/3-3.htm 20 October 2016 (accession date by Ayse Yilmaz).

On the left in Table 5, the Zwicky box shows the characteristic attributes or sub-functions of the research questions. On the right, the columns show the different values and characteristics of each variable (Zwicky, 1996). The next step was to specify the kinds of attributes which I had fixed based on the answers provided during the interview sessions. Based on my experience, I added some additional attributes to complete the morphological box in the context of my thesis in order to determine the different values in the context of change management and culture. Finally, I demonstrated the feasibility of the results and connected them to one 
another (Table 5, p. 84).

This study is structured to seek solutions to find recommendations for the middle managers in the context of an intercultural framework and change management in the automotive sector.

\subsection{Research as an Insider}

Being an insider in an organisation may have both positive and negative effects on research. First, regarding my understanding: I knew the people working in the departments because we worked together and shared our daily working lives in the company, including discussing our personal issues and backgrounds. During the interview sessions, I presented examples to encourage the interviewees to think more deeply about the questions and to better understand their intentions. Furthermore, as the interviewees and I already knew one another, the meetings were more comfortable and less forced. However, on the other hand, because I was already working in the organisation, I may have missed some elements. In German, this is referred to as 'work blindness'. Observation was a component of the middle managers' interests. To my mind, the constructivist concept should include the view of the stakeholders; thus, the interests of middle managers in the automotive sector should be part of the constructivist perspective that reflects my attitude. One negative aspect of being an inside researcher is that the interviewees may be afraid of telling me the truth, believing that I could hand over the information they provide to managers or other colleagues.

The context of the researcher is very important, as indicated by Silverman (2014). Regarding this situation, the results of this doctoral research might present different outcomes: the context could either positively influence the results as I as researcher had insider knowledge (Section 3.5, p. 88), or it might have a negative impact in the sense that one is influenced by the organisation in which one works or as a result of criticism from colleagues. As I was experienced and had previously worked for different companies, I believed I could understand the differences between the lived corporate cultures and reflect this in my work. Vygotsky (1962) identified the concept of 'social situatedness' which was subsequently further developed by Leve and Wenger (1991). The concept pertains to the development of each individual and his or her intelligence in terms of social and cultural influences. Situatedness describes the interplay between the researcher and the situation. The situation refers to the positioning of the researcher in different kinds of circumstances, with the context of these being the background. In considering organisational interrelations and the constructivist concept of Lave and Wenger (1991), the whole structure, cultural work of my interview questions, and the daily work of thinking and acting of my interviewees could shape my work and thus the results of this thesis. 
Lave and Wenger explain the theoretical notion of situated learning and hold that learning is a social process (Lave \& Wenger, 1991). As an insider, I should trust my colleagues and have a shared understanding of our daily work. However, since my colleagues were not in the same department, I think the insider perspective is better described by Vygotsky (1962): I am neutral, and I have my own way of thinking. Due to technical and organisational structures and the corporate culture we shared, I had my own opinion of the questions that I developed for this work. I agreed with some of the interviewees' responses and disagreed with others, as I had my own opinions on the issues. Reflecting on the answers that I received, I saw some common ways of thinking and understanding between the Chinese and German groups, but also observed some entirely different answers that were shaped by the different characters and their cultural and professional know-how and educational backgrounds.

The Chinese market is one of the most successful developing regions, with many foreign companies investing in it due to its enormous opportunities. In China, change is happening very quickly: things work dynamically, and employees are flexible when taking on tasks and finding ways to resolve issues. For these reasons, many companies delegate employees to go to China as well as integrating Chinese staff into their own countries. In the company of concern here, this is common: the German company has sent many employees to China to enhance results and develop outstanding benchmark products.

However, the interviewees may have been reluctant to give detailed information to me, an insider, for fear that the information would be shared with other employees or management. This point is further reflected upon in Section 3.6.

\subsection{Competences and skills}

Mason (2002) states that qualitative research has inimitable absorptive power and the capacity to convey arguments for specific situations. For me, this method was the most appropriate as I wanted the interviews structured more openly to allow the middle managers to guide the interviews on their own terms. This design assisted me in asking more questions. As a qualitative researcher, I wanted to gather the truth from individuals regarding their experience of daily work. Furthermore, the relationship between me, as researcher, and the interviewee, as participant, played a role in the interpretation of the findings. I used the recordings after the meeting to follow what was said. The interviewees' feelings were also important for me, as was how comfortable I was with the questions I asked and the flow and sequencing of the conversation. 
I was also concerned with my ability to use the vocabulary common to the company and the department. As indicated above, I prepared myself by conducting interviews with my action learning set group to obtain feedback about my voice and way of speaking, ensuring that I spoke loudly and clearly. It was important that I did not lead the topics or look for specific answers and that I pulled back and avoided confusing the interviewees. Rather, I let them answer as they thought was right, based on their own experience. I asked the questions and listened to the responses. This was sometimes difficult, notably when the middle managers wanted more input or examples. When I saw that it was difficult for the participant to answer a specific question, I gave examples from my experience and asked the questions again using different language. As a researcher using qualitative data, I had to develop particular skills. It is important to know or not to have presuppose that the research is up to date since there is a substantial amount of grey literature and much research that has not yet been published. Moreover, during the interview sessions, it was essential to quickly recognise what was interesting for the interviewee and what was difficult for them.

Nevertheless, I used the conceptual framework as a basis for the interview structure, which was influenced by the literature review, research questions, aims, and objectives.

\subsection{Summary and Interim Conclusion}

My complete doctorate research project was scheduled for a duration of three to four years. To identify the most appropriate research strategy and methodology, I considered the advantages of the different approaches and selected the qualitative approach with semistructured interviews, structured according to the phases of preparation, main, and closing. Improvements in automobile production using digital or industry 4.0 solutions and battery cars are becoming increasingly important as is enhancing corporate strategy to provide a greater focus on change management. For these reasons, it was important to analyse the middle management level of the observed company as this is the link between staff and upper management and the bridge between the Chinese company and its partner, the German competence centre (Section 2.1, p. 29 ff.).

In this chapter, I have introduced the organisation that employed the interviewees, along with the research methodology and systematic literature review, and explained why I selected the constructivist and qualitative approaches and the semi-structured interviews.

In Section 3.3, I provided a description of the collection technique. As the middle managers were busy with a considerable number of difficult projects and ramp-up times in production in March 2018, the plan to hold to a 1-2-day workshop day outside the company did not come to 
fruition. Consequently, I attempted to customise the process with an introductory meeting (Section 3.3.3, p. $74 \mathrm{ff}$.). With the verification and amendment of the research question during the first two phases, the preparation and the main phase of the semi-structured interviews formed the basis of their closing phase, which involved analysis of the findings from the main phase. Qualitative data gathered through a systematic literature research is the basis of the three phases of semi-structured interviews, as described by Yin (2014). In the closing phase, the confirmation and refining of the analysed items from the interviews, based upon literature research, was used to formulate a suitable conceptual framework. To start the analysis, first, the interview protocols written by me were transcribed and the recordings checked in order to write and adjust the protocols in detail. Important in this phase was the classification of the input from the interviews for the data analysing phase and finding the best-fitting model for the analysis and for setting up the results. I included ethical considerations in my whole research path. Before the interviews commenced, these had been integrated into the introductory meeting and hence provided me and the interview partners with a reliable point for starting the interviews with ethics and compliance in mind. In Section 3.4, I discussed the analysis and presentation of the collected data, and, in Section 3.5, explained 3.5 my role as an insider in the organisation.

Chapter 3 closes with a consideration of the competences and skills required for the methodology described in Section 3.6. Figure 10 depicts my ontological viewpoint and offers a visualisation of the period from beginning the DBA programme in November 2015 to the present day, with the research paradigm, methodology, and method used. It begins with the problem to be solved and describes the two paradigms of epistemology and ontology, noting the 3-4 years that I have been working on the DBA and writing this thesis. The left-hand side displays the methodology and the method used in my thesis. 


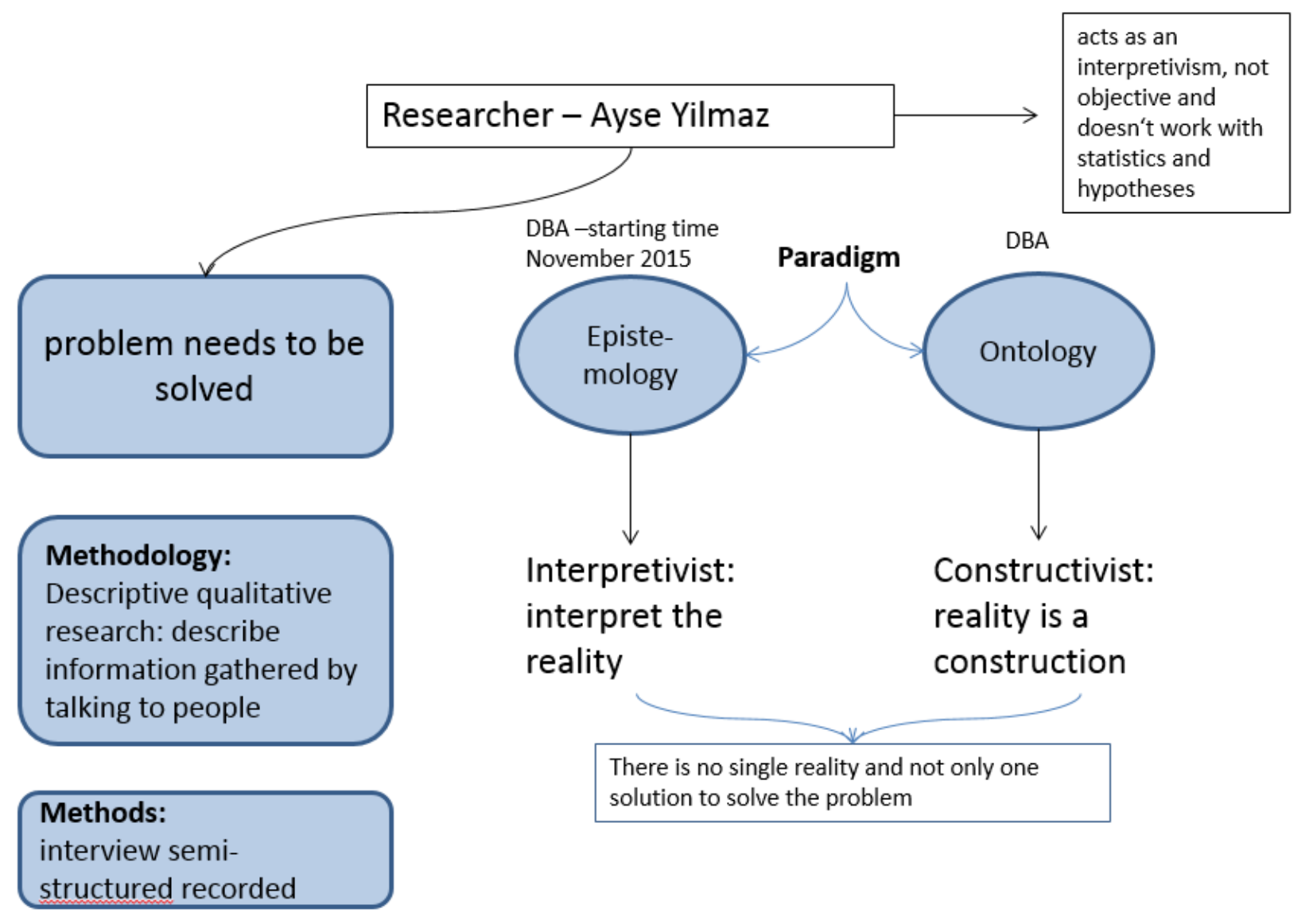

Important: Aims, objectives and research questions are the framework for research: the methodology helps to analyse and validate data!

Figure 10: The researcher's ontological viewpoint

Source: Ayse Yilmaz (October 2016)

I believe that this research is unique as I studied this particular issue in-depth and compared it with the findings of other research papers. First, I had my own insider knowledge (Section 3.5, p. 85 ff.) and, second, I had easy access to people with relevant knowledge and expertise required for the work. I have been looking forward to further enhancing the literature on the subject and supporting business partners and middle managers in automotive firms since we live in an increasingly globalised world and almost all employees in multinational companies come into contact with foreign cultures. For this reason, cross-cultural communication is very important for collaborative work: it is a key to the door of success. Companies must develop their people who are working internationally. In my view, this is exceedingly important for global business and determines its failure or success. 


\section{Chapter 4: Findings, analysis of the data, and observations by the researcher}

In this chapter, the findings from the interviews and my observations during the sessions are discussed. Dievernich et al. (2015), McCalman (2008), Berner (2010), Ghemawat and Reiche (2011), and Schein (1999) (Section 2.1, p. 29 ff. and Section 2.2, p. 44 ff.) stress the importance of a company preparing for change management and integrating it into its corporate culture, although they do not refer explicitly to joint ventures between Germany and China (Section 2.1, p. 29 ff.). All the responses from the interview sessions were clustered using the Zwicky method and morphological box recommended by Lorenz (2010) and as presented in Table 4 (p. 83) and Table 5 (p. 84). This method has helped to cluster nine findings and to identify the three main findings that I focus on in Section 4.2 (p. 92 ff.): qualifications and hiring (Hitt et al., 2007); communication (Wooldridge et al., 2008), information flow (McCalman, 2018), and collaboration (Aula \& Heinon, 2016); and relationship-building and guanxi (Mintzberg, 2018). These three main findings were the most important ones for the 12 middle managers in the interview sessions. In Section 4.3 (p. 108 ff.), I introduce a further six findings to show which additional topics and issues were discussed with the middle managers and were highlighted.

Additionally, in Section 4.4 (p. 120 ff.), I introduce that good management skills are required from both middle management and upper management. Further topics of interest for analysis in this chapter are my own observations during the interview sessions (Section 1.4, p. 25; Section 3.3, p. 67), the discussion of the atmosphere in the joint venture and the working conditions there, and Section 4.6 (p. 127 f.) which introduces the reflections of the middle managers. The chapter closes with a summary and an interim conclusion.

In the first section, I discuss the findings from the two pilot interviews I conducted in terms of their contribution to main interview sessions. In addition, I discuss how I employed these findings in the main interview sessions, especially in relation to the three main findings.

\subsection{Findings from the pilot interviews}

Here, I briefly introduce the relevant results from the two pilot interviews with the lean manufacturing experts. First, the German experts’ points of view are discussed and thereafter those of the Chinese experts.

Interviewee 1, a German expert, pointed out how difficult it was to work in a collaborative joint venture of this nature, in which some positions are occupied by local employees and managers engaged by the German headquarters (Section 4.3.4, p. 116). Such a structure could create difficult situations for staff. From his point of view, this was an important matter; for 
this reason, I decided to incorporate this point into the cluster of findings and analyse it in this part of my work. He underlined that, in China, the market demands ever-expanding collaborations between companies and therefore production volumes increase quickly; this issue is also highlighted in Section 1.1 (p. 9 ff.) and Section 1.2 (p. 14 ff.). Moreover, he stated that change management is a daily consideration in the joint venture company, unlike in the German central plant. The first interview indicated to me that I was on the right track and that I needed to conduct the second interview to confirm the questions for the main interview session. With the responses from the first pilot interviewee, I had already gained some input for the findings. For the first interviewee, national cultural differences and the topic of relationship-building and taking care of guanxi were major points which I also later identified as the most important finding of the interview sessions with the 12 middle managers. He also emphasized that better collaboration and better information flow was required due to the double functionality and working collaboration of two different corporate and national cultures. For him, middle managers definitely needed to adapt to the situation in the joint venture which is formulated in Chapter 1 as the research questions and research objectives for my thesis (Section 1.4, p. 25).

The second interviewee, the Chinese expert, pointed out how important change management is and how important it was to support middle managers, especially in terms of their qualifications and the hiring component of the task of the middle managers, which was selected as one of the three main findings from the interview sessions (Section 4.2.1, p. 95 ff.). He felt that German companies did more for their employees and that the Chinese company needed to adapt more to the situation of the joint venture. This was again a hint regarding my research questions and research objectives described in Section 1.4 (p. 25). This second interview showed me that the interview questions could be confirmed and taken forward to the sessions with the middle managers. With both of the pilot interviewees, I could confirm the questions in the interview schedule. My task was to adapt in the final result only questions 5, 8, and 11 as a guideline for my interview sessions. I took the findings from the pilot interviews that were important for me due to the responsibilities of the pilot interviewees who act as consultants for the middle managers, who are my main focus and whose input was required by me. Both interviewees mainly highlighted the three main findings described in Section 4.2 .1 (p. 95 ff.) to Section 4.2 .3 (p. 104 ff.) and this was the interesting point of view for me from the two pilot interviews.

In what follows, I discuss the analysis of the three main findings. 


\subsection{Findings from the main interviews}

This section describes the three most important findings from the interview sessions as a whole and the feedback and discussion points raised by German and Chinese middle managers. It is of interest that both the German and Chinese middle managers had the same clear understanding of the three main findings discussed in Section 4.2 .1 (p. $95 \mathrm{ff}$.) to Section 4.2.3 (p. 104 ff.). They differed from one another in terms of their understanding of the other findings.

Based on the Zwicky method and morphological box recommended by Lorenz (2010), as presented in Table 4 (p. 83) and Table 5 (p. 84), I grouped the nine findings into topics after the interview sessions and the discussions of the recordings with my action learning set group (Section 7.3, p. 179 ff.). I selected three key findings which I discuss in detail in this thesis and link to the literature review: qualifications and hiring; communication, information flow, and collaboration; and relationship-building and guanxi. These are highlighted in green on the right side of the new conceptual framework in Figure 11 (p. 93). These were commonly stressed by the middle managers as the most significant points they had reflected on, which they found important for consideration as recommendations, and which they thought they required support for.

In this section, I provide an overall introduction to all the findings. Lincoln and Guba (1985) refer to the qualitative method as a suitable one for both the researcher and reader. According to the criteria for good qualitative research described in Section 3.2.4 (p. 65 ff.), it was important to support the observations and understandings of the middle managers in relation to the experiences they referred to in the interview sessions (Section 4.1, p. 90 ff.). After grouping selected items from the interviews as further findings in Section 4.3 (p. $108 \mathrm{ff}$.), I very quickly realised that one item, collaboration, fits with all the other items from the interviews. Collaboration is reflected in the Zwicky model, as described in Section 3.4 (p. 81 ff.) and presented as outcome in Appendix 6 (p. 237 ff.), as one of the most important finding. I updated the conceptual framework (Figure 11, p. 93) that I had prepared based on the systematic literature review (Figure 5, p. 53). The framework concerns culturally based change management factors for middle managers working in cross-cultural joint ventures. It reflects concepts about appropriate communication and qualifications that are recommended for improving information transfer and supporting staff development and retention. Some forms of meeting already existed in the joint venture; however, my conceptual framework is new and will be beneficial for its middle managers. The local parameters identified through 
the interviews, my observations, and my experience as an insider are analysed together and form the basis of the recommendations, which are described in detail in Chapter 5 (p. 132 ff.).

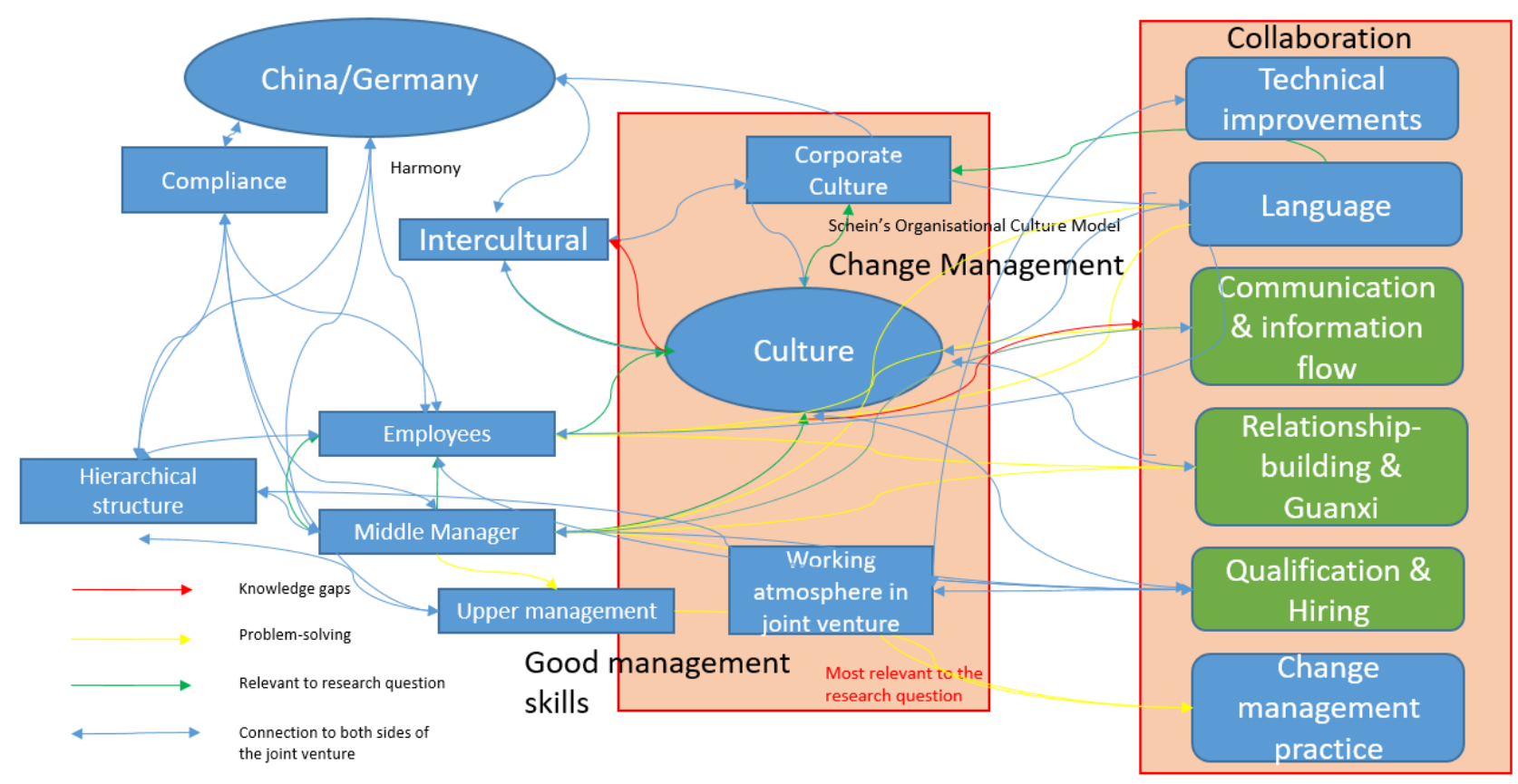

Figure 11: The revised conceptual framework

Source: Ayse Yilmaz (September 2018)

In the interview sessions, the middle managers described increases in efficiency and productivity as a goal. It is very important that, before the implementation of ramp-up times for the production departments for the new vehicle product, employees are strengthened for upcoming challenges, thus allowing them to perform their operational work. If the right direct is given for the exchange, process flow is enhanced, and fewer daily production problems will arise. This needs to be solved once and for all in the same way since cross-cultural exchange takes place within a common and understandable conceptual framework. The efficiency of the work will be enhanced by common resolutions to problems. This common level needed to be attained and therefore time needs to be invested in setting up the recommended process flow. This implementation is likely to produce positive results very quickly.

Time-saving was mentioned several times by the Chinese middle managers (No. 2, 3 and No. 6; Table 2; Section 3.3.3; p. 74); in my understanding, this would also mean cost savings. The cost benefits that would arise from new projects or change management is a dimension that should be left not unattended. Expansion forces management to plan for the future in greater 
detail and for the long term. This planning must take place at the right time, commonly and harmoniously (Section 4.2.3, p. 104 ff.), in order to derive benefits from it. This is highlighted by authors such as Ala and Cordeira (1999; Section 2.2, p. 44), Luo (2007; Section 2.2, p. 44), Praxenthaler (2018; Section 2.2, p. 44) and Preyer (2009; Section 2.2, p. 44).

If people working together do not understand one another's cultures, they struggle to collaborate, and communication does not take place as desired. This was highlighted by two Chinese middle managers (No. 3 and No. 6; Table 2; Section 3.3.3; p. 74) and four German middle managers (Nos. 1, 3, 4, and 5; Table 2; Section 3.3.3; p. 74), as seen in the findings below. The middle managers must reflect on the need to understand and accept the other national culture as a basis for their collaboration, as is also highlighted by Ghemawat and Reiche (2011; Section 2.2, p. 44 ff.). Furthermore, a common understanding and good strategies for corporate and national culture are required for success in a joint venture, in which two different corporate cultures must find a way to work together. The middle managers on both sides must educate their staff and all new employees as regards this type of cooperation. The expression ‘joint venture’ (Section 1.2, p. 14 ff. and Section 2.1, p. 29 ff.) itself refers to cooperation and collaboration.

The failure of communication can lead to a lack of trust, which can cause unhappiness, as described by Franken (2010; Section 2.1, p. 29 ff.) and Barmeyer (1996; Section 2.1, p. 29 f.). This may be the reason that BACF has such a high staff turnover, especially among the local employees. The expatriates are paid very high salaries by the German headquarters, which may be why they tend not to leave after completing their assignments. This was mentioned by two Chinese middle managers (No. 1 and No. 5; Table 2; Section 3.3.3; p. 74). It was of interest to me that none of the German middle managers mentioned the matter of the considerable salary difference even though I, as an insider researcher (Section 3.5, p. 85 ff.), was aware of it and that local employees were leaving due to their finding other jobs with a better salary, superior production models, and a better corporate cultures.

In the following sections - 4.2.1, 4.2.2, and 4.2.3 - I focus on the three selected key findings: communication, information flow, and collaboration; qualifications and hiring; and relationship-building and guanxi. Section 4.2.1 on communication, information flow, and collaboration seems to be the most important finding; relationship-building and guanxi, the second most important one, as reported by the middle managers; and then qualifications and hiring. 


\subsubsection{Communication, information flow, and collaboration}

Communication was mentioned repeatedly during the interviews by all 12 middle managers in relation to various questions. Communication usually takes place in groups; at least two people need to be present, and it occurs mutually, as indicated in Section 2.1 (p. 29 ff.; Berner, 2010; Umstaetter, 2000; Franken, 2010). For communication occur, people need to understand one another. This is the ideal state (Berner, 2010). Communication is not merely a matter of speaking; people also rely on non-verbal tools. With regard to communication, a procedure was mentioned by the interviewees in relation to how information processing worked and how people can orientate themselves to find a way to collaborate (Franken, 2010; Section 2.1, p. 29 ff.). Communication aids orientation and can support collectives to find normality in life, in this case, in working life and in relation to the flow of work, as one Chinese interviewee (No. 4; Table 2; Section 3.3.3; p. 74) mentioned (Franken, 2010 and Berner, 2010). This can be linked to the need for harmony and guanxi in Chinese culture (Lihua, 2013; Section 2.2, p. 44 ff.). As indicated by Lihua (2013), relationships and communication are very important in China, and traditional cultural values such as harmony and honesty play a fundamental role. These were extremely important for my study and were also one of the main outputs from the interview sessions, having been mentioned by two Chinese middle managers and five German middle managers.

All the participants used the expressions ‘collaboration' (Appendix 6; p. 237 ff.; morphological box using Zwicky model) and 'information flow', both of which have implications for communication. If collaboration takes place, communication also takes place. If information flow works, communication also works (Praxenthaler, 2018; Section 2.2, p. 44 ff.). Notions like these were regularly mentioned by all the middle managers on both sides, though they were always formulated in a different manner.

The middle managers expressed strategic perspectives and methods and noted the importance of information flow and communication, indicating that this was even more important in a joint venture due to the presence of two different corporate and national cultures. One Chinese interviewee (No. 4; Table 2; Section 3.3.3; p. 74) said:

'We try to take over and copy things from German plants which might be good for us or which we think are good to take over. Even here, communication is lacking. If they think some things or processes are not good, then there must be communication 
between us, and ideas need to be changed in order to optimise them for all the plants internationally and to ensure that the same standard applies to everybody’.

This manager had extensive knowledge of change management as she had been responsible for it for the whole department in both her former function and in her current position (No. 2; Table 3, Section 3.3.3; p. 74).

One German interviewee (No. 5; Table 2; Section 3.3.3; p. 74) maintained that not everything was discussed openly by upper management (Section 4.3.4; p. 116). Furthermore, three Chinese middle managers expressed the importance of a good top-down communication and indicated that they have the feeling that some information does not reach them. Due to the lack of information and communication flow, operations do not go according to plan, resulting in time pressures for them and their subordinates in relation to delivery dates. Ghemawat and Reiche (2011) explain the importance of information needing to cascade. This can maintain a high level of motivation for both managers and their staff due to the feeling of being integrated into and involved in the company's needs.

Another aspect discussed by three German participants concerned the cost that the Chinese company had to pay for each communication with the central headquarters and for support, which is considered a service. Even for established processes, the Chinese middle managers did not use the communication channel agreed upon by the departments at the central headquarters and on-site in Beijing in the joint venture to contact their German colleagues. However, they mentioned that it would be useful to exchange information since the same product is being produced in both countries, and it would improve collaboration. The desire for better collaboration provided me with a hint to think about the concept of collaboration and to work it out using the Zwicky method in the form of the morphological box (Appendix 6; p. $237 \mathrm{ff}$.). Some of the Chinese interviewees (Nos. 1, 2, and 5; Table 2; Section 3.3.3; p. 74) discussed upper management's instruction to minimise or eliminate costs. One Chinese manager (No. 2; Table 2; Section 3.3.3; p. 74) talked about exchanging ideas and ensuring better communication and information flow between the central headquarters and the partners in each department. Another Chinese middle manager (No. 5; Table 2; Section 3.3.3; p. 74) wanted to improve staff retention and stressed the importance of the German colleagues’ professional know-how and experience for developing local staff. Hence, collaboration between the two companies and their employees is a basic requirement which needed to be fulfilled; as described mainly by five Chinese middle managers, this is not currently handled in the best way.

Four German interviewees (Nos. 3, 4, 5, and. 6; Table 2; Section 3.3.3; p. 74) often mentioned 
electric vehicle production as a major change for both the production department and for the company as a whole. Therefore, it is important that the partner plants and central headquarters collaborate to implement the processes for the new production and for battery installation. In response to the question on strategic perspectives, three Chinese interviewees (Nos. 1, 2, and 6; Table 2; Section 3.3.3; p. 74) expressed the need for better systematic solutions that are more digitalised (Ghemawat \& Reiche, 2011). Two others (Nos. 3 and 4; Table 2; Section 3.3.3; p. 74) mentioned the importance of better information flow and communication. One interviewee (No. 5; Table 2; Section 3.3.3; p. 74) talked about lean processes and improving information flow. A major issue for the company seemed to be obtaining information relevant to its daily business and operations (Appendix 6; p. 237 ff.; morphological box using Zwicky model). For the German middle managers, much communication was needed to allow them to cope with upcoming changes and to prevent misalignment with the relevant departments and with their middle management colleagues. Two German interviewees (Nos. 1 and 5; Table 2; Section 3.3.3; p. 74) had had lengthy experience at the German central headquarters, with attendant know-how and expertise regarding standards. The need for support from central headquarters and from experts on-site in China was reiterated throughout the interviews by both German and Chinese managers (Appendix 6; p. 237 ff.; morphological box using Zwicky model).

\begin{tabular}{|l|l|l|l|}
\hline \multirow{2}{*}{ Attribute } & \multicolumn{3}{c|}{ Communication concept } \\
\cline { 2 - 4 } & $\begin{array}{l}\text { Characteristic } \\
1\end{array}$ & $\begin{array}{l}\text { Characteristic } \\
2\end{array}$ & $\begin{array}{l}\text { Characteristic } \\
3\end{array}$ \\
\hline Occasion & comprehensive & task employee & \\
\hline Centrality & central & decentral & peripheral \\
\hline Direction & upward & downward & horizontal \\
\hline $\begin{array}{l}\text { Formalisation } \\
\text { grade }\end{array}$ & formal & informal & \\
\hline $\begin{array}{l}\text { Media and } \\
\text { channels }\end{array}$ & verbal & printed & electronic \\
\hline
\end{tabular}

\section{Table 6: Morphological box showing the communication concept}

Source: Ayse Yilmaz (August 2018)

Table 6 is an example how the Zwicky morphological box was used for analysis (Appendix 6; p. $237 \mathrm{ff}$.) of collaboration and communication. The left column of Table 6 presents five attributes developed from the answers provided by the middle managers and derived from the literature review (Barmeyer, 1996) which characterise the communication model of collaboration. The remaining columns show the characteristics which each attribute can 
extract from the findings and which can take each of the characteristic for all attributes. For centrality, for example, the third characteristic needs to be integrated, since peripheral needs to be distinguished between three levels based on literature review (Barmeyer, 1996). The attributes are considered both separately and for each situation in the department, team, or organisation. All thoughts (Praxenthaler, 2018) based on the answers provided by the middle managers and derived from the existing literature on communication were considered to fill out the morphological box in Table 6. The attributes considered for the communication concept for implementation in the joint venture, especially in the observed department, are shown in orange in Table 6. In the decision matrix in Table 4 (Section 3.4, p. 81), I selected orange for the positively rated options and green for the negatively rated ones. This finalises the morphological box for the findings on communication. Informal and printed communication in the department were not considered as a clearly defined sequence needs to be communicated in each specific case. It is only in this way that it can be ensured that the necessary information reaches the relevant employees. It was for this reason that informal communication was omitted. Above all, it is necessary to ensure simultaneous communication regarding all employees' needs.

Using printed media, it is not possible to contact all relevant employees at the same time or to communicate quickly if the topics are important; the distance between the two countries makes using printed media implausible. The consequence would be a time delay. According to the morphological box based on the Zwicky method and the decision matrix, shown in Table 5 (Section 3.4, p. 81), communication that can take place formally, peripherally, or horizontally through a verbal, personal, or even an electronic channel is a concrete task-based requirement. In order to support the middle managers with a better structure and to allow better organisation, I created Figure 12 (p. 100), the communication model structure for the middle managers. Communication takes place at a working level and relies on cultural understanding. Exchanges occur regularly via alignment meetings on standards, upcoming changes, information exchange, and process implementations, as well as on current issues on the production line. They seek to solve issues in the same way that central headquarters does. If the issue occurs only in China, it is necessary to clarify with the headquarters what the difference to the existing process before is and what can be improved.

In Appendix 6 (p. 237 ff.), Tables 32 and 33 are presented because, for communication activities, verbal and electronic channels are suitable for my analysis and should be examined by means of comparison. Verbal and personal communication (Appendix 6; p. 237; Table 37) should be used in the framework, as described in Section 5.1 (p. $133 \mathrm{ff}$.), and each process 
step needs to be set up. Essentially, it is exceptionally important that, for all processes within the framework of communication activities, current topics concerning daily tasks be coordinated and that exchange take place, with problems and questions dealt with reciprocally. If a problem must be resolved immediately so that an employee can progress, this should take place through a personal channel, rather than in an exchange meeting. It does not make sense to wait. If the person cannot be reached by telephone, one should use an electronic channel, such as email (Appendix 6; p. 237 ff.; Table 38).

For one German participant (No. 4; Table 2; Section 3.3.3; p. 74), group affiliation was a mindset that, at first glance, did not seem to be culturally influenced. He stated how important it was for his team to discuss their vision and mindset. For me, this aspect requires deeper analysis and more research at a later date. He also mentioned that getting to know one another through face-to-face meetings helps people to work together more easily, and that travelling to meetings in China and Germany helps employees to understand the other culture and to accept colleagues with different backgrounds and different cultures.

Further communication channels should be implemented in the joint venture as several times two German middle managers emphasised that it should be ensured that know-how, experience, and knowledge can be exchanged quickly. International time differences often prevent employees from meeting with one another, but short telephone calls and emails, or platforms for sharing documents and videos, can enhance collaboration between the two production sites. An alternative communication channel would be invaluable for collaboration, yet this was not mentioned at all in the interview sessions. The exchange of documents and information too needs to be fostered and enhanced through networking between employees.

One Chinese interviewee used the phrase 'create pressure' in relation to other departments. However, I suspect that this was a linguistic error and that he intended to say 'escalation', as he did not use the term in the context of his own staff, but rather in relation staff in other departments. Nobody wanted to place pressure on their personnel; they want to guide their understanding and to improve communication in a top-down manner. This is why they so often referred to improving information flow and obtaining support from upper management. To improve information flow, logical intermediate steps and sequences should be considered so that an appropriate communication concept can be developed. 
Figure 12 (p. 100) presents a possible communication exchange mechanism for the department in question which could be adopted by BACF as a whole, as well as by other joint venture companies (Conger, 2013).

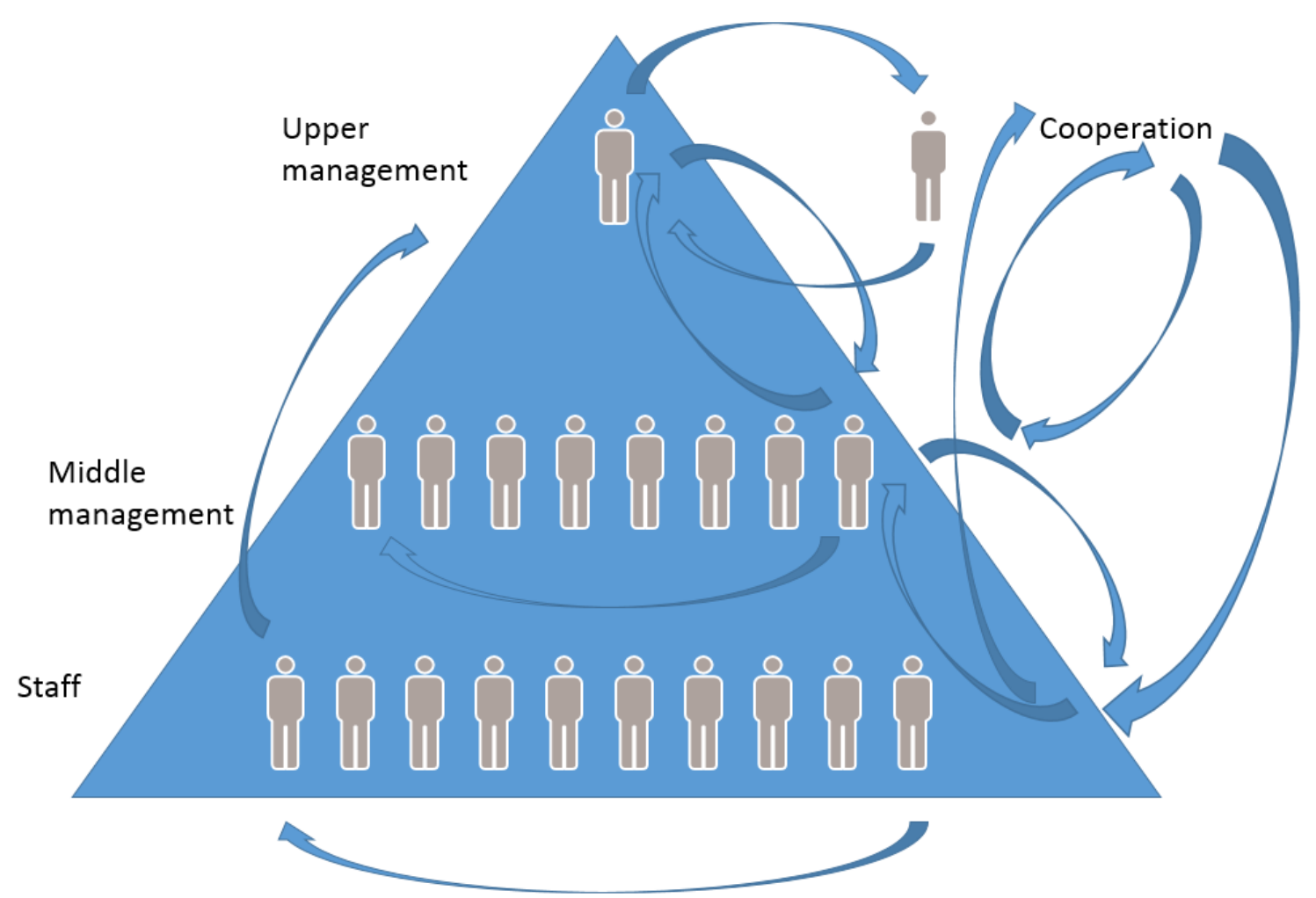

Figure 12: Communication model middle managers

Source: Ayse Yilmaz (August 2018)

The pyramid in Figure 12 represents the hierarchical structure of communication flow. Cooperation, in this case, refers to cooperation between the German and Chinese middle managers working together on-site in Beijing.

The Figure 12 shows upper management, but does not include the CEO level. Upper management is responsible for the department, with these managers reporting to the CEO, who is responsible for producing the vehicles at the required quality standards. In the communication model, it is possible to communicate with a partner on the same level, but exchange primarily occurs between the operational working levels, making information flow easier for staff who work with these processes on a daily basis. The arrows illustrate the communication activities. It is important that it is not only middle management that engages in communication and exchange in the partner plant and with central headquarters in 
Germany, as was described by the interviewees. Communication should also take place at the staff level, with regular exchanges between partner departments.

Middle managers on both sides talked about regular exchange meetings with their staff and the shop floor; however, they require these to be more frequent, since, for operative tasks, daily changes, and updates, one per week seems insufficient to inform them of new structures in the organisation or of new decisions and changes, as Ghemawat and Reiche (2011) also discuss in their work. However, they did not talk about convincing their staff to implement new decisions or even about supporting them through collaboration. Furthermore, the middle managers rarely talked about how to persuade staff not to refuse changes or become angry about or afraid of new technology or new organisational structures. Operators often refuse to implement new decisions when they are afraid of threats to their jobs, as was mentioned by one German interviewee (No. 1; Table 2; Section 3.3.3; p. 74). If things are not improving for the company and managers talk openly about cutting costs, this can create anxiety if it appears to refer to costs relating to headcount and manpower.

In the next section, I introduce one of the most important of the three main findings, one which was mentioned several times by all the middle managers, both German and Chinese, during the interviews.

\subsubsection{Relationship-building and guanxi}

The Chinese word guanxi was mentioned by managers on both sides several times. Meaning 'relationship-building', this concept is very important in Chinese culture (Lihua, 2013). It may be an additional reason for having more frequent relationship-building meetings and for improving communication. However, it was not merely the Chinese middle managers who were talking about improvements in communication and information flow - two of the Germans did too. One German interviewee (No. 1; Table 2; Section 3.3.3; p. 74) said that it was normal to meet regularly with colleagues and their family members and to attend department dinners and social activities. Chinese managers even have an annual budget for these activities, with middle managers investing their budgets in spending personal time with their staff in order to maintain good relationships (Section 1.2.3, p. 19). This is very important in Chinese national culture, as was noted by the German colleagues working on-site. One German interviewee wanted to have more team-building events, saying that, for him, dinners were not sufficient. Rather, he wanted to bring in the German tradition of team-building exercises. He wanted to work together with his Chinese middle management colleagues to build on the national culture of guanxi and mianzi described in Section 2.2 (p. 44 ff.; 
Mintzberg, 2018). One German interviewee (No. 1; Table 2; Section 3.3.3; p. 74) mentioned mianzi, or the threat of losing face, and explained how important this is for Chinese people. He said he recognised the need to be mindful of it and to avoid being too direct when working collaboratively (Appendix 6; p. 237 ff.; morphological box using the Zwicky model). The importance of relationship-building (Adler, 2002; Mintzberg, 2018; Schein, 2010; Ghemawat \& Reiche, 2011) and the need for middle managers to adapt was noted by all interviewees, both German and Chinese. One Chinese interviewee (No. 4; Table 2; Section 3.3.3; p. 74) explained that he had spoken directly to upper management about getting more support for on-site training sessions to improve relationship-building skills and to facilitate adaption to the joint venture situation (Section 4.2.1, p. 95 ff.). Another Chinese middle manager (No. 5; Table 2; Section 3.3.3; p. 74) stressed how much easier it was to work with German colleagues in terms of moving forward with production issues. This illustrated to me the benefit of experience: if local staff cannot be retained in the long-term, professional knowhow cannot be built up; thus, it is easier to complete tasks with the assistance of the more experienced and knowledgeable German colleagues.

As noted by the middle managers, guanxi constitutes the largest difference between German and Chinese national cultures and must be addressed before any changes can be implemented in processes or in the organisation. This can be achieved by sharing know-how and experience, as the German middle managers do when they come over from the central headquarters. Regarding German national culture, the concept of the 'social network' can be compared with guanxi for living and working in China. Social networking is increasingly important in German companies, with more training occurring for collaborating with international firms and improving social networks. German people are typically very sociable and interested in foreign contacts (Luo, 2007), which facilitates their working in China alongside Chinese people. This is reflected in the answers of the German middle managers who had worked for in Germany many years before coming to China as expatriates (Chapter 4, p. 90 ff.).

As indicated in Section 2.2 (p. 44 ff.), Lihua (2013) notes that traditional cultural values such as harmony (和谐), wisdom (智慧), courtesy (礼貌), honesty (诚信为本), and loyalty ( 忠诚) - are fundamental to the Chinese psyche. This was confirmed during the interview sessions, notably in a discussion with the German middle manager (No. 4; Table 2; Section 3.3.3; p. 74) who had the most working experience and the longest experience of working abroad. These values have proven extremely important in this study, particularly when I was 
developing the questions and during my analysis of the interview output. They were confirmed in the responses of the pilot experts and in interview sessions (Section 3.3.2, p. 71 ff.), and they are evident in the literature (Section 2.2, p. 44; Praxenthaler, 2018). One Chinese interviewee explicitly mentioned 'honesty' and 'loyalty' in combination with 'harmony'.

Another German middle manager (No. 4; Table 2; Section 3.3.3; p. 74) mentioned the cultural issue between human beings in general - it does not matter if it is the Chinese culture collaborating with the German culture or any other European culture collaborating with an African or other Asian culture. For this middle manager, the cultural issue involved the importance of generally taking care of the other culture and being honest with each other. Another mentioned guanxi (Section 4.2.3, p. $104 \mathrm{f}$.) in the sense of the need to celebrate together, to have fun, share private time, and enjoy after-work parties and dinners. Training and daily shop-floor meetings were also mentioned, which suggested to me the importance of communication and information flow and control.

In Chinese tradition, food tends to be shared and mealtimes are very sociable. Dallas (2018, p. 41) writes: 'Your Chinese partners will place more value on trusted relationships than on legal documents' - meaning that it is important to be patient and to build trust. One German interviewee (No. 5; Table 2; Section 3.3.3; p. 74) said that he tries to organise face-to-face meetings.

The German managers usually wanted to secure the contract and see results quickly, as described in the literature (Section 2.2, p. 44). I dispute this, based on the views of the German middle managers expressed in the interviews. They described their attempts to adapt to the culture they are living in, such as going for dinner with colleagues. Two German interviewees (Nos. 1 and 4; Table 2; Section 3.3.3; p. 74) described habits such as these that they had developed since joining the Sino-German joint venture. Chinese middle managers tend to seek closer relationships before going into business with other people, as described in the literature review in Chapter 2. On this point, my own findings align with those identified in the literature review.

Various Chinese interviewees (Nos. 1, 2, 3, and 5; Table 2; Section 3.3.3; p. 74) said that they found there to be no differences between themselves and their German colleagues, with relationship-building considered important by all. However, the German middle managers described adapting to the culture in which they were living and working, so it may be that the Chinese interviewees simply had not noticed this. The youngest of them mentioned that he 
had first needed to build trust in order for him to act as a bridge between China and the central headquarters.

In Chinese culture, harmony is very important. In fact, it has been a feature of Chinese culture and cultural thinking since Confucian times. It is as important today. European cultures, on the other hand, generally promote individualism, positivism, and materialism, as described in Section 2.2 (p. 44 f.) (Praxenthaler, 2018).

As noted in Section 2.2 (p. 44 ff.), Dallas (2018, p. 53) writes: 'Often the key to success is knowing how to navigate these differences in cultural values'. For the Chinese and German middle managers, this is a very interesting perspective. As one German interviewee noted (No. 1; Table 2; Section 3.3.3; p. 74), it is essential to understand cultural differences in order to understand one another and to work together on a daily basis.

\subsubsection{Qualifications and hiring}

One of the key findings concerned the qualifications and education of the employees and the middle managers and the hiring process, both for local staff and for the German colleagues who came to work in China on-site on assignments that might last five years, the maximum set by the headquarters. I ranked qualifications and hiring third among the three key findings due to the responses provided by the middle managers and the attribute rating derived from the Zwicky method and the morphological box, which are described in Section 3.4 (p. $81 \mathrm{f}$.). The maximum assignment length was mentioned several times by four German middle managers (Nos. 1, 2, 4, and 5; Table 2; Section 3.3.3; p. 74) during the interview sessions. For the middle managers, the topic of hiring was a very emotional one and they stressed that they have face problems in this regard. For the middle managers from Germany, it was a new situation and a challenge since they were not used to such high fluctuations in staff; one German manager stressed that in Germany, staff levels usually remained stable for years. To me, it was also observable that the middle managers probably needed additional training to understand the structures and the IT and HR frameworks of the joint venture company in order to follow instructions and adapt to it (Section 1.4, p. 25 f.). This is also described in my research questions and h objectives - I was looking for a way to recommend to close the gap (Section 1.2.1, p. 15). For the Chinese middle managers too, it was not easy to adapt to the joint venture and let the German middle managers understand the existing frameworks. Some of the Chinese (Nos. 1 and 2; Table 2; Section 3.3.3; p. 74) and German middle managers (Nos. 1, 2, 3, 4 and 5; Table 2; Section 3.3.3; p. 74) who had worked before in another company mentioned that in automobile production in Beijing it was much more difficult to 
retain staff due to the good market and the opportunity for employees to quickly find another job that was closer to their hometown or in which they could earn more money. These seven middle managers noted that with the staff fluctuations, such as with engineers leaving, and the need for staff to be properly qualified in the first place in order to maintain a high standard of work, it was almost impossible to maintain a high level of flexibility in their work.

To summarise the findings under the heading of 'qualifications and hiring', in what follows I provide information from the interviews:

One Chinese interviewee (No. 1; Table 2; Section 3.3.3; p. 74) had more than eight years work experience. Discussing qualifications and the hiring of local Chinese employees, this interviewee said that experienced and knowledgeable workers in automobile production who speak English very well are very difficult to find. She had experienced this herself during her long career with BACF and noted that this created ability gaps for Chinese middle managers seeking to manage change and ensure a stable team. Furthermore, retaining qualified people for periods longer than two years was becoming difficult due to the strong market conditions in Beijing and in China more widely. This was also mentioned by other Chinese (Nos. 2, 4, and 6; Table 2; Section 3.3.3; p. 74) and German interviewees (Nos. 1 and 3; Table 2, Section 3.3.3; p. 74). Two German middle managers aged 45-50 noted how important it was to ensure that German colleagues were on-site and working together. Local staff were proving difficult to retain, and the company was thus losing valuable experience and know-how. At the German headquarters, many employees had been working for the company for more than 25 years and staff fluctuation was very limited.

One Chinese interviewee (No. 3; Table 2; Section 3.3.3; p. 74) mentioned that the corporate culture in the Chinese company had begun to adapt to that of the German company; as inside researcher, I could confirm this (Section 3.5, p. 85 ff.). Similarly, the HR department was using the assessment centre in the same manner as German HR, including the tests and the structuring of the promotion of middle managers. Training sessions too were held in the same way as they were for German middle managers, as described by one Chinese middle manager (No. 4; Table 2; Section 3.3.3; p. 74). This suggested to me that the corporate culture of the Sino-German joint venture had adapted and that upper management was seeking to ensure the company remained stable in the market. It was also mentioned by a Chinese interviewee (No. 2; Table 2; Section 3.3.3; p. 74), who was younger than 35 years of age but was nonetheless experienced in the role, that upper management support for better recruitment was required to ensure the retention of local staff. None of the middle managers reported that they themselves 
treated their staff badly, but many hinted that they required more training and that something should be done to improve recruitment practices.

Andersen (2014), Apetrei et al. (2015), Bate (1997), Beugelsdijk (2016), Eisend et al. (2016), Floyd and Wooldridge (1999), Ghemawat and Reiche (2011), Hitt et al. (2007), Hoogan and Coote (2014), Kluckhohn (1951), Macharzina (2005), Sadri and Lees (2002), Sackmann (2004), Schein (1985), Waisfisz (2019), and Yin (2014) write about the terms and definitions of culture, as described in Section 2.2 (p. 44 ff.) on corporate culture and transculturation. Schein (1985) and Ghemawat and Reiche (2011) consider an establishment to be a clearly defined social group with social patterns, as observed in the Sino-German joint venture. The group should be able to solve problems that emerge externally or internally (Schein, 1996; Section 2.2, p. $44 \mathrm{f}$.) and it should be obligatory for new employees to learn these patterns (Schein, 1984; Section 2.2, p. 44 f.). All employees should integrate themselves into these organisational patterns, making it easier for them to follow the corporate culture. According to Schein (1985) and Ghemawat and Reiche (2011), and in line with the thoughts of the middle managers, this basic pattern should manifest itself in a certain set of moral concepts, standards, and norms of behaviour, which are then represented by artefacts and symbols (Schein, 1984; Ghemawat \& Reiche, 2011; Section 2.2, p. 44 f.). Four of the six German interviewees (Nos. 3, 4, 5, and 6; Table 2, Section 3.3.3; p. 74) spoke about standards in their work, norms, and behaviours, as indicated in Section 2.2 (p. $44 \mathrm{f}$.) and as noted by Schein (1984) and Ghemawat and Reiche (2011). According to McCalman et al. (2018) and Ghemawat and Reiche (2011), the first key factor for successful change management, as described in Section 2.1 (p. 29 f.), is the problem-owner or the manager who needs to deal with. In this case, the middle manager who was observed by me during the interview sessions (Section 4.4, p. 120 f.) must be involved in qualifications and hiring in order to better set the focus on how to keep employees in the company and to hire the right people. The interviewees mostly discussed the corporate culture, the hiring processes, and support they needed from upper management. They did not talk about strategy or how important they themselves were in promoting employee retention. This suggests that the middle managers require more training in order for them to better understand their roles.

In response to interview question 12, on the strengths and weaknesses in the system, three of the more experienced Chinese middle managers (Nos. 1-3; Table 2; Section 3.3.3; p. 74), mainly the most experienced one, said that they wanted more training for their local staff. It is good is that the middle managers on both sides recognise the matter of a lack of qualifications and the need for supporting employees (Ghemawat \& Reiche, 2011). The German 
interviewees mostly agreed with this, recognising that they needed to optimise their processes by using more systems-based solutions for data management (Hitt et al., 2007; Hoogan \& Coote, 2014; Schein, 2010), rather than paper-based archives which created frustrating amounts of paperwork. One Chinese interviewee (No. 5; Table 2; Section 3.3.3; p. 74) mentioned that technical data and product information was often missing, which highlights the need for improvements in communication (Section 4.2, p. 92 ff.), training and development, and information flow. Middle managers on both sides noted the existence of process issues.

In addition to the need for more training and better qualified local staff, one of the Chinese interviewees (No. 1; Table 2; Section 3.3.3; p. 74), who had been working on the German side of the company for over 14 years, cited the need for training in leadership and enhancing motivation and communication to additionally motivate employees and develop them so that they stayed with the company (Wooldridge et al., 2008). Middle managers especially need to ensure a good hiring strategy and to keep the qualifications of their employees high, as Wooldridge et al. (2008) emphasize in their study. The role of middle managers as key players is recommended by McCalman et al. (Section 2.2, p. 44 ff.), Wooldridge et al. (Section 2.2, p. 44 ff.) and Kotter and Cohen (Section 2.2, p. 44 ff.). Two Chinese interviewees (Nos. 4 and 5; Table 2; Section 3.3.3; p. 74) mentioned that they had observed local staff improving their presentation or project management skills through regular mentoring by German experts over a period of 6-8 months. This was also mentioned by one German interviewee (No. 2; Table 2; Section 3.3.3; p. 74), who had more than 10 years' experience in the German company and more than two years in the joint venture.

One German middle manager (No. 5; Table 2; Section 3.3.3; p. 74) mentioned that if this were not a joint venture, the Chinese colleagues would have needed to build up the plant and all the processes according to the standards given by the central headquarter by themselves, and that being in a joint venture had numerous benefits. For him, this had nothing to do with change management and culture. One interviewee (No. 3; Table 2; Section 3.3.3; p. 74) suggested that the company should not always only send people from central headquarters, but also allow local staff to visit the central plant to learn and improve their work as well as to learn more about culture and collaboration in the central plant. This would help to build up a better network and would build trust and a better understanding of corporate culture in the central headquarters. At present, this is often rejected by management due to the cost of travel and accommodation for the Chinese company. In the view of this interviewee, investing this money would help to build professional know-how and support staff retention as well as help with better understanding the 
standards provided by the central headquarters so that in China, they adapt to them more easily and faster.

In next section, I discuss the rest of the findings.

\subsection{Further findings}

Having introduced the three main findings in the previous section, I highlight and discuss further findings of interest in Sections 4.3.1 to 4.3.6. I begin with the most highly rated one, change management practice, in Section 4.3.1; thereafter, the others rated as important for the 12 middle managers are discussed. As with Section 4.2 on the three key findings, rating took place using the method of Zwicky (Section 3.4; p. 81) and the morphological box. An example rating is shown in detail in Appendix 6, p. 237 ff. All the findings were rated. In Section 4.3.1, I begin with the discussion of the content of change management practice and explain this based on feedback from the middle managers in the interview sessions to understand how they see its importance and what kind of explanation is important for them.

\subsubsection{Change management practice}

'Change management and cultural factors: A study of German and Chinese middle-managers' behaviour in a Sino-German automobile joint venture' is the title of this doctoral thesis. The middle managers described change management as important as regards the practical requirements they observe in the collaboration models in their daily work. For example, in response to interview question 11 (Appendix 5, p. 222), all 12 middle managers agreed that change management was important and that they must support their staff during change processes and projects. One Chinese interviewee (No. 4; Table 2; Section 3.3.3; p. 74) mentioned that if changes were imminent and staff refused to cooperate from the beginning, the changes could not be successfully implemented. This suggests that good communication (Section 4.2.1, p. 95 ff.) and good integration of all employees is required from the beginning. I observed that theoretical knowledge was available but that practice experience was missing to support the middle managers in their roles and to allow them to learn more and to learn how to better deal with their staff in changing situations - and to help staff to understand how to deal with changes.

For four of the six German interviewees (Nos. 1, 3, 4, and 6; Table 2; Section 3.3.3; p. 74), it was very important to integrate change management and to support staff understanding of upcoming changes and how to deal with them. It is also necessary to support them to learn and deal with daily operational tasks, not merely to explain theoretically the process of change 
but also to help and support them with their daily problems and with dealing with changes in a practical way.

For one German middle manager (No. 5; Table 2; Section 3.3.3; p. 74), change management has nothing to do with culture, yet changes and understanding change management and processes (Section 1.2.1, p. 15 f.) remain very important and should be considered separately from culture. One Chinese middle manager (No. 2; Table 2; Section 3.3.3; p. 74) claimed to have never thought about combining culture and change management and to consider both in terms of their correlations and links. For this manager, respect and humility were important for success, as were communication and the function of the middle manager. I recognise (Section 4.4, p. $120 \mathrm{f}$.) that the function of the middle manager, that of being a bridge between upper management and staff, is a very important one for understanding the middle management level too. This I recognized from the responses of all of the middle managers on both sides. For example, two Chinese middle managers (Nos. 2 and 4; Table 2; Section 3.3.3; p. 74) mentioned that without middle management in the company, the staff level would lack an understanding of the working level and of how to deal with upcoming issues. They talked about themselves (Section 4.2.3, p. 104 ff.) obtaining better qualifications and being better trained for the task being a middle manager, especially in terms of leadership behaviour (Wooldridge et al, 2008).

In the next section, I discuss national cultural differences in relation to change management practice.

\subsubsection{National cultural differences}

National cultural difference is considered as a topic separate from but linked to relationshipbuilding (Section 4.2.2, p. $101 \mathrm{ff}$.). It is important to consider the national culture the local Chinese employees have in common - their living, working, and family lives - compared to that of the German employees coming over as expatriates to live and work in China, especially in terms of their international experience and their German cultural background. Some German interviewees (Nos. 2, 3, and 6; Table 2; Section 3.3.3; p. 74) mentioned that, in China, many people come from the provinces to Beijing, the capital city, to find work. Many of these jobseekers are young and are looking to begin a career after completing their studies. Many inexperienced local staff apply for engineering and planning roles, and the operators in assembling processes are often people without qualifications. They are seeking to gain a foothold in the industry. In China, many people marry young, typically before the age of 25. 
The local employees' families often live in different provinces. One Chinese interviewee (No. 6; Table 2; Section 3.3.3; p. 74) noted that living costs in Beijing were extremely high for those coming in to work. If individuals are not married by the age of 25 , their parents are likely to ask them to return to their home provinces. Or, if they are married, they are expected to have children in the first year of their marriage; this was highlighted by two Chinese interviewees (No. 2 and 4; Table 2; Section 3.3.3; p. 74) and one German one (No. 1; Table 2; Section 3.3.3; p. 74). Due to difficult living conditions, both parents often need to work, and grandparents take care of their grandchildren. If these elders are unable to accompany their newly married children when they relocate to Beijing to work, many newly-weds have no option but to leave and return to their home provinces when they have children. This key characteristic of China's national culture should be considered in any comparison with the German national culture.

One Chinese middle manager (No. 2; Table 2; Section 3.3.3, p. 74) described how national culture plays a role alongside corporate culture:

I don't think culture has an impact on change management, from my perspective. I do not know how to say it.... Culture plays a very important role; when different cultures conflict, they both play an important role. However, I think for joint ventures, especially for our company, maybe how one can manage change management is the question.

Having lived in Germany for many years, this manager stated that national culture played less of a role for her. Rather, she focused on the influence of corporate culture and on change management.

All interviewees talked about national culture and cultural differences, with two Chinese middle managers (Nos. 2 and 4; Table 2; Section 3.3.3; p. 74) and three German middle managers (Nos. 4, 5, and 6; Table 2; Section 3.3.3; p. 74) indicating that corporate culture and change management were unaffected by national culture when working in joint venture or collaborating with German or Chinese colleagues. However, again, 'collaboration' is a term that suggests underlying communication (Appendix 6; p. 237 ff.; Section 4.2.2, p. 101 ff.). In a corporate or national culture, one can see a combination of attitudes, values, and practices among a group of people, as described by Hofstede (2005; Section 2.2, p. 44 ff.). Here, Hofstede’s view can be seen in the attitudes of these middle managers with the most work experience in total and most experience of working internationally. 
However, two of the six German middle managers (No. 1 and No. 6; Table 2, Section 3.3.3, p. 74) indicated that it had been much more difficult to integrate into Chinese culture than they had imagined, even as they suggested that training by their HR department in intercultural competencies and for life as an expatriate would be beneficial for them and their families. The expatriates had all arrived in China with a positive outlook, and they explained in their interviews that they faced different kinds of experiences or even the same kinds of experiences as their collective.

Three of the Chinese middle managers (Nos. 1, 2, and 4; Table 2; Section 3.3.3; p. 74) said that they experienced change management and cultural differences in the cooperative joint venture differently from what they had in the firms they have worked before. They described this as one of the negative aspects of working in the joint venture (Section 4.5, p. $124 \mathrm{ff}$.). Information flow and communication were again noted frequently in the answers to question 8 (Appendix 5; p. 222 ff.). One Chinese interviewee (No. 3; Table 2; Section 3.3.3, p. 74) said that it was easier to work with German colleagues than with Chinese colleagues. However, he was then referring to the R\&D department. Here, he noted the same problem mentioned by others (Nos. 1, 2, and 4; Table 2; Section 3.3.3; p. 74): in the development department, there were Chinese colleagues working without product data. This was a situation particular to a joint venture, as the product owner and brand owner (the German company) had retained the rights to their R\&D department and did not send out information in the early product development phases due to copyright issues. One Chinese interviewee (No. 2; Table 2; Section 3.3.3; p. 74) stressed the importance of communication (Section 4.2.1, p. $95 \mathrm{ff}$.), saying that some of his engineers needed to change their attitudes and collaborate; this was not really related to culture, just to the personal attitude of some of the employees working better with their German colleagues and the central German headquarters in order to develop their knowledge (Section 4.2, p. 92 ff.).

For one German middle manager (No. 5; Table 2; Section 3.3.3; p. 74), culture was not really an issue in the joint venture and in business collaboration at a working level to achieve a good business relationship and attain optimal results together. He stated that it was important to find a way together to deal with existing issues and tasks. He appeared to be more task-oriented too, a factor which is a feature of German culture (Section 2.2, p. 44; Luo, 2007).

One Chinese interviewee (No. 3, Table 2; Section 3.3.3; p. 74) stated that change management was a key process for information exchange and information transparency. He was responsible for engine planning, had many years of experience at the German headquarters, and had worked for a subsidiary company in the US for more than five years. 
Two Chinese interviewees (Nos. 4 and 6; Table 2, Section 3.3.3; p. 74) mentioned that they had no problems with the German national culture and, having both lived in Europe for several years, they seemed to feel comfortable in the joint venture. On the German side, one interviewee (No. 1; Table 2; Section 3.3.3; p. 74) had had many years' experience of working with Chinese colleagues in the joint venture before moving to China as an expatriate. He stressed that Chinese colleagues had different ways of working (Appendix 6; p. $237 \mathrm{ff}$., morphological box using Zwicky model). From the view of the production department, he explained that Chinese middle managers and employees often waited a while before responding to emails, tasks, and phone calls. He said that for his German colleagues at the central headquarters, this would not be an option. From his point of view, German people engage in a long planning phase and tend to take a structured and detailed approach. For him, this was the key difference between the two national cultures in terms of their working models (Praxenthaler, 2018; Preyer, 2009).

For one Chinese interviewee (No. 2; Table 2; Section 3.3.3; p. 74), national culture was a very minor issue. This manager had worked for another company and also had international experience. In my understanding, she had developed wider thinking and more acceptance during her experience so far. This is in contrast to the views of most of the other managers on both the Chinese and German sides, who felt national culture was very important for change management, communication, collaboration with other departments, and for the structure of joint venture. They each stated that it was important to have the same targets and to collaborate (Appendix 6; p. 237 ff.; morphological box using the Zwicky model), regardless of one’s own national culture. One experienced Chinese middle manager (No. 1; Table 2; Section 3.3.3; p. 74) said: 'First of all: know it, and know the processes. Get the input and implement it one hand in another. Work it out together'.

However, the manager did not mention training or better qualifications for this purpose. The most experienced German middle manager (No. 1; Table 2; Section 3.3.3; p. 74) said that cultural factors are always important. It is important to work in line with the standards and processes as this was required by headquarters. It was important for him as German middle manager to take care about this, even if he did not have a German manager above him he was reporting to. This was also important for the Chinese upper manager to whom he was reporting. Of the German interviewees, almost all mentioned the importance of being open to new things. Trust, guanxi, and mianzi (Section 4.2.2, p. $101 \mathrm{ff}$.) each play a major role in the Chinese national culture, and most of the German participants acknowledged this. As a result, 
they sought support from upper management (Section 4.2.2, p. 101 ff.), which was very important for them. This matter was mentioned by only two of the Chinese interviewees (No. 3 and 5; Table 2; Section 3.3.3; p. 74).

Four of the six German interviewees noted the importance of national culture, whilst one said that he did not really know whether it was important. Another said that, for him, there were no important cultural aspects to the collaboration (Appendix 6; p. $237 \mathrm{ff}$.; morphological box using Zwicky model); rather it was a case of showing sympathy to one's counterparts on-site, who in this case were the Chinese colleagues, though the practice would be the same for Germans working together at the central headquarters. One German middle manager (No. 1; Table 2; Section 3.3.3; p. 74) with experience of international work, said that the Chinese national culture had strongly affected him as when he started working in the joint venture, he first needed training to understand the cultural differences. As an example, he mentioned that he had learnt never to give to a Chinese person a watch as gift. In Europe, it is a normal occurrence to give friends or relatives a watch as a Christmas or birthday gift. However, in China, if someone is given a watch as gift for their birthday, it suggests that time is passing and that death is approaching. This demonstrates that understanding of a culture is required when one is working aboard in a country with a different culture. He stressed the importance of giving due consideration to cultural differences when working internationally, especially in a joint venture. All of the interviewees expressed the importance of learning about a culture when working in a joint venture as a middle manager. All the German and Chinese middle managers with longterm experience agreed that they had needed to learn and adapt (Appendix 6; p. 242 ff.; morphological box using Zwicky model). Their responses indicated that they experienced culture and change management differently in joint ventures and that they had needed to adapt themselves in order to support their staff to cope with change.

It was also important for me that the employees - in this case, the middle managers - had a cultural understanding, or had at least developed this during their time working in the joint venture. To ensure the best results for the company, cultural heterogeneity is important. This is why companies cite diversity as a success-related factor for managers (Adler, 2002). Diversity does not simply refer to differences in language and culture; it also concerns habits and preferences. An international firm is more effective when it has multinational personnel. In the next section, I discuss language. The middle managers considered this a key factor which needs to be highlighted; in the literature research (Section 3.2.1, p. $58 \mathrm{ff}$.), it was not found to be a factor in relation to change management and national and corporate cultural differences. 


\subsubsection{Language}

Even for me as an inside researcher (Section 3.5, p. 85), language was a new factor that needed to be considered. All 12 middle managers confirmed that they had issues with language.

In this section, I consider the varieties of language issues that are due to levels of experience and the number of assignments people have completed. Language issues primarily arise due to the third language, English, which is the language used in this joint venture. It is not the mother language of either the Germans or the Chinese.

One Chinese interviewee (No. 6; Table 2; Section 3.3.3; p. 74) described himself as halfChinese and half-German and said that he had lived in Italy and the UK for many years. He mentioned that language issues were a problem for him and his colleagues. These responses did not seem to align with one another: even though he had experience aboard, it seemed to have been an issue for him to observe his colleagues talking in German when he was aboard. This middle manager was the most recently promoted of the interviewees, with little work experience in the company. Even though he had experience in working in Europe, he did not have experience as a middle manager. Another Chinese interviewee (No. 3; Table 2; Section 3.3.3; p. 74) said that if German and Chinese middle managers shared an understanding of their work in the joint venture, their output would tend to be the same. This manager was the most experienced and the oldest, at more than 50 years of age. She was clear on her processes, had regular alignment meetings with the central headquarters, and indicated that she knew her counterparts at headquarters well. For her, language was not a problem at all. She mentioned that the German expatriates sat in on meetings where only Chinese was spoken all the time. Even if the Germans did not understand anything, they were polite and merely sat with them. Sometimes someone would translate for them, sometimes not. To her it would be the same if she needed to go Germany - then, in some meetings, only German would be spoken, perhaps due to some colleagues speaking no English, or perhaps for them to understand the situation and issue better in order to solve it faster. She seemed to be very experienced and had had much experience in cross-cultural collaboration and international collaborating firms.

However, the other Chinese participants did not share this view. The interviewees said that they struggled to obtain input and information. They reported that they were not being integrated into the early project phase and felt that the information flow was not efficient. Hence, for them, the corporate culture was more of a problem than the national culture was. However, in my understanding, the problem with integration in the early production phase is one of compliance and is not a collaboration deficit, as the central German headquarters is simply not allowed to provide early-phase product development information. As BACF is a joint venture between two 
companies work rather than one company, in the early phase, product information and information from development department must stay at headquarters. Sometimes, even for departments that belong to the headquarters company, no access to the development building is allowed and information flow needs to be double-checked.

The Chinese middle managers reported that they have far fewer assignments, but not fewer promotions, even if the staff are very young. Since the company is growing very quickly and there is a high fluctuation rate at the staff level, good employees get the opportunity to be promoted very quickly. In Beijing, the Chinese employees in production department are typically very young, with the middle managers being younger than the German middle managers. The employees are often new to the market and have had no experience prior to their position at BACF. The German middle managers, being much older, have had more previous assignments and have worked for different companies, including long periods at the central headquarters. One exception was 36 year old German manager who had been freshly promoted to a middle management position, having worked as a planner for several years in the same company and having been promoted quickly thereafter. One of the Chinese interviewees (No. 6; Table 2; Section 3.3.3; p. 74) explained that it was difficult for local employees to move departments since this process needed to be approved by upper management, which was not possible on the Chinese side. In contrast, many German middle managers had moved several times, gaining experience of different positions and departments and developing their understanding of foreign plants, thus allowing them to progress in their careers.

This is one of the differences in corporate culture and in HR recruiting regulations which could also make local Chinese employees unhappy and be one of the reasons they terminate their contracts. Doing a job for many years may be the wish of one employee, but changes are required to develop employees and to improve ones' thinking. It is necessary to develop employees to get them to better understand the needs and process of different departments. It can be very demotivating when there is no opportunity for local employees to change departments or positions.

Furthermore, I observed that the middle managers' respective levels of experience of working or studying abroad affected their understanding of the impact of language and culture.

The next section picks up the discussion point of one of the Chinese middle managers (No. 3; Table 2; Section 3.3.3; p. 74) regarding receiving or not receiving information in the early planning phase of a product and deals with the topic of compliance. 


\subsubsection{Compliance}

Two Chinese interviewees (Nos. 1 and 2; Table 2; Section 3.3.3; p. 74) mentioned that compliance with regulations was very important and that employees had to be trained in compliance regulations especially in the joint venture and that it should be discussed frequently. All change processes and projects related to organisational changes were to be checked by the middle managers, according to one experienced Chinese middle manager (No. 2; Table 2; Section 3.3.3; p. 74). Two Chinese interviewees (Nos. 1 and 2; Table 2; Section 3.3.3; p. 74) mentioned that compliance was far better in the joint venture than it had been in the other companies for which they had worked before. These statements could only have been made by those Chinese middle managers who had experience of other companies. Those who had come directly from university and had begun their careers at BACF were unable to make comparisons in terms of compliance and did not mention this in their responses. For all the German interviewees, it was important that they change their attitude regarding compliance and communication to make improvements in the joint venture. One German interviewee (No. 5; Table 2; Section 3.3.3; p. 74) mentioned the importance of teaching his local Chinese staff about standards and compliance, especially as regards the two corporate cultures, which, from this point of view, should be combined in one common corporate culture.

Due to the complicated organisational structure of the two companies which needs to be considered and discussed, in Section 4.3.5 I discuss hierarchical structure in the joint venture.

\subsubsection{Hierarchical structure}

The discussion of the hierarchical structure arose during the interview sessions when the middle managers on both sides were discussing what they needed to improve in the company and what they needed to do to help their staff build up a better understanding of change management and culture, both national and corporate culture, and integrate these into their daily production processes.

One Chinese interviewee (No. 3; Table 2; Section 3.3.3; p. 74) mentioned something that none of the other 11 middle managers talked about, which is the double functionality of the middle and upper management organisational structure. He explained that some manager positions were occupied only by one side, either German or Chinese. However, some positions were doubled, with each Chinese manager having a German partner with the same function and contract requirements. In his opinion, this was inefficient for daily processes, 
such as signature processes that managers need to sign on both sides of the joint venture in all approval processes. However, for cultural understanding and communication with the German headquarters, he explained that it made sense to have a German manager as a partner to a Chinese manager and to have a Chinese manager on-site for meetings on the Chinese side. Moreover, he explained that tasks could be separated, especially for daily work at the operational level, when improvements needed to be implemented quickly.

Analysing the attitudes of middle managers, Ventris (2004; Section 2.2, p. 44 f.), as described in Chapter 2, found that, in most instances, managers act in a theoretical rather than in a practical manner and therefore struggle with hierarchical structure. They use change management methods and forget that they are working with human beings. This is one of the key messages for middle managers that I explored during the interview sessions. Namely, whether middle managers and their bosses concentrate on theoretical change management and whether they should make use of it for operational-level work. This point of view is described in Section 2.2 (p. 44 ff.). Praxenthaler (2018) refers to it in his work, and McCalman et al. (2008) describe this point of view as the fifth key factor in their work (Section 2.1, p. 29 f.).

The most experienced of the German middle managers mentioned that the quick growth of both China and the company had affected him and his staff. Specifically, the speed of the changes and the ever-changing processes. He described how difficult it was for him and his staff, highlighting the need for technical improvements and good change management processes. One German interviewee (No. 3; Table 2; Section 3.3.3; p. 74) spoke positively about the speed of change in the organisation, and stressed the importance of upcoming changes for customer satisfaction and product improvements in the market. This manager also emphasised the importance of the middle management level and of there being a good communication channel (Section 4.2.1, p. 95 ff.) between upper management and staff. In the next section, I discuss the importance of good management skills, which are required at middle management level and which was recognised by all the middle managers and discussed in the interview sessions.

\subsubsection{Good management skills}

Question 14 was intended to ascertain the kind of support that the middle managers needed for themselves, to support their staff during organisational change, and to manage associated fears. Two Chinese interviewees (Nos. 2 and 5; Table 2; Section 3.3.3; p. 74) revealed that their staff did sometimes fear change and needed to be convinced by their middle managers to accept new processes and, for example, to recognise the benefits of the change. These 
interviewees explained that supporting their employees individually was very timeconsuming. One noted that he had a team of 18 employees, and it was difficult for him to progress with daily operational business tasks due to several upcoming changes.

However, one Chinese interviewee (No. 2; Table 2; Section 3.3.3; p. 74) spoke about other managers putting pressure on their staff. He mentioned that, in China, practices are often more successful when pressure is applied. Some of the Chinese middle managers (Nos. 1 and 6; Table 2; Section 3.3.3; p. 74) thought it varied from one individual to another, regardless of nationality. One Chinese middle manager, with more than seven years of experience, said that the Chinese employees are open to change (Section 2.2, p. $44 \mathrm{ff}$.). This is not easy to achieve without the support of their German middle manager colleagues, who may contact central headquarters for input and information regarding the standardisation of processes and equipment.

Three German middle managers (Nos. 1, 4, and 5; Table 2; Section 3.3.3; p. 74) said that upper management needed to be more deeply embedded in the change management process, and not simply make decisions and leave middle managers to implement them with their staff (Section 2.1, p. 29 f.; Wooldridge et al., 2008; Andersen, 2004). One German interviewee (No. 3; Table 2; Section 3.3.3; p. 74) described the need for a change management structure that would allow managers to discuss the changes with staff, plan the next steps together and explain the importance of the upcoming changes before providing upper management with recommendations.

In the next section, I discuss the topic of technical improvements and the requirements for this in the joint venture that were discussed by the middle managers in the interview sessions.

\subsubsection{Technical improvements}

The lapse of time between discussions on alignments or exchanges with German colleagues in the production department in Germany was extended, starting with daily shop floor and communication rounds (Section 2.1, p. 29; Barmeyer, 1996) or alignments, to occur only bimonthly, as was mentioned by one of the German interviewees (No. 3; Table 2; Section 3.3.3; p. 74). Furthermore, one Chinese middle manager (No. 1; Table 2; Section 3.3.3; p. 74) explained that exchanges via communication channels such as telephone and video conferencing were not popular in the Chinese company. The middle managers and their staff complained of an insufficient number of meeting rooms. Furthermore, there were few video conferencing facilities and no company phones. One German interviewee (No. 4; Table 2; 
Section 3.3.3; p. 74) explained that employees and managers were expected to use their own cell phones for work purposes. He also mentioned that cell phones were available to German middle managers and planners or engineers, but not to Chinese employees. As a result, on the Chinese side, everybody had to use their own mobile phone, even the managers.

Skype for example as communication channel did not appear to be used regularly, according to one German interviewee (No. 2; Table 2; Section 3.3.3; p. 74). As noted by a Chinese interviewee (No. 1; Table 2; Section 3.3.3; p. 74), this could be significant if Chinese employees became aware of the difference in the treatment of the respective groups and, as a consequence, chose to leave the company. Employees could be retained better if they were subject to the same regulations by IT and HR.

One German interviewee (No. 4; Table 2; Section 3.3.3, p. 74) mentioned that he saw the increased growth of the company as a tremendous strength. A Chinese middle manager (No. 6; Table 2; Section 3.3.3; p. 74) wanted the IT department to be improved. Another (No. 6; Table 2; Section 3.3.3; p. 74) stated that, as the team members were very young, it was not difficult to implement new ideas; however, on the other hand, he often needed to teach them more, unlike with some of other teams which benefited from a mix of younger and more experienced employees.

All the German middle managers mentioned that, in China, changes often arose that had to be dealt with very quickly, which was not the case at the central headquarters. This kept them busy and was something they often discussed. Even the Chinese interviewees (Nos. 1, 2, 4, and 5; Table 2; Section 3.3.3; p. 74) observed this, identifying this an area in need of technical improvement. China is a fast-growing country, and the company needs to grow equally quickly in order to align with market conditions and requirements (Section 1.1, p. 9 ff.). For this reason, one Chinese interviewee (No. 1; Table 2; Section 3.3.3; p. 74) could not understand why the company was not improving its IT department by implementing the hardware required for video conferencing. For her, this was a must, and she asked me, as the researcher, to make a note of this and integrate it into my recommendations to the company since this was very important for her point of view.

In the following section, I discuss, as additional point in this chapter, my observations and impressions as a researcher, especially in relation to the interview sessions, since, to my understanding, this is of interest and is important to add. 


\subsection{Observations by the researcher}

In this section, I describe my own observations during the interview sessions and the feeling I had when I received responses which I did not expected and thus surprised me.

As Schein (1999) describes, and as indicated in Section 2.1 (p. 29 ff.), it can be difficult for managers in changing organisations to find a balance between tasks and employee requirements while appropriately managing fear of change among staff. The middle managers focused more on their own needs than on how specifically to deal with their tasks and upcoming changes. If they cannot keep their people and had identified a need for support to progress with tasks and focus on daily tasks, then it is very difficult to attain consistency in daily operational work and to develop a routine for staff with regular work instructions. Rituals are collaborative activities designed to strengthen the social solidarity of a group. As Hofstede (2001) describes, as explained in Section 2.1 (p. 29 ff.), this means the team members must share common values, such as emotions, and that middle managers must work closely with their staff.

As discussed in Section 4.3.1 (p. 108), one of the Chinese middle managers made the very interesting point that, if staff refused to cooperate with changes, there would be no chance of successful change management. This showed me that there was understanding at the middle management level of the importance of integrating staff as early as possible with approaching changes to the structure, the organisation, and to the processes, as almost all the middle managers spoke about the importance of change management and that further training for middle managers and their staff were required. Appropriate communication, information flow, and change management practices are key for successful shop-floor implementation of changes (Section 2.1, p. 29 ff; Barmeyer, 1996), as was mentioned by two Chinese middle managers (Nos. 2 and 5; Table 2; Section 3.3.3; p. 74) and four German middle managers (Nos. 1, 3, 4, and 6; Table 2, Section 3.3.3; p. 74).

Another point which I found very interesting was that all the interviewees spoke about their own experience in terms of their projects gave me examples directly from the shop floor and from their own teams and tasks. Each interviewee had their own story, which they told me about their own team structure and their own area. Throughout the interview, it was interesting to hear how one of the middle managers was talking about issues relating to when he had with the increase of the number of tasks per hour in production and how difficult it was for him and his team members to deal with the changes or even, initially, to implement them. One experienced German middle manager (No. 3; Table 2; Section 3.3.3; p. 74) told me that he had issues with other departments' needs, and not simply those of his own team 
members. He talked about preparing for a new generation of a car that was run on a battery rather than using an internal combustion engine, describing this as a big change and a challenge for him and his team members. Another German middle manager (No. 4; Table 2; Section 3.3.3; p. 74) told me how difficult it was for him to come to China and experience a culture that he could never have imagined, despite his prior experience with international collaborations. For both employees and management, it was of the greatest importance to have a vision and challenging goals for the company. Dallas (2018, p. 30), introduced in Section 2.2 (p. 44) states: 'It's about instilling belief and empowering employees to surpass those seemingly high hurdles. It gives purpose to a firm and its employees’. I agree with this point entirely, having had the opportunity to observe these 12 middle managers and to reflect on their contributions. A vision is not a dream: it is a plan that needs to become reality. Operating in the Chinese market, this joint venture must work with its employees to connect with the vision of China's markets and future.

The German interviewees spoke about their experiences as being exciting and new, as offering opportunities for exploring, learning, and developing, and about improvements in technology, such as ongoing digitalisation processes and being innovative, since these improve very quickly in a country like China.

Furthermore, I got the sense that if a person had previous experience living abroad, they were often able to add in their behaviour and way of thinking about the new culture, as the Chinese middle managers noted. For example, one young Chinese middle manager (No. 6; Table 2; Section 3.3.3; p. 74) said, 'I am kind of half and half'. He identified himself as half Chinese and half European due to his way of thinking. This told me that he had been able to adapt to European culture after spending several years in Europe. Another Chinese middle manager (No. 2; Table 2; Section 3.3.3; p. 74), who was older and more experienced and had studied and worked in Germany for several years, told me that, for her, there was no difference between the two national cultures. She said she understood the German culture and that it was not new to her. This perception was very interesting for me: even though I was born in Germany, my parents are from Turkey, which has an entirely different culture. Therefore, this was a view that had implications for my own life: while I think and act as a German, I feel entirely comfortable when visiting my relatives in my parents' country of origin. This was evidently also the experience of the Chinese and German middle managers who had experience working in other countries. They knew how to behave and how to adapt to the other culture, as also described by McCalman (2008), and noted in Section 2.2 (p. 44 ff.), as 
the first of his six key factors: the owner of the change is the important person. To my understanding, if the owner of the change - in this case, the middle manager - brings with him- or herself an understanding of another culture, the process of change will be made much easier for the entire group.

Another topic I observed in the interview sessions was that it may be that German companies seek to make workers feel more comfortable and offer more training to develop their people skills, such as presentation skills and other soft skills, such as change management and intercultural cooperation. This is an important topic which, perhaps, needs to be optimised. To my understanding, based on the findings from the interview sessions, communication is a basic requirement for culture to arise, and, for good communication, a strong information flow is required. This, in turn, can be achieved by effective collaboration (Appendix 6; p. 237 ff.; morphological box using the Zwicky model). People can distinguish between what is correct and what is not. Communication is therefore important, not only cross-culturally, but also for looking inside a culture - for example, when exploring the corporate culture of this joint venture company.

Although all of the middle managers reported the need for better communication, it is generally considered that, it is the middle managers' own responsibility to promote better communication among their staff and, additionally, to book and arrange additional training sessions for themselves and to align further development sessions for their own employees, as recommended by Barmeyer (1996) in Section 2.2, p. 44. I would argue that this is the one of the main reasons that the middle management level exists: those in upper management do not have the time to support staff in their daily operational work, and the middle management level needs to take care of the development of staff and improvements in communication and information flow in their departments (Section 2.1, p. 29). The aim should be for middle managers to collaborate in a way that aids understanding of matters that are discussed in the various meetings (collaboration, exchange, lessons learned, alignment, staff, shop floor, and so on). The development of cross-cultural understanding should also be a focus when working in an international environment and should be considered when recruiting expatriate middle management-level overseers to work onsite in China in the joint venture.

The hints provided in the interviews were unique to the communication problem, the information transfer-securing process, and for building better bridges with headquarters. It was already in the closing phase of the semi-structured interviews possible for me to look for an appropriate solution to support the middle managers. For the middle managers to support 
their staff not to fear change, but to accept it and to accept the culture, whether this is the national culture or a new corporate culture, and develop a suitable model for working collaboratively from the newly established conceptual framework (Figure 11, p. 93) was the last objective in my doctoral thesis. The amending of my research questions was undertaken before their refinement and the validation supported starting the interviews and obtaining confirmation after the pre interviews underlined the research sequence strategy for my doctoral thesis.

For the Chinese colleagues who had never worked in an international environment and had never been to Europe, there are differences between the cultures which they deal with in their daily working lives. This was clear from the stories they told me about their daily routine tasks and collaboration with their staff, which was not easy for them. They also reported asking upper management for support in dealing with these issues and with cultural differences.

Among the German middle managers, I observed different groupings. For the middle managers with experience of working in different countries, it was much easier to adapt, and I observed that they were able to reflect easily on the issues on hand. It was the same for the Chinese middle managers who had experience aboard: they could also more easily adapt to the German culture of their colleagues and staff. However, it was clear that, even for the experienced German managers, adapting to Chinese culture had posed challenges. Even the most experienced middle manager told me how difficult it was to grasp guanxi, mianzi (Section 4.2.3, p. 104 ff.) and the Chinese national culture more generally when he started at the Sino-German joint venture. This was because it is so different to the culture of Germany, the US, and Italy, where he had previously lived and worked. The only interviewee who expected much more from his Chinese middle management (No. 6; Table 2; Section 3.3.3; p. 74) colleagues was a young middle manager who had recently arrived in China and was fairly inexperienced. Being so new to his position and working in an intercultural and cross-cultural joint venture for the first time, he may simply need to gain more experience in my opinion. International collaboration is becoming increasingly important in the global markets, as explained in Chapter 1 (Section 1.1, p. 9 ff.), and international HR development is progressing alongside this. For the German headquarters in this case, this means selecting the ideal staff for deployment to China. Those identified are sent to live as expatriates in Beijing and are tasked with maintaining the process standards defined by the central headquarters in order to ensuring the same quality of product in the overseas production departments. As part of the hiring process, expatriates need to be well prepared for their time abroad, with training for 
themselves and adequate preparation their families. For local international HR development, this means selecting Chinese people with international experience who speak English fluently. If they also speak German, so much the better.

The benefits of a joint venture collaboration are multifaceted and reflected in different aspects. There are exceptional advantages, both within and outside the company, to stabilising the joint venture and the entire automobile production supply chain. These can be attained through intensive collaboration and exchange so that, afterwards, the picture from outside is a homogenous one. For this reason, it is important to ensure common and comparably high standards internationally. Knowledge transfer and knowledge assurance are the major advantages of the conceptual framework (Figure 11, p. 93). With good qualifications, knowledge and expertise could be gained by personnel and transferred to new employees.

Good morale can be maintained by means of good, regular cultural training and by supporting understandings of cultural differences within the collaboration, especially in relation to changing processes and the changing environment within the company. Employees develop their expertise over many years; this should be supported by middle managers, who must also lead staff to transfer their expertise and exchange more within the joint venture and in collaboration with the German headquarters. Support for the exchange of new ideas, for building trust, and for developing a deeper collaborative structure for the future are also necessary (Section 2.1; p. 29 ff.). Knowledge is not consolidated in merely one place anymore; rather, it exists and is known at the employee level and could be used for problemsolving in another places. In this way, knowledge can be retained in the long term.

Only one of the six Chinese middle managers (No. 2; Table 2; Section 3.3.3; p. 74) could speak and understand German well. Two of the middle managers had a basic level of German. The interviewees indicated that the company does not support employees with language training in either English or German. In my view, this resource would be a valuable addition and would provide essential support to the local employees.

\subsection{The working atmosphere in the joint venture}

It is essential to begin a joint venture with the right partner, as described in Section 1.2 (p. 14 f.) by Devonshire-Ellis et al. (2011). Since this joint venture has existed for several years, the cooperation appears to be functioning well. However, improvements are required at the employee level - meaning those workers who assemble the cars - and a focus on middle management is required for this, which is the goal of my work. The German partner is able to create a good operating environment, and the Chinese partner works on-site in Beijing to fast- 
track the local market and has local business links and supplier contacts, as described by one German middle manager (No. 2; Table 2; Section 3.3.3; p. 74). The interviewees suggested that the German partner should assist in ensuring that both parties were compliant with rules and processes. The local partner should assist with regulations and with the government authorities, as described in Section 4.2 (p. 92 ff.) and by the middle managers.

The Chinese participants did not mention it in the interview sessions but, speaking to a German colleague during a break, one Chinese colleague said:

It is easy to keep employees if you have add-ons, like the ability to take a taxi to a meeting without thinking about the cost, company cell phones, good hotels, meal allowances on business trips, business class air travel. Making things easy and comfortable for employees does not happen on the Chinese side in the way it does for you.

This made me think for the first time about the benefits that the German employees receive. This actually depends on each company's regulations and on the size of the company. In a mid-level company, the employees do not get business-class air travel. For the company under study here though, he was entirely right. For me, working for the German headquarters, this was normal: I had not experienced anything else while working for German companies, having always benefited from these types of 'add-ons' in addition to my salary. Here, such things are very important for employees.

Examination of these kinds of factors is essential when two companies are working collaboratively. In this case, the Chinese middle managers raised the matter because they felt that the situation was unfair and that changes were required in order to retain local staff. This is as discussed in Section 4.3.6 (p. 117 f.), with the additional requirement that there be technical improvements in Beijing to make them comparable to those at the central headquarters.

When asked if it was preferable to work in a joint venture, the most experienced middle managers on both sides were able to compare their experiences at BACF with those in other companies. Among the younger and less experienced interviewees, some only had experience of their current situations with BACF. On the Chinese side, all the interviewees said that they enjoyed working in the joint venture and appreciated the benefits of international cooperation, with frequent additional support for the Chinese middle managers coming from the central headquarters and from the German expatriates on-site. This was even the case for the most experienced Chinese middle managers and those with experience of working outside of joint 
ventures.

It was frequently mentioned on the Chinese side by all of the middle managers that they were able to learn a lot from this joint venture and that, for those who wanted to develop themselves, this company was a very good choice. They saw it as chance to improve themselves and to benefit from ideas and standards from Europe and Germany. In my view, the company allows younger and less experienced Chinese middle managers to launch their careers, to learn, and gain status in the Chinese market, and ultimately to seek better opportunities with other companies. In terms of keeping experienced people in the company, this may be positive or negative.

The German middle managers (with the exception of no. 6; Table 2; Section 3.3.3; p. 74) said that they enjoyed working for BACF and had learned more than they had in their previous working lives. One German middle manager (No. 1; Table 2; Section 3.3.3; p. 74), who had experience of working abroad - albeit at a partner plant of the central headquarters -noted how much he had learned in his time with BACF. He mentioned that the corporate culture and processes were often very different, as were the technical and HR aspects, and that he had learned much about the national culture. One young German middle manager who did not have much experience in his role and was working abroad for the first time said that he found things worked far too quickly - with too much information disseminated at once and too many meetings - and said he struggled to balance and coordinate things. He talked about Chinese employees and Chinese middle managers being disorganised and failing to conduct preplanning. Due to the fast growth of the company, processes were being implemented without adequate planning and, as a result, he was not happy working there.

One Chinese interviewee (No. 3; Table 2; Section 3.3.3; p.74) made the very interesting point that the two companies are working together and both want to push themselves to the front; however, in reality, the joint venture is not Company A or B, but rather Company C. It is striking that this interviewee was relatively young (aged 32) and fairly inexperienced at the middle management level, but nevertheless recognised and was able to express this. Indeed, the corporate cultures of the two firms are being melded together into a third version that combines the two. This was something I could observe in the responses of all the middle managers, both German and Chinese. The interview sessions all variously hinted at the existence of a common corporate culture; at the same time, the original, individual cultures were being maintained through differential HR recruitment and IT practices, such as the matter of company phones, as described in Section 4.2 .1 (p. 95 ff.) and Section 4.3 .6 (p. 117 ff.).

One Chinese middle manager (No. 4; Table 2; Section 3.3.3; p. 74) talked about the distance 
from the central headquarters. This was first time that I had heard this distance described as an issue, but the interviewees then talked about internationality and how important it was in the market to work globally. One Chinese middle manager (No. 5; Table 2; Section 3.3.3; p. 74) mentioned that he had heard privately that many other local companies spent a significant amount of time on meetings and reporting, rather than implementing especially new processes with many changes. Based on this information from his friends and contacts, he was happy to work for BACF, even though he did not have any other experience so far, having joined the company immediately after graduating from university.

Only one German middle manager, the youngest of the interviewees, said he did not want to work in the joint venture. He said there were political reasons for this. I asked him twice to clarify what these issues were, but he was unwilling to do so. However, the other five German middle managers said they enjoyed the cooperation and working atmosphere of the joint venture with the Chinese colleagues very much. The cultural development, training, and implementation of new processes - which seemed to be easier in China than in the German central headquarters - were the focus of their responses. Two of the more experienced German middle managers mentioned the lack of a staff association, which would allow improvements and implementation to progress very quickly and without lengthy discussions and the possibility of rejection. In contrast, the young, freshly promoted middle manager on the German side said he preferred to work in Germany.

Of course, for most of the middle managers on both sides, it was important to achieve their department's goals to reach a portion of the target picture, but for them as middle managers, it was necessary to get the whole picture. In my view, the goal should go hand-in-glove with the vision of the joint venture. It was very interesting for me to listen to the responses of the middle managers and to observe them talking.

In next section I introduce the reflections of the middle managers during the interview sessions.

\subsection{Reflections on the interviews}

This section is included in this chapter since reflection is important for improving and gaining knowledge to change and for improving things in the future with the help of lessons learned (Bolton, 2001; Moon, 2004). For me as researcher, it was important to consider the reflections of the interviewee individually and also to have a separate, additional reflection chapter in my thesis that deals with my own reflections (Chapter 6, p. 159 ff.). In this section, I merely consider the reflections of the middle management level during the interview sessions. 
Following detailed consideration of the interview responses, the importance of change management and of the respective national and corporate cultures were highlighted in combination with the need for good communication and information flow. This is intended to allow changes to be made easily, with consideration of the features and functions required for implementing the changes.

One more aspect that arose in the interview sessions was the experience of the Chinese middle managers in Europe. Two Chinese interviewees (Nos. 2 and 4; Table 2; Section 3.3.3; p. 74) had experience in Europe; one had many years' experience of international cooperation with German colleagues and spoke German fluently. This group expressed how important it was for them to work in the joint venture, and they gave no hints that they wanted to change jobs. They did, however, insist on the need for guidance in relation to motivating their employees to stay. I also recognised that, for one member of this group, national culture was of less importance. To my understanding, this person had a very good understanding of the German national culture. Therefore, cultural misunderstandings were unlikely to occur. This interviewee appeared, in all his responses, to be unhappy. However, he did state that he had no issues with his Chinese colleagues or staff: he simply did not see a future for himself in the Sino-German joint venture and intended to return home soon.

All the middle managers worked in the same department. This means that the results presented here may be different if one were to examine other departments or upper managers or even middle managers who had arrived at the company in the last two years. As the German side primarily comprised experienced experts, and the Chinese side was a mix of younger and more experienced middle managers, I believe I have a very good sample. However, it is a small sample and the findings may differ if this were a larger work or if it had taken a quantitative approach.

My findings suggest that both the German and Chinese middle managers must consider both the corporate cultures of the respective sides of the business as well as the common corporate culture. I find the second research question, which asks whether middle managers must adapt their skills to the corporate culture of the joint venture, particularly in terms of relationshipbuilding skills in situations of change, to be very important. The need for relationshipbuilding skills - under the heading of guanxi and mianzi - in Chinese national culture was mentioned several times by most of the interviewees.

As indicated by Schreiter (2015) and noted in Section 2.1 (p. 29 ff.), since 2001, of the German companies working in China, 68\% are wholly foreign-owned enterprises. However, 
these companies struggle to hire good, experienced local employees from the Chinese market. For me, this is a key finding of the interviews, and it will form the basis of a recommendation for improving collaboration and change management practices in the company. As a German company in China, BACF faces the challenge of finding well-trained personnel and retaining them for long periods.

Beijing is the capital of China, the fastest-growing ecnomincally country in the world. The cost of living is very high, as are rents, which lead to increasing labour costs. The original idea of building low-cost plants and production sites in low-cost countries around the world has transformed into the idea of servicing a fast-growing market and the major demands in the vehicle production market. Moreover, very short cancellation deadlines for the contracts of local employees makes it difficult to retain good staff, replace those who leave, and complete handovers through work shadowing of other colleagues on the team. The challenge of employee retention was highlighted in the interviews, as were the difficulties of finding new employees. Applicants often claim that they speak English, but their interviews are then held in Chinese when this proves not to be the case. However, in pre-selection by HR, these applicants were selected for interviews as English-speaking individuals.

The findings from the interview sessions were sometimes topics that I recognised, as an insider, and could have reflected on myself. However, as a researcher, I sought to avoid being biased by my own experiences and feelings. I began each interview session by putting aside my partiality, as described in Section 3.2.4 (p. 65 ff.) and as advised by Silverman (2014). I was often surprised by the answers given, and sometimes noted that the colleagues' remarks were not what I would have expected, despite use having worked so closely together since mid-2017.

The BACF corporate culture influences the behaviour of its employees. The behaviour and support of upper management were also discussed in the interviews, especially leadership behaviour. The interviewees mentioned several times that they struggled to retain employees and thus to keep in the company the knowledge that is needed to develop experts. This is also the case for training new employees, so they felt right at the beginning very good and had a good start. In addition, intercultural collaboration is an aspect that needs to be considered. Every corporate culture has its own system of special meanings and signs which should be interpreted and understood in the same way by all employees. If two different operational systems meet, this can of course lead to problems with compatibility, as discussed indirectly several times during the interviews. In these circumstances, information transfer processes can be damaged. This is very important to realise and to reflect upon. Therefore, good 
professional competence is required, as discussed in Section 2.2 (p. 44 ff.) and described by Barmeyer (1996).

In BACF, we have two national cultures working together. According to Kluckhohn (1951), and as discussed in Section 2.2 (p. 44 ff.), culture consists of patterns of thoughts, feelings, and actions characteristically acquired in groups and pictured in artefacts. Culture is transferred through symbols which characteristically denote the achievements of certain groups of people. The core of culture traditionally comprises ideas and values. For this thesis, the connection between the cultures is important. It is imperative to consider in the analysis that corporate culture is an important aspect, as described in Schein’s work (2010) and indicated in Section 2.2 (p. 44 ff.). The moral concepts and norms of a company are implicit in the behaviour of its employees, as discussed in Section 1.2 (p. 14 ff.) and by Homma and Bauschke (2010). I developed the first conceptual framework (Figure 5, p. 53) during the literature review, when I was starting the DBA programme, and assessed during the interview sessions whether this framework fit BACF and could be confirmed by means of the research questions I formulated. The relevance of the research questions can be confirmed, but the conceptual framework required revision, and a new version was presented in Section 4.2 (Figure 11, p. 93), where the changes are also described (Section 4.2, p. 92 ff.).

In the interviews, I observed the importance of national belonging, which has a clear impact on daily work. It was of interest to me that nobody talked about 'the Germans' or 'the Chinese'; rather, it was always 'the colleagues' or 'the central headquarters', or even 'upper management', who could be either Chinese or German. I realised during the interview sessions that the expression 'German expatriates' hints at a collective approach, as described in Section 2.1 (p. 29 ff.) on Hansen (2009). This means that the German headquarters should bring a Chinese colleague over to Germany to benefit from their know-how and expertise for a period of time.

\subsection{Summary and interim conclusion}

Following the introduction to the findings of the pilot interviews, Chapter 4 focuses on, first, the three key findings. In Section 4.2.1 (p. 95 ff.), communication, information flow, and collaboration are introduced as the most important key finding, followed by relationshipbuilding and guanxi, and, finally, qualifications and hiring. The key findings were selected after the analysis based on the Zwicky method and were rated as having the most outcomes based on the answers of the middle managers, show the importance and the selection rating as most for Section 4.2.1, as next in Section 4.2.2 and Section 4.2.3 as the third most rated 
outcome.

Furthermore, certain interactions and different kinds of relationships between the middle managers and their staff can be hypothesised. Those Chinese middle managers who have variously lived, studied, and worked in European countries, even in Germany itself, have Chinese culture as their mother national culture, which they have combined with experience of life in a European country. They are thus more adept at collaborating with their German colleagues. The experienced middle managers on both sides evidenced a better understanding of how to manage employees and support them through organisational change.

The aim of this work is to offer the middle managers in this Sino-German joint venture solutions for better collaboration. As a qualitative researcher, it was possible to gain much information on the daily practice of those middle managers; they can easily compare their own experiences with those in the research description. Practitioners can therefore learn and add their own experience, knowledge, and approaches to the findings of my study.

The findings gathered during the interview sessions have made it possible for me to contribute to closing the research gap and to formulating recommendations (Chapter 6, p. $159 \mathrm{ff}$.) for the middle managers.

In Chapter 5, I explain my aim and objectives and how I achieved these objectives by creating an appropriate communication model. 


\section{Chapter 5: Achieving the Aims and Objectives of the Study}

Chapter 4 summarised the principal findings from the interview sessions and how I fulfilled my aims and objectives in relation to my research questions and objectives. Based on the literature review, the research questions and the objectives of this thesis, which are formulated in Section 1.4 (p. 25) and the research gap, in the interview sessions I focused on gathering insights into practice in order to gain knowledge and formulate the recommendations and contributions to knowledge and practice in Chapter 6 (p. $159 \mathrm{ff}$.). The aim of the systematic literature review in Section 1.3 (p. 20) is, as indicated by Nieswandt (2015), to explore how middle managers in the automotive sector execute 'change projects', especially in an international cultural context, as observed in the joint venture company in Beijing. The literature review also explored how middle managers can support their staff during these transitions by reducing apprehension and resistance. The interview sessions provided the middle managers' responses on this topic. The main three findings described in Chapter 4, specifically in Sections 4.2.1 to 4.2.3, are as follows:

- Communication, information flow, and collaboration (Section 4.2.1, p. 95 ff.)

- Relationship-building and guanxi (Section 4.2.2, p. $101 \mathrm{ff.})$

- Qualifications and hiring (Section 4.2.3, p. $104 \mathrm{ff.})$

In Chapter 4, Section 4.3 (p. 108 ff.), I also discussed findings additional to the three main ones.

Following the additional findings in Section 4.3 (p. 1108 ff.), I presented my own observations in Section 4.4 and the working atmosphere in the joint venture, as described by the middle managers, in Section 4.5. As regards the aforementioned findings, first, in Section 4.2 (p. 92 ff.) I analysed the communication and collaboration practices, and, using Zwicky’s (1969) morphological box, formulated a suitable communication model for the joint venture company and those middle managers working in the relevant department. The distinctiveness of the study is the use of the Zwicky method in combination with the morphological box, which helped me to structure all the complex responses regarding the experience of the middle managers from a practical point of view. This complexity can be presented in a straightforward manner using the boxes to indicate the various possibilities for the practical use of complex change processes in companies, especially at the shop floor level (Chapter 6, p. 159 ff.).

Of the three main findings selected for in-depth discussion in Chapter 4, I want to highlight 
communication and collaboration which, especially in a joint venture, require a special focus and the strengthening of relationship-building. A better focus on the qualifications and development of local employees in the joint venture is a contribution to practice from my point of view (Chapter 6, p. $159 \mathrm{ff}$.). This can be adopted by the company as a whole at a later point. It can also be adapted to other companies as it is a formulation that contributes to the practices of middle managers to enhance their collaboration in joint ventures (Chapter 6, p. 159 ff.).

I have also described in detail the various findings for presenting possible solutions and thereby contributing to the practices of communication, information flow, and collaboration in 36 morphological boxes in Appendix 6 (p. 237 ff.) and in Section 4.2 and Section 4.3. Furthermore, in addition to the conceptual framework, Figure 11 (p. 93), together with the communication and collaboration model in Section 6.1.2 (p. 167) contribute to understanding of the issues middle managers face in a Sino-German context. These could be generalised to other settings in joint ventures, other model of collaborative work, and other factories besides vehicle manufacturing companies.

The communication model is highlighted and described in detail in Section 5.3 (p. 147 ff.) From this, middle managers can derive practical actions to support doing their job better. In the following sections, I describe how my work contributes to the knowledge I found in the literature on national culture, joint ventures, middle management, and managing changes involving the two cultures. I foreground the differences relative to the literature that I discovered during the interview sessions and my analysis. Furthermore, I contribute to knowledge which may provide practical solutions to middle managers.

In Section 5.1, I discuss how I achieved the aim of this study in terms of the research questions and objectives with the results of my interviews with the middle managers and the results of the findings in the analysis chapter.

\subsection{Achieving the aim of this study}

Regarding the standing of the research described in Section 1.3 (p. 20 ff.) I stated how important it is today to adapt to changing situations, to ensure that teamwork occurs, and to prepare companies to operate globally. The data for this thesis was collected in a SinoGerman joint venture company based in Beijing, China, using a qualitative approach based on semi-structured interviews and from a constructivist perspective. The interaction of middle managers, who work together through dialogue, and the real situations and emotions involved 
in such experiences were analysed to determine what is important to and required from them. I realised during the interview sessions how important it is to assist middle managers to actively use known methods and to integrate change management into processual and organisational changes. As indicated by Albach et al. (2015; Section 2.1, p. 29 ff.), the change process should begin at the staff level - thus it affects the entire organisation. Following the analysis of the interviews, I can confirm that this point of view is reflected in the responses of the middle managers (Section 4.6, p. $127 \mathrm{ff}$.). For this firm, it was an open question as to whether cultural aspects, such as its corporate culture and the national cultures involved, have substantial importance in the daily working life of the employees. As it turns out, these aspects do indeed have a substantial impact on both the German and Chinese middle managers concerned and on their staff.

$\underline{\text { Relation to objectives: }}$

As described in Section 1.3 (p. 20) the objective one of this thesis is to identify how the German and Chinese middle managers working together in the joint venture make decisions, communicate instructions to their staff, and handle process changes, despite their differing cultural backgrounds. This was analysed in Chapter 4 (p. $90 \mathrm{ff}$.) based on the results from the interview sessions, which were in turn based on the methodology described in Chapter 3 (p. 55 ff.). The question concerned how German and Chinese middle managers in a cooperative joint venture in the automotive sector in China cope with organisational changes and national cultural differences.

As formulated in Section 1.3 (p. 20 ff.) based on the responses of these experienced middle managers and depicted in the new conceptual framework in Figure 11 (p. 93), the collaboration represented on the left side of the figure has a greater role than the conceptual framework depicted in Figure 5 (p. 53; also see below), which was drawn from the fundamental elements of the systematic literature review. In the conceptual framework in Figure 11 (p. 96), national culture has a greater impact than corporate culture and change projects are affected by differences in national culture, process management, and relationshipbuilding. 


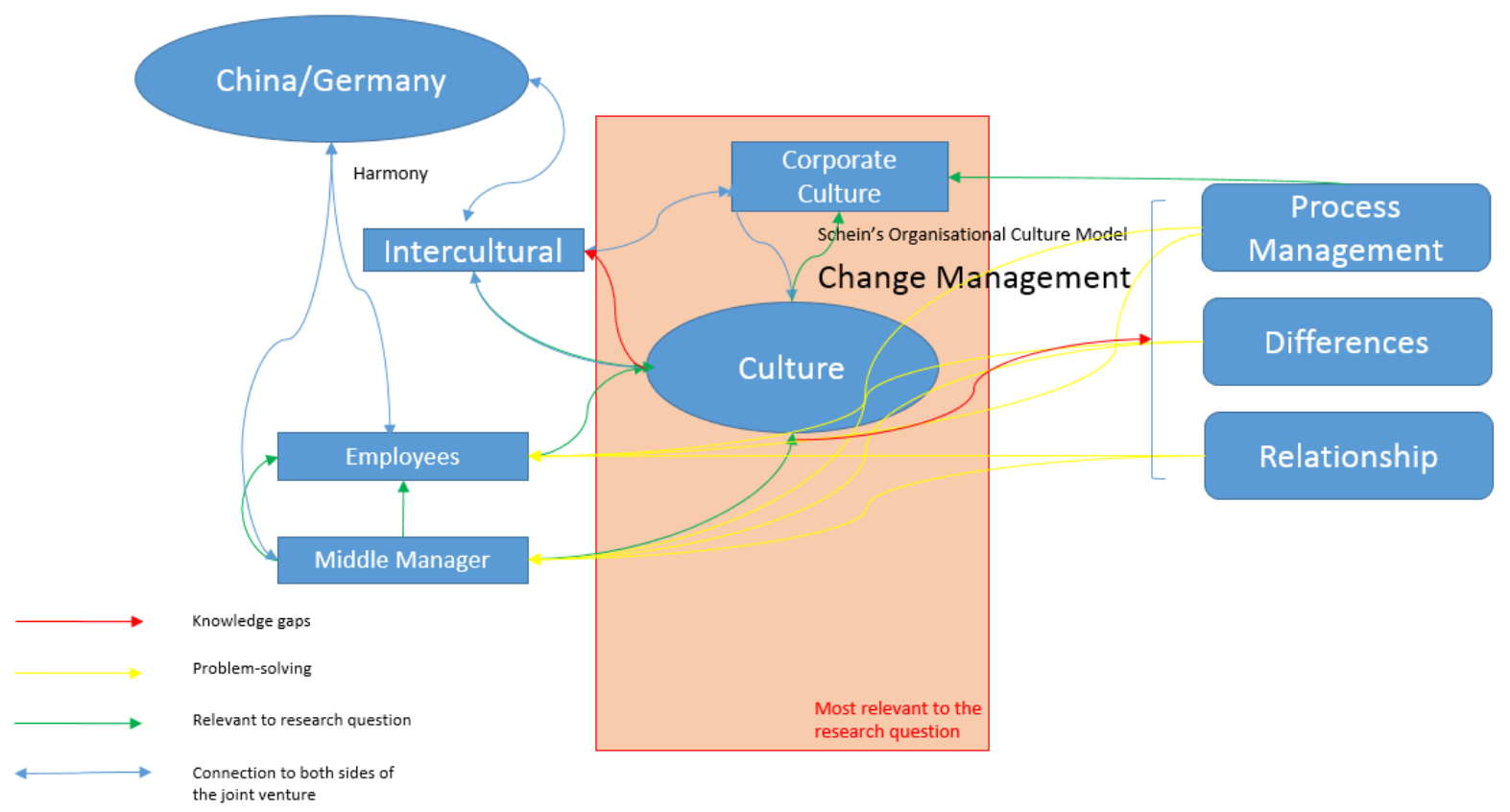

Figure 5: The conceptual framework

Source: Ayse Yilmaz (March, 2016)

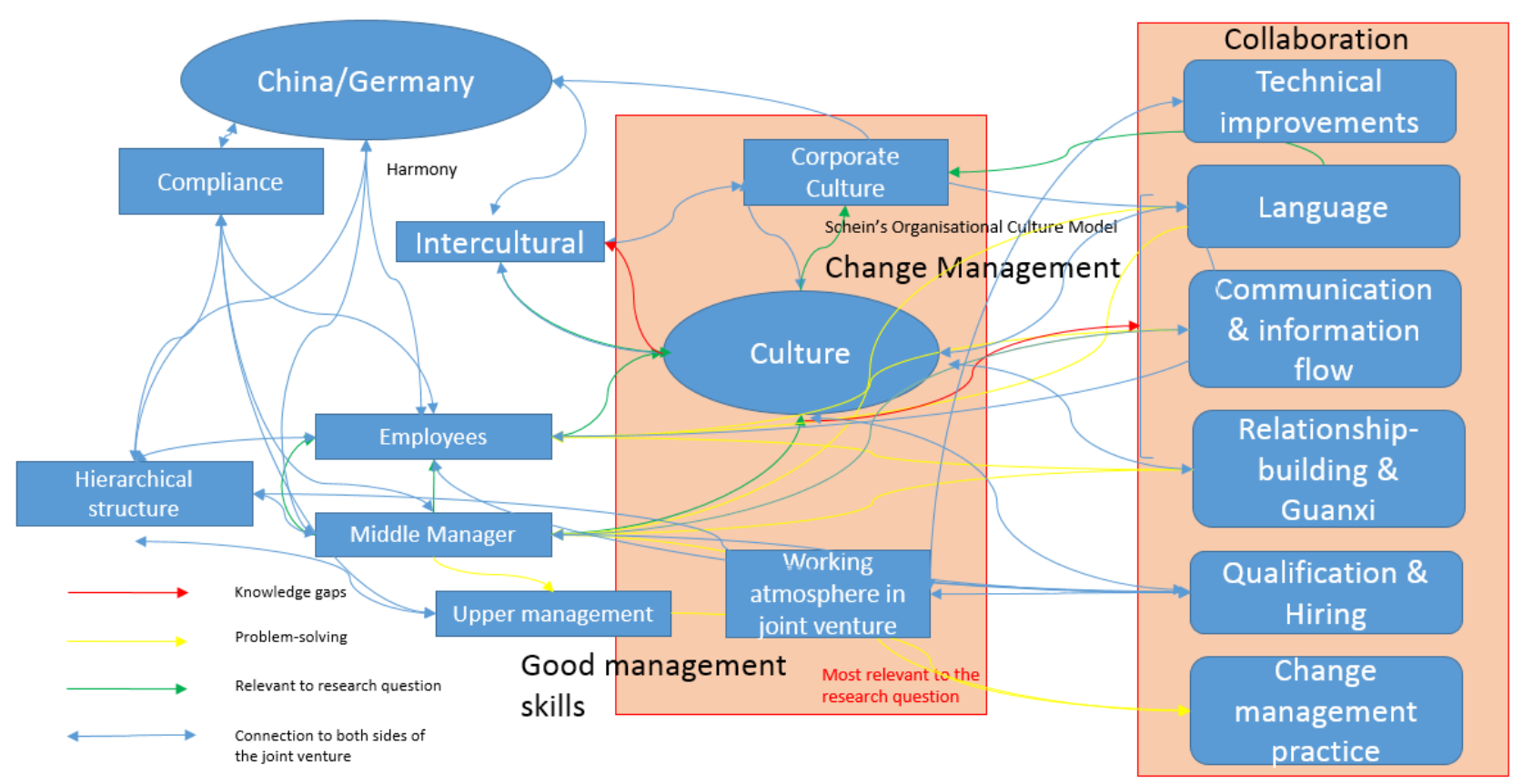

Figure 11: The revised conceptual framework

Source: Ayse Yilmaz (September, 2018)

Following the interview sessions, I realised that there were topics and new insights missing 
from the conceptual framework I had formulated based on the literature review, as, for example, collaboration seems to be the basic requirement to cope with organisational changes and national cultural differences. This was mentioned by all 12 middle managers (Section 4.2.1, p. 95 ff.). Therefore, based on Appendix 6 (p. 237 ff.) and the Zwicky method and morphological box rating, collaboration and communication are basic requirements which should be considered by all middle managers in the joint venture. Collaboration, represented on the right side of Figure 11, is therefore the basic requirement.

Communication and clear information flow can support employees and middle managers to better administer organisational changes and manage national cultural differences. This is especially the case in the joint venture concerned, in which relationship-building and guanxi, depicted on the right side in Figure 11, are of critical importance. Culture and corporate culture thus both have a major impact on change projects and change management. As is also shown in Figure 11, other important aspects were derived from the interviews. The working atmosphere in this specific joint venture was emphasised as being different from their previous experiences by both Chinese middle managers (Nos. 1 and 2; Table 2; Section 3.3.3; p. 74) who had worked in other companies, and all the German middle managers who came to China from the central headquarters in Germany. The difference involves having two different corporate cultures and a higher expectation of tolerance and understanding of the partner's corporate culture. For example, the Chinese middle managers show understanding of the joint venture partner's corporate culture and show respect to their German partners when celebrations occur.

The relevance of the involvement of upper management, especially in a joint venture, is different in comparison to not joint venture companies and requires more attention due to the double functionality of the managers as well as to ensure better alignment between the two joint venture partners and more circuits for discussions (Section 2.1, p. 29; Hitt et. al, 2007). The importance of the hierarchical structure in the joint venture is also described in Figure 11 - this too was a relevant outcome of the interviews and needs to be reflected on (Section 4.6, p. 132 ff.; Andersen, 2004; Section 2.1, p. 29) in the course of work in a joint venture that is an international collaboration between two hierarchically structured organisations.

As described in Section 4.3 .5 (p. 116) the middle managers mentioned the need for better qualifications and a focus on hiring high quality employees in order to maintain a good employee base at the foundational level across the entire organisation. The requirement of a third language (Section 4.3.3, p. 114) in the context of change management and the 
significance of cultural factors for organisations was not found in the literature review and was therefore not included in Figure 5. This particular factor was specifically mentioned by two Chinese middle managers (Nos. 2 and 5; Table 2; Section 3.3.3; p. 74) and one German middle manager (No. 4; Table 2; Section 3.3.3; p. 74; Section 4.3.5, p. 116). As described in Section 4.3 .5 (p. 116) for some of the middle managers, communication (Bate, 1997; Section 2.1, p. 29) was a major issue. This can be linked to the finding on language (Section 4.3.3, p. 114) since all the employees need to communicate in a third language, English. All the middle managers felt that some information was not being conveyed properly due to differences between the German and Chinese languages and the use of the third language, English. The middle managers mentioned that finding employees based in China who are able to communicate in English was not easy. As regards the assembly line operators, there was no need to find English speakers since the operators' main task is to understand the production process and assemble the cars. Conversely, for engineers and planners, this criterion is used in hiring; a German middle manager (No. 4; Table 2; Section 3.3.3; p. 74) mentioned that even if employees had learnt English at school and had been hired, communication remained an issue as they usually did not speak English fluently and may therefore experience many difficulties in meetings and in collaborative projects. Therefore, language is highlighted in the right-side box in the new conceptual framework in Figure 11 as a new insight that contributes to knowledge and practice that did not seem to be in the literature that was reviewed. Communication is vital for improving collaboration and information flow; it is necessary to be mindful of this as a middle manager working in this Sino-German joint venture.

Due to the current digitalisation boom in the market, a special focus of the middle managers was their current additional projects and changing the current automotive production model on the basis of observations of innovations and digitalisation in order to find technical improvements. Almost all the middle managers could provide examples of digitalisation projects and challenges they faced using digital solutions to improve processes. Change management practice is a component of one of my objectives in order to identify factors that influence joint venture change practices, and hence it is present on the right side of Figure 11 too.

Technical improvements, listed in the box on the right side of Figure 11, are also among the principal findings from the interviews. The German middle managers were able to compare the technical hardware and facilities, such as the video conference rooms, with those at the plant at the central headquarters. They recognised that the plant in China required 
improvements to reach the standard of the other plants. For example, they were still using reservation forms on the door of each meeting room. The feedback from the Chinese middle managers was just as clear: it is necessary to improve the facilities. In order to create better information flow and enhance communication (Section 2.1, p. 29 ff.) with other plants and with the central headquarters, plants must have facilities available for dial-in video conferences, phone calls, and meetings across the plant. System-wide reservation capabilities would make possible a better structure and ensure a clear tracking system. To enhance and improve communication, it is important to enhance the ability of the middle managers and the staff to access the facilities they need to make communication effective.

Change management practice, especially for middle management functions, was mentioned by the middle managers as being critically important (Section 4.2, p. 92 ff.). Middle managers view themselves as the bridge between their staff and the upper management level, which drives corporate culture and obtains feedback from the shop floor. The middle management level also enhances the culture of feedback and improves change management practices between the staff level and upper management. This simultaneously enhances communication and information flow from the bottom up and from the top down in the hierarchical structure (Section 4.3.5, p. 116). This is further demonstrated in Figure 11 (p. 93). A major contribution to knowledge is the feedback culture for improvements and the integration of the staff level, via the middle management level, into change projects in their early phases and improving quicker communication and information flow via an interface team which can be established. A possible communication model is highlighted and described in detail in Section 6.1.2 (p. $167 \mathrm{ff}$ ). Additionally, enhancing the motivation of staff using this method demonstrates their staff's acceptance of changing situations by the middle management level and underscores their importance for the company as a whole, which improves employee retention.

$\underline{\text { Relationship-building and guanxi: }}$

Relationship-building and guanxi, which were introduced in the literature review in Sections 2.1 (p. 29; Mintzberg, 2018) and 2.2 (p. 44), have been highlighted by many authors, such as Praxenthaler (2018), Luo (2007), Jing (2006), and Gesteland and Seyk (2002). Guanxi is specified in the literature as an essential component of Chinese national culture.

In the interviews with the 12 middle managers (Section 4.2, p. 92 ff. and Section 4.3, p. 108 ff.), it was also determined that the Chinese middle managers hold that guanxi is important for all middle managers working in China, not just for Chinese staff and Chinese middle managers. It is also important for German middle managers to have relationship-building 
skills, as described by the Chinese middle managers in Section 4.2 (p. 92 ff.).

Many local employees go back to their home provinces in China and look for other job possibilities closer to their home provinces, where their parents live, so that they can take care of their children. This is a significant issue even for the German middle managers working at the plant, and they describe it as a national cultural difference. Primarily, this is a matter of the impact of the high cost of living in Beijing, besides being a matter of national culture. As a researcher, it was interesting to observe the middle managers responses regarding how important guanxi and mianzi are to working in the company (Section 4.2.2, p. $101 \mathrm{ff}$.). Rather than saying that they have to do something to improve relationship-building and national cultural differences, the middle managers stressed the need for support from upper management. In the new conceptual framework in Figure 11 (p. 93), I have incorporated upper management, which was not in the initial conceptual framework in Figure 5 (p. 53). For this reason, I maintained the focus on the culture of feedback and on improving feedback between upper management and the middle management level, which is also the focus of Section 4.3 .5 (p. 116 ff.) in the analysis chapter.

Compliance was also mentioned, and I discussed it in Section 4.3 .4 (p. 116) a separate section in Chapter 4. In the reflection chapter (Chapter 7, p. 175 ff.), I explain how the middle managers reflected on with the examples they gave me from practice in order to highlight the contribution to knowledge and practice.

Another significant finding that differs from what was found in the literature review (Section 2.1, p. 29 ff.; Kim et al., 2016) was the plan of the middle managers to transform the standards provided by the central headquarters and adapt these to the joint venture situation. The literature mentions maintaining standards but says nothing about adapting them (Section 4.2.3, p. 104). The point of these is to standardise all the plants around the world - though they can be optimised according to the organisational structure of each plant, as described by one of the Chinese middle managers and discussed in Section 4.2 .3 (p. 104). For change management and communication, the maintaining of standards is vital. For change management, this means that every change to a given standardised process must be communicated by the central headquarters to the middle managers so that they can implement the change according to the requirements. Thus, regular exchange of information and communication is required.

According to three German middle managers (No. 2, 4 and 5, Table 2, Section 3.3.3, p. 74), an adaptation to the situation of the joint venture by enhancing and improving the given 
standards is necessary. However, changes can also occur directly within the joint venture, such as with the local implementation of new digital projects, or even organisational changes which are decided upon at the local plant by the upper managers. In terms of contributing to existing practice, the communication and collaboration model (Figure 11, p. 93) provides a solid basis for fulfilling this requirement of following the standardised processes provided by central headquarters. As regards the costly issue of obtaining responsible people selected by the central headquarters for regular exchange with each department, no literature was found regarding joint ventures and communication or information flow. A solution must be found for this issue because, if it is not, each department would have to pay the costs from its own budget. A general solution can be discussed and aligned with the stipulations of central headquarters.

Regarding communication and information flow, sharing knowledge and expertise was also mentioned as a potential solution. All the Chinese middle managers described how important their German colleagues at the middle management level are, or how important it is to use expatriate experts from central headquarters to teach and develop local staff. However, in my understanding, it is also important for German middle managers or German experts coming to Beijing to learn from their Chinese manager colleagues, especially in relation to how to act in a joint venture that is a collaboration between two nations and has two different national cultures and two different corporate cultures. This was asserted by a German middle manager (No. 1; Table 2; Section 3.3.3; p. 74). He indicated how much he had learned since working on-site at the joint venture. At times, listening to the interviewees during the interview sessions, I felt that the Chinese middle managers underrated their own performance and that their partners from central headquarters could also learn from them. However, I also heard from all of the Chinese middle managers' descriptions of the German experts that it is obvious that the expatriates who are referred to as experts are hired to bring in new knowledge and expertise. The communication model can be depicted by means of Zwicky's morphological box, which is included in Appendix 6 (p. 237 ff.). As an example, in Table 6 (p. 97), there are three characteristics and their selected attributes, such media and channels or the direction of communication. Every attribute depicted in orange can be accepted by the department concerned in the joint venture.

I have presented 36 possibilities in the morphological boxes based on the Zwicky method in Appendix 6 (p. $237 \mathrm{ff}$.). Simply put, the middle managers can select one of the morphological boxes presented in that appendix and combine it with Figure 12 (p. 100), the communication 
and collaboration model. The advantage of the Zwicky method for gathering knowledge and achieving my objectives and aims using the morphological box is that it proposes a variety of ideas for the middle managers working in the joint venture. It is not only the department concerned that can make use of it; the entire company can use these morphological boxes to create new ideas and use the communication and collaboration model in combination with Figure 11 (p. 93). However, the morphological boxes can help to provide new configurations between the different ideas in the morphological box, something which cannot be so easily undertaken with other methods. It is for this reason that I selected Zwicky's morphological box for this work. I can also demonstrate the limitations of given communication characteristics and attributes using this method. It can be also used for other findings and can be adapted for the joint venture company as a whole. The variety of possibilities are presented in Appendix 6 (p. 237 ff.); the ability to find the best one is immensely helpful.

\begin{tabular}{|l|l|l|l|}
\hline \multirow{2}{*}{ Attribute } & \multicolumn{3}{c|}{ Communication concept } \\
\cline { 2 - 4 } & $\begin{array}{l}\text { Characteristic } \\
1\end{array}$ & $\begin{array}{l}\text { Characteristic } \\
2\end{array}$ & $\begin{array}{l}\text { Characteristic } \\
3\end{array}$ \\
\hline Occasion & comprehensive & task employee & \\
\hline Centrality & central & decentral & peripheral \\
\hline Direction & upward & downward & horizontal \\
\hline $\begin{array}{l}\text { Formalisation } \\
\text { grade }\end{array}$ & formal & informal & \\
\hline $\begin{array}{l}\text { Media and } \\
\text { channels }\end{array}$ & verbal & printed & electronic \\
\hline
\end{tabular}

Table 6: The morphological box showing the communication concept

Source: Ayse Yilmaz (August, 2018)

In Figure 12 (p. 100 and shown above), a communication model was presented which enables a directly bottom-up approach which was not previously available in the department. Rather, the middle management level was always the bridge between staff and upper management, as described by the middle managers in the interview sessions (Section 4.3.5, p. 116). In my communication and collaboration model, I break down the hierarchical structure so that upper management is still communicating tasks via the middle management level; however, there is a communication channel open for the staff level to report directly to upper management in order to obtain the required decisions more quickly, as this was a major point discussed by all middle managers. The middle managers regularly communicate with one another. This is a point I could not really discern from the interview sessions. Some interviewees mentioned 
that they talk to and know one another, but somehow there is not really a fixed communication channel within the middle management level which is used regularly. This should definitely be amended.

Regarding the second of my research questions (Section 1.4, p. 25), the middle managers need to adapt their skills to the corporate culture of the joint venture partner since two different corporate cultures work together. As per Section 4.5 (p. 124 ff.) the middle managers mentioned that there are two different corporate cultures but that the firms also work together within a common corporate culture, that of the joint venture. If the middle managers do not demonstrate acceptance and understanding of these three corporate cultures, then collaboration, as described in Section 4.5 (p. 124 ff.) will be difficult for them. Furthermore, the vision and culture that they and their staff have will also suffer difficulties in terms of leading and managing daily tasks and forthcoming change projects (Paton \& McCalman, 2008; Section 2.1, p. 29). This is especially the case for relationship-building skills (Section 2.2., p. 44; Hofstede, 2005), which were mentioned in responses to questions I asked during the interview sessions even though those questions did not concern relationships.

The corporate culture of a company working in a joint venture can be a disadvantage or a factor for success, especially if two companies with two different corporate cultures, as is in the case with the two companies based in China, also have two different national cultures and use a third language, English, to work collaboratively. On the basis of the analysis of the interviews, it can be stated that problems may occur if middle managers overly rely on the processes prescribed by the joint venture company and merely want to find a solution to technical issues without thinking about national and corporate culture. This can also effect change projects and organisational changes. It should not be forgotten that their daily work is always with their operators and engineers who work on each line to produce high-quality vehicles.

Firms and organisations today increasingly work in a more complex business environment and are involved to a greater degree in networking with one another and working collaboratively - this leads to social and economic complexity, as described in Section 1.1. (p. $9 \mathrm{ff}$.) and as indicated by Glaser et al. (2015). Therefore, firms need to be flexible regarding change management, executing new projects, and integrating new ideas. Furthermore, management, especially middle managers, have to adapt to changing situations within an adequate timeframe, and they should focus on supporting their staff so that they feel more satisfied at work. 


\subsection{Achieving the objectives}

With my research topic and as I was an inside researcher (Section 3.5, p. 85) in the joint venture, I add to existing research the practical experience and expertise of the middle managers. Conducting the interviews in a setting like Beijing constitutes a significant new perspective which contributes additional insights to existing knowledge and practice.

The responses relating to current trends in the market, especially the digitalisation of automotive production, are also significant. These also provide new insights into existing knowledge. The market is changing to using digital solutions to enhance company operations. Automotive production companies are making more use of digital solutions for some processes. Asking the right questions in order to accomplish the research objectives and answer the research questions presented at the beginning of the thesis adds knowledge and allows the formulation of recommendations for the focus group that is middle managers who work in joint ventures.

Another major contribution to knowledge is the development of a unique approach and of conceptual frameworks, one from the existing literature (Figure 5, p. 53), and the new one developed following the analysis of the interview material (Figure 11, p. 93). There are advantages and disadvantages to the new conceptual framework. The risk is that knowledge transfer from the central headquarters will not occur in a manner that will allow employees to work independently in China since there are too many new standards which need to be implemented in a short time. Additionally, stabilising the new automotive product in the operational processes and preparing the equipment for the planned high-production cycle and peak will not be easy to implement. There may be a risk that the staff who are hired are not sufficiently qualified (4.2.3, p. $104 \mathrm{ff}$.). If there is a lack of qualified employees, then it will be not easy to implement a communication model that features regular exchange activities with the central headquarters.

The second risk is that the central headquarters may not accept so many exchanges since they have no alignment regarding service agreements between the plants and departments and this may desire to be compensated for this additional service. Paying additional costs would be not acceptable to the Chinese production site since it is meant to be a low-cost enterprise and should keep costs down. This is another point which was not discussed in the interview with the middle managers - it could not be discussed with them because such decisions needs to be aligned with upper management and with the central headquarters in Germany, as mentioned by an experienced German middle manager.

The third aspect is the time-consuming nature of the proposal for both sides to have regular meetings or exchanges, which would require planning of daily routines in both Germany and 
in Beijing. As a result of the alignment and exchange meetings, there may not be sufficient time and capacity for them to complete their own daily tasks. Changes demonstrate that the production plant is developing; this was mentioned regularly by almost all the middle managers, both Chinese and German (Section 4.3.1, p. 108).

Too many changes in a short time period can increase employee frustration. Human beings need time to understand the underlying corporate culture (Section 4.5, p. $124 \mathrm{f}$.), which would be necessary if many new Chinese employees needed to be hired due to fluctuations, or the work of the employees leaving needed to be compensated for by other teams of employees that remain with the company. As mentioned by Chinese middle manager (No. 1; Table 2; Section 3.3.3; p. 74), the local hiring process takes between three and six months, and, as mentioned by the German middle managers, the process of hiring an expatriate from the German central headquarters can take six to eight months. New expatriates coming to work as experts also need to get used to work in the joint venture due to the different corporate and national cultures and the fast-growing nature of the company (Section 1.2, p. 14 f.; Speier-Werner, 2006). Due to the requirement of the quick completion of the required tasks and the short time in which to do so, it may be that certain processes are skipped, as one Chinese middle manager mentioned (No. 2; Table 2; Section 3.3.3; p. 74). Sometimes work in the joint venture cannot be planned perfectly and step-by-step work becomes impossible (Section 2.1, p. 29). In such cases, standard-based work would be difficult if an adequate number of employees is not available and if employees cannot be retained because salaries in Beijing are not good enough.

The following issues may occur in the course of the improvement process:

- Manpower requirements covering demands, knowledge, and expertise may be inadequate, since the headcount is insufficient on the Chinese side, and, on the German side, not enough expatriates want to join the joint venture to undertake knowledge and expertise transfer.

- More daily work processes may need to be implemented by one staff member who does not have the required qualifications and expertise.

- The short production times to establish the product in production, raise capacity, and the many changes that are required may frustrate employees, since processes cannot be followed step-by-step and standards cannot be followed; this may lead to high employee turnover.

- The qualifications and training of employees may not work well since attendance may be lacking due to the high workload of each employee. 
The current situation requires a comprehensive analysis to capture the weak points and to formulate a conceptual framework to eliminate them. The conceptual framework and the recommendations require empirical confirmation and validation. A plan for further verification is required to test the model in a manufacturing company in the relevant industry in order to determine its practical value.

As indicated by Homma and Bauschke (2010; Section 2.1, p. 29), the trend of the last few years in the automotive industry has been observed in the changes of the last 12 to 20 years. This can be observed in automotive production: I am especially aware of this as I work in this sector of manufacturing - the development phase for cars has changed remarkably.

Companies producing cars previously needed seven years from development time to produce a vehicle, whereas today the production and even the development phase has been reduced to less than two years. This brings further pressure to bear on employees and middle managers in the course of their daily work and pushes employees to deal day by day with the implementation of the new car production line. Therefore, for other aspects such as collaboration or communication, the focus is limited as, in my opinion, instead of focusing on employees, middle managers would need to focus on managing collaboration and communication or information flow between the staff levels in the course of their daily work. Having conducted the interviews, I recognised that the adaption of middle managers is critically important. Some managers have already recognised that they have to adapt themselves, which shows that I obtained an answer to research question no. 2 (Section 1.4, p. 25). However, some of them are still not aware that living in China and working in a SinoGerman joint venture in China requires adaption to the national culture. This is much more the case for German middle managers in relation to the Chinese national culture than for Chinese middle managers in relation to German culture. Nevertheless, for the Chinese middle managers, understanding German culture also helps and demonstrates acceptance of their collaboration.

Due to changing organisational structures, other market demands, and requirements such as digitalisation of tasks, equipment, or processes, middle managers need to adapt themselves to changing situations. Learning to adapt to a new situation can happen if small changes occur. However, I recognised that if major changes are planned, then the middle managers need more than adaption or a learning environment (Section 4.2.3, p. $104 \mathrm{ff}$.) that enables them to support their staff and to adapt more easily to the changes so they can handle possible resistance arising from their staff. Rather, they need to encourage their staff to step out of their comfort zone. They mentioned that they need new training, better qualifications, and 
have to teach themselves (Section 4.2.3, p. $104 \mathrm{ff}$.).

Temporary changes and measures will not help the situation. Hence, the middle managers need to react before negative issues, such as loss in revenue, occur in the company, as indicated in Section 3.2 (p. 57 f.). If loss of revenue were to occur, then it would be too late for remedial action. In principle, major changes take place in companies. This is even more necessary in a joint venture since two corporate cultures are merging - in addition to the corporate culture of the joint venture being installed - as described in Section 4.5, p. $124 \mathrm{ff}$. If changes originate as far away as the German central plant, it is very important that communication occurs, as is indicated in the literature (Section 2.1, p. 29 ff.) by Franken (2010) and Umstaetter (2000), was confirmed by the interviewees, and is described in the analysis chapter (Section 4.2, p. 92 ff.).

Communication should occur regularly and in a planned manner. The complaint of the youngest German middle manager was that he observed that the Chinese employees do not plan in advance as well as the German central headquarters' employees do. It is important that middle managers adapt themselves to change very quickly and are able to deal with them effectively (Section 2.1, 29 ff.; Wooldridge et. al, 2008; Barmeyer, 1996). Exchange is an essential value of the company, in this case, for the production department. Therefore, people, especially middle managers, need to begin rethinking the processes involved, since they fulfil an interface function and lead by example. Furthermore, fast-growing markets and international cooperation, as occurs in the company, lead companies to be more dynamic and to create better development plans (Section 1.2, p. $14 \mathrm{f}$.).

Everything is becoming dynamic and leaders are facing situations in which they have to react quickly by beginning to think differently. Many firms engaged in digitalisation projects, as indicated in the literature review in Sections 3.2, p. 57 and 3.3.4, p. $75 \mathrm{ff}$. and described in the analysis chapter in Sections 4.2, p. 92 ff. and 4.4., p. 120 ff., have indicated that they want their employees to think differently and 'outside the box'. They have to find new solutions and new ways to differentiate themselves from others in the market and to try to be the benchmark for the industry. It is important for middle managers to have the ability to adapt to these new trends and to continuously be flexible. This is why a compatible corporate culture, which is supported by the national culture and the ability of middle managers to be adaptable, is important.

In the next section, I present an appropriate communication model as an answer to how I achieved my aims and objectives. 


\subsection{An appropriate communication model}

In all companies, it is always important to have positive collaboration and communication with all the departments, with other companies, and with the market (Section 2.1, p. 29; Umstaetter, 2000). Having analysed the interviews, I have observed (Section 4.2.1, p. 95 ff.) that communication is not effective in the joint venture; however, due to the great distance between the central German plant and the joint venture in China, and the standardised process planning and reporting that occurs, it must be improved. It would be helpful to create an appropriate communication model, as described in Section 4.2.1 (p. 95 ff.) and in Figure 12 (p. 104) and to formulate this as recommendation.

Using the morphological box (Table 6, p. 97) and its detailed execution in Appendix 6, p. 237 ff., it is possible to select the appropriate option for the joint venture. Should any other company working in collaboration with others wish to adopt this method, it is possible to use the morphological box developed in the appendix and adapt it to the needs of that company. This method has been developed as a recommendation for the middle managers in the joint venture, for the particular department, and exactly fits its needs and those of its middle managers, though of course it can be adapted to the company as a whole or, as indicated above, to any other cross-cultural collaboration between two companies. This method seems to me to be useful; it is a creative technique, as described by Ritchey (2011) in Section 3.4, p. 81. The features described in Section 3.4, p. 83, and in Section 4.2, p. 95 ff. of the analysis chapter, can be integrated into a communication model. The left side of the morphological box (Table 6, p. 97) displays the features by means of which a communication model can be implemented. In the columns of Table 6 (p. 97) the characteristic that can be used for all of the features is presented (as described in Table 6, p. 97). This was the starting point for the entire analysis and underpins the recommendations and the contribution to knowledge and practice chapter.

Communication is essential for companies, as it is in a joint venture when two companies cooperate with each other, as described in the analysis in Section 4.2, p. 92 ff., and pointed out in the literature review chapter, Section 2.1, p. 29 ff., by several authors, such as Berner (2010), Umstaetter (2000), and Franken (2010). Company goals and visions need to be communicated to employees. This also aids in satisfying employees and reducing employee turnover. In Section 4.2 .3 (p. 104 ff.), the middle managers describe qualifications and hiring as a significant issue in the company. However, in my understanding, based on the answers of the middle managers, and as described in Section 4.5, p. $124 \mathrm{f}$., the problem is not merely 
qualifications and hiring - it is also components of the corporate culture of the joint venture, as described in Section 4.4 (p. $120 \mathrm{ff}$.) in my observations on the interview sessions. In this sense, it is also about how to implement change management practice (Section 4.3.1, p. 108 f.). It is a matter of how the middle management level can support their staff in coping with change management, as described in first research objective (Section 1.4, p. 25). These goals can only be achieved through communication and the exchange of information, as per Section 4.2, p. 92 ff., and as stated by Franken (2010) and Umstaetter (2001) in the literature review (Section 3.2.1, p. 58 ff.) and as presented in Franken’s (2010) adapted sender-receiver communication model in Figure 2 (p. 41).

Via the interview responses, as described in the analysis chapter in Section 4.2 (p. $92 \mathrm{ff}$.), I can confirm the efficacy of this model. As described by Franken (2010) and indicated in Section 2.1, p. 29 ff., communication takes place in any company. In the joint venture, it occurs with different kinds of people and at different levels in the company. For intracompany communication, which was mentioned several times by the middle managers during the interview sessions and is described in Section 4.2 (p. 92 ff.), information and knowledge transfer needs to be enhanced. In the view of the middle managers, upper management needs to support them by communicating changes in their early phases so they can start preparing their staff for these and can clearly convey the vision and direction of the changes to them. Additionally, a core task of the company is communication to inform the staff. Employees need the right information at the right time and in the right place so that they can complete their tasks properly. In terms of communication with central headquarters, the middle managers discuss this as a form of external communication since it occurs outside the joint venture; however, it still provides direction and changes due to the central headquarters' functionality. Here, greater enhancement and support are required if one adopts the point of view of the Chinese middle managers (Section 4.2, p. $92 \mathrm{ff}$.). Better communication is required, especially for the middle management level, since in the joint venture they build the important bridge between upper management and staff level, as described in Section 4.3.5, p. 116.

Management needs to support their staff, and staff need to be mobilised and procedures embedded for them gain knowledge and information which can be worked out and further developed together. This is very important - that it needs to take place together: staff with managers; middle managers especially have the task of informing their staff. Commitment goals, as described by a German middle manager (No. 1; Table 2; Section 3.3.3; p. 74) and two Chinese middle managers (Nos. 2 and 5; Table 2; Section 3.3.3; p. 74), mean that 
employees need to be bonded to the company and integrated into it.

Motivation can be induced and common values negotiated, especially by the middle management level, which works closely with the staff on a daily basis to together drive the operational processes in the production department. A common, collective feeling can be generated in all employees in the company if the results, in the form of recommendations and the communication model described in Chapter 4, were to be disseminated throughout the company. Company internal communication will furthermore have the function of getting the employees to act as ambassadors and to support the company, to talk positively about it and the collaboration within the company itself. This will also help to keep the employees motivated, happy, satisfied, and retain them in the company. Employees can thus serve as brand ambassadors and company ambassadors, since, as mentioned in the interview sessions, factors other than payment can be crucial to retaining employees (Section 4.2.3, p. 104 ff.). Features from the morphological box based on the Zwicky method shown in Appendix 6, p. $237 \mathrm{ff}$., and as demonstrated in the example in Figure 6 (p. 58), are the level of formality, centrality, motives, direction, and media. Internal communication can be formal or informal. Formal communication is communication that takes place officially, with predetermined, fixed rules and clearly defined cycles. The situation and content here are standardised. As the interview partners on both the Chinese and the German sides, especially the most experienced ones, mentioned several times (Section 4.2.2, p. $101 \mathrm{ff}$.), there are some standards they have to follow, and this is sometimes not easy for them.

One Chinese middle manager (No. 2; Table 2; Section 3.3.3; p. 74) mentioned that his team follows the standards and attends the same regular meetings to share information and remain up to date. I observed that the experienced middle managers can figure things out with the central headquarters and, without any additional contract realignments or additional payments from the joint venture to the central headquarters, can share information and have regular meetings to maintain standards and keep their staff up to date. However, with some of the middle managers on both sides, I observed that, even though the German ones came from headquarters, it was not easy for them to remain aligned with the central headquarters without the alignment of upper management. This is an issue of the hierarchical structure of the company, as mentioned by the middle managers (Section 4.3.5, p. 116 f.) or, for my point of view and as found in the literature, a gap (Section 1.3, p. $20 \mathrm{ff}$.).

The middle management level in the joint venture needs to be stronger and they need support to better manage this kind of situation in a changing environment in which there are two national cultures. The content is not merely standardised; the roles are given according to each 
person's status or tasks in the company. 'Informal' means that there is no communication or that communication according to general social norms is implemented in the environment, as is evident in the responses of the most experienced middle managers (Table 2; Section 3.3.3; p. 74). Company internal communication may be centralised or decentralised (Table 6, p. 97). Activities are steered through central communications, through centrally steered departments, or through the management in a company. These decentralised communication activities are accompanied by central communications that occur in a certain area of a company (Table 6, p. 97).

Communication may be a component of the concrete tasks of employees or of a company department - in this case, the production department. Furthermore, there are topics that are relevant to the company as a whole and can, for example, apply to the values or structures of the company. Employees or teams and departments need information to complete their tasks. This needs to occur at the right time and in the right place, as indicated by Umstaetter (2000) and Franken (2010) in Section 2.1 (p. 29 ff.). Communication procedures in companies can progress in different directions, as demonstrated in the analysis in Table 6 (p. 97) and as depicted in Appendix 6, p. 237 ff. based on Zwicky’s morphological box.

One can distinguish between downward, upward, and horizontal communication. Downward or top-down communication describes the information flow from above to the lower levels of the hierarchy, that is, from management to the employees directly involved in production. Upward or bottom-up communication describes communication from the lower levels to the higher levels, from the employees to their superiors in the company. Horizontal communication, also known as in-between communication, takes place between employees at the same hierarchical level.

Communication can take place via different types of media and channels. One can distinguish between verbal or personal and printed or electronically mediated communication. Verbal communication can take place through direct discussions within the framework of conferences, workshops, or telephone calls. Written communication usually occurs in the form of newsletters or meeting minutes, as demonstrated in the different executions in the morphological box for communication in Appendix 6, p. $237 \mathrm{ff}$.

We live in an era of rapid globalisation and work internationally and, increasingly, supraregionally. Accordingly, direct, personal communication in the form of face-to-face meetings can be overly elaborate, complex, or even impossible. The different cultural backgrounds of the participants, language issues, and time zone differences impede such communication and collaboration. Intercultural teams and working environments that include differences and 
diversity are immensely positive and should be fostered. Compared to monocultural groups in companies, results are often much better in international and cross-cultural collaborations. The premise therefore is that, with exposure to different cultures, competences are developed and become available, as described in Section 2.3 (p. 52 ff.).

The method involving the Zwicky morphological box has been used to create as many solutions as possible in order to compare them with one another. The possible attributes of a communication model and its characteristics are demonstrated in the Zwicky box.

In the next step, I combine all possible attribute characteristics with one another, and, at the end, all possible alternatives are provided - these are analysed in Appendix 6, p. 237. With this method, I can evaluate how each possibility can be implemented and whether the attribute characteristics are in opposition to one another.

For the communication model that I developed for the middle managers of the joint venture, the first result is that all combinations of the attribute characteristics are central upward, as one possible solution, as indicated in Appendix 6, p. 237, tables 3, 4, 11, and 12. Further determination comes from the fact that decisions that originate with upper management are centrally organised. All occasions for communication are combined with decentralised and peripheral ones and will be invalid, as depicted in Appendix 6, p. 237, tables 15 to 20 and 27 to 32. The next necessary step is the direction of the communication. A group of peripheral communications will occur in each group in different departments of the company, including with the operational working employees, who are the lowest level of the hierarchy. Summing up the results of the tables in Appendix 6 (p. 237) will determine whether a possible solution for an appropriate conceptual framework for the company is feasible.

To work out the appropriate communication model, the remaining solution possibilities are further analysed in the next step to determine the most adequate solution. The possibilities are evaluated using the following questions:

- Does communication occur in the right direction?

- Is it required that communication occurs with each cooperation partner?

- Is there a concrete occasion and do topics exist for a communication activity?

- Which communication channel is the most appropriate?

Middle managers should support their new staff who cannot always use the same systems as headquarters due to contact and compliance issues and should have them trained by their key multiplicator personnel. Special attention to improvement and networking is required in the 
joint venture situation. For this purpose, it makes sense to have additional information and exchange platforms at the joint venture disposal. On the platform, there should be a profile for each employee, with their role and contact details so that the contact person can easily and quickly access these and determine the counterpart or the person sought for exchange. This is currently an issue, as 10 of the interviewees reported.

In addition, there should be a platform to share knowledge or expertise in the joint venture, since expatriates are continually coming and going. Sharing expertise and knowledge is one aspect of this kind of platform; another pertains to retaining knowledge even if the employee cannot be retained in the company, which is one of the problems that the joint venture experiences. By virtue of this platform solution, new employees can obtain information right from the beginning without the help of other employees; in this manner, time can be saved and expertise secured. For example, if there is a special issue or problem in production, with the help of this common platform, another employee, whether at headquarters or in Beijing, can ascertain whether this is an identical or similar problem and what the solution is. The platform can be used with an intelligence service fast and directly for communication with another individual. This kind of solution is more pragmatic than email and can be used as an alternative to emails and phone calls. The exchange can be fast-tracked and effectively and efficiently worked out together. With the documentation and the common platform, the option should be to use this system within the department, with a special group of access rights given to these employees and to the partner departments at the headquarters. Due to legal and compliance issues, the joint venture partner cannot have access to all the other plants nor share information on the other vehicles produced within the whole system and at production sites around the world. Access needs to be specified for the relevant departments, those that collaborate, so that the important documents and information required can be shared. Before implementing such a platform, the rights pertaining to this and the legal situation needs to be clarified.

Topics can be communicated via the communication activities are shown in Appendix 6, p. 237, Tables 23, 24, 35, and 36. These topics are a component of methodological topics, as processes or structures, or pertain to cooperation issues in the course of collaboration. Problematic and critical topics should also be integrated into the communication cascade form and will be escalated up the hierarchy in the pyramid, as depicted in Figure 12 (p. 100). Discrepancies and deviations between the plants in Germany and Beijing need to be eliminated and decisions implemented. This should take place within a joint venture communication channel and may be a way to combine a communication channel with the 
collaboration and communication model in Figure 12 (p. 100). For example, besides expatriate functionality, each department could use a key account person who is responsible for taking care of matters that need to be clarified between the plants. Information would be bundled, and the solution would be spread to all relevant communication partners in the department. Hence, there needs to be a person who is centrally responsible for this. This would save costs and time for both locations; the contact person could act centrally within the joint venture and topics could be passed along and in this way discussed efficiently and easily by both German and Chinese middle managers - which would be a relief for them.

Communication between middle managers and their staff is another major point where it is important to receive top-down and bottom-up information, as is also demonstrated in Figure 12 (p. 100). The responsibility for taking all relevant topics to upper management and discussing solutions there or bringing decisions back to the working level is the task of the middle manager, as indicated in Figure 12 (p. 100). The hierarchical level is already described in this form; this kind of communication should already be provided for in their relationship, as laid out in their contracts, and communication channels should be used in this constellation. In Appendix 6, p. 237, in Tables 23 and 35, oral or personal communication fits the conceptual framework that some middle managers have already implemented on the shop floor, in staff meetings, or in regular meetings with the employees, as mentioned in the interviews. In urgent cases, if the person cannot wait until the next regular communication with the middle manager or if the employee needs to receive support in relation to standards from headquarters, the employee can use another channel of communication. As per Appendix 6, p. 237, Tables 23, 24, 35, and 36, for this purpose, a direct talk, call, or email within the electronical channel is possible. From upper management, the communication arrows for direct cooperation are needless since important topics can be discussed in steering committees and decisions can be made by them.

In some cases, topics can be conveyed through horizontal communication, as depicted in Appendix 6, p. 237, Tables 25 and 26. This is symbolised by the pyramid in Figure 14. Since these topics are not regularly discussed issues and a 'deep dive' is not really required, a direct verbal or personal channel in the form of a personal conversation or phone call can be selected. With these topics, it is sufficient to inform the middle management level about the meeting afterwards. In this manner, it can be ensured that communication takes place and that not too many people are involved, so that the communication is not be hindered. In Tables 9, 19, 21, and 22 in Appendix 6, p. 237, in the pyramid, the upward arrows mentioned above and the escalated topics and issues can be taken back to the cooperation 
partner or forward as decisions to the employee level via middle management. Using this path, board decisions and solutions can be communicated because feedback is always required if a demand or escalated topic comes from the employee level to upper management.

Characteristically, as depicted, these communication activities differ from the upward arrows merely in terms of direction. Here, communication should also take place via the steering committee, which is important for the middle managers to obtain support via this newly installed communication channel. From the steering committee to the working or process level, owners in the department should forward the communication from the bottom up as consultation and the regular communication of staff with their middle managers takes place; alternatively, direct conversation or email can be used as channels in urgent cases. The service platform can additionally be used as a communication channel. Announcements regarding issues or employee-relevant topics can be circulated as information. In this manner, decisions can be accelerated, and the information can reach each employee at the same time and not through time-consuming, hierarchical, top-down communication. Furthermore, direct dialogue between upper management and the employees can be improved, as was desired in the interview sessions. Even a selected employee group can be informed by means of the communication platform.

As it stands, information and decisions usually reach the employee level and middle managers only after a lengthy period of time, and sometimes only partial information - or none at all is relayed to them. This matter was raised in the interview sessions; it is not a particularly effective or efficient way of communicating. Existing communication occurs within the hierarchy level of each plant and has not thus far been defined as the communication sequences make information flow difficult. Using the downward communication activities described, all information that the employees and the middle managers need for their daily work should be communicated, as should decisions that pertain to other employee or middle manager tasks.

If required for some issues described in Appendix 6, p. 237, the following tables can be taken into consideration: 7, 8, 13, and 14 . Here, personal, verbal feedback discussions regarding the communicated topics are expedient.

Appendix 6, p. 237, characterises communication activity as being directly formal, peripheral, upward, verbal, or personal communication and refers to the task of each employee or department. The employee level can take the information communicated and use it to further deepen exchanges and personal networks via planned workshops with the central headquarters. These would involve visiting each other regularly to observe improvements, to 
learn from each other, and to establish a good level of know-how for the joint venture employees. At the same time, the cooperation partners from headquarters can communicate down the communication cascades information of the same quality for middle managers and their staff as occurs the exchange partners in regular meetings. For this purpose, the communication channel of the workshops should strengthen communicating tasks and department-related matters.

In the interviews, the middle managers revealed that they feel that they do not receive sufficient support from upper management. This means they are not really deeply involved in the decision-making process and are not receiving feedback from the steering committees. With many tasks, without the right information, the implementation is not sufficient, and the employees become unsatisfied to the point that they want to leave. The high level of staff fluctuation in Beijing could well be due to this, as was suggested during the interviews with the middle managers. At the end of the hierarchical chain, the employees are pressured enough to implement and fulfil the required tasks. If one examines the responses of some of the middle managers, the upward communication activities are especially relevant to them and need to be implemented so that information transfer can take place and information can also be sent to the cooperation partner at the headquarters.

The aforementioned communication possibilities are an instrument for selecting the appropriate communication model for the department concerned. This can give the employees and the middle managers the feeling that they are becoming involved in the processes and the decisions of the company and are part of the whole process of change. The communication model is especially required for intercultural collaboration since different people from different cultures are working and communicating with one another.

Language competence is another aspect of communication, and because English is the commonly spoken language in the joint venture, this is a requirement for communication. If the language is not available or adequate, then proper communication cannot occur. The other dimensions in the matrix are also important and taking care of them is required since problems can occur in the collaboration if there is no intercultural and geographical competence. One could make the assumption that management made the decision that the lingua franca should be English; however, this is not always the case since Chinese-speaking people begin to speak Chinese with one another and German-speaking employees and middle managers tend to speak German with one another. Furthermore, some people who do not speak English that well are being hired locally, since, with the current high staff turnover in the company, it is becoming difficult to find good employees, as was mentioned by the 
interviewees.

Communication is even more difficult if English-speaking employees are not available locally. The older people on the German side do not speak English that well either; the language is a basic communication dimension that needs to be fulfilled, as described in Section 4.2 (p. 92 ff.). However, when hiring expatriates from headquarters, there is a considerable focus - it is a hiring requirement - on getting those who at least speak understandable English. Indeed, one Chinese middle manager mentioned several times that the language issue was the principal one for him and his team members. Moreover, people working at the operational level, such as on a production line, do not speak English at all; here improving processes together becomes even more difficult. In fact, English should be essential for those employees and middle managers who work in intercultural collaboration and a requirement in the hiring process, at least for the planning and engineering levels, even if the operational workers cannot speak English. Furthermore, English courses and training should be provided; these are not currently regularly offered to get the employees to improve their language competence. If this does not occur, a language barrier can arise and then an interpreter would be required for communication; this would reflect a negative situation in the intercultural joint venture and would also involve additional costs.

As regards the communication and collaboration model described, future researchers should consider further analysing the communication culture and structure in cooperative companies and should conduct either a quantitative or a qualitative analysis to determine how structures - and whether the recommendations - for future collaboration in the communication structure can be formulated.

As described in Section 2.1 (p. 29 ff.) and as indicated by Lipp (2008), the planned workshops should provide an opportunity to improve communications. These workshops could help to optimise the communication model and the interface team to further enhance communication; conferences can also be planned, as indicated in the literature review (Section 2.1, p. 29 ff.) by Meier (2015). Enhancing communication in companies and, at the management level, exchanging topics that can support middle managers to make quick decisions, as required and as described in Chapter 4, can be accomplished by means of a steering committee.

To track these communication forms within the company, an activity plan can be used which summarises the communication activities in a certain area, department, or organisation. To create an appropriate activity plan, appropriate activities need to be organised right from the beginning. The coordinator can subsequently determine the right temporal sequence using a 
time plan. The purpose of an activity plan is to make appointments and milestones mandatory. To better keep track of the milestones, it would be useful to integrate traffic light functionality, which would provide a better overview of the achieving of the milestones and mandatory appointments. This was a proposal from the youngest Chinese middle manager for improving the current situation. If using this kind of traffic light to show, for example, the status of an activity is not implemented, then the milestones might not be reached. If one critically examines the different forms of communication, reporting refunds involves the risk that employees can select and filter information. Furthermore, middle managers or employees may obtain irrelevant or unimportant information or might not receive enough information.

\subsection{National cultures in the joint venture}

There are two main national cultures in the joint venture, the German culture and the Chinese culture.

It is inevitable that there will be considerable differences between these; understanding these differences is critical. In the literature review (Section 2.3, p. 52 ff.), German people are described as being more detail-oriented while Chinese people tend to be more relationshiporiented; however, this could not be generally confirmed in the interviews with the middle managers. It depends on the experience the German middle managers have. The most experienced ones, who have experience abroad, are also relationship-oriented, have a wider view, and show more acceptance. The younger one, as described in Section 4.2 (p. 92 ff.) tended more to be detail-oriented.

I observed the same pattern with the Chinese middle managers. Those who have experience abroad and have worked or studied in Europe, perhaps even in Germany, tend to demonstrate more acceptance and understanding of German culture; however, those who do not have such experience tend to describe relationship-building as the same in both cultures and do not distinguish between the two national cultures. This is the challenge for the joint venture, as described in Section 4.5 (p. 124 ff.). For successful collaboration between these cultures, employees need to have broad professional competence in linguistic, applied geographical, and intercultural fields, as described in the literature review in Section 3.2, p. 57, and as confirmed in the analysis chapter in Section 4.2. (p. 92 ff.) and in Figure 12 (p. 100).

\subsection{Summary and interim conclusion}

Chapter 5 concerns the recommendations and the contribution of this study to knowledge and 
practice. Chapter 6 presents the recommendations for the joint venture and department concerned and has been formulated as a contribution to practice. The new conceptual framework was developed relative to the one presented in the literature review chapter and is mainly a result of my reflections. The major contributions to knowledge of the new conceptual framework are described and highlighted. All the findings formulated in Chapter 4 can be found in the conceptual framework. Table 6 and Figure 14 demonstrate further contributions to knowledge by means of the use of the morphological box. The communication model is described and possible solutions are depicted in 36 different morphological boxes in Appendix 6, p. 237 ff.

The communication and collaboration model displayed in Figure 14 was developed by me and is to be implemented for the middle managers, though the company as a whole can use it to support the middle managers (as described in the research questions in Section 1.3, p. $20 \mathrm{ff}$.) to improve communication, information flow, and collaboration - as mentioned by the middle managers in Section 4.2 (p. 92) of the analysis chapter. 


\section{Chapter 6: Contribution to Knowledge and Practice}

In this chapter on the contribution to knowledge and practice, I summarise the main findings of this study to close the research gap and answer the research questions. I also remind the reader of the aims and objectives and explain how I have addressed them in my thesis with the final results from the conceptual framework, and I provide important recommendations that contribute to existing knowledge and practice for middle managers. The research highlights some important tools which can be implemented in the joint venture company and can be adapted as best-practice solutions for other companies.

\subsection{Conclusion: research gap and research conclusion}

This study focuses on a joint venture between a German company and a Chinese company in the automotive sector. The right side of Figure 5 (p. 53) depicts the first conceptual framework I developed in the course of the literature review while considering the research questions and research objectives and introduces the concept of process management (Section 1.2.1, p. 15). This concept involves a consideration of changes in decision-making about current processes in the production department and refers to the first objective of this study, which is described in Section 1.4 (p. 25).

In the literature, process management has been shown to be indispensable for organisations to achieve the most appropriate culture for implementing required process changes (Section 1.2.1, p. 15 ff.; Speier-Werner, 2006; Thommen \& Grösser, 2012). Before discussing cultural differences, organisational changes must be considered (Schein, 2010). The second concept introduced in the figure is that of coping with cultural differences (Section 1.2.2, p. $17 \mathrm{ff}$.). This relates to the second research objective and involves analysing behaviour. In the literature on joint venture organisations, there is little discussion or analysis of middle management behaviour, although the studies I consulted considered it to be an influence that may require indepth analysis. The last objective concerns relationship-building (Section 1.2.3, p. 19 ff.), which directly affects the employees and middle managers, as shown in the conceptual framework presented in Figure 5 (p. 53). This is a particularly important issue for collaboration between different countries.

Regarding the research questions, I explain in what follows how I reached my aims. In relation to the first question, 'How do German and Chinese middle managers working in a joint venture learn about organisational change and national cultural differences?' (Section 1.4, p. 25), in the interviews with the middle managers and based on their own reflections (Section 4.6, p. 127 
ff.), I came to understand the importance of learning and change management. The middle manager highlighted their respective national cultures and corporate cultures and the need for good communication and information flow. In my analysis, I observed that those middle managers who had experience aboard, in working internationally, and in gaining knowledge of how to deal with other national cultures found it easier to work in the Sino-German joint venture. Regarding organisational change, as highlighted in Section 4.2 .1 (p. 95 ff.), communication and good information flow were the most important aspects to be derived from the interview in terms of supporting joint ventures of this nature, particularly their middle managers. I have present Figure 12 (p. 100) as communication model for middle managers.

For the middle managers, learning applies to both to the hiring process, in terms of the qualifications of the employees, and it applies to improving by themselves by means of additional leadership training (Section 4.2.3, p. $104 \mathrm{ff}$.). As regards the question, 'Is it necessary to learn to work in a joint venture, especially in one that is a collaboration between German and Chinese cultures?', based on the understandings of the middle managers, it was clear it was clear that this was the case (Section 4.3.1, p. $108 \mathrm{ff}$. and Section 4.3.2, p. $109 \mathrm{ff}$.).

As also described in Section 4.3 .5 (p. 116 ff.), the joint venture has a specific, complex hierarchical structure. In this context it is important to learn about national differences and organisational changes. This high level of complexity, as I describe in my observations in Section 4.4 (p. $120 \mathrm{ff}$.), is why, to my mind, the three main findings of this study were those pertaining to, communication, information flow, and collaboration; relationship-building and guanxi; and qualifications and hiring.

The answer to the second research question, 'How can middle managers adapt their skills to the culture of the joint venture partner, especially the relationship-building skills that required in situations of change?', was obtained by means of the ratings using the Zwicky method and the morphological box and comprises the second key finding (Section 4.2.2, p. $101 \mathrm{ff}$.). According to the middle managers, those arriving from Germany were offered special cultural training at the beginning of their assignment aboard. However, the Chinese middle managers were offered no such training by the joint venture partner. I recommendation that it do so. It seems to be very important when working in China to understand relationship-building and guanxi in order to enter into good business relations and to achieve good results together. In addition, it should be mentioned that, in the joint venture, where the staff all work together, middle management is an important fulcrum between upper management and staff level.

Based on these research questions, I formulated research objectives which I discuss in what 
follows. First, 'To determine how middle managers in a Sino-German joint venture recognise and cope with factors associated with organisational change and national change that might inhibit or promote their awareness of the effects of cultural differences in the organisation'. In fulfilling this objective, I especially want to highlight the reflections of the middle managers themselves (Section 4.6, p. 127 ff.). The middle managers recognise problems and also speak out about what they need. However, not all of them adequately reflect on issues; to my understanding, they need to learn more about how to reflect better and about how to improve their leadership skills through additional training.

As regards the second objective - 'To identify how cultural differences affect middle managers' change management behaviour in relation to organisational issues in a GermanChinese joint venture and how middle managers support their employees in situations of change' - I can say, based on the results of the interviews, that cultural differences affect middle managers' behaviour and that the observed middle managers need to learn more about how to support their staff. They already have some basic knowledge, but to my understanding, it is not insufficient and needs to be enhanced by means of better structures, such as those depicted in the communication model in Figure 12 (p. 100). In relation to the last objective 'To formulate an appropriate conceptual framework for culturally based change management factors affecting middle managers working in cross-cultural joint ventures' - I drew on the literature research to generate a conceptual framework (Figure 5, p. 53) and then, based on the interview sessions and the results of my analysis, redeveloped this into a new conceptual framework (Figure 11, p. 93).

This distinctiveness to this study relates to the use of the Zwicky method in combination with the morphological box; this helped me to practically structure all the different, complex insights from the experiences of the middle managers. Dealing with this complexity is made easier way by the boxes, which simplify the different possibilities for practical use in companies, particularly at the shop floor level. Among the three main findings that were discussed in depth in Chapter 4, I want to highlight communication and collaboration. Especially in a joint venture, this requires a special focus and the strengthening of relationship-building. 


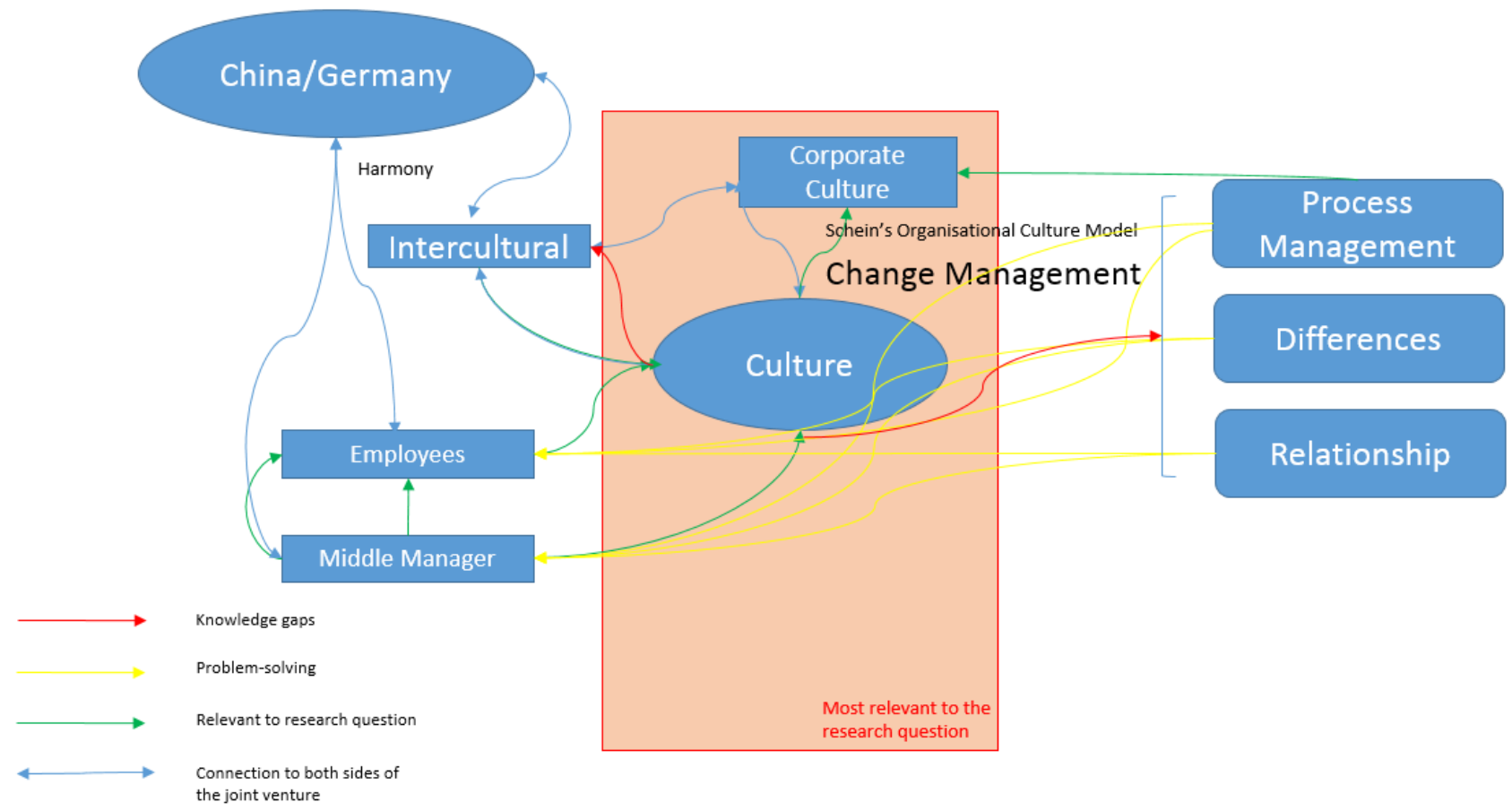

Figure 5: Conceptual framework

Source: Ayse Yilmaz (March, 2016)

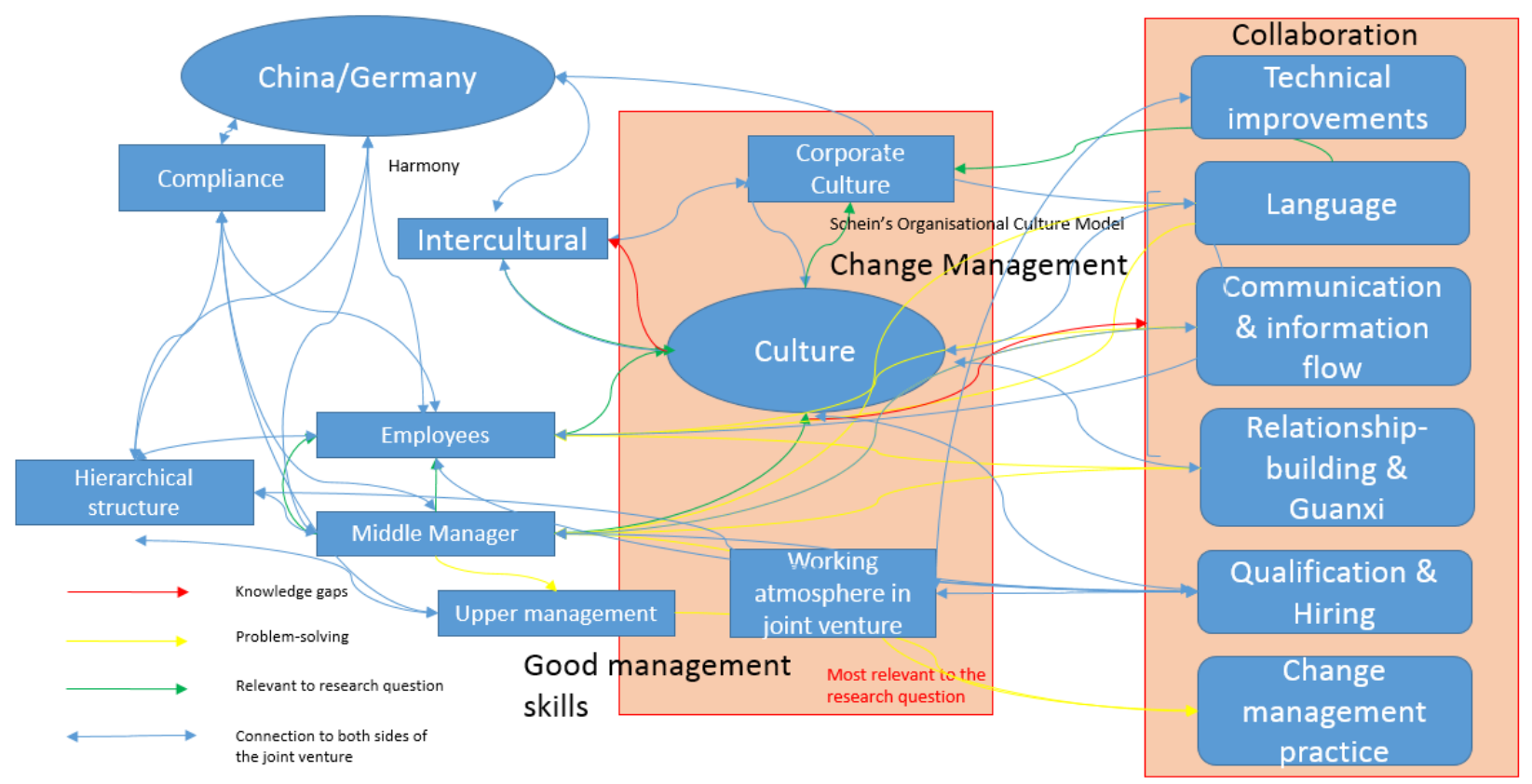

Figure 11: The revised conceptual framework

Source: Ayse Yilmaz (September, 2018) 
In relation to the three research questions I summarized in Section 1.3, below, I discuss the results of my thesis and the outcomes of the analysis of the interviews. First, though middle managers recognize and cope with the factors associated with organisational change and national culture, it was not that easy for them to explain in detail. From the nine findings discussed in Chapter 5, here, I discuss the three main findings in detail. First, in the interviews, communication, collaboration, and information flow was highlighted by all the middle managers, both German and Chinese, as being important for coping with organisational change and national culture.

For the second research question regarding determining how cultural differences affect middle managers' change management behaviour, the most important findings relating to the production department concerned language differences and to hiring employees with the right qualifications, as these matters affected the behavior of the middle managers.

For the third research question, which relates to formulating a conceptual framework, I worked out an initial conceptual framework (Figure 5, p. 53), which was reworked to produce the new conceptual framework in Figure 11 (p. 93).

The most important contribution to practice is the enhancement of communication with the central headquarters and between the two companies cooperating in the joint venture. This means that communication with the cooperation partner and the central headquarters should occur regularly at all levels in the hierarchical structure. Furthermore, an interface team should be installed to improve this communication channel and make it efficient and more effective for all in the joint venture. The joint venture should also regularly conduct exchange meetings with the staff level of the central headquarters to implement the new standards for change projects or change processes more quickly. In Section 4.2, this was described as an issue for the middle managers. The interface team and its communication structure can be organised via the ideas emanating from the morphological box based on the Zwicky method (Appendix 6, p. 237 ff.). This can also be undertaken for communication at the middle manager and staff levels between the joint venture and the central headquarters. 


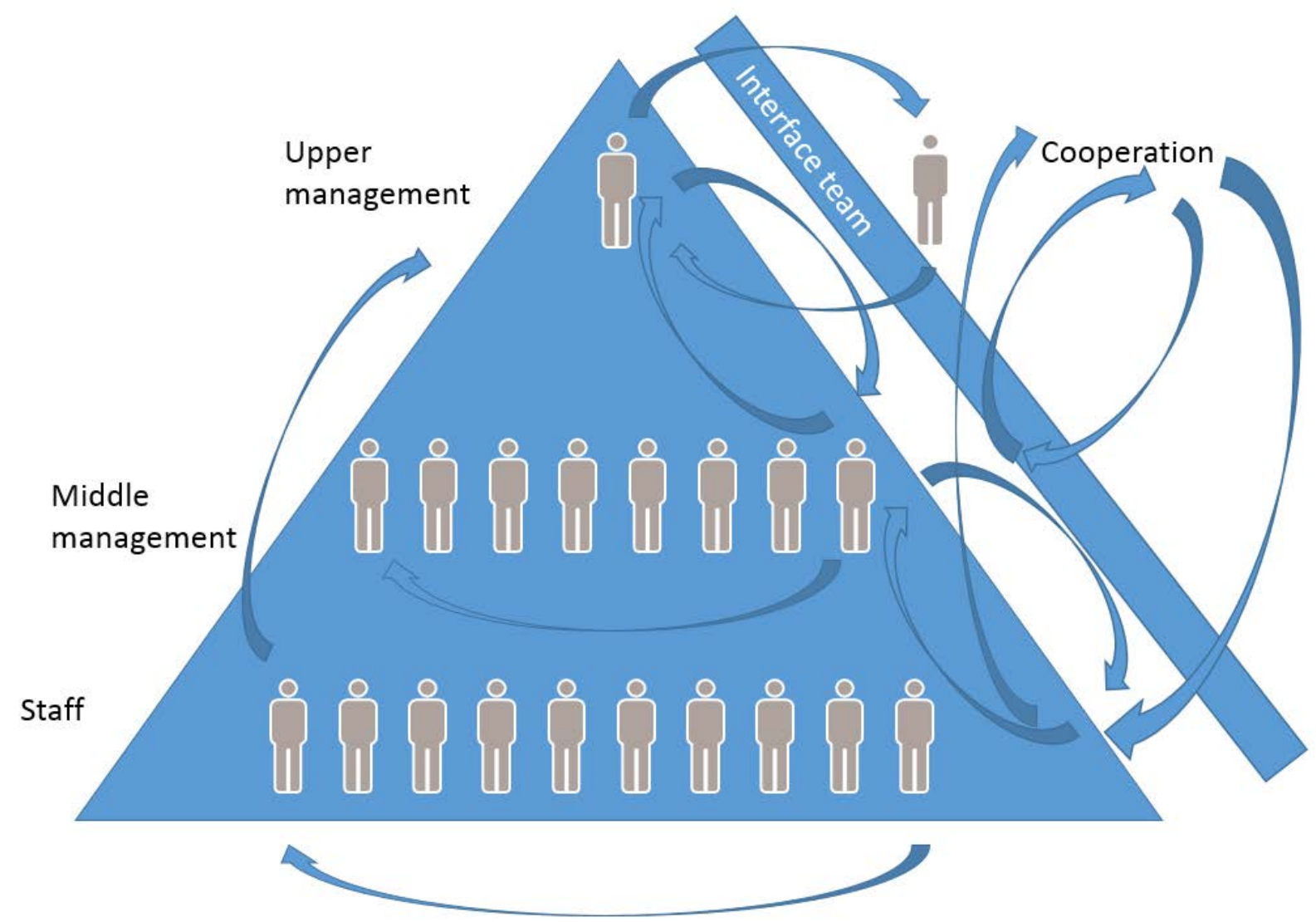

\section{Figure 12: Communication model middle managers}

Source: Ayse Yilmaz (August, 2018)

In Section 1.3, p. 20, I formulated two research questions:

1) Do German and Chinese middle managers working in a joint venture need to learn about culture? Is this necessary for working in a joint venture?

2) Do middle managers need to adapt their skills to the culture of the joint venture partner, especially the relationship-building skills required in situations of change?

In light of the information derived from the interviews and the analysis of these, positive answers to both questions can be confirmed. Most of the Chinese and German middle managers confirmed that they needed to learn about national culture; there were three who did not, as described in Section 4.2 (p. 92 ff). These were the two Chinese middle managers who had worked in Europe and had already experienced German national culture and one German middle manager, who was the youngest and was freshly appointed to the middle management level. These three middle managers were either used to interacting with other national cultures or raised other issues and did not reflect on the main topic that the question posed. It can be 
stated that, generally, it is necessary for all middle managers in the joint venture to learn about national culture.

The contribution and originality of this thesis lies with its focus on intercultural aspects, middle managers, and employees in the framework depicted in Figure 5 (p. 53), namely the joint venture decision-making of middle managers (a group not often considered in the literature in the circumstances described in my thesis) from two different cultures in a specific, highpressure setting (Schein, 1985; Kotter, 1996; Sackmann, 2004; Speier-Werner, 2006; Thommen \& Grösser, 2012). This study adds to understanding the inter-relationship between these factors at this level of organisational structure. A reading of the literature reveals little existing work that combines these areas.

The Hofstede (2001) framework has been both criticised and highly recommended. I adapted the framework shown in Figure 5 (p. 53) with the help of the literature research, developing it further to produce Figure 11 (p. 93) in Chapter 4. Those aspects that have been most severely criticised are the dimensions, the wording used for analysing behaviour, the groups mentioned, and the lack of a definition of culture. Culture can have many different meanings depending on the context of its use.

Being an inside researcher in the automotive joint venture was a unique situation which allowed me to add substantial knowledge and new insights to the existing research. This was a result of the interviews I conducted and the information I gained from the interviewees, which was based on knowledge of their personal lives and the experience they had gained.

Additionally, having reflected on the time I have spent on the DBA, I can say that conducting the interviews in Beijing, China, adds a further contribution to practice as I was able to access the combination of working modes of the German expatriates and Chinese employees, their colleagues, and their managers in the joint venture.

A further contribution to theoretical knowledge is the selected method presented in Chapter 3 -the Zwicky method in combination with the decision matrix. This is unique in that it is the first time this combination has been used and, hence, also first time it has been used in analysis in an automobile production environment in a joint venture collaboration. In using this method, I wanted to show how it is useful for the purposes of research and how a variety of results and new insights into the literature can be obtained. The use of semi-structured interviews with a specified sample size of participants, six German and six Chinese middle managers, adds a different point of view to my thesis. Even the pilot interviews with the lean manufacturing 
experts add unique information and contribute to practice. Following the interviews, in my position as an inside researcher and in my collaboration with them, I observed some changes in the practices of the middle managers, especially in terms of them better structuring their communication (Figure 12, p. 100). This seemed easier for them to establish than where the other points discussed. in addition, I observed them starting to reflect more and also using the method of reflecting when collaborating with interface departments, and not merely in their own department in collaboration with their employees. This was a positive outcome for me as we talked about and tried to reflect on relevant issues in the interviews.

The recommendations that emerged from the interview sessions and the clustering of those findings are a major contribution to practice and will improve both the practitioners' knowledge base and research with the help of new insights.

The unique contribution is the conceptual framework (Figure 11, p. 93) which I developed following the interview sessions in order to add new insights to the original conceptual framework which I had compiled in the course of the literature research (Figure 5, p. 53). I found major differences between the original framework and the later one, such as collaboration and language issues. In the literature, collaboration is always a key word, but it is not mentioned in the context of communication flow and the absence of information flows.

Analysis of all of the relevant data, including the interview results, leads to an understanding that the existing situation needs to be re-evaluated. Challenges, and many changes, will arise in the near future and need to be managed effectively.

In reviewing the literature research and the interviews, I realised that there is no mandatory or binding criterion, or even a handbook of criteria, that can be used in companies or has been in use in the case company. In a company like this one, which is growing rapidly and is in China, which is experiencing rapid overall growth, continual improvement, an aptitude for learning, and compliance play an important role in supporting companies to react quickly to changing situations, to a changing environment, and to changing demands.

Below, in sub-sections 6.1.1 to 6.1.6, based upon the outcomes of the interviews, I summarise six recommendations regarding change management generally for middle managers working in the joint venture and for similar cross-cultural contexts.

\subsubsection{Interface team}

As with the joint venture, firms can use an interface team, as demonstrated in the collaboration and communication model (Figure 12, p. 100), since the communication channel with the other firm in the joint venture should co-ordinate all issues pertaining to the 
special technical departments and should let all employees collaborate and exchange with the central headquarters. Via the interface team, the engineers and planners working in such a joint venture could remain in communication with central headquarters and with each department there, and could communicate internally with each department of the joint venture to clarify matters and communicate information concerning technical issues or standardised new processes or changes. This may be a way to solve the communication problem and enhance collaboration both within the joint venture and with central headquarters, as desired from the middle managers by upper management.

Moreover, it is important to have an understanding of Chinese and German cultures. In this regard, the interface team contact staff at the central German headquarters should receive training as regards Chinese national culture and a contact key-account function should be established, such as a planner or engineer who is in regular communication with this interface team and is trained to understand German national culture. Furthermore, regular on-site visits at the joint venture are required for the interface team employees in order for them build up a good working collaboration, come to know one another personally, and be able to strengthen communication and collaboration. As shown in Figure 12 (p. 100), collaboration is one of the important outcomes of the interviews and is a basic building block for the new conceptual framework. The key-account staff member should also be allowed to travel regularly to the German central headquarters for face-to-face exchange meetings and in order to get to know people personally as this pertains to his or her capacity. This would furthermore enhance learning by foregrounding technical issues or process-wide changes directly on-site at the central headquarters and enhance communication and feedback to the existing organisation and teams. It would also be a considerable supportive function for the middle managers in terms of their communication with upper management and with staff and would improve the information flow from the central headquarters.

\subsubsection{The communication model}

Firms and their managers need to supervise change processes and should communicate change issues to their employees at the right time. In the case of the joint venture, this means that upper management should involve the middle managers as soon as possible in the greater organisational structure and in relation to major changes so that they can prepare their staff step by step for upcoming changes, and the plan can be implemented better. I mentioned the interface cooperation team in relation to the changes required in processes by the central headquarters and the key account staff in the Chinese departments in Beijing. Communication is important 
when changes occur quickly and continually in the course of daily business. As analysed using the Zwicky morphological box, this has an immense meaning for work in a joint venture when two firms are working together as one corporate culture and one company and are promoting the interests and aims of one company. Lack of communication means poor change management since changing processes or changes in major organisational tasks are not communicated at the right time, making implementation difficult. Effective communication would help retain staff on both sides. Additionally, on the Chinese side, implementing technical improvements, such as providing all employees with company phones, this would demonstrate equality - as was mentioned by a German middle manager no. 2 (Table 2, Section 3.3.3, p. 74) and analysed in Section 4.2 (p. 92). Managers have to know that their staff are the key to communication with the central headquarters and they need to be involved in this in some manner. This can be effected either by means of an interface team, with the establishment of a key account function, in each department in the joint venture, as described in Section 5.2.1, or by finding a solution or implementing a regulation that employees, such as engineers and planners, can contact their counterpart departments and employees at the central headquarters, as they are both involved in the same processes and manufacture the same brand of car.

\subsubsection{Multiplicator principle}

Understanding culture on both sides of the joint venture will help to better train and qualify Chinese or German employees in the company and in the relevant department. The employees of the joint venture should be qualified to implement manufacturing processes of the required quality and to bring their understanding of national culture to the cooperating partner as it is part of the daily business to discuss such matters and to communicate with one another. Misunderstandings due to mistranslations may lead to wrong decisions; however, if an understanding of the other culture exists, understanding might be easier for daily operational tasks in the production department. It is also important to include to each other's working style and the daily working habits of the Chinese and German cultures when working with and teaching employees, in both China and in Germany, but especially when teaching in China and implementing the processes and standards of the central headquarters for Chinese staff. From my general experience, a useful tool for enhancing cultural understanding is the use of the multiplicator principle in training; that is, for the purpose of qualifying them, one or more people teach others, as described by experienced a German middle manager no. 1 (Table 2, Section 3.3.3, p. 74) - he stated that he had seen that the multiplicator principle functioned well at the central German headquarters. He wanted to implement this kind of process of obtaining 
qualifications in the joint venture too since staff fluctuation was high and one-by-one training could not be implemented. It is always better to qualify the Chinese staff in Germany, or at least by using a German expert, in order for them to implement the standardised processes used at the German headquarters to produce the same cars and to familiarise them with the equipment, $90 \%$ of which is the same, and the suppliers, as mentioned by Chinese middle manager no. 5 (Table 2, Section 3.3.3, p. 74). The multiplicator principle could also be used by selected multiplicators, who can be also Chinese employees, to train and qualify staff. Based on existing processes and actual themes and topics, demonstrating the German spirit in the plant would be sufficient to give key people on the local side or the key process owners in the joint venture the option of travelling to Germany and staying for a longer period, such as 3 to 6 months to be trained and qualified directly at the headquarters. As mentioned several times by both the Chinese and German middle managers, it is mandatory to do so.

\subsubsection{Understanding national culture}

Understanding Chinese culture is important since the joint venture company is based in Beijing and all the employees live and work in China. However, whether one is a German middle manager or a Chinese middle manager, it is also important to understand one's own culture. Support is required - and supporting one another enhances mutual understanding. German culture is part of European culture: if one looks inside many German factories, one does not see only German people working. Workers in Germany are an interesting mix of different cultures within an intercultural framework (Section 4.5, p. 124). Chinese people find it interesting to see all of these nationalities working together, as mentioned by Chinese middle manager no. 2 (Table 2, Section 3.3.3, p. 74). In the plant in China, one sees only local people employed by the Chinese joint venture partner; however, as mentioned by Chinese middle manager no 3 (Table 2, Section 3.3.3, p. 74), if one examines the German expatriates in the other departments, many of them have different cultural heritages but are hired as experts by the central German headquarters. Of course, German expatriates are also present to support local employees and to develop them as experts in special functions. I think it is important to bring people closer together in order for them to share the same spirit and also to promote their own culture, as indicated in Section 4.2 (p. 92 ff.) and reflected in my own observations in Section 4.4 (p. 120 ff.). Sharing national culture on German side and sharing national culture through living and working in China is vital to business success. 


\subsubsection{Combining national culture and change management}

The combination of culture and change management means bringing people together in a process of growth. Working together sometimes means being closer to co-workers than to one's own family members. Therefore, it is important to have joint workshops, planned activities, and social events, such as team dinners after work, and to combine team events with lunch or family days. This entails guanxi, as described in the literature review (Sections 2.1, p. 29 ff., 2.2, p. 44 ff., and 2.3, p. 52 ff.) and as mentioned by the interviewees. Both the German and Chinese middle managers stressed the importance of relationship-building skills and national culture (Section 4.2, p. 92 ff.) for enhancing collaboration. This recommendation confirms the appropriateness of research question 2, as formulated in Section 1.3, p. 20 ff., and Section 4.7, p. $130 \mathrm{ff}$.

National culture, alongside organisational culture, is a dimension of change management and should be integrated into deliberations, as mentioned by the interviewees. This is especially the case in a joint venture and when two different national cultures, such as the German and Chinese cultures, work together.

\subsubsection{The corporate culture of automotive joint ventures}

Understanding the company's corporate culture and realising the vision of this culture is one aspect of a joint venture; however, much more important for working in a joint venture is understanding and accepting the corporate culture of the partner in the joint venture. It is also important to recognise and understand the corporate culture of the joint venture as a combined one. As described by the middle managers, it is necessary to maintain the third corporate culture that is lived in a joint venture company. Therefore, it is of immense importance that the middle managers understand the differences and accept the corporate culture of the partner firm. Furthermore, working together is necessary for realising the vision of the common corporate culture of the joint venture.

\subsection{Limitations}

In this section, I discuss the limitations of my work and how these limitations have affected the scope of my research objectives, the methods I have used in my thesis, and the scope of literature that has been used for research. For this study of the joint venture, only one specific department was analysed. The findings from the interview sessions and the subsequent analysis are the basis for the recommendations and the ideas behind improving the weak points in order to make life easier for the middle managers working in the joint venture 
company.

Furthermore, the period during which I observed the department preceded the ramp-up phase of production in this company, so there is no reflection on how the middle managers would react if they were pushed hard and had to work under pressure (Section 3.3.1, p. 69 ff.).

While corporate culture is described as important in the literature and is a matter that requires consideration in order for companies to achieve positive results, it sometimes seems that management has not paid particular heed to it. This is what I read between the lines in the course of the interview sessions. I am of the opinion that several different matters are responsible for the lack of attention to corporate culture, even without considering the different national cultures and the combined corporate culture in the joint venture. First, from my perspective, based on the responses of the middle managers during the interviews, it is a lack of understanding and deep insight into change management that is the issue. This is especially the case in companies in which the focus is on the product, as is the case here. The upper management of the automobile branch is always focused on the product and on operational work in order to avoid quality issues, for example, while middle management focuses on technical issues, whether employees need to be hired, and on technical professional expertise. Issues relating to corporate culture and leadership style, or their association with conflict, are not really on the radar of many middle managers.

The second point, in my understanding, concerns largely intangible soft factors. With the multitude of tasks managers need to focus today, they often do not have time for these socalled soft factors. Soft factors concern personal issues. This is the thinking of many people, and, in general, middle managers do not want to explore these depths. During the interview sessions, I realised one more point: middle managers have the notion that there should be more focus on aims, requirements, the standards of processes, and so on that need to set up and communicated by the central German plant. All other topics they can somehow regulate by themselves over time. The final issue I want to mention is the financial factor, which is always important for every company, and savings, which are always part of the focus of all managers. If one can move forward and at the same time save money, then one does not have to spend money on things such as measurements for optimising corporate culture, bringing people in from the outside, organising workshops, providing language courses, sending employees on business trips to the headquarters in Germany to become qualified, and so on. When managers are confronted with economic crises and financial hard times in companies, then it is even more important to search for ways to reduce costs since the budget of the entire 
department is being cut. In such cases, which things might be the easiest to downsize or even ignore? Might it be corporate culture?

When companies come together through a merger or any other kind of collaboration, such as a joint venture, and management pays no attention to the consequences of different cultures working together, then losses from friction may occur. This could have been handled easily had there been adequate planning and attention to cultural matters with respect to the changing situation for both employees and the company as a whole, as indicated by Kotter and Cohen (2002) in Section 2.2 (p. 44 ff.).

Here, I want to add that the data collection method using semi-structured interviews, the sample size and the sampling, the piloting of the interviews, and the entire data analysis chapter are unique to my thesis. No secondary data formed part of the analysis since the interview sessions were unique. My own observations are also unique in that no other observations are similar to those presented in Chapter 4.

Corporate culture can affect a good collaboration in terms of its internal organisation and, at the same time, can be a useful pre-condition for a company that takes care of its environment and reacts to its own needs and demands. For me, if a company wants to do something for its corporate culture, wants to enhance and improve it, this does not mean that major changes are required in the company. If changes can be undertaken in step-by-step fashion through a number of small interventions, then the entire situation can be improved, as indicated by Chinese middle managers no. 1 and no. 4 (Table 2, Section 3.3.3, p. 74) and German middle manager no. 1 (Table 2, Section 3.3.3, p. 74). However, if a company faces a significantly complex and fast-growing situation, such as is the case in the company that is the subject of this study, then it might be better to implement moderate adaptions, as described by Kim et al. (2016) in Section 2.1, p. 29. If one is attempting to deeply reorganise the internal workings of departments, then issues need to be recognised at the middle management level so that middle managers can talk to their staff about them, since it is these managers that form the bridge between their staff and upper management, as demonstrated in the analysis in Section 4.2 (p. 92). Frequently, companies or managers think that the change they require needs to be a paradigm shift and that to reach the best flexibility and enhancement of their staff and departments, they need to change their way of thinking and their actions in order to be more competitive than other companies. When examining the interviews - and as was mentioned by middle managers who had worked at the company for a long time, that is, the highly experienced middle managers on both sides - the meaning and relevance of corporate culture 
is not actually considered a success story; however, today it is becoming increasingly important and middle managers recognise that their situation in the company and their collaboration is becoming stronger. This is even more so when one examines the combined national culture of the two companies with two corporate cultures that have now grown together. In my understanding, something like a new, combined corporate culture seems to have been established.

\subsection{Future Research}

In summary, I can say that my research journey so far has been very exciting. According to Bolton (2004), reflection is more effective than merely reading and following instructions in the literature. Thinking back to three to four years ago, I was wondering how to manage my doctorate while combining it with full-time work and my family life. By understanding that the quantitative approach would be less helpful for me, and in discovering that I could conduct interviews with the middle managers and be an inside researcher in the joint venture company, I decided to take the methodological path of semi-structured interviews within the qualitative approach.

To my mind, the world can be described as a social construct. This is especially the case regarding research findings about communication, collaboration, and information flows (Section 4.2, p. 92) that need to be enhanced and implemented better. Many researchers and practitioners base their work on quantitative research, which may involve a much greater number of interviewees; however, the inflexible nature of this approach made me decide against it. For future research, I would recommend making use of more insights into companies and of expert know-how to obtain feedback to contribute to knowledge and practice. It was essential to obtain all the information from the interview sessions I conducted to provide an immense contribution to practice for practitioners.

When I begin to keep a diary and record my experiences (Section 1.3, p. $20 \mathrm{ff}$.) in the course of my DBA journey, I recognised that there are a variety of beliefs pertaining to my research area. I gained many new insights from the practical interview sessions with the middle managers which I could not find in the literature research. During the interview sessions, the diary also helped me to reflect as the interviews were conducted over a number of days. Methods such as the use of the morphological box based on Zwicky, combined with the decision matrix, helped me to gain new insights into my research. However, it was not merely the interview sessions that influenced me; by observing the middle managers, I gained insights and knowledge for my research. The several discussions with the action learning set 
group members, with my two DBA supervisors, my family members, and my colleagues at work helped me considerably enhance the DBA thesis, improve my problem-solving skills, and to make this thesis an important piece of research for the joint venture. Publishing nonmagazine materials as articles internally in the company was one major step during my DBA, since I had never previously been encouraged to write articles and papers. It was very interesting for me to share my knowledge, research interests, findings, and new ideas with others in the company. Being a part-time lecturer in DHBW Horb and teaching automotive studies was another major step I attained during my DBA.

For future researchers, it is important to gain knowledge about change management in relation to cultural differences based on the know-how and experience of employees and managers who can provide information, offer their knowledge, and want to talk about the experiences they have had.

In conclusion, I can say that changing processes, change projects, and change are not merely part of the title and topic of my research - they were part of the DBA as a whole and of my whole life. On further examination, I can imagine connections relating to cultural differences between China and Mexico or between Thailand and Russia. These are the next two possibilities I imagine while working for the same company and while exploring new insights into cooperation, collaboration, and change management as these concern corporate and national culture in the automotive sector. 


\section{Chapter 7: Reflection}

In this chapter, I describe the journey of my DBA from November 2015 to the present. The research journey should be committed to writing, as many well-known authors (Pollard, 2005; Moon, 2004; Schön, 1983), my module tutor, and my supervisors have advised. In the course of the analysis of the interviews with the middle managers, I increasingly recognised this as being important. Reflection is important for middle managers who work with staff; it is especially important if changes occur in daily life. Reflection on changing situations makes it easier to adapt to those changes.

Here, I illustrate the difference between the past and present research, and why my personal attitude changed in the course of writing the assignments for the DBA programme, my RD1, and my DBA thesis. Mintzberg (2018) highlights that reflection as very difficult for human beings to think about and for us to add knowledge from lessons learned. This is especially the case in attempting to distinguish between what went well and what not so well with a project, for example. From the literature, I considered especially Bolton (2001) and Moon (2004) when reflecting on my DBA, and I also considered their discussions on reflection when I discussed the reflection component of the interview sessions with the middle managers (Section 4.6, p. 127 ff.). Confucius (Southhill, 1910) mentioned that we can learn wisdom from three important things: reflection, imitation, and experience. Reflection helped me to find answers to my research questions and to close the research gap. Part of this chapter shows my reflections during the whole period of my DBA; this I link to the reflections of the middle managers during the interview sessions. I show the importance of reflection for my work as a whole and its importance for my research questions and when critically reflecting the findings.

In the following section, I discuss my research journey and describe my professional development.

\subsection{Research Journey and Professional Development}

Self-reflection is key for effective leadership. It is important not only for me as researcher and supervisor, but also for those middle managers in the Sino-German joint venture company that forms the basis of this study. First of all, it makes sense to glance back and examine what went well and what not so well in the course of writing my DBA thesis.

Following Bolton (2001) and Moon (2004) and as discussed in Section 4.6 (p. 127 ff.), this thesis describes how reflection must be considered from various perspectives, at different 
levels, and as an active process. For me, it has been - and will continue to be - important to see the process of reflection as one that has improved my life as a whole and those of the middle managers.

All the different viewpoints that arose and kept me busy reflecting on myself. Germane here are the fact of being an inside researcher and working with the middle managers I studied, who are involved in some of the same projects as I am. The variety of feedback I received during my research journey and the beliefs I brought with me, helped me and pushed me forward through the literature review and the methodologies I studied and ranked. I integrated all of this into a coherent approach and realised how important it is for the middle managers to reflect. As an inside researcher, I was aware of the matter of language issues but had not realised that it was important for all of the middle managers to reflect on this. Several of them mentioned it as being important (Section 4.3.3, p. $114 \mathrm{ff}$.). From the responses of the middle managers, I understood that they mostly appreciated the importance of reflection and that they automatically started to reflect when I asked them questions about what had gone well and what could have been done better in terms of lessons learnt. Sometimes I realised that they should and could do more. This is also one of my contributions to practice: to get the middle managers to learn how to reflect in order to improve relations with their staff and to develop a better understanding of the changes occurring in the joint venture in which two different corporate cultures have melded into one.

In the interviews, the middle managers reflected on some of the challenges in the joint venture that they had confronted so far and those that they faced daily. For them, a considerable challenge is the finding clustered in Section 4.2 (p. 92 ff.): the qualifications and hiring of local employees in Beijing due to the market and their national cultural background. Another challenge seems to be improving communication, information flow, and collaboration in order to attain a better understanding of what is required to fulfil the targets relating to daily business in the production environment. It was impressive to observe how some of the middle managers reflected on their challenges. What was much more important for me, however, was understanding why the middle managers were not using existing tools and knowledge to reflect, why they only partially reflected so that I always needed to ask them to reflect. Was it a matter of further training that was required? Should the middle managers learn more about how to improve themselves and not face so many issues in collaboration? Communication is an issue that is common in the literature (Section 1.2.3, p. 19; Section 2.1, p. 29 ff.). Many authors (Ghemawat \& Reiche, 2011; McGurk, 2011; Kotter \& Cohen, 2002) have researched 
ways to improve communication. However, I have the feeling that a far greater challenge for the middle managers was the combined constellation of all nine findings. The conceptual framework in Figure 11 (p. 93), which was formulated following the analysis of the interviews shows the scale and complexity of the challenge.

Contributions to practice should be an active process, as Bolton (2001) and Moon (2004) describe. Constant reflection was also overwhelmingly important while I was writing my DBA and while I was listening to the middle managers in the interview sessions. I experienced a considerable learning process in the course of the systematic literature research over the four years of the research, as a result of observing the middle managers as an inside researcher, and as a result of having conducted the interviews and the analysis. For this reason, this thesis has described my own development and my changes of mind, ideas, and paradigms. It has shown me how I have improved and how the middle managers can support their staff to improve by means of their reflections (Section 6.1, p. $159 \mathrm{ff}$ ). I had the feeling that, for some middle managers, reflection is part of their daily work; they always answered my questions by reflecting on each of them, though, for most of them, I had the feeling that it was very difficult to reflect and that they needed to learn and need to improve. The responses of some of the middle managers, both Chinese and German, gave me the feeling that they reflect unknowingly and had only partly reflected on my questions. The challenge for me in relation to this limited reflection was to understand and to ask additional questions about the past, such as whether they had already had some form of training in cultural difference or in relation to collaboration between China and Germany. The challenge for me was to understand whether reflection was lacking or whether improvement was necessary based on a lack of learning or experience.

Furthermore, as regards improving, Bolton (2001) emphasises how important strategies are for changing one's life and for reflective personal change. Some of the middle managers, both German and Chinese, could reflect very well; this helped me to more easily undertake the analysis afterwards based on the reflective parts of their answers. I maintained an awareness of this fact in the course of working on this thesis and have done so in my life as a whole. This awareness has extended to my environment and should extend to the middle managers' environment - one in which they work with staff and help them to avoid fearing change and be more open, even when working in an intercultural environment. As change management and culture form a substantial part of this thesis, I have shown - as Bate (1997) avers - how different kinds of influences are important for changes in one's life, and how difficult it 
sometimes is to accept these changes. However, the past years, including aspects such as the modules organised by the university, have made a considerable impression on me. I have become aware of how I made quantum leaps from one module to another. In addition to my personal and my business life, I have described the period of my research and the connections I made since starting the DBA. My private and personal life played an enormous role in my decision to embark on the DBA programme.

This chapter shows how I started the project in November 2015, how I personally improved my research, how completing each module and writing the assignments helped me to develop my thoughts, and how I could understand the importance of reflection for the middle managers and for closing the research gap by answering the research questions. I can make use of my thesis results in my professional working life, and I am proud of having had this experience to gain knowledge, to apply that knowledge in practice, and to contribute to this field of research by supporting the middle managers in automotive joint ventures.

\subsection{Research Choice and Philosophical Attitude}

When I commenced the DBA programme in November 2015, philosophically, I viewed the world around me from the perspective of an interventionist. Learning through action seemed to be a suitable way to find a convenient method for middle managers to reduce fear and resistance among their staff. I recognised during the interview sessions how important reflection should be for middle managers. For me, the focus of interventionism is on fostering knowledge and experience. Resistance can arise if employees begin to think that, aside from the elimination of jobs, the changes they encounter will have a negative effect on their own positions. In addition to cultural differences, age plays a role in this regard. Thus, in the interview sessions, my interactions with middle managers of different ages and different levels of experience showed me that, whether one is Chinese or German, encounters abroad in an international environment help one to develop an understanding of national culture. The same applies to experiences in one's professional life. The necessity of communicating effectively was one of the main findings that developed out of the interview sessions; from these I learnt just how much knowledge one can gain by asking questions and talking with others. Communication and collaboration can help to improve a group as a whole, as well as helping one to understand what others need from one another in order to improve.

This entailed creating a conceptual framework based on a literature review (Figure 5, p. 53) and then adapting this framework as a result of the analysis of the responses provided by the middle managers (Figure 11, p. 93). Berner (2012) states that different cultures brought 
together through mergers or joint ventures have to confront different world views, norms, and values. This is indicated in Sections 1.1 (p. 9) and 2.1 (p. 29) and is confirmed in Section 4.2.3 (p. $104 \mathrm{ff}$.) of the analysis chapter by the responses of middle managers. Such encounters may lead to pressure at work; however, they can also be productive because they may generate better solutions than one culture could on its own. Blending cultures, as is the case at the plant in China, certainly supports the fostering of diversity and can be productive and efficient. To my mind, as a researcher, there was one significant tendency that I wanted to analyse in depth in the interviews. Collecting statements from the middle managers involved obtaining data that reflected their viewpoints. It was very important for me to have a practical viewpoint because it is not so easy to obtain information from such a viewpoint, and it is especially rare to be an inside researcher. Examples from their daily shop floor experience, as can be observed in the analysis chapter (Chapter 4), are illustrated in the new conceptual framework (Figure 11, p. 93). A practical viewpoint can aid understanding of theoretical concepts; future researchers should note that it is important to capture practical viewpoints from interviewees.

I began shifting to a constructivist viewpoint (Section 1.2, p. 14), which was not easy. I understood the constructivist viewpoint much better after gaining further insight into my surroundings in the company based on the viewpoints of the interviewees. I selected the qualitative method for this thesis and, through existing thoughts and concepts, have constructed a theory of how to assist middle managers to reduce resistance to change on the part of their staff by recommending a suitable method and theory to the former. I changed to a constructivist viewpoint following my reflections in the course of the DBA assignments, before the approval of my RD1, by undertaking reflection and enhancing my ability to reflect. This is also a recommendation for those middle managers I talked to in the interview sessions: to integrate reflections on changing situations in order to improve. I understood that the constructivist approach would help me to consider the social context and social outcomes of the different cultural viewpoints that were reflected in the answers of the middle managers.

\subsection{Action Learning Sets}

The doctoral students in our course set up an action learning set (see the literature review, Section 2.1, p. 29) in Cologne in November 2015 in the course of the first module session organised by the University of Gloucestershire. To this end, the plan was to make one phone call each month as a form of regular meeting in order to exchange information on all forthcoming topics and to support each other with advice. Half of the course members did not 
take part in the first meeting, though three of us met and it was helpful from the start. On the second occasion, the whole doctoral student group met. This did not really work out as everybody was working in full-time jobs and living in different places. To catch up with all those in the doctoral student group and plan a time that suited us all was not easy. Even considering a timeslot on the weekend was not easy since two of the doctoral students worked on weekends. The action learning set was a helpful new learning environment for me due to the exchange of literature sources and the exchange of reflections and lessons learnt. The whole doctoral student group decided to form up a WhatsApp group so that every time a person in the course voiced their concerns or issues directly using WhatsApp, a response could always be provided by at least one of the group members.

However, after I concluded that having an action learning set would not work for the doctoral student group - as almost the half of the course missed the appointments - I contacted a colleague who had started the DBA course in 2014. I participated in an action learning set with him every two months in the form of a personal meeting to talk about problems and to exchange ideas about my situation. I looked forward to these meetings since he was a year ahead of me. This was a positive experience for me as I was able to see his viewpoint about having regular exchanges with doctoral students in an action learning set group. His experience improved his doctoral thesis. He told me about reflecting on the past and how important it was to do so for the DBA process as a whole. He explained to me that students sometimes get into bad moods and difficult situations when writing their assignments and DBA theses. He told me about his action learning set group and the experiences he had had so far within that group. He told me about all the sleepless nights he had had and all the problems which arose with his work, his wife, and his son - he always felt remorse about the lack of time spent with his family. It was a good decision to stay in touch with him as I did not feel alone. He explained me what my upcoming year of study would be like. He was facing the same issues as I was in trying to obtain a doctorate, and I recognised how important it was to hear about another person's experiences. It was also interesting for me when he told me about the experiences he had had in his interview sessions with different companies. His topic was totally different from mine, but he helped me to reflect in order to formulate good questions for the interview sessions and to be well prepared too. When the middle managers did not begin to reflect automatically while answering the questions, I asked the question again in order to allow them to better reflect and to provide me with examples from their experiences in their daily work of collaborating with their staff and facing resistance to change. They had to provide solutions in the face of changing situations and had to incorporate both national cultures and corporate culture to engrain a different way 
of understanding.

This was especially the case with the RD1 approval quality loop in the DBA programme, which is the quality loop for obtaining approval for the DBA project as a whole. It was extremely difficult for my colleague who was one year ahead of me to obtain approval, and it was not easy for me either - I struggled for 6 months with RD1. Two more members who started the DBA course programme with me later joined our action learning set group. The four of us stayed in touch - it was a good mix of different DBA topics and different supervisors, and after the first two years had passed, we were on different implementation levels of the DBA. Together we decided to hold a monthly meeting with two colleagues in the current course, one from a former course, and me to establish an action learning set. This also provided further motivation for all of us to talk about the current level of one another's work and to discuss the challenges each of us had experienced in the previous months. It also helped us to stay on track all the time and to be able to report again in four weeks about what had happened with our work during that period - at least that was what it was like for me. We met via telephone conferencing, email, and WhatsApp. This helped us submit our assignments on time and allowed us to talk about upcoming issues and problems. We met personally, face-to-face, twice a year to exchange ideas, to talk about the hard times, to support each other by listening and giving each other advice, and to reach our goals together. We were able to spend time together over dinner and sometimes also laugh together about past experiences by reflecting on them. Of course, everybody was around at the time when the projects would be approved though RD1 process. Yet, at around the time of the RD1 process, we were no longer working according to the same timeframe as one of us might have moved faster, while another required more time to move forward. Since the DBA course is part-time, it was often not easy to find a time and place for such exchanges. This was especially the case for me when I left for China in July 2017 and moved to a different time zone.

As a group of four members, we were always open to talk about ideas and insights into our research. This process helped me to reflect on each module and the work required to complete the assignments so that I might better understand the tutors' lessons, their viewpoints, and the meanings other colleagues gained from each lesson, from their studies, and from preparing their assignments. Talking about these things was refreshing and reflecting on everything produced good results. In module DB8001, I learnt how to reflect in a better way, especially in relation to my doctoral research as I had a recording in a monthly diary, for example, to reflect back on from time to time. In module DB8002, I learnt for the first time how systematic literature research really works and learnt to criticise everything I had studied and learnt before, even the 
manner in which I had previously conducted the literature research.

When I moved to China with my family at end of July to begin my new job in Beijing, it was not at all easy for me to stay in touch with the action learning set group and my student colleagues due to the considerable time difference between Europe and Beijing. However, I still tried to find time to talk with them on a one-by-one basis via Skype. I quickly realised how difficult it was for all of us DBA students to pass the RD1 process in order for us to obtain approval for our DBA projects. For me, this was a useful time for learning, reflecting, and updating and correcting my RD1 once I had received feedback from my supervisors. I learned much during this period. Receiving final feedback from the Research Degree Lead at the University of Gloucestershire in Cheltenham and Gloucester pushed me to progress and to look ahead. I was happy to hear that I could move forward once I had received approval for my DBA project. This occurred in December 2017, and it was good motivation, as I had been in China for 4 months already. And yes, for me, it was the right decision to change my job, take my family, and move to China to join the joint venture company as an insider researcher (Section 3.4, p. 81). I learnt to reflect. I had experience of the headquarters which I brought to China; in China, I gained experience and knowledge aboard within the same company. I observed the middle managers and talked with them in the interview sessions in order to find appropriate answers to my research questions and recommendations for the middle managers themselves. I managed to close the research gap I had found in the literature review, or at least to come a little closer to the answers that would close it.

At that time, I realised that I was the only one in the action learning set group who had already passed the RD1. At the time, it was difficult for me to stay in touch with my learning group members because they have mentioned that I was further than them. However, to my way of thinking, it was important - I could help them based on my experience of RD1 and further research I had conducted, and they could help me with their feedback. Though not being in contact with the members of the group had not been a problem for me, I wanted to be in touch with them regularly again. It was a great support to me to exchange my ideas and preparatory points for the interview sessions with them. They reviewed my questionnaire and together we checked my interview questions. This was of great importance to me and it was very helpful to obtain their advice. They were really strict and pushed me with many helpful questions as well as giving me many ideas about how to improve the questionnaire and about what content I should think about to prepare me for the main interview sessions. The exchanges with the action learning set group were not only important for my DBA - they were also extremely important for my personal development and allowed me to learn from my daily working experience and 
to improve myself as a supervisor at work.

\subsection{Personal Development}

With regard to my project plan for my DBA studies, I found that change was not only part of my research topic but also played a major role in all of the different stages in the DBA programme. I had had changes occurred in my life during the period before starting the DBA programme - changes in quality of life, finances, and in the amount of time I spent with my children, who were aged two and four at the time I started the DBA. My family needed my much more attention than before, especially on the weekends since no other family members and friends were present at the beginning when we moved to Beijing. However, this changed after the first 6 months and I was happy that they had new friends and that I could focus much more on my DBA again. There were also major changes in my work life. During the time of the DBA, I had three different managers and twice the department in which I worked was restructured. Then there was also the move from Germany to China. On one hand, I experienced change management based on organisational restructuring myself and saw how difficult it could be for employees as well as managers. On the other hand, I was very busy with my DBA and with all the new situations in my daily business life.

I found that in reflecting on the time before the DBA and during the DBA, from October 2015 to January 2019, I experienced times of high motivation and times of lower motivation due to the substantial amount of work in my business life. This I also could see in the reflections of the middle managers - how they faced boundaries with regard to their motivation levels when working with their staff to enhance the latter's level of understanding of changes. However, getting back the assignments and the RD1 result made it easier for me to move forward and brought the degree closer, making it much more of a reality. My whole life, my opinions, and my perspectives changed. I started thinking in terms of a wider view and found myself accepting different kind of problems in my business life. I started thinking about different kinds of situations. The semi-structured interviews were a major highlight of the DBA study as a whole since getting feedback and input directly from middle managers and talking about their experience and their point of view was incredibly useful and stimulating. The preparation phase took long time - I changed the questions and received feedback from my DBA supervisors. During the interview sessions, I started reflecting on what I had learned during the systematic literature research, such as the concepts of the main authors regarding change management. I also thought about culture in the joint venture. It was interesting to hear the different answers and to understand that the Chinese and German middle managers 
had a common way of thinking. As a result of having conducted the literature review, I could connect some of their answers to literature; however, some aspects were new to me. For example, one middle manager could observe two corporate cultures, the Chinese company's corporate culture and the corporate culture of the German headquarters. In addition, he saw a common corporate culture in the joint venture company in which all three corporate cultures were accepted and lived out - I had not found references to this in the literature review. This made the interviews and the writing of the analysis chapter very interesting.

Looking back over my time in the DBA programme, I found that I had undergone significant stages of personal development. For my point of view, first, when starting with the modules, I gained many new insights into how to undertaken better systematic literature research, for example. Every module and the exchange with the tutors and the students in the DBA programme helped me to improve in the theoretical content as well as with my own topic and my research. Additional possibilities to visit the university to attend courses and classes or to exchange information with the university staff and my own supervisors was additionally an improvement step for me in that I received critical and positive feedback that improved the content of my DBA.

I now know that I want to move forward and continue to teach. I realised what a wonderful family I have and, looking back, I can reflect that, even during difficult times, I could take out my DBA and work on research. I am happy to support the middle managers in their daily working life in the joint venture with the recommendations from my work. They can use them to improve change management while supporting their staff and while keeping national and corporate culture in mind too.

I want to do more research and I want to move forward with the topics of national cultural differences, cultural improvement, the corporate culture of mergers and joint ventures, and change management in an intercultural aspect in future after finishing my DBA. I can and will do it.

\subsection{Ontology and Epistemology}

Transferring to a new company in Germany as an engineer in the quality management department in 2013 and starting the DBA in October 2015 helped me develop my philosophical attitude (Section 1.3, p. 20). I switched to being more of a constructivist and moved forward with qualitative methods in order to find the most suitable answers to my research questions. For me, being a constructivist means showing how people share their 
experiences and knowledge with others (Berger \& Luckman, 1996). Indeed, this was the most familiar aspect that I took from all the modules and my studies, from Reflective Professional Development to the present in the DBA course.

I started rethinking the beliefs I had developed as an interventionist. It was indeed a change to think as a constructivist, but it was much easier for me to do so because I realised it was more applicable to me and my work than being an interventionist was. I rethought my research topic on change management and cultural factors as these relate to the behaviour of German and Chinese individuals in joint ventures comprising German and Chinese automotive companies. Living and working in China as an expatriate was interesting for my whole family and for me. Working as supervisor during my time at the joint venture company, I realised that one begins to understand the way of thinking of one's Chinese co-partners and employees - one even start adopting behaviours of cultural thinking. My children started learning the Chinese language very quickly and enjoyed eating Chinese food and playing with Chinese children. This was amazing for me to observe, and I enjoyed living and working in China. As the German middle managers mentioned, they recognised very quickly that they needed to adapt to the different culture, language, and to working in a joint venture with two corporate cultures.

After my first meeting with my supervisor, Prof Dr Marc Helmold, he encouraged me to write and publish articles. This was the first time anyone had encouraged me to write and publish. I started writing the first article. He also motivated me to write further articles and I began doing so for the web channel of my current firm. After I moved to China, I encouraged the department managers to open a channel on the WeChat on-air channel, which is popular in China, and have an on-air WeChat page for the department. WeChat is very commonly used in China and is comparable with WhatsApp. All of the employees in the department started to write articles. It was so much fun for the employees to talk and write about what they were doing and the projects they were involved in. They reflected on the projects they were driving and on all the innovative topics they were involved in. The piece I am working on now is a report about an internal workshop in Germany organised by Chinese employees in the SinoGerman joint venture. The workshop involved various departments, the staff of which discussed integrating an electric vehicle into the main production line and implementing the processes required for this new era of automotive production. The report will be published on the firm's internal WeChat posting page in China and translated into the local language. It provided me with a great opportunity when my supervisor advised me to write from my perspective and experience. 
Beyond these activities, in June 2016, I started supervising students writing bachelor's theses. From January 2017 to March 2017, I supported a bachelor's student doing his practical semester. He wrote his assignment on the 'digital paper factory' in the department in which I worked before I started in Beijing. From January to March 2018 and January and March 2019, I took a number of bachelor's students from Germany to China so that they could learn to work in an international environment. I began to encourage them to write and publish for the WeChat channel and for the central German headquarters of the company. Supporting students helped me to reflect on my research topic in a different way, and I have learned what reflective teaching actually means.

I also learnt what reflection means for my research questions and, with this reflection chapter, I can see that, during the interview sessions, many reflections were made by the middle managers, whether knowingly or not knowingly. In this chapter, I highlight the importance of reflection for practice and knowledge. I also suggest that the middle managers keep being reflective in order to support their staff and teach them, as well to be more reflective in order to learn and improve together for the sake of the company and break the ice together during changing times in the company. The qualitative research path I followed and the interview method I used are highlighted in the next section.

\subsection{Impact on Research Questions and Interview Method}

Many authors (Schein, 1996, Section 2.2, p. 44, Section 2.3, p. 52; Thommen \& Grösser, 2012; Section 1.4, p. 25) have pointed to the need to include change management in international collaboration in organisations and to devote attention to this as a middle manager. There was still a gap in relation to how managers - especially at the middle management level (Wooldridge et al., 2008) - communicate change to employees and manage change (Speier-Werner, 2006; Thommen \& Grösser, 2012). This gap related to the research questions for my doctoral research topic (Section 1.3, p. 20). It was a matter of determining how middle managers in the Sino-German joint venture recognise and cope with factors associated with organisational change that might either inhibit or promote their awareness of the effects of cultural differences on the organisation, for example, the challenge they face with the language issue. There are two languages, German and Chinese, though another, a third language, English, which had not been learned as mother language in either culture, was the language the company used. The language issue relates specifically to these two countries, especially to their middle managers in the automotive factory who have experienced working in these positions in such a joint venture. In order to make the comparison between the 
Chinese and German middle managers, I had selected the company I work in to ensure better, closer, and faster access to such managers. I was familiar with them due to my work in another department, where I prepared the planning for the processes for the production department; however, as mentioned in Section 3.5 (p. 87) being an inside researcher also entailed subjective detachment. This step could either be positive or negative in relation to gaining knowledge or know-how in order to improve my research and obtain findings to close the research gap I found in the literature research (Chapter 2 and Section 3.2.1, p. 58) and to find specific knowledge and practice to contribute with subjective detachment by formulating recommendations for those middle managers. Being an insider researcher can be supportive if the researcher already knows the tasks, the ongoing projects, and is familiar with the persons interviewed; however, it can be negative if the interviewees are afraid of providing true information.

Being part of the organisation was a great opportunity for me to analyse the situation and to conduct the interviews. Another research objective involved identifying how cultural differences affect middle managers' change management behaviour as this concerns organisational issues in the German-Chinese joint venture. This objective was based on my experience of working in an international environment and having experienced organisational issues and change management with managers. Furthermore, it was reflected on by the middle managers during the interview sessions and provided me with insights to reflect on for my work and to let them reflect on to support their staff. Hence, I have been able to provide insights to the middle managers in order for them to reflect on the interview sessions and on my results in my thesis. I had already observed situations in which middle managers required help and needed to work on self-improvement, as was shown in the responses in the interview sessions. The qualitative research method, combined with a consideration of ethics and an evaluation of the interviews (Section 3.2.2, p. $63 \mathrm{ff}$.) was the best way to gain information about this situation. The eventual goal was to formulate recommendations for middle managers with regard to how they could help their staff in difficult times. It was also important to understand how to help middle managers cope with organisational changes. This also applies to the third research objective, that of formulating an appropriate conceptual framework for culturally based change management factors for middle managers working in such cross-cultural joint ventures. This was especially the case for changes in the corporate culture which may affect the behaviour of the subordinates of the middle managers. Further research could be valuable to close this gap - by providing best practices and recommendations for middle managers regarding how they can help their staff in such 
conditions - and how they can help themselves and their organisations.

Quantitative methods (Section 3.2.2, p. 63) were not considered because they would not show the truth of the issues nor provide help in this specific case, in my opinion, since I would not have been able to take my own observations into consideration (Section 4.4, p. 120) and would not have been able to ask questions that were not part of the prepared questionnaire. The specific case of collaboration in a Sino-German joint venture firm in China, with a joint venture partner in Germany for which the Chinese automotive sector produces cars, was a new insight in the literature for me. This is a new insight in the contribution to practice and knowledge, especially for middle managers in general - not merely those working in the automobile sector. The results can also be adapted for other companies.

I really wanted to undertake the research and help to close the gap I found in literature - at least a little. The brand of the German partner is unique. The best motivation for me to reach my goal and to show progress was to complete this research and open up future views for further studies in order to improve the practices of middle managers.

\subsection{Reflective Professional Development: The Future}

Rethinking the past and the present, it is difficult to talk about future; however, my plans for the future and for reflective professional development include development along academic, educational, and professional paths. In my development plan, I hope to improve on being a middle manager in the Sino-German company and, in the next three to five years, to move to the next management level and again become a part-time lecturer, though this time at a university in China, in order to support both local students and those going to China to study. My desire is to improve my reading and improve myself as concerns the topic of my doctoral research.

Commencing teaching at the Horb campus of DHBW Stuttgart opened my eyes - it felt like a fresh breeze passing through my life. The degree programme leader has given me the opportunity, following the completion of the DBA (Figure 13, p. 189), to begin teaching MBA students in Manchester. In the future, after finishing my DBA thesis, I want to stay in China and want to support Chinese students by being a part-time lecturer at university.

I started my research journey as an interventionist and transformed into a constructivist who, as described by Berger and Luckman (1996), understands that people share their experiences and knowledge with other human beings. In the course of my research journey, I recognised that I had made a significant change to my ontological viewpoint as an interventionist. I thus needed to adjust the methodology for my research. Using semi-structured interviews, I gathered 
information, especially hidden information that interested me. In reflecting on the past and considering the future, I can state that all of the points listed thus far led to me switching my ontological viewpoint.

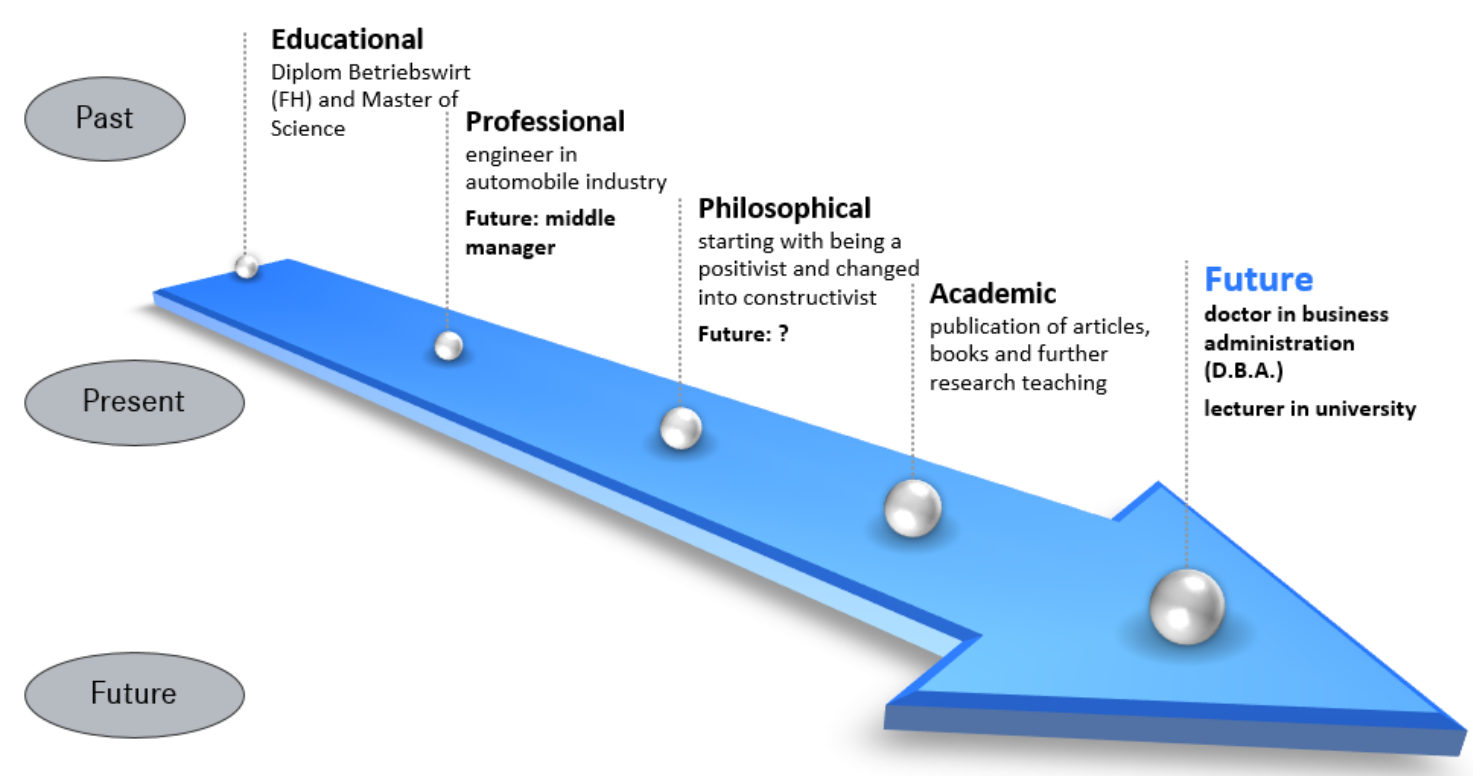

\section{Figure 13: Future plan}

Source: Ayse Yilmaz (January, 2018)

\subsection{Summary and Conclusion}

In summary, I can say, as I reflect on the past several years since starting the DBA programme at the University of Gloucestershire, that it was a pleasant time - though sometimes very difficult and stressful. However, obtaining approval for my project and for the research for my DBA in RD1 in November 2017 was a significant milestone. Receiving regular feedback from my supervisors on the updated version of my DBA thesis during 2018, I was happy to see that I could continue moving step by step to reach my goal of getting closer to closing the research gap. Reflective professional development is a process, as Pollard (2005) describes, that drives the doctoral candidate through development while learning during the entire period that he or she is writing the thesis. The combination of a full-time job, a family, and working on the doctorate was difficult to master. However, I have worked on it over the last three to four years with strict discipline.

A major part of my thesis has involved gathering information as an insider researcher from selected middle managers at the company at which I worked (as described in Section 3.5, p. $85 \mathrm{ff}$.). Reflecting on the interviews, I have to say that I learned much, especially about how 
reflection is important and how a lack of reflection can lead to forgetting, not improving, and not learning lessons. In such cases, middle managers begin to struggle with continuous improvement and can make the same mistakes as they have in the past. I also gained a considerable amount of information, such as that regarding the importance of language or the technical improvements that are required to improve international collaboration. These insights were also occurred in the analysis phase of my DBA, which followed from the interviews. The interview sessions helped me to formulate recommendations and to create a new conceptual framework for research with new insights. Together these form a contribution to knowledge and practice. Before the interview sessions, I could not have imagined what the results would be and how they would influence and affect me. They did indeed influence me and the way of thinking I had established in the course of the literature research and the work I had completed in the DBA modules up to that point. Furthermore, the interview sessions were very reflection-inducing for some of the middle managers, as described in Section 4.6, p. $127 \mathrm{ff}$. For others, I could see that the reflective aspect was partly lacking. Even as they were answering the questions, I sometimes had the feeling that they struggled to find appropriate answers. However, after I had supported them by asking more questions and providing examples from my experience and my reflections on my work, they started reflecting on their own situation. Therefore, in addition to the recommendations that are based on the answers they provided, it is also important to take into consideration the importance of the reflections, or of how to reflect, and why one should reflect, in order to improve or gain a better understanding of the situation so that the middle managers can support their staff. In December 2015, following the recommendation in first module, DB8001, to record everything in the form of a diary, I began to do so, if not on a daily basis then on a monthly basis, for new impressions and information from my environment and from the literature review. The diary helped me prepare the reflective professional development assignment since it made it easier to reflect; after the passage of time, I looked back and remembered everything in a different way, and everything became easier for me to reflect on. I could then easily split the time since starting DBA into past experience, present experience, and the future. Reflecting on this, time was of paramount importance for me as I was working in parallel in so many different capacities.

A core item in my last three years was the modules, including contact with the tutors, with my colleagues, and with the action learning set group. Added to this are all of the discussions with advisers, with my supervisors, with family members, and with work colleagues in the joint venture - all of which helped me continually develop my research topic. My supervisors 
were most encouraging during this time, pushing me to write articles, book chapters, and internal reports for work, and to continually improve my DBA thesis. I took the opportunity to publish articles internally in the company in 2016, 2017, and 2018, and have some outstanding for internal publication in 2019.

Commencing teaching at DHBW Stuttgart at Campus Horb was an exciting experience as I reflected on the time and the two semesters I taught quality management and automotive production to bachelor's students. This experience showed me how important it is to support new generations and to pass on my industry experience in order to combine theory with practical experience. The feedback from my students was constructive. They explained to me that the best classes are those that combine theory with a practical point of view; this is what they wanted to learn in order to use later in their working lives.

Even though the salary for lecturing students is lower than for working in the industry as an engineer, I have decided to continue with it after completing the DBA programme. After graduation, I want to undertake further research on the topics of change management and cultural exchange. Culture is very interesting to me as it shows how change management is lived in organisations. I want to help middle managers and their staff cope with various change processes in international settings among different cultures around the world. My aim is to make a meaningful contribution as a middle manager and to improve internally in order to reach the next step, while being a part-time consultant and continuing to work as a lecturer at a university. I frequently think about how my future will be influenced by my reflecting on my professional development in the course the DBA. 


\section{Literature}

Adler, N. J. (2002). International Dimensions of Organizational Behavior. Boston, MA: Cencage Learning.

Ahmadjian, C. L., \& Lincoln, J. R. (2001). Keiretsu, governance, and learning: Case studies in change from the Japanese automotive industry. Organization Science, 12(6), 683701.

Ala, M., \& Cordeiro, W. P. (1999). Can we learn management techniques from the Japanese Ringi process? Business Forum, 24(1/2), 22-23.

Albach, H., Meffert, H., Pinkwart, A., \& Reichwald, R. (2015). Management of permanent change. Wiesbaden, Germany: Springer Verlag.

Ali, A., \& Ivanov, S. (2015). Change management issues in a large multinational corporation: A study of people and systems. International Journal of Organizational Innovation, 8(1), 24-30.

Alvesson, M., \& Skoldberg, K. (2009). Reflexive Methodology: New Vistas for Qualitative Research. London, United Kingdom: SAGE.

Andersen, T. J. (2004). Integrating decentralized strategy making and strategic planning processes in dynamic environments. Journal of Management Studies, 41 (8): 12711299.

Andrews, C. G. (2003). Comparative analysis of management and employee job satisfaction and policy perceptions (Doctoral dissertation). University of North Texas, Texas.

Anney, V. (2014). Ensuring the Quality of the Findings of Qualitative Research: Looking at Trustworthiness Criteria. Journal of Emerging Trends in Educational Research and Policy Studies 5(2). 272-281.

Apetrei, A., Kureshi, N., Horodnic, I. (2015). When culture shapes international business. Journal of Business Research, 68, 1519-1521.

Arnold, I. (2014). Personalentwicklung von Führungskräften in Zeiten von Change (Doctoral dissertation). Johannes Gutenberg-Universität, Mainz.

Aula, P., \& Heinonen, J. (2016). The Reputable Firm: How Digitalization of Communication is Revolutionizing Reputation Management. Zürich, Switserland: Springer International Publications.

Aycan, Z., Kanungo, R. N., Mendonca, M., Yu, K. Deller, J., Stahl, G., \& Kurshid, A. (2000). Impact on culture on human resource management practices: a 10-country comparison. Applied Psychology, 49(1), 192-221.

Bakos, A., Miller, C., Packham, G., Pickernell, D., \& Brychan, T. (2016). Internal electronic 
information as a competitiveness-enhancing resource in German automobile industry suppliers. Journal of Strategic Change, 25(1), 61-80.

Barghorn, K. (2010). Einstellungen und Verhalten von Mitarbeitern in betrieblichen

Veränderungsprozessen (Doctoral dissertation). Universität Osnabrück, Osnabrück.

Retrieved from http://www.fachsymposium-

empowerment.de/Verschiedenes/Einstellungen\%20und\%20Verhalten\%20channgemana gement.pdf

Barmeyer, C. (1996). Interkulturelle Qualifikationen im Deutsch-Franzoesischen

Management kleiner und mittelstaendischer Unternehmen. St. Ingbert, Germany: Roehrig.

Bast, H. (2008). Mercedes-Benz baut ein Werk in Ungarn. Retrieved from

http://www.stern.de/auto/fahrberichte/nachrichten--mercedes-benz-mercedes-benz-bautein-werk-in-ungarn-3738674.html

Bate, P. (1997). Cultural Change, Strategien zur Änderung der Unternehmenskultur. Munich, Germany: Murmann Verlag.

Beck, U., \& Beck-Gernsheim, E. (2010). Varieties of Individualization. In M. H. Hansen \& R. Svarverud (Eds.). The rise of the individual in modern Chinese society. Copenhagen, Denmark: NIAS.

Becker, H. S., \& McCall, M. M. (1982). Symbolic Interaction and Cultural Studies. Chicago, IL: University of Chicago Press.

Becker, W., Kunz, C., \& Mayer, B. (2009). Shared Service Center: Konzeption und Implementierung in internationalen Unternehmen. Stuttgart, Germany: W. Kohlhammer Druckerei GmbH \& Co.

Beech, N., \& Macintosh, R. (2012). Managing change, enquiry \& action. New York: Kindle Edition.

Beer, M., Eisenstat, R., \& Spector, B. (1990). Why change programs don’t produce change. Harvard Business Review, 68(6), 160-164.

Bhaskar, R. (2008). A Realist Theory of Science. London, United Kingdom: Routledge.

Bellman, L. \& Gerner, H.-D. (2012). Company-level pacts for employment in the global crisis 2008/2009: First evidence from representative German establishment-level panel data. The International Journal of Human Resources, 23(16), 3375-3396.

Bendt, A. (2000). Wissenstransfer in multinationalen Unternehmen. Wiesbaden, Germany: Gabler Verlag.

Berger, P. L., \& Luckman, T. (1996). The Social Construction of Reality. London, United 
Kingdom: Penguin.

Berner, W. (2010). Change! 15 Fallstudien zu Sanierung, Turnaround, Prozessoptimierung, Reorganisation und Kulturveränderung. Stuttgart, Germany: Schäffer-Poeschel Verlag. Berner, W. (2012). Culture Change: Unternehmenskultur als Wettbewerbsvorteil. Stuttgart, Germany: Schäffer Poeschel Verlag.

Beugelsdijk, S., Kostova, T., Roth, K. (2016). An overview of Hofstede-inspired countrylevel culture research in international business since 2006. Journal of International Business Studies (2017) 48, 30-47.

Bleicher, K. (2005). Das Konzept Integriertes Management: Visionen, Missionen, Programme. Frankfurt, Germany: Campus Verlag.

Bogner, A., Littig, B., \& Menz, W. (2014). Interview mit Experten: Eine praxisorientierte Einführung. Berlin, Germany: Springer.

Bolton, G. (2005). Reflective practice: Writing and professional development. London, United Kingdom: SAGE.

Booth, S. (2015). Crisis Management Strategy: Competition and Change in Modern Enterprises. New York, NY: Routledge.

Brumer, J. (1986). Actual Minds, Possible Worlds. Cambridge, MA: Harvard University Press.

Brunner, F. J., \& Wagner, K. W. (2011). Qualitätsmanagement: Leitfaden für Studium und Praxis. Munich, Germany: Carl Hanser Verlag.

Bryman, A., \& Bell, E. (2007). Business research methods. Oxford, United Kingdom: Oxford University Press.

Burgess, A. (1982). The End of the World News: An Entertainment. London, United Kingdom: George Hutchinson.

Burghardt, M. (1997). Projektmanagement: Leitfaden für die Planung, Überwachung und Steuerung von Entwicklungsprojekten. Munich, Germany: Siemens Aktiengesellschaft Burrell, G., \& Morgan, G. (1979). Sociological Paradigms and Organizational Analysis. London, United Kingdom: Heinemann Educational Books.

Cameron, E., \& Green, M. (2015). Making Sense of Change Management: A Complete Guide to the Models, Tools and Techniques of Organizational Change. London, United Kingdom: Kogan Page Limited.

Chase, S. E. (2008). Narrative Inquiry: Multiple lenses, approaches, voices. In N. K. Denzin \& Y. S. Lincoln (Eds.), Collecting and interpreting qualitative materials. Thousand Oaks, CA: SAGE. 
Cheema, D. S. (2010). Knowledge Management: Analysis, Design and Implementation. Delhi, India: Abhishek Publications.

Cheng, P.-K., \& Fan, K. W. (2013). New Perspectives on the Research of Chinese Culture. London, United Kingdom: Springer.

Chin, G. T. (2010). China’s Automotive Modernization: The Party-State and Multinational Corporations. Basingstoke, United Kingdom: Palgrave MacMillan.

Conger, J. A. (2013). On Communication. Boston, MA: Harvard Business Review Press.

Conan, A. D. (1986). The Complete Sherlock Holmes. London, United Kingdom: Vance.

Cooper, H. \& Hedges, L.V. (1994). The Handbook of Research Synthesis. New York, NY: Russel Sage.

Crotty, M. (2015). The Foundations of Social Research. St. Leonards, NSW: SAGE.

Culture Vulture. (2016). Guanxi: The Chinese Cultural Concept. Retrieved from https://www.commisceo-global.com/blog/guanxi-the-chinese-cultural-concept

Dallas, N. (2008). How to do business in China. 24 Lessons to make working with China more profitable. New York, NY: McGraw Hill.

Deal, T. E., \& Kennedy, A. A. (2000). Corporate cultures: The rites and rituals of corporate life. Boston, MA: Perseus Books.

Deal, T. E. \& Kennedy, A. A. (2000). Corporate cultures. Retrieved on 10 March, 2016, from http://www.perseuspublishing.com

Dellner, A. (2009). Kulturdimensionen: Das Fünf-Dimensionen-Modell von Geert Hofstede. Norderstedt, Germany: GRIN Verlag.

Denison, D., Hooijberg, R., Lane, N., \& Lief, C. (2012). Leading Culture Change in Global Organizations. Hoboken, NJ: Jon Wiley \& Sons.

Deonshire-Ellis, C., Scott, A., \& Wollard, S. (2011). Setting Up Joint Ventures in China. Berlin, Germany: Springer Verlag.

Dievernich, F. E. P., Tokarski, K. O., \& Gong, J. (2015). Change management and the human factor: Advances, challenges and contradictions in organizational development. Zürich, Switzerland: Springer International Publishing.

Denison, D., Hooijberg, R., Lane, N., \& Lief, C. (2012). Leading culture change in global organizations: Aligning culture and strategy. San Francisco, CA: Jossey-Bass.

Denzin, N. K., \& Lincoln Y. S. (2000). Handbook of Qualitative Research. London, United Kingdom: SAGE.

Doerfel, L. (2012). Social Media in der internen Kommunikation. Berlin, Germany: Prismus Communications. 
Doppler, K., \& Lauterburg, C. (2008). Change Management: Den Unternehmenswandel gestalten. Bielefeld, Germany: Campus Verlag.

Drever, E. (2003). Using Semi-Structured Interviews in Small-Scale Research. Glasgow, Scotland: University of Glasgow.

Dubina, I., Ramos, S. \& Ramos, H. (2016). Culture as a Driving Force of Individual and Organizational Behavior. New York, NY: Springer Verlag.

Easterby-Smith, M., Thorpe, R., \& Jackson, R. R. (2008). Management research. London, United Kingdom: SAGE.

Eden, C., \& Huxham, C. (1996). Action research and the study of organisations. In S. R. Clegg, C. Hardy, \& W. R. Nord (Eds.), Handbook of Organisation Studies. London, United Kingdom: Sage.

Eisend, M, Evanschitzky, H. \& Gilliland, D. (2016). The Influence of Organizational and National Culture on New Product Performance, The Journal of Product Innovation Management. Volume 33, 3.

Emmett, S., \& Crocker, B. (2009). Excellence in Supplier Management: How to better manage contracts with suppliers and add value. Cambridge, United Kingdom: Cambridge Academic.

Ender, N. (2016). SharePoint 2016 für Anwender. Mainz, Germany: Rheinwerk-Verlag. Entrekin, L., \& Scott-Ladd, B. D. (2014). Human resource management and chance. New York, NY: Cenveo Publisher Services.

Ergeneli, A. (2012). A cross cultural comparison of ethical behavior in business relqted dilemmas: a comparison among Turkish, Egyptian, Kirghiz and Kazak marketing employees. Global Management Journal, 3(2), 135-147.

Evans, J. (2015). Modern analytics and the future of quality and performance excellence. Quality Management Journal, 22(4), 6-17.

Farrimond, H. (2012). Doing Ethical Research. New York, NY: Palgrave Macmillan.

Floyd, S. W., \& Wooldridge, B. 1999. Knowledge creation and social networks in corporate entrepreneurship: The renewal of organizational capability. Entrepreneurship Theory and Practice, Spring: 123-143.

Franke, S. (2010). Verhaltensorientierte Führung: Handeln, Lernen und Diversity in Unternehmen. Wiesbaden, Germany: Gabler Verlag.

Frei, A., Niemand, H, Stäuble, C., \& Wittmer, P. (2005). Change Management Prozesse und die Rolle des HRM. Retrieved from http://docplayer.org/19691665-Changemanagement-prozesse-und-die-rolle-des-hrm.html 
Fritzenschaft, T. (2014). Critical success factors of change management: An empirical research in German small and medium-sized enterprises. Wiesbaden, Germany: Springer Fachmedien.

Galletta, A. (2001). Mastering the Semi-Structured Interview and Beyond. New York, NY: New York University Press.

Gan, L. (2003). Globalization of the automobile industry in China: dynamics and barriers in greening of the road transportation. Energy policy, 31(6), 537-551.

Gattermeyer, W., \& Al-Ani, A. (2001). Change Management und Unternehmenserfolg: Grundlagen - Methoden - Praxisbeispiele. Wiesbaden, Germany: Gabler Verlag.

Garcia, J. L. V. (2015). Intercultural Competence: A conductive factor of managers' Readiness for organizational change.

Ghemawat, P. \& Reiche, S. (2011). National cultural differences and Mulitnational Business. Globalization Note Series.

Gerstner, L. V. (2002). Who says elephants can’t dance? New York, NY: Harper Collins.

Gesteland, R., \& Seyk, G. (2002). Marketing across cultures in Asia: a practical guide. Copenhagen, Denmark: Copenhagen Business School Press.

Giebel, M. (2010). Wertsteigerung durch Qualitätsmanagement: Entwicklung eines Modells zur Beschreibung der Wirkmechanismen und eines Vorgehenskonzepts zu dessen Einführung. Kassel, Germany: Kasseler Schriftenreihe Qualitätsmanagement

Glaser, L., Fourne, S. P., \& Elfring, T. (2015). Achieving strategic renewal: The multi-level influences of top and middle managers’ boundary spanning. Small Business Economics, 45(2), 305-327.

Golafshani, N. (2003). Understanding Reliability and Validity in Qualitative Research The Qualitative Report, 8 (4), 597-606.

Gomez, M., \& Bleicher, K. (1994). Unternehmerischer Wandel - Konzepte zur organisatorischen Erneuerung. Wiesbaden, Germany: Gabler.

Grochla, E. (1995). Grundlagen der organisatorischen Gestaltung. Stuttgart, Germany: Schäffer Poeschel Verlag.

Guba, E., \& Lincoln, Y. S. (1989). Fourth Generation Evaluation. London, United Kingdom: SAGE Publications.

Guba, E., \& Lincoln, Y. S. (1985). Naturalistic Inquiry. London, United Kingdom: SAGE

Guba, E., \& Lincoln, Y. S. (2016). The Constructivist Credo. New York, NY: Routledge. Guirdham, M. (2005). Communicating across cultures at work. New York, NY: Anchor. 
Haberfellner, R. (2002). Systems Engineering: Methodik und Praxis. Zürich, Switzerland: Verlag Industrielle Organisation.

Haeske, U. (2001). Beschwerden und Reklamationen managen: Kritische Kunden sind gute Kunden! Weinheim, Germany: Beltz Verlag.

Hale, R. I. (2014). How Training Can Add More Value to the Business: Industrial and Commercial Training. London, United Kingdom: Training Journal.

Hall, E. T. (1976). Beyond Culture. New York, NY: Anchor.

Hamlyn, D. W. (1995). Epistemology, history of The Oxford Companion to Philosophy. Oxford, United Kingdom: Oxford University Press.

Hansen, K. P. (2009). Kultur, Kollektiv, Nation. Passau, Germany: Stutz.

Hartwich, I. (2013). Daimler-Werk in Peking: Mercedes “made in China”. Retrieved from https://www.berliner-zeitung.de/wirtschaft/daimler-werk-in-peking-mercedes--made-inchina---3168748

Helmold, M. (2013). Establishing a best practice model of supplier relationship management (SRM) for multinational manufacturing companies in the European transportation industry. Cheltenham, United Kingdom: DBA Thesis.

Heyse, V., \& Erpenbeck, J. (2007). Kompetenzmanagement: Methoden, Vorgehen, Kode \& Kodex im Praxistest. Münster, Germany: Waxmann Verlag.

Hillman, C. (2012). Course guide for COM-205 Research Methods. Retrieved March $10^{\text {th }}$, 2016, from

http://www.librarydevelopment.group.shef.ac.uk/showcase/tutorials/lit_review/intro.ht $\underline{\mathrm{ml}}$

Hitt, M. A. \& Beamish, P. W. \& Jackson, S. E. \& Mathieu, J. E. (2007). Building theoretical and empirical bridges across levels: Multilevel research in management. Academy of Management Journal, 50: 1385-1399.

Hofstede, G. (2001). Lokales Denken, globales Handeln, Interkulturale Zusammenarbeit und globales Management. Munich, Germany: Verlag C. H. Beck.

Hofstede, G. J., \& Hofstede, G. (2005). Cultures and Organizations: Software of the Mind. New York, NY: McGraw-Hill Professional.

Hogan, S. \& Coote, L. (2014). Organizational culture, innovation, and performance: A test of Schein’s model. Journal of Business Research 67, 1609-1621.

Holian, R., \& Coghlan D. (2012). Ethical Issues and Role Duality in Insider Action Research: Challenges for Action Research Degree Programmes. Systemic Practice and Action Research, 26(5), 399-415. 
Homma, N., \& Bauschke, R. (2010). Unternehmenskultur und Führung: Den Wandel gestalten - Methoden, Prozesse, Tools. Wiesbaden, Germany: Gabler Verlag.

Inversini, S. (2005). Wirkungsvolles Change Management in Abhängigkeit von situativen Anforderungen: Organisationale Veränderungsprozesse im Spannungsfeld von betrieblichen Voraussetzungen und Umweltanforderungen unter Berücksichtigung der wirtschaftlichen, organisationsbezogenen und qualifikatorischen Erfolgskriterien (Doctoral dissertation). Humanwissenschaftlichen Fakultät der Universität Potsdam, Potsdam.

Jacobides, M., MacDuffie, J. P., \& Tae, J. (2015). Agency, structure and dominance of OEMs: Change and stability in the automotive sector. Strategic Management Journal, 37(9), 1942-1967.

Jing, C. (2006). 30 Minuten für mehr China-Kompetenz. Offenbach, Germany: GABAL Verlag.

Jost, H. R. (2003). Unternehmenskultur. Wie weiche Faktoren zu harten Fakten werden. Zürich, Switserland: Orell Fuessli Verlag.

Jung, B., Schweißer, S., \& Wappis, J. (2013). 8D und 7STEP - Systematisch Probleme lösen. Munich, Germany: Carl Hanser Verlag.

Kahn, J., Hatch, T., Fritzmaurice, J., \& Desroches, D. (2010). Federal government managerial cost accounting. Retrieved from http://www.oracle.com/us/solutions/business-intelligence/fed-gov-managerial-costaccounting-254758.pdf

Kaiser, R. (2014). Qualitative Experteninterviews: Konzeptionelle Grundlagen und Praktische Durchführung. Wiesbaden, Germany: Springer Verlag.

Kanter, R., Stein, B., \& Jick, T. (1992). The challenge of organizational change: How companies experience it and leaders guide it. New York, NY: Free Press

Keuper, F., \& Oecking, Chr. (2008). Corporate Shared Services. Wiesbaden, Germany: GWV Fachverlage.

Kim, K., Yoon, K., Cho, B., Li, L., \& Choi., B. (2016). Do all Chinese employees have the same cultural values? An exploratory investigation on differences in Chinese cultural values among state-, privately-, and US-owned firms. Personal Review, 45(5), 827-849.

Klemaltenkamp, M., \& Rohde, H. (1988). Absatzwirtschaft: Mit Kompetenzzentren Barrieren überwinden. Düsseldorf, Germany: Handelsblatt Media Group

Kluckhohn, C. (1951). The study of culture. Cambridge, United Kingdom: Harvard University Press. 
Kotter, J. (2012). Leading Change. Boston, MA: Harvard Business Review Press.

Kotter, J. (2011). On change management. Boston, MA: Harvard Business Review Press.

Kotter, J. (2006). Our iceberg is melting. London, United Kingdom: Macmillan Print.

Kotter, J., \& Cohen, D. (2002). The heart of change. Real life stories how people change their organization, Boston, MA: Harvard Business School Press.

Kotter, J., \& Heskett, J. (1992). Corporate culture and performance. New York, NY: Free Press.

Krulis-Randa, J. S. \& Ergenzinger, R. (1998). Unternehmen im Wandel - Change Management. Berlin, Germany: Springer Verlag.

Kugler, M., Sinn-Behrendt, A., Bruder,R., Baumann, G., Hodek, L. \& Niehaus, M. (2016). Empowering Corporate Ageing Management by Interconnecting Existing Data: A case study from the German Automotive Industry. Berlin, Germany: Springer Verlag.

Ksuter, J. (2011). Handbuch Projektmanagement. Dordrecht, The Netherlands: Springer.

Laozi, in the Tao Te Ching, Chapter 64. Retrieved on 10 February, 2017, from http://www.egreenway.com/taoism/ttclz64.htm

Lave, J., \& Wenger, E. (1991). Situated Learning. Legitimate Peripheral Participation. Cambridge, United Kingdom: Cambridge University Press.

Lauer, T. (2010). Change management: Grundlagen und Erfolgsfaktoren. Aschaffenburg, Germany: Springer Verlag.

Le Compte, M., \& Goetz, J. P. (1982). Problems of reliability and validity in ethnographic research. Houston, GE: Houston Independent School District \& University of Georgia.

Lehner, F. (2012). Wissensmanagement: Grundlagen, Methoden und Technische Unterstützung. Munich, Germany: Carl Hanser Verlag.

Leont'ev, A. N. (2012). Tätigkeit Bewusstsein Persönlichkeit. Berlin, Germany: Lehmann’s Media GmbH.

Lewin, K. (1946). Action Research and Minority Problems. Journal of social issues, 2(4), 3446.

Lewin, K. (1947). Frontiers in group dynamics: Concept, method and reality in social science; social equilibria and social change. San Diego, CA: Human Relations 1947.

Leitl, M., \& Sackmann, S. (2010). Unternehmenskultur als Erfolgsfaktor. Boston, MA: Harvard Business Manager.

Lihua, Z. (2013). China’s traditional cultural values. Retrieved from http://carnegietsinghua.org/2013/11/21/china-s-traditional-cultural-values-and-nationalidentity/. 
Lincoln, Y., \& Guba, E. (1985). Naturalistic Inquiry. Los Angelas, CA: SAGE

Linß, G. (2011). Qualitätsmanagement für Ingenieure. Leipzig, Germany: Carl Hanser Verlag.

Lipp, U., \& Will, H. (2008). Das grosse Workshop-Buch: Konzeption, Inszenierung und Moderation von Klausuren, Besprechungen und Seminaren. Weinheim, Germany: Beltz.

Liu, Y., \& Cohen, A. (2010). Values commitment and OCB among Chinese employees. International Journal of Intercultural Relations, 4(5), 493-506.

Luff, P., Hindmarsch, J., \& Heath, C. (2000). Workplace studies: Recovering Work Practice and Informing System Design. Cambridge, United Kingdom: Cambridge University Press.

Lorenz, H. (2017). Das Unternehmerhandbuch: Management und Controlling: Entscheidungsmethoden - Komplexitaet reduzieren, Klarheit schaffen. Retrieved on 25 February 2018, from http://dasunternehmerhandbuch.de/2010/10/18/entscheidungsmethoden-komplexitaet-reduzierenklarheit-schaffen/

Luo, Y. (2007). Guanxi and business. Trenton, NJ: World Scientific.

Luo, Y. (2010). Business and technology in China. Oxford, United Kingdom: ABC - Clio.

Luther, M. (2013). Diplomatie im Change Management. Diplomatischen Verhalten zwischen lateral interagierenden Führungskräften in Veränderungsprozessen. Munich, Germany: Rainer Hampp Verlag.

Macharzina, K., \& Wolf, J. (2008). Unternehmensführung. Wiesbaden, Germany: Springer Verlag.

Makumbe, W. (2016). Predictors of effective change management: A literature review. Academic Journals in African Journal in Business Management.

Managers Magazine (1996). The voice for middle managers. Managers Magazine, 71(1), 3-4. Mason, J. (2002). Qualitative researching. London, United Kingdom: SAGE.

McCalman, J., Paton, R., \& Siebert, S. (2016). Change Management: A Guide to Effective Implementation. London, United Kingdom: SAGE

McGurk, P. (2011). The contingent role of management and leadership development for middle managers: Cases of organizational change from the public services (Doctoral dissertation). The London School of Economics and Political Science, London.

Mantere, S., \& Aula, P. (2013). Making and braking sense. An inquiry into the reputation change. Journal of Organizational Change Management, 26(2), 340-352. 
Mason, J. (2002). Qualitative Researching. Manchester, United Kingdom: SAGE

Mast, C., Huck-Sandhu, S., \& Hubbard, M. (2006). Unternehmenskommunikation: Ein Leitfaden. Stuttgart, Germany: Lucius \& Lucius.

McCabe, D. L., Dukerich, J. M., \& Dutton, J. (1993). Value and moral dilemmas: a crosscultural comparison. Business Ethics Quarterly, 3(2), 117-130.

Meier, H. (2015). Diskussion und Debatte: Wie man in Gremien zu guten Entscheidungen kommt. Wiesbaden, Germany: Springer.

Meyer, E. (2014). The Culture Map. New York, NY: Public Affairs.

Messer, A. (1923). Geschichte der Philosophie von Kant bis Hegel. Leipzig, Germany: Verlag von Quelle \& Mener.

Mintzberg, H. (1978). Patterns in strategy formation. Management Science, 24(9): 934-948.

Mintzberg, H. (1985). Of strategies, deliberate and emergent. Strategic Management Journal, Vol 6 (3), 257-272.

Moore, R. (2015). Morphlogical Analysis Map in Software Engineering Project Management. East Carolina Univeristy. Research and creative achieve week.

Morrison, M. (2014, July 7). Kurt Lewin change theory three step model - unfreeze, change, freeze. Retrieved from https://rapidbi.com/kurt-lewin-three-step-change-theory/

Moses, J. W., \& Knutsen (2012). Ways of Knowing Competing Methodologies in Social and Political Research. Houndsmill, United Kingdom: Palgrave MacMillan.

Münstermann, T. (2011). Kulturgerechte Gestaltung von betrieblichen Veränderungsprojekten mit einem unternehmenskybernetischen Ansatz (Doctoral dissertation). Rheinisch Westfälische Technische Hochschule, Aachen.

Negyesi, P. (2011). Cars made in Hungary. Budapest, Hungary: Ceauto GmbH.

Neil, R., Wagstaff, Chr., Lewer, E., \& Lewis, R. (2016). Leader behavior, emotional intelligence and team performance at a UK government executive agency during organizational change. Journal of Change Management, 16(2), 97-122.

Neubauer, W. (2003). Organisationskultur. Stuttgart, Germany: Kohlhammer.

Neumann, A. (2012). Integrative Managementsysteme. Berlin, Germany: Springer Verlag.

Nieswandt, M. (2015). Fast cultural change: The role and influence of middle management. Hampshire, United Kingdom: Palgrave McMillan.

North, K. (2011). Wissensorientierte Unternehmensführung: Wertschöpfung durch Wissen. Wiesbaden, Germany: Gabler Verlag.

Oddou, G. R., Mendenhall, M. E., \& Stahl, G. K. (2012). Readings and cases in international human resource management and organizational behaviour. New York, NY: 
Routledge.

Ogbonna, E. (1993). Managing organisational culture: fantasy or reality? Human Resource Management Journal 3(2), 42-54.

Ogbonna, E., \& Harris, L. C. (2002). Managing organizational culture: insights from the hospitality industry. Human Resource Management Journal, 12(1), 33.

Olfert, K. (2009). Organisation. Kiehl, Germany: Kompendium der Praktischen Betriebswirtschaft.

Pappas, J. M., \& Wooldridge, B. 2007. Middle managers'divergent strategic activity: An investigation of multiple measures of network centrality. Journal of Management Studies, 44(3): 323-341.

Paton\&McCalman (2008). Change Management: A Guide to Effective Implementation. London: SAGE.

Patton, M. Q. (2002). Qualitative evaluation and research methods. Thousand Oaks, CA: Sage Publications.

Peräkylä, A. (2011). Validity in research on naturally occuring social interaction. In D. Silverman (Ed.), Qualitative Research: Theory, Method and Practice. London, United Kingdom: SAGE.

Petticrew, M. \& Roberts, H. (2006). Systematic reviews in the social sciences. Oxford, United Kingdom: Blackwell Publishing.

Pike, K. L. (1967). Language in relation to a unified theory of the structure of human behavior. Den Haag, The Netherlands: Mouton

Pircher, R. (2010). Wissensmanagement, Wissenstransfer und Wissensnetzwerke: Konzepte, Methoden und Erfahrungen. Erlangen, Germany: Publicis KommunikationsAgentur $\mathrm{GmbH}$.

Poerner, M. (2011). Chinesisch in der Fremde: Interkulturelles Rezeptwissen, kollektive Identitaetsentwuerfe und die international Expansion chinesischer Unternehmen. Münster, Germany: Wachsmann.

Pollar, A. (2005). Reflective teaching. London, United Kingdom: British Library Cataloguingin-Publication Data.

Praxenthaler, T. (2018). Business Cultural Differences between China and Germany. Norderstedt, Germany: GRIN Verlag.

Preyer, G. (2009). In China erfolgreich sein: Kulturunterschiede erkennen und ueberbruecken. Stratgien und Tipps fuer den Umgang mit chinesischen Geschaeftspartnern. Wiesbaden, Germany: Gabler Verlag. 
Przeworski, G. M. (2011). Widerstände gegen Kulturwandel in Unternehmen: Ursachen und Lösungsansätze im Change Management. Hamburg, Deutschland: Diplomica Verlag $\mathrm{GmbH}$.

Ratajczak, O. (2010). Erfolgreiches Beschwerdemanagement: Wege zu

Prozessverbesserungen und Kundenzufriedenheit. Wiesbaden, Germany: Gabler Verlag.

Rees, G. \& Hall, D. (2013). Managing Change, in Leading, Managing and Developing People by Gary Rees and Ray French. CIPD: www.cipd.co.uk/Bookstore.

Reich, H. (2010). Mit dem Geldkoffer zum Finanzamt. Retrieved from http://www.managermagazin.de/unternehmen/artikel/0,2828,676194,00html

Reiss, M., von Rosenstiel, L., \& Lanz, A. (1997). Change Management-Programme, Projekte und Prozesse. Stuttgart, Germany: USW Schriften für Führungskräfte.

Ritchey, T. (2011). Wicked Problems - Social Messes: Decision support Modelling with Morphological Analysis. Berlin, Germany: Springer.

Ritchey, T. (1998). Fritz Zwicky, Morphologie and Policy Analysis. Brussels: presented at the $16^{\text {th }}$ Euro Conference on operational analysis.

Rosenstiel, L. V., Regnet, E., \& Domsch, M. (2003). Führung von Mitarbeitern. Stuttgart, Deutschland: Schäffer-Poeschel Verlag.

Rost, M. (2014). Kompetenzmanagement und Dynamic Capabilities: Eine empirische Fallstudie bei einem Unternehmen aus der Automobilzulieferindustrie. Munich, Germany: Eul Verlag.

Ruedel, I. (2008). Workshops: Optimal vorbereiten, spannend inszenieren, professional nachbereiten. Wien, Austria: Linde.

Sackmann, S. A. (2004). Erfolgsfaktor Unternehmenskultur: Mit kulturbewusstem Management Unternehmensziele erreichen und Identifikation schaffen - 6 Best Practice-Beispiele. Wiesbaden, Germany: Gabler Verlag.

Sadri, G., \& Lees, B. (2002). Developing corporate culture as a competitive advantage. Journal of Management Development, 20(10), 853-859.

Sandelowski, M., \& Barroso, J. (2002). Reading qualitative studies. International journal of qualitative methods, 1(1), 74-108.

Sandkühler, H. J. (1991). Ontologie, Epistemologie und Methodologie. Bremen, Germany: Zentrum Philopsophische Grundlagen der Wissenschaften.

Saunders, M., Lewis, P. \& Thornhill, A. (2012). Research Methods for Business Students (6 $6^{\text {th }}$ Ed.). Harlow, United Kingdom: Pearson Education.

Schein, E. (1984). Coming to a new awareness of organizational culture. Boston, MA: Sloan 
Management Review.

Schein, E. (1985). Organizational culture and leadership. Human Resource Management Journal, 3(2) 42-54.

Schein, E. (1985). Organizational culture and leadership: A dynamic view. San Francisco, CA: Jossey-Bass.

Schein, E. (1992). Organizational culture and leadership. San Francisco, CA: Jossey-Bass.

Schein, E. (1996). Culture: The missing concept in organization studies. London, United Kingdom: SAGE

Schein, E. (1999). The corporate culture survival guide. San Francisco, CA: Jossey-Bass.

Schein, E. (2010). Organisationskultur. Bergisch Gladbach, Germany: Edition Humanistische Psychologie.

Schein, E. \& Schein, P. (2019). A New Era of Culture, Change and Leadership.

Massachusetts Institute of Technology: Management Review.

Schneier, C. E., \& Beatty, R. W. (1994). Making Culture Change Happen. New York, NY: McGraw-Hill

Schön, D. (1983). The Reflective Practioner. San Francisco, CA: Jossey Bass.

Schreiter, A. (2015). Deutsch-Chinesische Arbeitswelten: Einblicke in den interkulturellen Unternehmensalltag in Deutschland und China. Bielefeld, Germany: Transcript Verlag. Schreyögg, G. (2000). Neuere Entwicklungen im Bereich des Organisatorischen Wandels. In R. Busch (Ed.), Change Management und Unternehmenskultur, Konzepte in der Praxis. Munich, Germany: Rainer Hampp Verlag.

Schreyögg, G., \& Conrad, P. (2000). Organisatorischer Wandel und Transformation. Wiesbaden, Germany: Verlag für Sozialwissenschaften.

Schreyögg, G., \& Koch, J. (2011). Grundlagen des Managements: Basiswissen für Studium und Praxis. Cologne, Germany: Springer.

Schulte, G. (1996). KANT: Ausgewählt und vorgestellt von Günter Schulte. München, Germany: Diederichs Verlag.

Seibert, M. (2011). Enterprise Wikis: Die erfolgreiche Einfuehrung und Nutzung von Wikis in Unternehmen. Wiesbaden, Germany: Springer Fachmedien Wiesbaden GmbH.

Shaw, M. T. (2016). Social Reconstructions of the world automobile industry. New York, NY: Palgrave MacMillan.

Siegfried, P. (2015). Trendentwicklung und strategische Ausrichtung von KMUs. Cologne, Germany: EUL Verlag.

Silverman, D. (2013). Doing Qualitative Date. London, United Kingdom: SAGE 
Silverman, D. (2014). Interpreting Qualitative Data. London, United Kingdom: SAGE

Smith, P. B., \& Bond, M. H. (1993). Social Psychology across cultures: Analysis and perspectives. London, United Kingdom: Harvester Wheatsheaf.

Smith, N.-J. (2009). Achieving your Professional Doctorate. New York, NY: Open University Press.

Smith, K. (2015). Coming together is a beginning, staying together is progress, and working together is success. Corporate Citizen Magazine, 13(2), 16-22.

Southhill, W. E. (1910). The Analects of Confucius. London, United Kingdom: Oxford University Press.

Speier-Werner, P. (2006). Public change management: Erfolgreiche Implementierung neuer Steuerungsinstrumente im öffentlichen Sektor (Doctoral dissertation), Universität Hamburg, Hamburg: Deutscher Universitäts-Verlag.

Strasser, M. \& Albayrak, S. (2016). The current situation and future trends of marketplaces for mobility services. Findings from Qualitative Expert Interviews. Retrieved: https://www.researchgate.net/publication/293605683_The_Current_Situation_and_Futu re_Trends_of_Marketplaces_for_Mobility_Services_Findings_From_Qualitative_Exper t_Interviews.

Steinmann, H., \& Schreyögg, G. (2000). Management: Grundlagen der Unternehmensführung. Wiesbaden, Germany: Gabler Verlag.

Tan, J., \& Chow, I. H.-S. (2009). Isolating cultural and national influence on value and ethics: A test of competing hypotheses. Journal of Business Ethics, 88(1) 197-210.

Thommen, J.-P., \& Grösser, S. N. (2012). Organization and change management. Zürich, Switserland: Verlag Versus.

Tidd, J., Bessant, J., \& Pavitt, K. (2001). Managing Innovation: Integrating technological, market and organizational change. London, United Kingdom: John, Wiley and Sons.

Todnem, R. (2005). Organizational Change Management: A critical Review. Edinburgh: Journal of Change Management, Vol. 5, No. 4, 369-380.

Tranfield, D., Denyer, D., \& Smart, P. (2003). Towards a Methodology for Developing Evidence-Informed Management Knowledge by Means of Systematic Review. British Journal of Management, 14(3), 207-222.

Trompenaars, F. (1996). Resolving international conflict: Culture and business strategy. London, United Kingdom: Business Strategy Review.

Tooley, M. (1987). Causation: A Realist Approach. Oxford, United Kingdom: Clarendon Press. 
Tracy, S. (2010). Qualitative Quality. Eight “Big-Tent” criteria for Excellent Qualitative Research. Retrieved: http://qix.sagepub.com. Qualitative Inquiry.

Turk, Z. (2006). Construction informatics: Definition and ontology. Advanced Engineering Informatics, 20(2), 187-199.

Umstaetter, Prof. Dr. Walther (2000): Digitales Handbuch der Bibliothekswissenschaft:

Definitionen: Kommunikation. Retrieved on 10 February, 2017, from http://www.ib.huberlin.de/ wumsta/wistru/definitions/da4.html

Vahs, D., \& Weiand, A. (2013). Workbook change management: Methoden und Techniken. Stuttgart, Germany: Schäffer-Poeschel Verlag.

Van de Ven, H. (2007). Engaged scholarship: A guide for organizational and social research. New York, NY: Oxford University Press.

Ventris, G. (2004). Successful change management: The fifty key facts. London, United Kingdom: Bloomsbury Academic.

Vlasic, B., \& Stertz, B. A. (2001). Taken for a Ride: How Daimler-Benz drove off with Chrysler. New York, NY: Harper Collins Publishers.

Vygotsky, L. S. (1962): Thought and Language. Cambridge, United Kingdom: MIT Press.

Waisfisz, B. (2019). An organisational cultural perspective. Itim international: http://geerthofstede.com/culture-and-strategy.html.

Wang, K. (2015). Ana Hatlariyla Cin Kueltuerue: Cince Tuerkce. Ankara, Turkey: Sinolingua.

WFC Resources Managers quarterly (2010). Company culture is a critical driver of success. Managers quarterly, 10(1), 22-106.

Wibbeke, E. S. (2009a). Global business leadership. London, United Kingdom: Elsevier Inc.

Wibbeke, E. S. (2009b). Managing cultural differences series. Oxford, United Kingdom: Routledge.

Will, M. G. (2015). Change-Management gestalten: Pro-aktiv und im wechselseitigen Interesse Organisationen wandeln. Berlin, Germany: Wissenschaftlicher Verlag Berlin.

Wirth, I. (2006). Der Wissenstransfer in Unternehmen - das Problem der Überwindung personeller Barrieren bei der Kommunikation von implizitem Wissen. Munich, Germany: GRIN Verlag.

Wolf, C. (2018). Not lost in translation: Managerial career narratives and the construction of protean identities. Retrieved on 28 March, 2019, from https://journals.sagepub.com/doi/10.1177/0018726718778094.

Wooldridge, B., Schmid, T., W Floyd, S. (2008). The Middle Management Perspective on 
Strategy Process: Contribution, Synthesis and Future Research. Massachusetts: Journal of Management.

Yin, R. K. (2014). Case study research: Design and methods $5^{\text {th }}$ ed.. Thousand Oaks CA: SAGE.

Zerfass, A. (2014). Handbuch Unternehmenskommunikation: Strategie - Management Wertschoeopfung. Wiesbaden, Germany: Springer Gabler.

Zwicky, F. (1969). Discovery, InventioBn, Research through Morphological Approach. Ney York, NY: Macmillan. 


\section{Appendix 1: List of databases}

\begin{tabular}{ll}
\hline Name & Link to database \\
\hline Google & http://scholar.google.com/ \\
Scholar & \\
\hline E-Journals & http://web.ebscohost.com \\
\hline ABI/INFORM & http://www.proquest.com/libraries/academic/ \\
\hline Emerald & http://www.emeraldinsight.com/ \\
\hline Insight & \\
\hline Amazon & http://www.amazon.com \\
\hline Business & http://web.ebscohost.com \\
\hline Source & \\
\hline Complete & \\
\hline Environment & http://web.ebscohost.com \\
\hline Complete & http://www.springer.com \\
\hline Compendex & http://www.elsevier.de \\
\hline IEEE Journals & http://www.ieee.com \\
\hline \& Magazines & \\
\hline
\end{tabular}




\section{Appendix 2: Meta-analysis of the systematic literature review}

\begin{tabular}{|c|c|c|c|c|c|}
\hline Authors & Year of publication & Type & & Reserach questions & \\
\hline & & $\begin{array}{l}\text { B: Book } \\
\text { A: Article } \\
\text { R: Report }\end{array}$ & $\begin{array}{l}\text { Explore how managers deal } \\
\text { with changes and focus on } \\
\text { pragmatic handling in an } \\
\text { international framework }\end{array}$ & $\begin{array}{l}\text { Identify habits of 'middle } \\
\text { managers'and why do } \\
\text { managers need to re-learn } \\
\text { their habits in order to } \\
\text { transform their life or work } \\
\text { in a changing environment } \\
\end{array}$ & $\begin{array}{l}\text { Working with people in a } \\
\text { changing environment, } \\
\text { especially managing changes } \\
\text { in 'corp orate culture' that } \\
\text { relate to the behavior of } \\
\text { individual employees } \\
\end{array}$ \\
\hline $\begin{array}{l}\text { Albach, H., Meffert, H., Pinkwart, A., } \\
\text { \& Reichwald, R. }\end{array}$ & 2015 & B & 0 & 0 & O \\
\hline Ali, A., \& Ivanov, S. & 2015 & $\mathrm{R}$ & 0 & $\mathrm{O}$ & ? \\
\hline Andrews, Ch. G. & 2003 & $\mathrm{R}$ & O & - & ? \\
\hline Arnold, I. & 2014 & $\mathrm{R}$ & 0 & 0 & 0 \\
\hline Aula, P. \& Heinonen, J. & 2016 & $\mathrm{~A}$ & 0 & O & 0 \\
\hline Babcock, T., Riley, A., \& Wagner, E. & 2015 & $\mathrm{~A}$ & ? & ? & ? \\
\hline $\begin{array}{l}\text { Bakos, A., Miller, Chr., Packham, G., } \\
\text { Pickernell, D. \& Brychan, T. }\end{array}$ & 2016 & A & O & 0 & 0 \\
\hline \begin{tabular}{|l|} 
Barghorn, K. \\
\end{tabular} & 2010 & $\mathrm{R}$ & ? & 0 & 0 \\
\hline Beech, N., \& Macintosh, R. & 2012 & $\mathrm{~B}$ & 0 & 0 & ? \\
\hline Bellman, L. \& Gerner, H.-D. & 2012 & $\mathrm{~A}$ & O & $\mathrm{O}$ & 0 \\
\hline Bellman, L. \& Gerner, H.-D. & 2000 & $\mathrm{~B}$ & ? & 0 & 0 \\
\hline Berner, W. & 2010 & $\mathrm{~B}$ & ? & - & ? \\
\hline Berner, W. & 2012 & $\mathrm{~B}$ & 0 & 0 & ? \\
\hline Becker, W., Kunz, C., \& Mayer, B. & 2009 & $\mathrm{~B}$ & 0 & 0 & ? \\
\hline Bleicher, K. & 2005 & $\mathrm{~B}$ & O & 0 & ? \\
\hline Booth, S. & 2015 & $\mathrm{~A}$ & O & 0 & 0 \\
\hline Brunner, F. J., \& Wagner, K. W. & 2011 & $\mathrm{~B}$ & O & 0 & 0 \\
\hline Bryman, A., \& Bell, E. & 2007 & $\mathrm{R}$ & O & (2) & 0 \\
\hline Cameron, E. \& Green, M. & 2015 & $\mathrm{R}$ & ? & O & ? \\
\hline Cheema, D. S. & 2010 & $\mathrm{~A}$ & 0 & O & O \\
\hline Chen, T.-J., Ku, Y.-H. & 2010 & $\mathrm{R}$ & 0 & 0 & O \\
\hline Chin, G. T. & 2010 & $\mathrm{R}$ & O & - & O \\
\hline Conger, J. A. & 2013 & $\mathrm{R}$ & O & O & O \\
\hline Deal, T. E. \& Kennedy, A. A. & 2000 & A & ( & - & - \\
\hline Deal, T. E. \& Kennedy, A. A. & 2010 & $\mathrm{~B}$ & 0 & (2) & - \\
\hline Dellner, A. & 2009 & $\mathrm{~B}$ & O & O & 0 \\
\hline $\begin{array}{l}\text { Denison, D., Hooijberg, R., Lane, N., } \\
\text { \& Lief, C. }\end{array}$ & 2012 & B & 0 & $\mathbf{0}$ & 0 \\
\hline $\begin{array}{l}\text { Dievernich, F. E. P., Tokarski, K. O., } \\
\text { \& Gong, J. }\end{array}$ & 2015 & A & 0 & - & 0 \\
\hline Doppler, K., \& Lauterburg, Chr. & 2008 & $\mathrm{~B}$ & 0 & O & (9) \\
\hline Dubina, I., Ramos, S. \& Ramos, H. & 2016 & $\mathrm{~B}$ & O & 0 & O \\
\hline $\begin{array}{l}\text { Easterby-Smith, M., Thorpe, R., \& } \\
\text { Jackson, R. R }\end{array}$ & 2008 & $\mathrm{R}$ & - & - & ? \\
\hline Entrekin, L., \& Scott-Ladd, B. D. & 2014 & $\mathrm{~A}$ & O & O & ? \\
\hline Evans, J. & 2015 & $\mathrm{~A}$ & O & 0 & ? \\
\hline $\begin{array}{l}\text { Frei, A., Niemand, H, Stäuble, Ch., \& } \\
\text { Wittmer, P. }\end{array}$ & 2005 & A & 0 & 0 & 0 \\
\hline \begin{tabular}{|l|} 
Fritzenschaft, T. \\
\end{tabular} & 2014 & $\mathrm{~B}$ & O & ? & O \\
\hline \begin{tabular}{|l|} 
Garcia, J. l.V. \\
\end{tabular} & 2015 & $\mathrm{~A}$ & O & O & 0 \\
\hline Gattermeyer, W., \& Al-Ani, A. & 2001 & $\mathrm{~B}$ & 0 & 0 & 0 \\
\hline Gerstner, L. V. & 2002 & $\mathrm{~A}$ & 0 & 0 & ? \\
\hline Giebel, M. & 2010 & $\mathrm{~A}$ & 0 & O & ? \\
\hline Glaser, L., Fourne, S. \& Elfring, T. & 2015 & A & 0 & 0 & 0 \\
\hline Haeske, U. & 2001 & $\mathrm{~B}$ & 0 & 0 & ? \\
\hline Hillman, Chr. & 2012 & $\mathrm{~A}$ & O & - & O \\
\hline Hofstede, G. & 2001 & $\mathrm{~B}$ & 0 & 0 & 0 \\
\hline Homma, N. \& Bauschke, R. & 2010 & $\mathrm{~B}$ & 0 & ? & 0 \\
\hline Inversini, S. & 2005 & $\mathrm{~A}$ & O & O & 0 \\
\hline $\begin{array}{l}\text { Jacobides, M., MacDuffie, J. P. \& } \\
\text { Tae, J. }\end{array}$ & 2015 & A & 0 & 0 & 0 \\
\hline Jost, H. R. & 2003 & $\mathrm{~B}$ & 0 & 0 & 0 \\
\hline $\begin{array}{l}\text { Jung, B., Schweißer, S. , \& Wappis, } \\
\text { J. }\end{array}$ & 2013 & $\mathrm{~B}$ & 0 & 0 & 0 \\
\hline $\begin{array}{l}\text { Kahn, J., Hatch, T., Fritzmaurice, J. \& } \\
\text { Desroches, D. }\end{array}$ & 2010 & $\mathrm{R}$ & 0 & 0 & 0 \\
\hline Keuper, F. \& Oecking, C. & 2008 & $\mathrm{~B}$ & ? & 0 & 0 \\
\hline Kotter, J. & 2012 & $\mathrm{~A}$ & ? & ? & ? \\
\hline Kotter, J. & 2011 & $\mathrm{R}$ & 0 & O & O \\
\hline Kotter, J. & 2006 & $\mathrm{~A}$ & 0 & 0 & 0 \\
\hline Kotter, J. \& Cohen, D. & 2002 & $\mathrm{R}$ & 0 & - & 0 \\
\hline $\begin{array}{l}\text { Kugler, M., Sinn-Behrendt, A., } \\
\text { Bruder,R., Baumann, G., Hodek, L. } \\
\text { \& Niehaus, M }\end{array}$ & 2016 & A & 0 & 0 & 0 \\
\hline Lauer, T. & 2010 & $\mathrm{~B}$ & O & O & 0 \\
\hline
\end{tabular}




\begin{tabular}{|c|c|c|c|c|c|}
\hline Lehner, F. & 2012 & $\mathrm{~B}$ & - & ? & 0 \\
\hline Leitl, M., \& Sackmann, S. & 2010 & $\mathrm{~B}$ & 0 & 0 & 0 \\
\hline Lihua, Z. & 2013 & $\mathrm{R}$ & 0 & 0 & 0 \\
\hline Linß, G. & 2011 & A & - & 0 & 0 \\
\hline Linß, G. & 2010 & $\mathrm{~A}$ & - & 0 & 0 \\
\hline Luther, M. & 2013 & $\mathrm{~B}$ & 0 & 0 & 0 \\
\hline Macharzina, K., \& Wolf, J. & 2008 & $\mathrm{~B}$ & 0 & 0 & 0 \\
\hline Mason, J. & 2002 & $\mathrm{R}$ & 0 & 0 & 0 \\
\hline McGurk, P. & 2011 & $\mathrm{~B}$ & 0 & 0 & 0 \\
\hline Mantere, S. \& Aula, P. & 2013 & $\mathrm{~A}$ & 0 & 0 & 0 \\
\hline Morrison, M. & 2014 & $\mathrm{~A}$ & 0 & 0 & 0 \\
\hline Münstermann, T. & 2011 & $\mathrm{R}$ & 0 & 0 & 0 \\
\hline Negyesi, P. & 2011 & $\mathrm{~B}$ & 0 & 0 & 0 \\
\hline $\begin{array}{l}\text { Neil, R., Wagstaff, Chr., Lewer, E. \& } \\
\text { Lewis, R. }\end{array}$ & 2016 & A & 0 & 0 & 0 \\
\hline Neumann, A. & 2012 & $\mathrm{~B}$ & O & O & 0 \\
\hline Nieswandt, M. & 2015 & A & 0 & 0 & 0 \\
\hline North, K. & 2011 & $\mathrm{~B}$ & O & 0 & 0 \\
\hline $\begin{array}{l}\text { Oddou, G.R., Mendenhall, M. E. \& } \\
\text { Stahl, G. K. }\end{array}$ & 2012 & B & 0 & 0 & 0 \\
\hline Paton, R. A., \& McCalman, J. & 2008 & $\mathrm{~B}$ & 0 & 0 & 0 \\
\hline Petticrew, M. \& Roberts, H. & 2006 & $\mathrm{~A}$ & 0 & 0 & 0 \\
\hline \begin{tabular}{|l|} 
Pircher, R. \\
\end{tabular} & 2010 & $\mathrm{~A}$ & 0 & 0 & 0 \\
\hline Przeworski, G. M. & 2011 & $\mathrm{~B}$ & 0 & 0 & 0 \\
\hline Ratajczak, O. & 2010 & A & 0 & 0 & 0 \\
\hline $\begin{array}{l}\text { Rosenstiel, L. v., Regnet, E., \& } \\
\text { Domsch, M. }\end{array}$ & 2003 & B & 0 & - & - \\
\hline Rost, M. & 2014 & $\mathrm{~B}$ & 0 & O & 0 \\
\hline Sackmann, S. A. & 2004 & $\mathrm{~B}$ & 0 & 0 & 0 \\
\hline Sadri, G. \& Lees, B. & 2002 & $\mathrm{~A}$ & 0 & 0 & 0 \\
\hline Sandelowski, M., \& Barroso, J. & 2002 & A & 0 & 0 & 0 \\
\hline Schein, E. & 2003 & $\mathrm{~B}$ & 0 & 0 & 0 \\
\hline Schein, E. & 2010 & $\mathrm{~B}$ & 0 & 0 & 0 \\
\hline Schreyögg, G. & 2000 & $\mathrm{~B}$ & 0 & 0 & 0 \\
\hline Schreyögg, G., \& Conrad, P. & 2000 & $\mathrm{~B}$ & 0 & 0 & 0 \\
\hline Schreyögg, G., \& Koch, J. & 2011 & $\mathrm{~B}$ & 0 & 0 & 0 \\
\hline Siegfried, P. & 2015 & $\mathrm{~A}$ & 0 & 0 & 0 \\
\hline Smith, K. & 2015 & $\mathrm{~A}$ & 0 & O & 0 \\
\hline Speier-Werner, P. & 2006 & $\mathrm{R}$ & 0 & 0 & 0 \\
\hline Steinmann, H., \& Schreyögg, G. & 2000 & $\mathrm{~B}$ & 0 & - & 0 \\
\hline Thommen, J.-P., \& Grösser, S. N. & 2012 & $\mathrm{~B}$ & 0 & 0 & 0 \\
\hline Tidd, J., Bessant, J., \& Pavitt, K. & 2001 & $\mathrm{~B}$ & 0 & 0 & 0 \\
\hline Tranfield, D., Denyer, D., \& Smart, P. & 2003 & A & 0 & 0 & 0 \\
\hline Vahs, D., \& Weiand, A. & 2013 & $\mathrm{~B}$ & 0 & 0 & - \\
\hline Ventris, G. & 2004 & $\mathrm{~B}$ & 0 & 0 & 0 \\
\hline WFC Resources Managers quarterly & 2010 & $\mathrm{~A}$ & 0 & 0 & 0 \\
\hline Wibbeke, E. S. & 2009 & $\mathrm{~B}$ & 0 & 0 & 0 \\
\hline Wibbeke, E. S. & 2008 & $\mathrm{~B}$ & 0 & 0 & 0 \\
\hline Will, M. G. & 2015 & $\mathrm{~A}$ & 0 & 0 & 0 \\
\hline Wirth, I. & 2006 & $\mathrm{~B}$ & 0 & 0 & 0 \\
\hline Yin, R. K. & 2003 & A & - & - & - \\
\hline
\end{tabular}




\section{Appendix 3: Comparison of approaches in relation to research questions}

\begin{tabular}{|c|c|c|c|c|}
\hline \multirow{2}{*}{\multicolumn{2}{|c|}{ Approaches }} & \multicolumn{3}{|c|}{ Research questions } \\
\hline & & $\begin{array}{l}\text { How do German and } \\
\text { Chinese middle- } \\
\text { managers in a } \\
\text { cooperative joint } \\
\text { venture in the } \\
\text { automotive sector in } \\
\text { China cope with } \\
\text { organisational } \\
\text { changes and cultural } \\
\text { differences? }\end{array}$ & $\begin{array}{l}\text { Do German and } \\
\text { Chinese middle- } \\
\text { managers working in } \\
\text { a joint venture need } \\
\text { to learn about } \\
\text { culture and is it } \\
\text { necessary in order to } \\
\text { work in a joint } \\
\text { venture? }\end{array}$ & $\begin{array}{l}\text { Do middle managers } \\
\text { need to learn to } \\
\text { adapt their skills to } \\
\text { the culture of the } \\
\text { joint venture } \\
\text { partner's skills, } \\
\text { especially the } \\
\text { relationship-building } \\
\text { skills needed in } \\
\text { change situations? }\end{array}$ \\
\hline & Ontology & $\begin{array}{l}\text { External influences } \\
\text { can manipulate } \\
\text { managers' attitudes }\end{array}$ & $\begin{array}{l}\text { Human beings live } \\
\text { in a permanently } \\
\text { changing and } \\
\text { externally } \\
\text { determined } \\
\text { environment } \\
\end{array}$ & $\begin{array}{l}\text { Each individual staff } \\
\text { member has his/her } \\
\text { own external } \\
\text { influences which } \\
\text { he/she brings into } \\
\text { work life }\end{array}$ \\
\hline & Epistemology & $\begin{array}{l}\text { Managers are } \\
\text { affected by the } \\
\text { processes their } \\
\text { employees are } \\
\text { involved in and are } \\
\text { dependent on the } \\
\text { attitude of their staff } \\
\end{array}$ & $\begin{array}{l}\text { Managers need to } \\
\text { relearn their habits } \\
\text { connected to the } \\
\text { habits of their } \\
\text { employees who live } \\
\text { the work processes }\end{array}$ & \begin{tabular}{|l} 
Process-related \\
changes can be \\
affected through \\
possible individual \\
behavioural \\
resistance of staff \\
members \\
\end{tabular} \\
\hline & Measurability & $\begin{array}{l}\text { A process flow } \\
\text { which is actually in } \\
\text { revision and needs to } \\
\text { be changed can be } \\
\text { measurable for } \\
\text { managers, but the } \\
\text { implementation can } \\
\text { also be socially } \\
\text { identified because of } \\
\text { the intercultural } \\
\text { aspect, which is a } \\
\text { major challenge }\end{array}$ & $\begin{array}{l}\text { Habits of middle } \\
\text { managers can be } \\
\text { measurable, but to } \\
\text { identify and } \\
\text { transform them in } \\
\text { connection with a } \\
\text { changing } \\
\text { environment will be } \\
\text { a challenge in the } \\
\text { social context } \\
\text { observed for each } \\
\text { country (China/ } \\
\text { Germany) }\end{array}$ & $\begin{array}{l}\text { The epistemological } \\
\text { point of view } \\
\text { underlines the } \\
\text { measurability of } \\
\text { changes in corporate } \\
\text { culture and } \\
\text { individual behaviour }\end{array}$ \\
\hline
\end{tabular}




\begin{tabular}{|c|c|c|c|}
\hline Social aspect & $\begin{array}{l}\text { The individual } \\
\text { approach of the } \\
\text { researcher will play } \\
\text { a role in interpreting } \\
\text { the collected data } \\
\text { and seeing how } \\
\text { middle managers act }\end{array}$ & $\begin{array}{l}\text { To analyse middle } \\
\text { managers' habits, } \\
\text { the social } \\
\text { interactions must be } \\
\text { finalised relative to } \\
\text { intercultural change } \\
\text { management and } \\
\text { how they live } \\
\text { through changing } \\
\text { processes }\end{array}$ & $\begin{array}{l}\text { The social } \\
\text { intercultural aspect } \\
\text { will be not easy for } \\
\text { the researcher to } \\
\text { discover since there } \\
\text { is no interaction in } \\
\text { the observed firm } \\
\text { with the two } \\
\text { countries }\end{array}$ \\
\hline $\begin{array}{l}\text { Approach of } \\
\text { the researcher }\end{array}$ & $\begin{array}{l}\text { Interactions between } \\
\text { managers and } \\
\text { employees and the } \\
\text { development of } \\
\text { pragmatic handling } \\
\text { in changing } \\
\text { processes will affect } \\
\text { the researcher's } \\
\text { attitude }\end{array}$ & $\begin{array}{l}\text { The researcher's } \\
\text { attitude will be a part } \\
\text { of analysing and } \\
\text { forming a } \\
\text { recommendation on } \\
\text { the observed habits } \\
\text { and how middle } \\
\text { managers are willing } \\
\text { to relearn their } \\
\text { habits for a good } \\
\text { transformation } \\
\text { process with the use } \\
\text { of existing literature } \\
\text { and methods }\end{array}$ & $\begin{array}{l}\text { The researcher can } \\
\text { develop an } \\
\text { interesting analysis } \\
\text { and can put the } \\
\text { results into a } \\
\text { generalisable } \\
\text { recommendation not } \\
\text { just for the } \\
\text { automobile concern } \\
\text { but also for other } \\
\text { firms working in an } \\
\text { international context }\end{array}$ \\
\hline Methodology & $\begin{array}{l}\text { Quantitative method } \\
\text { underlines this } \\
\text { approach where an } \\
\text { existing model can } \\
\text { be confirmed }\end{array}$ & $\begin{array}{l}\text { Quantitative method } \\
\text { will not really be } \\
\text { suitable for } \\
\text { scrutinising the } \\
\text { relearning process of } \\
\text { middle managers' } \\
\text { habits in the } \\
\text { intercultural context }\end{array}$ & $\begin{array}{l}\text { Quantitative method } \\
\text { cannot really help } \\
\text { the researcher to } \\
\text { identify the focal } \\
\text { points of the } \\
\text { differences between } \\
\text { the two countries } \\
\text { and the behavioural } \\
\text { aspects of each } \\
\text { employee }\end{array}$ \\
\hline $\begin{array}{l}\text { Research } \\
\text { design }\end{array}$ & $\begin{array}{l}\text { A clearly structured } \\
\text { interview method } \\
\text { can show the right } \\
\text { measurability for } \\
\text { this research } \\
\text { approach }\end{array}$ & $\begin{array}{l}\text { The researcher must } \\
\text { find data through a } \\
\text { systematic literature } \\
\text { review, for example, } \\
\text { and must } \\
\text { contextualise these } \\
\text { data to find the right } \\
\text { measurability to } \\
\text { underline this } \\
\text { research question }\end{array}$ & $\begin{array}{l}\text { The interview study } \\
\text { will help the } \\
\text { interviewee to use } \\
\text { naturally based data } \\
\text { with the collected } \\
\text { information through } \\
\text { research }\end{array}$ \\
\hline
\end{tabular}




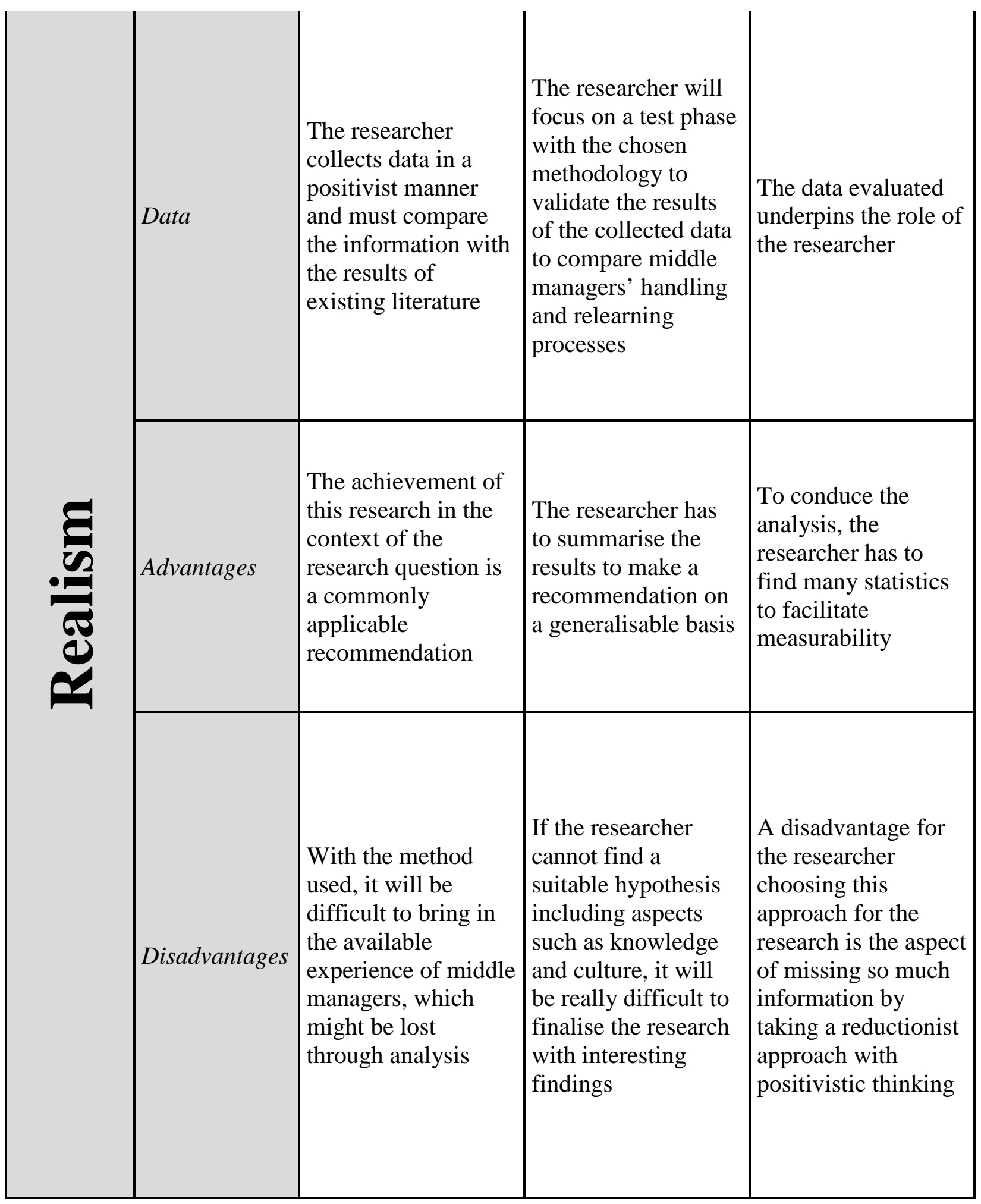




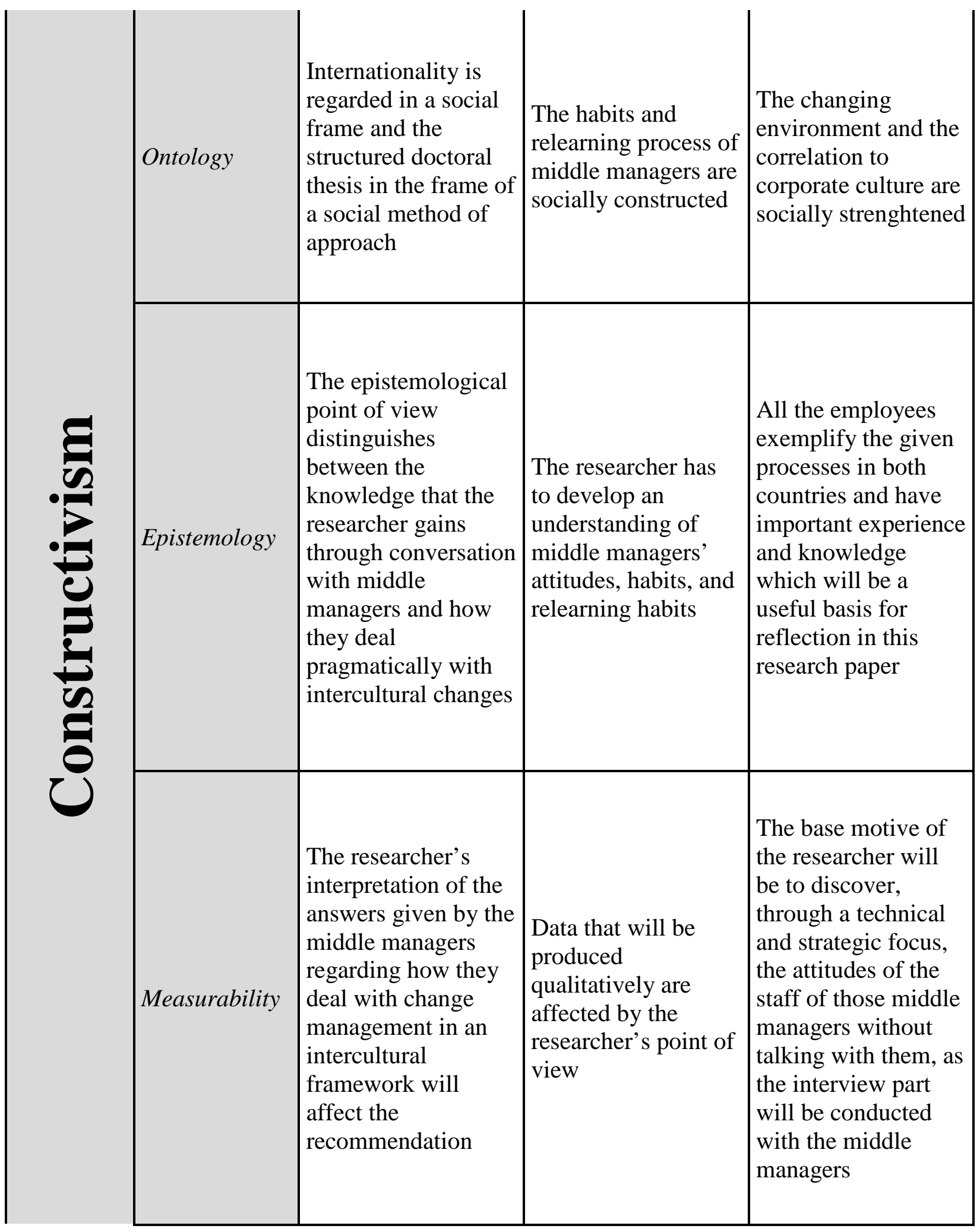




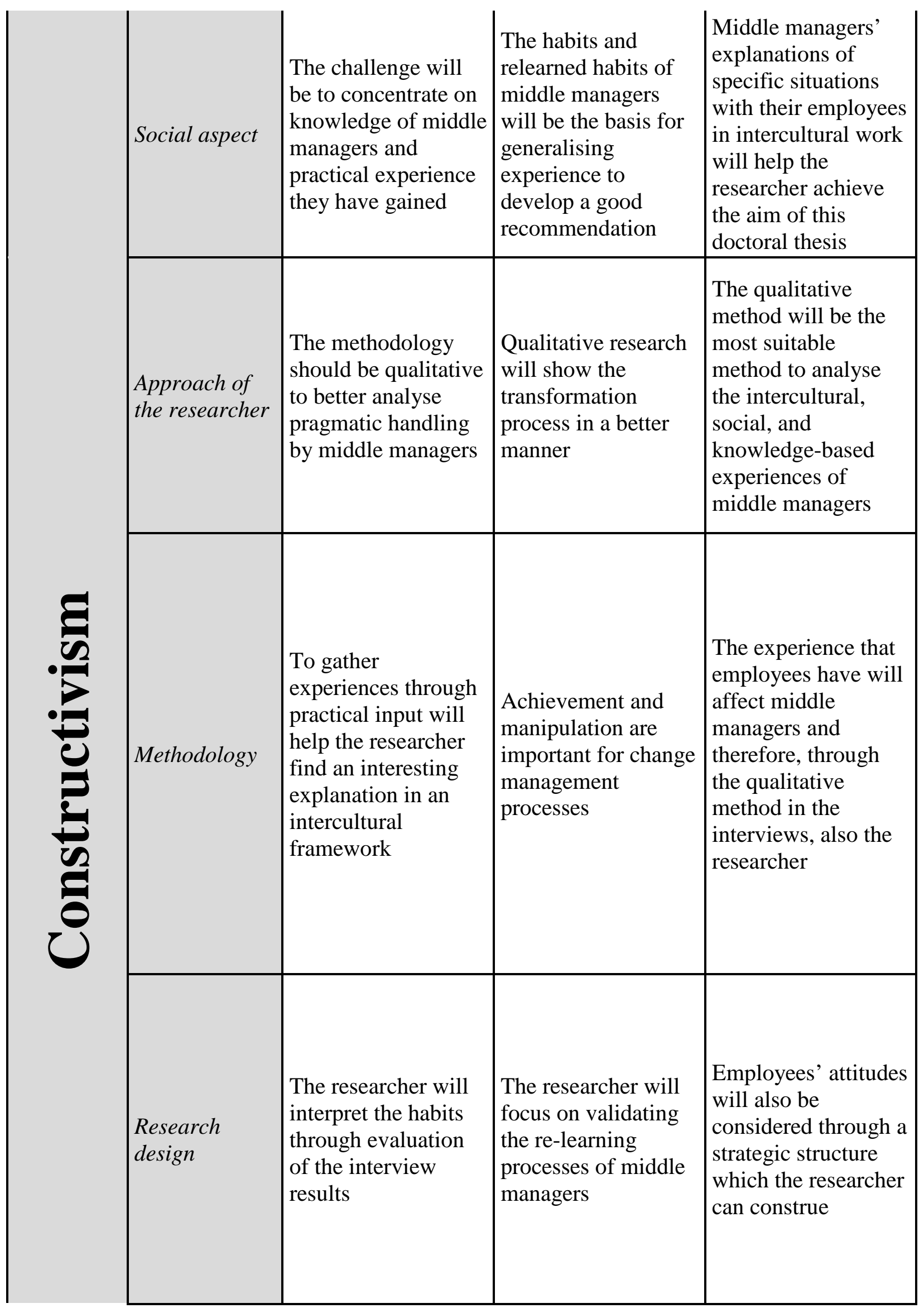




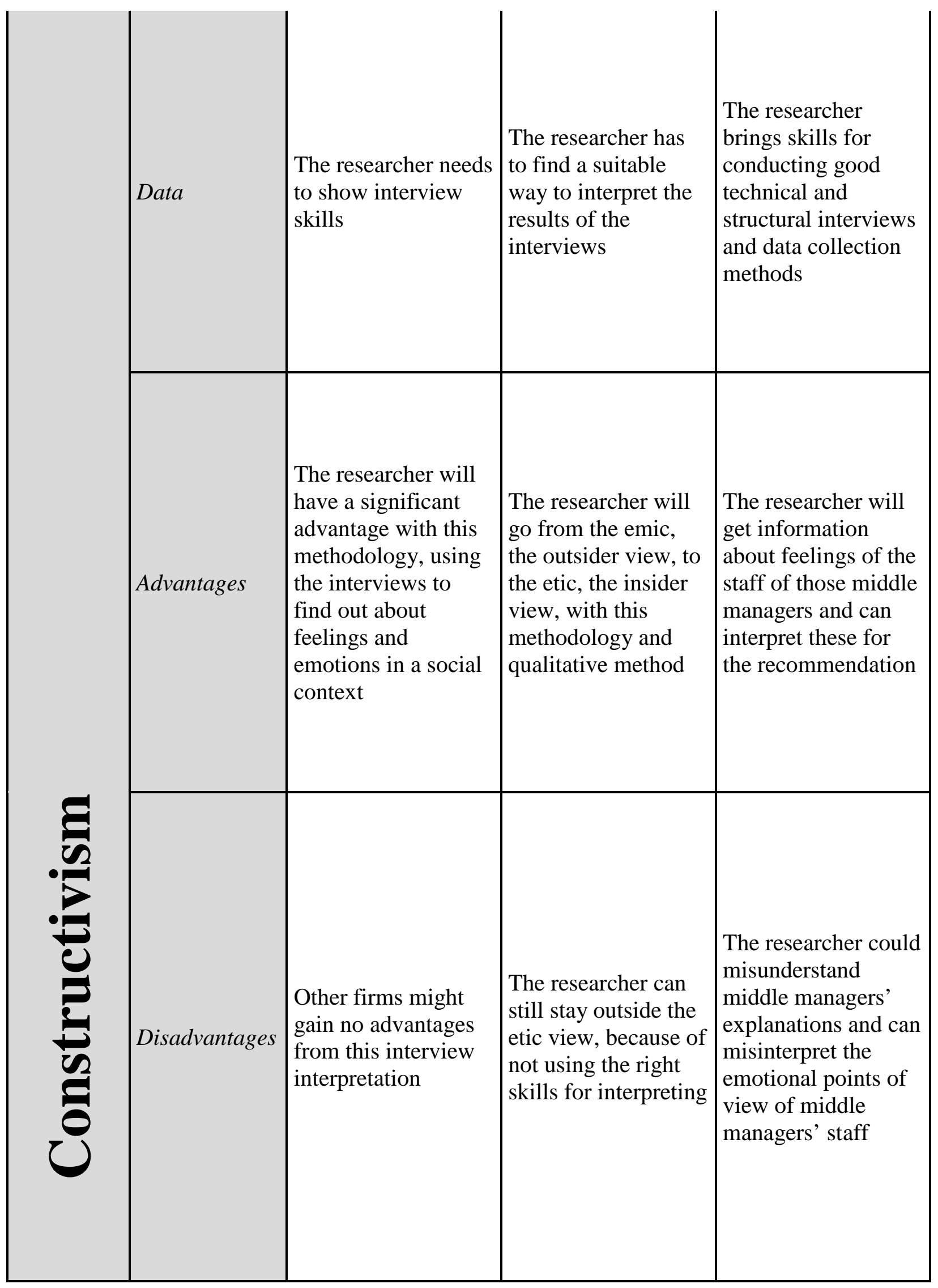




\begin{tabular}{|c|c|c|c|}
\hline Ontology & $\begin{array}{l}\text { Natural facts from } \\
\text { outside are less } \\
\text { important for } \\
\text { analysing the habits } \\
\text { of middle managers }\end{array}$ & $\begin{array}{l}\text { It is important to use } \\
\text { social aspects for } \\
\text { interpretation of } \\
\text { middle managers' } \\
\text { relearning processes }\end{array}$ & $\begin{array}{l}\text { Employee } \\
\text { involvement plays a } \\
\text { major role in this } \\
\text { methodology }\end{array}$ \\
\hline Epistemology & $\begin{array}{l}\text { Change management } \\
\text { and changing } \\
\text { processes create new } \\
\text { knowledge and } \\
\text { experience for } \\
\text { middle managers }\end{array}$ & $\begin{array}{l}\text { Middle managers' } \\
\text { attitudes are } \\
\text { important for } \\
\text { business } \\
\text { management since } \\
\text { their knowledge and } \\
\text { experience are } \\
\text { important key } \\
\text { factors for change } \\
\text { management }\end{array}$ & $\begin{array}{l}\text { All employees are } \\
\text { involved in changing } \\
\text { processes and will } \\
\text { be key in looking for } \\
\text { a solution }\end{array}$ \\
\hline Measurability & $\begin{array}{l}\text { The researcher will } \\
\text { be important for the } \\
\text { change processes } \\
\text { and analysis of the } \\
\text { view and } \\
\text { interpretation of } \\
\text { middle managers' } \\
\text { habits } \\
\end{array}$ & $\begin{array}{l}\text { Relearning means } \\
\text { motivation for a new } \\
\text { process and } \\
\text { willingness to accept } \\
\text { new views and } \\
\text { change }\end{array}$ & $\begin{array}{l}\text { Employees' } \\
\text { motivations is as } \\
\text { important as } \\
\text { researchers' } \\
\text { motivations to } \\
\text { answer the research } \\
\text { question }\end{array}$ \\
\hline Social aspect & $\begin{array}{l}\text { The research } \\
\text { methodology should } \\
\text { be action research }\end{array}$ & $\begin{array}{l}\text { Action research will } \\
\text { underline the } \\
\text { researchers' point of } \\
\text { view and the } \\
\text { relearning process } \\
\text { during changes }\end{array}$ & $\begin{array}{l}\text { An action research } \\
\text { project can be } \\
\text { interesting if the } \\
\text { middle managers } \\
\text { have the task of } \\
\text { finding a solution } \\
\text { with their staff } \\
\end{array}$ \\
\hline $\begin{array}{l}\text { Approach of } \\
\text { the researcher }\end{array}$ & $\begin{array}{l}\text { Action research will } \\
\text { be exploratory for } \\
\text { the researcher and an } \\
\text { interesting task and } \\
\text { project in practical } \\
\text { terms for the middle } \\
\text { managers }\end{array}$ & $\begin{array}{l}\text { The researcher can } \\
\text { get and find new } \\
\text { aspects of coping } \\
\text { and relearning } \\
\text { through change } \\
\text { management }\end{array}$ & $\begin{array}{l}\text { The researcher will } \\
\text { aim to improve the } \\
\text { change management } \\
\text { process through } \\
\text { interesting project } \\
\text { results }\end{array}$ \\
\hline
\end{tabular}




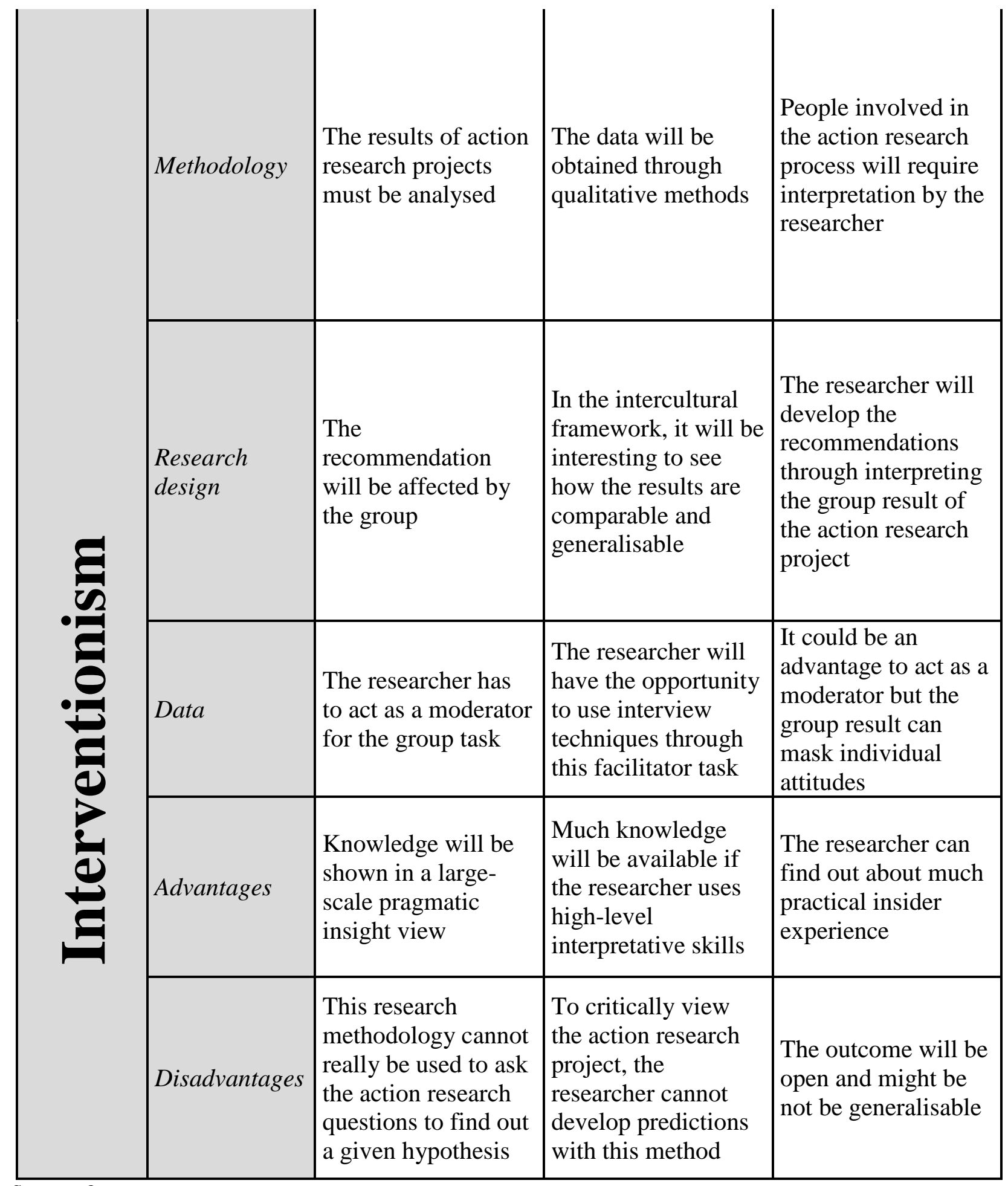




\section{Appendix 4: Questionnaire for the Pilot}

My question list included the following questions:

1) Do German and Chinese middle managers working in a joint venture need to learn about culture? Is this necessary to work in a joint venture?

2) Do middle managers need to learn to adapt their skills to the culture and skills of the joint venture partner, especially the relationship-building skills required in situations of change?

The following questions from the interviews found a strong acceptance in the pilot:

1. What do you understand by change management?

2. Why do companies change?

3. How do you live change management in your company and department? Do you think it is important? If yes, why?

4. What processes and structures do you think combine corporate culture and change management?

5. Is there anything different between the cultures of China and Germany?

6. How do change management and the cultural differences between China and Germany affect you as a middle manager? How do they affect your staff?

7. Do you have any strategic perspective or any methods you use to assist employees in coping with change?

8. Do you need to consider the culture factor in your daily work?

9. Do you need to consider the culture factor in your daily work when working with staff and partners in the joint venture in the automotive production sector?

10. What about relationship-building skills? Do you have to adapt yourself due to the cooperative joint venture and cultural differences to do a better job?

11. What do you think would help you to improve cultural understanding in the joint venture as regards change management?

12. Where do you see strengths and weaknesses in the system regarding situations that change daily when you look today at the daily working business of a middle manager?

13. If you receive new information, how do you use this and new skills in your daily working life as middle manager? 
14. What do you think would help you to improve cultural understanding in the joint venture regarding change management?

15. What do you need to support your staff to be more open and show more acceptance, rather than sometimes fearing new things and the new and changing situations in daily working life?

16. Why did you choose to be a middle manager? What was the relevant factor for you to move to this position?

17. Have you sometimes faced difficult times in the joint venture, and do you think it would be better for you to work in a company that does not work in such a cooperative joint venture with another country? 


\section{Appendix 5: Interviews with the middle managers}

\section{Middle manager interview on the topic 'Change management and cultural factors in joint-venture collaboration'}

Interview partner: Li Hua (Pseudonym)

Location: Beijing

Position: Marriage Supervisor

Date: 21.03 .2018

\section{What do you understand by change management?}

I think change management is important between $R \& D$ and production - the information flow and contact we have. In this phase, we have lots of information we have to transfer and lots of people with information, not just for planning and production, and the information needs to be shown to the relevant people and related departments or persons, to make sure that no information is missing and that no misunderstandings happen. This is the main point for change management. But working in joint venture not that easy and critical because lots of information are due to compliance issues (or sometimes I have the feeling a lot of things are just named compliant t not share and refuse easily). That's why communication and information flow is very important for my understanding and should be considered and should be made more transparent. Especially if two countries like German culture and Chinese culture work together. Chinese people tend to share and work due to good relationshipbuilding and German culture is very different because relationship tend to be not that important than rules and a working environment to be safe and strict, more bureaucratic. This is just what I think about. I don't work in R\&D but sometimes I have the feeling, if change management doesn't work out in the production environment than lots of mistakes can happen while assembling the car, that's why it is much more important for my understanding.

\section{Why do companies change?}

The technology is revolutionary and then our product and production are also changing. So, our plant, and our planning will also change because of production and new technology. Industry 4.0 is getting more and more important in manufacturing industry and intelligent manufacturing is important to improve the company, their processes, be lean, more green and safe energy while producing cars. Change is also important due to better organisational structures and also a better planning and collaboration due to the joint venture constellation. If 
everything stays stable with no change for a long time, then I have the feeling something is missing and something tends to go into the wrong direction for my understanding.

\section{How do you live change management in your company and department? Do you think it is important? If yes, why?}

For example, for production change, management is related to quality or if, for example, torque value and for process, if it is well related to the quantity we produce, if we miss some change management between related people that could have an impact on our quality. Of course, change management is very important. If no change management in our company and department, then we cannot improve on quality aspects while producing the cars. For example with the gaps in between the parts or if mistakes in the production manufacturing environment happens. Important is to have good process and live those with a good reaction process to solve the upcoming issues. Just to say, we have change management, but not really take care about and not really have a process behind to solve the issues, then change management is not lived for my understanding. And for my feeling, we need to improve on the afterwards process to solve all the issues to improve better and have less or minimized quality problems and quality issues out of the produced cars. Since, the customer should be the focus for us for whom we should produce high quality cars.

\section{What processes and structures do you think combines corporate culture and change management?}

I think, we have, for our internal team, we have shop-floor meetings and also, from team member's side and management side, we have staff meetings. And in meetings we could share our information and highlight our open issues. So, people have the same understanding of our status, and we could work together from working level and high-level management to solve issues. And also, we have tools, like a SR tool to help us to be more efficient to solve the problems with all the relevant departments together. But this tool is not implemented with the help of the change management processes, it is more a new innovation topic out of industry 4.0 implementation and being in a more digital environment for all related departments and work in a common tool together. But, I think we could do more and have better processes related to change management which also should consider culture and corporate culture of our joint venture company. 


\section{Is there any link between the different cultures of China and Germany and change management?}

I think, yes, for Chinese culture, it is more flexible in the joint venture. When I was in the other company, I had a very straight workflow process. So, I can learn more in this company due to the joint venture constellation. But sometimes you have two sides. For the next new type model car, for example, we had to apply very fast in production in production hall 1 , very fast. But for my understanding, this is not a normal process if you look back to Germany. Actually, in China, this is not a normal process, in China and in Chinese culture we work more flexible now in this joint venture situation and everybody is forced to work out everything very fast and deliver everything within the next minutes always asap. But I think this is related to culture, much more to national culture than to the culture of organizational culture. And, by the way, China is developing very fast, especially Beijing and this could be one of the reasons why, because of shorten planning and preparation or alignment times between the levels in hierarchy. Just working in an implementation and very fast decision modus.

\section{How do change management and the cultural differences between China and Germany affect you as middle manager? And how do they affect your staff?}

Generally, from my understanding, culture is not the main point for different teams and working together. It is important to find a way to deal with the open issues. This means for my understanding much more the tracking is important of all the open topics which needs to be worked out. National culture should be considered in the working collaboration but not in the change management process for my understanding.

\section{Do you have any strategic perspective or any methods you use to assist middle managers in coping with change?}

I think for equipment change management, first of all, for any equipment that is not unique but not critical, actually you need lots of experience. That's why a common tool or system to document experiences and keep it for further employees to be trained will be very good. Because lots of employees we can't keep in our company due to a good automobile market conditions in China and good salaries or other kind of reasons. First of all, you need to collect the information about the equipment and discuss this with all the related people, for example, with all the different halls. Strong communication is important. For example, also with production and maintenance, everything should be in detail discussed. For the specifications 
also, you need to go to purchase department and you need to discuss the items beforehand with your supervisor, your bosses, and all the related departments. Yes, communication is really important to have a good planning basement and a good changing process afterwards or let's say easy process for an adjustment of an equipment or further enhancement due to improvement or digital new solutions.

\section{Do you think you experience change management and cultural differences in the co- operative joint venture differently and do you have to change your attitude to cope them?}

No, I did not change my attitude. The other company I worked before was also an automotive company. I think, for an automotive company, it is less important than how you work with each other. Collaboration and communication is important. But, it depends on how you define change management as well. For my understanding change management in an automobile company and production related department is considering the part and process changes or equipment changes related processes.

Same workflows we had in the planning in German plant, but now this is a difference with the international company. I think, for communication, I need to change, because in my former company, it was not so flexible, now it is in this joint venture very important to consider compliance. Before, we did not have so many compliance issues. On the Chinese side, everything is more flexible. Before we did not have so many compliance issues that now we have in this joint venture mix. Maybe we had, but it was not so strict at the working level and also different national culture. Just Chinese employees and managers work with each other. But now, it is very important when working cross-cultural and especially with a German partner on the same side and for the needs of a German brand of automobile car which we produce in China.

\section{Do you need to consider the culture factor in your daily work when working with staff and partners in the joint venture in automotive production sector?}

For different people, of course, we should have different working methods and for production, and they are our customers. They have lots of complaints, like process and equipment should be better, and also operators and engineers complain, but this is normal. Our task is to get these complaints and solve them. We have to solve the open issues, and for the supplier, we are the customer and we must be very strict on them. So, vice versa. Cultural differences I can 
also see, if working with Chinese local suppliers and if looking to the German suppliers coming over here to Beijing to make adjustments or changes on the robots or equipments.

\section{What about relationship-building skills: do you have to adapt yourself due to the co- operative joint venture and cultural differences to do a better job?}

Sometimes, yes, I have to adapt myself. For example, in our Original Equipment Manufacturer (OEM) meetings, we could help each other, we are just not working with one another, not just colleagues, but also friends. It is not just your responsibility, sometimes it is not really clear, processes are not really clear. Good communication is very important. We are also friends. Sometimes you need your colleagues' help. So it is better also to help your colleagues, and in the other production planning team, it is very clear, if it is their responsibility, they will do it. But if there are other tasks, then they say, 'Sorry, it is not my responsibility', so it is clear for German colleagues just to do their tasks and not more. But for Chinese people, it is also OK to still work like that and support each other, even if it is not their business. This is a big national cultural difference, which I could observe so far. I think not just the Chinese side, also the German colleagues and employees need to adapt to the joint venture situation to improve together and have a better common understanding of the daily tasks and the manufacturing processes. Without any kind of adaptation to the joint venture situation, it will be very hard to cooperate.

\section{What is success-related in terms of being a middle manager working in the joint venture, if you look at change management and the leading staff?}

I think we have two directions, one is equipment and one is process. For the process, it is very clear for our process planners: we have KPIs and, for example, utilisation; we need to do at least line balancing, we need to make sure that our process is according to the KPI and this process should be practised onsite. Because, in my experience as manager in this plant, we have at the beginning very beautiful KPIs and the process looks very good, the KPIs look very good. And when we applied them to the reality, some problems happened. And I think for the new type model car, when we realise the planning in the practice, we will have some open issues. But at least, for the ramp-up process, like the milestones for the car production ramp up which we have with quality releases, we had workshops and we need to work on it on the process side. We need to check in detail all process steps in change management and solve the issues and see what we are doing with all the issues to make sure the process is in practice in the future. And for the equipment, it is more the timeline, in my understanding. If you apply 
for new equipment or you do the modification, you must to find the related issues. For example, if you apply for new equipment in marriage. At first you need to write the specification and need to align with maintenance and production as the first step and in future, when you apply for this equipment, you need to do a station readiness check, and for IT and IT system connection, you need to check everything to get the OK, and you also need to do the Q-release and modify all the PCs in Q-gate production, and you need to do the installation and get the permission and you need to ask all the related people to work together, also over the weekend, to do the commissioning to do the modification. To make sure that the modification is finished well, and the production line can work well. From the equipment side, you should have a big picture of all the related people.

\section{Where do you see strengths and weaknesses in the system regarding situations that} change daily when you look today at the daily working business of a middle manager? Why I came here 4 years ago, into this joint venture system to work together, everything in the other company worked with paper and cards. It was also an automobile company. Four years ago, we did not have any cards here to stick your working time and register. Everything was by paper. But now it is improved and really fast implemented in China. Everything has improved. Today, we have big changes with our daily work, with being paperless, for example, and this is our strength - we have working in China with Chinese culture. From my side, we still need to change, we have lots of work still to do in China. Actually, sometimes we do the work and sometimes we have equipment, with not so many benefits according to the costs. But the upper management still say 'OK, let’s get it'. In Germany, we call it industry 4.0. It is a very general topic. We buy some robots to get integrated into innovation. But, actually, you look at the costs and benefits. On the other side, it is innovation, but from the benefit side, it is like a show for me.

\section{If you receive new information, how do you use this and new skills in your daily working}

\section{life as middle manager?}

Training - we have two kinds of training. First professional skills, like system-related, working with tools and line balancing systems, it is very helpful and kind of necessary training; we share with our colleagues to improve. And on the other hand, we have training like skills of presentations and how to communicate, something like this. From my understanding, it is also very helpful, but you cannot see the benefit immediately. We know lots of communication skills, but I think everybody knows these kind of communication 
skills: listen to other quietly, be polite to one another, and so on. But, some people know it, but also can apply for these kind of training. One kind is very necessary and important, but the other kind of training, it is more just a need to apply for normal work and daily communication.

\section{What do you think would help you to improve cultural understanding in the joint} venture as regards change management?

I think any team and any company can use innovation, and the responsibility is very essential to the attitude. Because lots of open issues, for example, need to sometimes, from my experience, like regarding equipment change management, my feeling is, you need to write down all the open issues and tell all the relevant people, tell them the status and tell those next steps, get the feedback. Make it clear, who needs to do what and track the status and the people, work together and ask your colleague. Remember, if you need to attend the meetings and if you have to work on open points in your team and you are the responsible person, you need to solve the open points in time.

\section{What do you need to support your staff to be more open and show more acceptance,} rather than sometimes fearing new things and the new and changing situations in daily working life?

I think, for new things coming up, first of all, I change something that is not so good. But, from my understanding, no matter for locals or colleagues from Germany like me, for both sides, you need to know everything has two sides, you just need to figure out what is the benefit and what are the costs and prepare well. Accept it if the benefit is more than the costs and if you can see a business case behind. Then accept it, and when you do the judgment, at least you need to understand what this is and what is the new change. If new changes come up, I talk to the staff-level and tell them or explain them to understand it, compare the benefit and costs and figure it out, what could happen when changes comes up? That's it, I think. But, some colleagues on middle management level sometimes do more with workshops and teambuildings. I don't really know if this helps. I just try to have a good conversation and a good communication top down in my staff meetings.

Why did you choose to be a middle manager? What was the relevant factor for you to move to this position? 
I think everyone wants to change to a better position, because I have more co-operation work and more responsibility. I have worked before as planner for years and I think it is good for me to see new opportunities to improve myself. To earn more money and to develop myself into a new direction, like leadership skills and to learn how to communicate and work out with team-members to improve together. I wanted to have better conditions as well for my whole life and being integrated into management level to also be integrated in the decisions and get more information than on staff-level.

\section{Have you sometimes faced difficult times in the joint venture, and do you think it would be better for you to work in a company that does not work in such co-operative joint venture with another country?}

Actually, I think, the joint venture is good for us. In my former company, every month we worked with much more pressure and they were more focused on no training, just working. Here, the company supports more people. A lot of training is provided here in this jointventure company. China is more flexible. I think it is because of the joint venture that a lot of training is offered. Now, we have half-half situation: it is not just a German company or just a Chinese company, yes, we are in China, but for me it is half-half. And I think Chinese employees get offered more training. And I think respect is better. In Germany, you can change from department to department. Here, in China, it is not like that, but due to the joint venture situation, it is becoming more and more open with the help of German colleagues, and you can observe more respect regarding the employees and normal staff members. 
Middle manager interview on the topic 'Change management and cultural factors in joint-venture collaboration'

Interview partner: Anna Klein (Pseudonym)

Location: Beijing

Position: Production Hall 2 Supervisor

Date: 06.03.2018

\section{What do you understand by change management?}

Series New Type is change management for me. Series New Type means if you get a new product and you want to integrate the New Type Model after the ramp-up time into a series production. In series production you get part changes, and this is change management for me in my role here as supervisor in production department. This means, I need to think about integrating the parts change related into the process in manufacturing stations and also have a good communication behind for all related departments as well for my colleagues and employees to implement the new changed processes or parts or equipment related changes. But change management could also mean if looking to leadership related topics how to deal with regularly changing conditions, changing processes or organisational changes.

\section{Why do companies change?}

I just have worked for this company so far. I can’t compare with other companies. But I think, efficiency, and also, it is a market request. To develop the company. To improve, to have new ideas and efficient improvements. But also if thinking about industry 4.0 this could be also a need of a company why it needs to be change. Or also reorganizational changes to save headcount and money. I think companies need to change. If no change, this means no improvement, no adaptation to the market needs with new type developed cars for customers. Not just the product also, the development of employees is related to changing conditions. Everything is related to change. And change is required and mandatory in every single company not just in a joint venture collaboration for my understanding.

\section{How do you live change management in your company and department? Do you think it is important? If yes, why?}

I think it is important because we are following production changes and to prepare manufacturing changes. This is daily work and sometimes it is huge work. A lot of people, especially high management level always forget this point of view. Change management is lived daily and always, but if managers do not think about it or integrate change management 
in their daily processes then it can be lost and forgotten, and especially in a joint venture it can cause bad results.

\section{What processes and structures do you think combine corporate culture and change management?}

Right now, the processes and structures are good, but still we still have some deviations and some different points between German plant and here within the joint venture. Right now, it is starting to Series management (production of vehicle in series production, after the ramp-up phase of a new vehicle which comes into the market), it is important to implement the new type. To improve, we have many points, if you look into the production. Especially we should do in China much more regarding industry 4.0. Since we live in the joint venture constellation and live in two different corporate cultures and need to understand each others corporate culture to live and work together one combined solution and structure it is mandatory.

\section{Is there any link between the different cultures of China and Germany and change management?}

We have some differences, but most of the time we focus on local production. I think in the middle management level definitely working with employees of those two different national cultures, it is required to have an understanding for the national culture and should be considered in the change management processes if changes come up.

\section{How do change management and the cultural differences between China and Germany affect you as middle manager? And how do they affect your staff?}

I think the culture does not affect me so much; in our company, we already have a complete process work flow. One side is that we want to optimise our company, but on one side, we track the German company from Germany. The process from Germany, but also the culture, even if it is living here in our company. Because most of the people here are local. We want to find the good side from the German plant, like processes, and we want to find the good points; and even from process and culture, then we want to bring it over. The cultural differences here we cannot change, but we can try to optimise.

Do you have any strategic perspective or any methods you use to assist middle managers in coping with change? 
I think to integrate one type of car to the other hall is much easier. A good decision, but just my point of view. One standard car to bring to the other hall. Here we currently have one standard car. We have only a very low and a very high option car. It must be much difficult to integrate the car here. But in the other hall, it would be very easy to integrate and change the production there. This is, from my point of view, much better.

From project management side, to integrate in China a totally different type of car, will show the German central department, as a showcase that it is possible and China could make it as first plant all over the world possible. This is a great change and chance for us working in China Germans and Chinese managers together, how up more and get the opportunity to grow more.

\section{Do you think you experience change management and cultural differences in the co- operative joint venture differently and do you have to change your attitude to cope them?}

Just my idea, but I don't know very well. If new types cars, like preparing the car for the ramp up, if the planning is finished and the timelines for new projects to implement, you can combine them. But if the car ramp up starts later, during that time you cannot let do the planner other tasks. And all the people from the planning side and project side, they cannot cover it. The capacity and the headcount issue is also important.

From my point of view, some of the people's attitude needs to change, some employees attitude needs to change, but not all of them. Normally, from my side, I will introduce the current situation and the situation in the future. Try to let them understand the situation. A long time ago, the project changed really often, even ramp up-times, not even at the same level and we have big different changes from jut now to later. This does not happen like this in the central German plant as, but in China it is really common to have a lot of changes in short times, without talking in detail about before and preparing the staff to the new situation. Something which needs to be better and I think it needs to be improved if you look to upper management. This they should definitely think about and make it better.

\section{Do you need to consider the culture factor in your daily work when working with staff and partners in the joint venture in automotive production sector?}

Yes, it is very important to consider cultural factors. We lose a lot of local staff here onsite due to many different reasons. They quit and they go really fast, we cannot build up professional know how as German colleagues can do in the central headquarter due to better 
working conditions. This is a point we should definitely think about how to improve regarding our staff in the joint venture and find a way together with both partners of the joint venture.

\section{What about relationship-building skills: do you have to adapt yourself due to the co- operative joint venture and cultural differences to do a better job?}

Yes, very important to have a good relationship. It is even more important in Joint Venture Company. From my point of view, I just look and observe. I think German colleagues and Chinese colleagues, they have many similar points while working. But the cultural differences help sometimes. Such as, if we have time, we want to have some dinner together, or we want to go somewhere together to have a party, or just go together outside to walk in the park. We talk together, everybody likes it the same. And if I think about the daily working day, and the working style, there are some differences, working with German colleagues, you can speak up directly and learn from them and they can discuss it on the working level and also vice versa I can learn from my Chinese middle management colleagues how to work with Chinese staff and as well learn to improve in leadership behaviours. On the Chinese side, you maybe should consider what they think and you cannot discuss everything directly. You can just start to discuss some points but not everything. This is the main difference.

\section{What is success-related in terms of being a middle manager working in the joint venture, if you look at change management and the leading staff?}

I think I need two points, I need a good team, or I have to build up a good team. The other one is, I need to work on myself. Like I have some things that are not good enough. I have to develop myself. I need to gain more knowledge, which I am currently missing. I would need some kind of training, one is management training and the other one is how to communicate efficiently and how to control the project. Right now, we have a similar training discussion with our manager's schedule, like our German colleagues have in German headquarter plant. We discuss the points and join some training until the end of the year. Of course, in every department or company change management plays a role, but I think in a joint venture constellation you need to adapt to each others culture or even in China the Chinese partner needs to adapt or improve in some processes to learn from the central headquarter and gain the standards. 


\section{Where do you see strengths and weaknesses in the system regarding situations that}

change daily when you look today at the daily working business of a middle manager?

OK, just from my point of view. The company right now, if we look back, the company is growing really fast. Five years ago, the joint venture had changes every year. They had three to four year model changes, now we have, right now, like 24 or nearly 30. This one is really a big change, and also the capacity and ability. Also, other departments they are growing really fast. And weak points are technical inputs, which are missing. Such as, we have one new product, we plan to produce it here in China. And product information and other information, like Failure Mode and Effect Analysis (FMEA) and how to control the quality. This is really missing in China. This is something we have to talk about with the German central plant and my colleagues in the central to get the same standards. Such as process - we still have many bugs and some functions in the system or like ergonomic issues we should consider in production for the operators, for me still not so smart. Operators and engineers still spend so much time on it. IT needs to support on this one. German IT especially. Currently as I heard local IT is having no German Expats, since they have centralized the IT department in German plant and call it Center of Competence (CoC) which should be able to support each international production place out of the central place. If this is the right solution, I am not really sure about. It is better like we have it and live it today in production. To keep a high standard and get the main standards into the joint venture, it is important to have Expatriates onsite in the joint venture who join the teams to support onsite and live for a couple of years here in China. This is a much better working collaboration model in a joint venture company.

\section{If you receive new information, how do you use this and new skills in your daily working} life as middle manager?

Normally, we have shop-floor meetings three times a week, and also meetings with related departments, like different production teams. We have some personal discussions and meetings or even on the phone, it depends on the topic. But I share some interesting points and share information with them, and we discuss how we can make it together. Or how we can get training, for example. Open communication culture is very important. Sometimes I have the feeling, I have so much pressure from upper management and so many tasks that I just focus on the important facts for our daily processes and do not really talk in detail about the changes which might be important for staff level. But this is enhancement and improvement on leadership behaviour I think 


\section{What do you think would help you to improve cultural understanding in the joint venture as regards change management?}

I think only we have the cultural problems sometimes. And for me these are very small. I sit together with my employees and we compare together why we have differences and compare the benefits together. My employees are just Chinese but we get support on one process planner from German side. Why we have to do it like this. And we talk about it so that the operator or engineer can understand. We very often have situations like this. We sit together and, for example, try to solve some bottleneck problems in the stations out in production line. Not everybody likes these kind of situations, but we have to discuss them - why do we have to do like this, and which way is the better way we have to go together? At the beginning I had the feeling, it is very hard to work with Chinese employees together since they act differently than German employees and they are not really openly talking about everything openly and also about their feelings and what they think. But I think since I am here already a while, they are getting more and more familiar with me and regarding trust as well.

\section{What do you need to support your staff to be more open and show more acceptance, rather than sometimes fearing new things and the new and changing situations in daily working life?}

My team, we are working for this plant on a lot of Job per Hour (JPH) ramp ups, but we have some days that we sit together and discuss and share ideas. And we write it down on the white board and discuss it. And also, I explain the targets and also some requirements about the upcoming time of the ramp up. From the beginning, everybody think we cannot achieve it. Since last year we had a big changing times. And also, I know that some people did not want to do it and they feared. I let them write the requests from their side. What they think is very important, and this time which condition and good job they need to do. If they need me to clarify some target issues, then I try to support them and discuss this with my managers and with other production leaders. Some leaders I am very familiar with them, I talk personally with them and we align together what we can do to cope with the different upcoming changes we need to face with our staff. During the ramp-up times, it is very hard to discuss and also I discussed this with my guys one by one to find a way to solve the issues we need to face. And finally, we get one plan, maybe this plan is not so deep and detailed, and not the same for each station. But still it was prepared. For example, one time we just focussed on one production line, the group leader did not want to do it, then the other leader wanted to try; we started with him and explained the results to the other leader who did not want to do it. And 
then we explained him and showed that we started at the same time with both the leaders, and then we explained that the issue is in his line, and finally the leader who did not want to accept the change, needed to do something. For me, it is kind of a pressure situation. When the group leader is pressured, then they will push their people and it will work, and I don't have so much time to do the work on top of the other supervisor. We all have a lot of pressure, but without we cannot move sometimes forward. This is the feeling I have in the culture in China and working in the joint venture constellation in Beijing plant. That without pressure it is not working. Sometimes we have some bottleneck stations with two different group lines in production and it is very hard to discuss. Then I go to the planners one by one to discuss the problem. I think the supervisor is a very important function in our joint venture company. Each planner is responsible for each production line in my team. Without me, the next upper management step would be our manager who has many production halls without the direct supervisor sitting with the team directly close to the production hall and lines. It would be impossible to solve the daily product issues we face.

\section{Why did you choose to be a middle manager? What was the relevant factor for you to move to this position?}

I think everybody is working for a better life, better work. I think to be a supervisor was my next step several years ago. I wanted to develop myself, before I was an engineer. First, be the best engineer and then next step. I want to get more challenges and have a better work condition. Learn more and develop myself in leadership behaviour to reach the next milestone in my professional working life.

\section{Have you sometimes faced difficult times in the joint venture, and do you think it would be better for you to work in a company that does not work in such co-operative joint venture with another country?}

Before I come to this company, I was working for the headquarter in Germany. I don't have any problems with joint venture. I like to work for this company. But I think I really often faced difficult times because of the two different corporate cultures. And the different national cultures behind. In the headquarter change management is been lived totally different, employees are getting involved much more and a long planning period is beforehand when starting to change things or organisational structures. 
Appendix 6: Morphological box for building a concept of collaboration in joint venture and enhance a culture of learning due to change management

\begin{tabular}{|l|l|l|l|}
\hline \multirow{2}{*}{ Attribute } & \multicolumn{3}{c|}{ Communication concept } \\
\cline { 2 - 4 } & Characteristic 1 & Characteristic 2 & Characteristic 3 \\
\hline Occasion & comprehensive & task employee & \\
\hline Centrality & central & decentral & peripheral \\
\hline Direction & downward & upward & horizontal \\
\hline Formalization grade & formal & informal & \\
\hline Media and channels & verbally & printed & electronically \\
\hline
\end{tabular}

Table 14: Morphological box: Communication concept 1

\begin{tabular}{|l|l|l|l|}
\hline \multirow{2}{*}{ Attribute } & \multicolumn{3}{c|}{ Communication concept } \\
\cline { 2 - 4 } & Characteristic 1 & Characteristic 2 & Characteristic 3 \\
\hline Occasion & comprehensive & task employee & \\
\hline Centrality & central & decentral & peripheral \\
\hline Direction & downward & upward & horizontal \\
\hline Formalization grade & formal & informal & \\
\hline Media and channels & verbally & printed & electronically \\
\hline
\end{tabular}

Table 15: Morphological box: Communication concept 2

\begin{tabular}{|l|l|l|l|}
\hline \multirow{2}{*}{ Attribute } & \multicolumn{3}{c|}{ Communication concept } \\
\cline { 2 - 4 } & Characteristic 1 & Characteristic 2 & Characteristic 3 \\
\hline Occasion & comprehensive & task employee & \\
\hline Centrality & central & decentral & peripheral \\
\hline Direction & downward & upward & horizontal \\
\hline Formalization grade & formal & informal & \\
\hline Media and channels & verbally & printed & electronically \\
\hline
\end{tabular}

Table 16: Morphological box: Communication concept 3 


\begin{tabular}{|l|l|l|l|}
\hline \multirow{2}{*}{ Attribute } & \multicolumn{3}{c|}{ Communication concept } \\
\cline { 2 - 4 } & Characteristic 1 & Characteristic 2 & Characteristic 3 \\
\hline Occasion & comprehensive & task employee & \\
\hline Centrality & central & decentral & peripheral \\
\hline Direction & downward & upward & horizontal \\
\hline Formalization grade & formal & informal & \\
\hline Media and channels & verbally & printed & electronically \\
\hline
\end{tabular}

Table 17: Morphological box: Communication concept 4

\begin{tabular}{|l|l|l|l|}
\hline \multirow{2}{*}{ Attribute } & \multicolumn{3}{c|}{ Communication concept } \\
\cline { 2 - 4 } & Characteristic 1 & Characteristic 2 & Characteristic 3 \\
\hline Occasion & comprehensive & task employee & \\
\hline Centrality & central & decentral & peripheral \\
\hline Direction & downward & upward & horizontal \\
\hline Formalization grade & formal & informal & \\
\hline Media and channels & verbally & printed & electronically \\
\hline
\end{tabular}

Table 18: Morphological box: Communication concept 5

\begin{tabular}{|l|l|l|l|}
\hline \multirow{2}{*}{ Attribute } & \multicolumn{3}{c|}{ Communication concept } \\
\cline { 2 - 4 } & Characteristic 1 & Characteristic 2 & Characteristic 3 \\
\hline Occasion & comprehensive & task employee & \\
\hline Centrality & central & decentral & peripheral \\
\hline Direction & downward & upward & horizontal \\
\hline Formalization grade & formal & informal & \\
\hline Media and channels & verbally & printed & electronically \\
\hline
\end{tabular}

Table 19: Morphological box: Communication concept 6 


\begin{tabular}{|l|l|l|l|}
\hline \multirow{2}{*}{ Attribute } & \multicolumn{3}{c|}{ Communication concept } \\
\cline { 2 - 4 } & Characteristic 1 & Characteristic 2 & Characteristic 3 \\
\hline Occasion & comprehensive & task employee & \\
\hline Centrality & central & decentral & peripheral \\
\hline Direction & downward & upward & horizontal \\
\hline Formalization grade & formal & informal & \\
\hline Media and channels & verbally & printed & electronically \\
\hline
\end{tabular}

Table 20: Morphological box: Communication concept 7

\begin{tabular}{|l|l|l|l|}
\hline \multirow{2}{*}{ Attribute } & \multicolumn{3}{c|}{ Communication concept } \\
\cline { 2 - 4 } & Characteristic 1 & Characteristic 2 & Characteristic 3 \\
\hline Occasion & comprehensive & task employee & \\
\hline Centrality & central & decentral & peripheral \\
\hline Direction & downward & upward & horizontal \\
\hline Formalization grade & formal & informal & \\
\hline Media and channels & verbally & printed & electronically \\
\hline
\end{tabular}

Table 21: Morphological box: Communication concept 8

\begin{tabular}{|l|l|l|l|}
\hline \multirow{2}{*}{ Attribute } & \multicolumn{3}{c|}{ Communication concept } \\
\cline { 2 - 4 } & Characteristic 1 & Characteristic 2 & Characteristic 3 \\
\hline Occasion & comprehensive & task employee & \\
\hline Centrality & central & decentral & peripheral \\
\hline Direction & downward & upward & horizontal \\
\hline Formalization grade & formal & informal & \\
\hline Media and channels & verbally & printed & electronically \\
\hline
\end{tabular}

Table 22: Morphological box: Communication concept 9 


\begin{tabular}{|l|l|l|l|}
\hline \multirow{2}{*}{ Attribute } & \multicolumn{3}{c|}{ Communication concept } \\
\cline { 2 - 4 } & Characteristic 1 & Characteristic 2 & Characteristic 3 \\
\hline Occasion & comprehensive & task employee & \\
\hline Centrality & central & decentral & peripheral \\
\hline Direction & downward & upward & horizontal \\
\hline Formalization grade & formal & informal & \\
\hline Media and channels & verbally & printed & electronically \\
\hline
\end{tabular}

Table 23: Morphological box: Communication concept 10

\begin{tabular}{|l|l|l|l|}
\hline \multirow{2}{*}{ Attribute } & \multicolumn{3}{c|}{ Communication concept } \\
\cline { 2 - 4 } & Characteristic 1 & Characteristic 2 & Characteristic 3 \\
\hline Occasion & lomprehensive & task employee & \\
\hline Centrality & central & decentral & peripheral \\
\hline Direction & downward & upward & horizontal \\
\hline Formalization grade & formal & informal & \\
\hline Media and channels & verbally & printed & electronically \\
\hline
\end{tabular}

Table 24: Morphological box: Communication concept 11

\begin{tabular}{|l|l|l|l|}
\hline \multirow{2}{*}{ Attribute } & \multicolumn{3}{c|}{ Communication concept } \\
\cline { 2 - 4 } & Characteristic 1 & Characteristic 2 & Characteristic 3 \\
\hline Occasion & comprehensive & task employee & \\
\hline Centrality & central & decentral & peripheral \\
\hline Direction & downward & upward & horizontal \\
\hline Formalization grade & formal & informal & \\
\hline Media and channels & verbally & printed & electronically \\
\hline
\end{tabular}

Table 25: Morphological box: Communication concept 12 


\begin{tabular}{|l|l|l|l|}
\hline \multirow{2}{*}{ Attribute } & \multicolumn{3}{c|}{ Communication concept } \\
\cline { 2 - 4 } & Characteristic 1 & Characteristic 2 & Characteristic 3 \\
\hline Occasion & comprehensive & task employee & \\
\hline Centrality & central & decentral & peripheral \\
\hline Direction & downward & upward & horizontal \\
\hline Formalization grade & formal & informal & \\
\hline Media and channels & verbally & printed & electronically \\
\hline
\end{tabular}

Table 26: Morphological box: Communication concept 13

\begin{tabular}{|l|l|l|l|}
\hline \multirow{2}{*}{ Attribute } & \multicolumn{3}{c|}{ Communication concept } \\
\cline { 2 - 4 } & Characteristic 1 & Characteristic 2 & Characteristic 3 \\
\hline Occasion & comprehensive & task employee & \\
\hline Centrality & central & decentral & peripheral \\
\hline Direction & downward & upward & horizontal \\
\hline Formalization grade & formal & informal & \\
\hline Media and channels & verbally & printed & electronically \\
\hline
\end{tabular}

Table 27: Morphological box: Communication concept 14

\begin{tabular}{|l|l|l|l|}
\hline \multirow{2}{*}{ Attribute } & \multicolumn{3}{c|}{ Communication concept } \\
\cline { 2 - 4 } & Characteristic 1 & Characteristic 2 & Characteristic 3 \\
\hline Occasion & comprehensive & task employee & \\
\hline Centrality & central & decentral & peripheral \\
\hline Direction & downward & upward & horizontal \\
\hline Formalization grade & formal & informal & \\
\hline Media and channels & verbally & printed & electronically \\
\hline
\end{tabular}

Table 28: Morphological box: Communication concept 15 


\begin{tabular}{|l|l|l|l|}
\hline \multirow{2}{*}{ Attribute } & \multicolumn{3}{c|}{ Communication concept } \\
\cline { 2 - 4 } & Characteristic 1 & Characteristic 2 & Characteristic 3 \\
\hline Occasion & comprehensive & task employee & \\
\hline Centrality & central & decentral & peripheral \\
\hline Direction & downward & upward & horizontal \\
\hline Formalization grade & formal & informal & \\
\hline Media and channels & verbally & printed & electronically \\
\hline
\end{tabular}

Table 29: Morphological box: Communication concept 16

\begin{tabular}{|l|l|l|l|}
\hline \multirow{2}{*}{ Attribute } & \multicolumn{3}{c|}{ Communication concept } \\
\cline { 2 - 4 } & Characteristic 1 & Characteristic 2 & Characteristic 3 \\
\hline Occasion & comprehensive & task employee & \\
\hline Centrality & central & decentral & peripheral \\
\hline Direction & downward & upward & horizontal \\
\hline Formalization grade & formal & informal & \\
\hline Media and channels & verbally & printed & electronically \\
\hline
\end{tabular}

Table 30: Morphological box: Communication concept 17

\begin{tabular}{|l|l|l|l|}
\hline \multirow{2}{*}{ Attribute } & \multicolumn{3}{c|}{ Communication concept } \\
\cline { 2 - 4 } & Characteristic 1 & Characteristic 2 & Characteristic 3 \\
\hline Occasion & comprehensive & task employee & \\
\hline Centrality & central & decentral & peripheral \\
\hline Direction & downward & upward & horizontal \\
\hline Formalization grade & formal & informal & \\
\hline Media and channels & verbally & printed & electronically \\
\hline
\end{tabular}

Table 31: Morphological box: Communication concept 18 


\begin{tabular}{|l|l|l|l|}
\hline \multirow{2}{*}{ Attribute } & \multicolumn{3}{c|}{ Communication concept } \\
\cline { 2 - 4 } & Characteristic 1 & Characteristic 2 & Characteristic 3 \\
\hline Occasion & comprehensive & task employee & \\
\hline Centrality & central & decentral & peripheral \\
\hline Direction & downward & upward & horizontal \\
\hline Formalization grade & formal & informal & \\
\hline Media and channels & verbally & printed & electronically \\
\hline
\end{tabular}

Table 32: Morphological box: Communication concept 19

\begin{tabular}{|l|l|l|l|}
\hline \multirow{2}{*}{ Attribute } & \multicolumn{3}{c|}{ Communication concept } \\
\cline { 2 - 4 } & Characteristic 1 & Characteristic 2 & Characteristic 3 \\
\hline Occasion & comprehensive & task employee & \\
\hline Centrality & central & decentral & peripheral \\
\hline Direction & downward & upward & horizontal \\
\hline Formalization grade & formal & informal & \\
\hline Media and channels & verbally & printed & electronically \\
\hline
\end{tabular}

Table 33: Morphological box: Communication concept 20

\begin{tabular}{|l|l|l|l|}
\hline \multirow{2}{*}{ Attribute } & \multicolumn{3}{c|}{ Communication concept } \\
\cline { 2 - 4 } & Characteristic 1 & Characteristic 2 & Characteristic 3 \\
\hline Occasion & comprehensive & task employee & \\
\hline Centrality & central & decentral & peripheral \\
\hline Direction & downward & upward & horizontal \\
\hline Formalization grade & formal & informal & \\
\hline Media and channels & verbally & printed & electronically \\
\hline
\end{tabular}

Table 34: Morphological box: Communication concept 21 


\begin{tabular}{|l|l|l|l|}
\hline \multirow{2}{*}{ Attribute } & \multicolumn{3}{c|}{ Communication concept } \\
\cline { 2 - 4 } & Characteristic 1 & Characteristic 2 & Characteristic 3 \\
\hline Occasion & comprehensive & task employee & \\
\hline Centrality & central & decentral & peripheral \\
\hline Direction & downward & upward & horizontal \\
\hline Formalization grade & formal & informal & \\
\hline Media and channels & verbally & printed & electronically \\
\hline
\end{tabular}

Table 35: Morphological box: Communication concept 22

\begin{tabular}{|l|l|l|l|}
\hline \multirow{2}{*}{ Attribute } & \multicolumn{3}{c|}{ Communication concept } \\
\cline { 2 - 4 } & Characteristic 1 & Characteristic 2 & Characteristic 3 \\
\hline Occasion & comprehensive & task employee & \\
\hline Centrality & central & decentral & peripheral \\
\hline Direction & downward & upward & horizontal \\
\hline Formalization grade & formal & informal & \\
\hline Media and channels & verbally & printed & electronically \\
\hline
\end{tabular}

Table 36: Morphological box: Communication concept 23

\begin{tabular}{|l|l|l|l|}
\hline \multirow{2}{*}{ Attribute } & \multicolumn{3}{c|}{ Communication concept } \\
\cline { 2 - 4 } & Characteristic 1 & Characteristic 2 & Characteristic 3 \\
\hline Occasion & comprehensive & task employee & \\
\hline Centrality & central & decentral & peripheral \\
\hline Direction & downward & upward & horizontal \\
\hline Formalization grade & formal & informal & \\
\hline Media and channels & verbally & printed & electronically \\
\hline
\end{tabular}

Table 37: Morphological box: Communication concept 24 


\begin{tabular}{|l|l|l|l|}
\hline \multirow{2}{*}{ Attribute } & \multicolumn{3}{c|}{ Communication concept } \\
\cline { 2 - 4 } & Characteristic 1 & Characteristic 2 & Characteristic 3 \\
\hline Occasion & comprehensive & task employee & \\
\hline Centrality & central & decentral & peripheral \\
\hline Direction & downward & upward & horizontal \\
\hline Formalization grade & formal & informal & \\
\hline Media and channels & verbally & printed & electronically \\
\hline
\end{tabular}

Table 38: Morphological box: Communication concept 25

\begin{tabular}{|l|l|l|l|}
\hline \multirow{2}{*}{ Attribute } & \multicolumn{3}{c|}{ Communication concept } \\
\cline { 2 - 4 } & Characteristic 1 & Characteristic 2 & Characteristic 3 \\
\hline Occasion & comprehensive & task employee & \\
\hline Centrality & central & decentral & peripheral \\
\hline Direction & downward & upward & horizontal \\
\hline Formalization grade & formal & informal & \\
\hline Media and channels & verbally & printed & electronically \\
\hline
\end{tabular}

Table 39: Morphological box: Communication concept 26

\begin{tabular}{|l|l|l|l|}
\hline \multirow{2}{*}{ Attribute } & \multicolumn{3}{c|}{ Communication concept } \\
\cline { 2 - 4 } & Characteristic 1 & Characteristic 2 & Characteristic 3 \\
\hline Occasion & comprehensive & task employee & \\
\hline Centrality & central & decentral & peripheral \\
\hline Direction & downward & upward & horizontal \\
\hline Formalization grade & formal & informal & \\
\hline Media and channels & verbally & printed & electronically \\
\hline
\end{tabular}

Table 40: Morphological box: Communication concept 27 


\begin{tabular}{|l|l|l|l|}
\hline \multirow{2}{*}{ Attribute } & \multicolumn{3}{c|}{ Communication concept } \\
\cline { 2 - 4 } & Characteristic 1 & Characteristic 2 & Characteristic 3 \\
\hline Occasion & comprehensive & task employee & \\
\hline Centrality & central & decentral & peripheral \\
\hline Direction & downward & upward & horizontal \\
\hline Formalization grade & formal & informal & \\
\hline Media and channels & verbally & printed & electronically \\
\hline
\end{tabular}

Table 41: Morphological box: Communication concept 28

\begin{tabular}{|l|l|l|l|}
\hline \multirow{2}{*}{ Attribute } & \multicolumn{3}{c|}{ Communication concept } \\
\cline { 2 - 4 } & Characteristic 1 & Characteristic 2 & Characteristic 3 \\
\hline Occasion & comprehensive & task employee & \\
\hline Centrality & central & decentral & peripheral \\
\hline Direction & downward & upward & horizontal \\
\hline Formalization grade & formal & informal & \\
\hline Media and channels & verbally & printed & electronically \\
\hline
\end{tabular}

Table 42: Morphological box: Communication concept 29

\begin{tabular}{|l|l|l|l|}
\hline \multirow{2}{*}{ Attribute } & \multicolumn{3}{c|}{ Communication concept } \\
\cline { 2 - 4 } & Characteristic 1 & Characteristic 2 & Characteristic 3 \\
\hline Occasion & comprehensive & task employee & \\
\hline Centrality & central & decentral & peripheral \\
\hline Direction & downward & upward & horizontal \\
\hline Formalization grade & formal & informal & \\
\hline Media and channels & verbally & printed & electronically \\
\hline
\end{tabular}

Table 43: Morphological box: Communication concept 30 


\begin{tabular}{|l|l|l|l|}
\hline \multirow{2}{*}{ Attribute } & \multicolumn{3}{c|}{ Communication concept } \\
\cline { 2 - 4 } & Characteristic 1 & Characteristic 2 & Characteristic 3 \\
\hline Occasion & Comprehensive & task employee & \\
\hline Centrality & central & decentral & peripheral \\
\hline Direction & downward & upward & horizontal \\
\hline Formalization grade & formal & informal & \\
\hline Media and channels & verbally & printed & electronically \\
\hline
\end{tabular}

Table 44: Morphological box: Communication concept 31

\begin{tabular}{|l|l|l|l|}
\hline \multirow{2}{*}{ Attribute } & \multicolumn{3}{c|}{ Communication concept } \\
\cline { 2 - 4 } & Characteristic 1 & Characteristic 2 & Characteristic 3 \\
\hline Occasion & comprehensive & task employee & \\
\hline Centrality & central & decentral & peripheral \\
\hline Direction & downward & upward & horizontal \\
\hline Formalization grade & formal & informal & \\
\hline Media and channels & verbally & printed & electronically \\
\hline
\end{tabular}

Table 45: Morphological box: Communication concept 32

\begin{tabular}{|l|l|l|l|}
\hline \multirow{2}{*}{ Attribute } & \multicolumn{3}{c|}{ Communication concept } \\
\cline { 2 - 4 } & Characteristic 1 & Characteristic 2 & Characteristic 3 \\
\hline Occasion & comprehensive & task employee & \\
\hline Centrality & central & decentral & peripheral \\
\hline Direction & downward & upward & horizontal \\
\hline Formalization grade & formal & informal & \\
\hline Media and channels & verbally & printed & electronically \\
\hline
\end{tabular}

Table 46: Morphological box: Communication concept 33 


\begin{tabular}{|l|l|l|l|}
\hline \multirow{2}{*}{ Attribute } & \multicolumn{3}{c|}{ Communication concept } \\
\cline { 2 - 4 } & Characteristic 1 & Characteristic 2 & Characteristic 3 \\
\hline Occasion & comprehensive & task employee & \\
\hline Centrality & central & decentral & peripheral \\
\hline Direction & downward & upward & horizontal \\
\hline Formalization grade & formal & informal & \\
\hline Media and channels & verbally & printed & electronically \\
\hline
\end{tabular}

Table 47: Morphological box: Communication concept 34

\begin{tabular}{|l|l|l|l|}
\hline \multirow{2}{*}{ Attribute } & \multicolumn{3}{c|}{ Communication concept } \\
\cline { 2 - 4 } & Characteristic 1 & Characteristic 2 & Characteristic 3 \\
\hline Occasion & Comprehensive & task employee & \\
\hline Centrality & central & decentral & peripheral \\
\hline Direction & downward & upward & horizontal \\
\hline Formalization grade & formal & informal & \\
\hline Media and channels & verbally & printed & electronically \\
\hline
\end{tabular}

Table 48: Morphological box: Communication concept 35

\begin{tabular}{|l|l|l|l|}
\hline \multirow{2}{*}{ Attribute } & \multicolumn{3}{c|}{ Communication concept } \\
\cline { 2 - 4 } & Characteristic 1 & Characteristic 2 & Characteristic 3 \\
\hline Occasion & Comprehensive & task employee & \\
\hline Centrality & central & decentral & peripheral \\
\hline Direction & downward & upward & horizontal \\
\hline Formalization grade & formal & informal & \\
\hline Media and channels & verbally & printed & electronically \\
\hline
\end{tabular}

Table 49: Morphological box: Communication concept 36 


\section{Appendix 7: DB8004: Research methods assignment and Analysis DB8004}

\section{A Dissertation title}

Change management and cultural factors: A study of German and Chinese individual behaviour in joint venture between German and Chinese cooperation in the automobile companies.

\section{B Research questions}

This study focuses on the most appropriate way to determine a methodological approach, and to offer recommendations.

This paper poses the following research questions:

1) How do middle managers deal with organisational changes in joint venture cooperation under extremely short product ramp-up time in automotive sector in China and Germany?

2) Why do middle managers need to re-learn their skills in order to transform their life or work in a changing environment working in joint venture cooperation between Chinese managers and German managers?

3) How do middle managers take decisions in a changing environment, especially managing changes in a corporate culture that relate to the behaviour of their employees connected to the collaboration between Chinese and German employees?

\section{Research paradigm}

The objective of this thesis is to provide relevant support for middle managers on how to behave and to deal with employees during change management projects in the automotive industry in two different locations and with two different cultures, producing cars for the same brand during periods of short product ramp-up times.

The researcher is an idealist in her ontological stance. The particular thinking of each individual contitutes, for her, a collective reality. Change management reflects the enormous influence of culture. The various social aspects and the relations between different languages lead her to be a constructivist in the chosen epistemology. The author will use, through the interpretation method, the social context and the social outcomes of different cultural viewpoints, as these are quite different for each of the countries under consideration regarding the challenges and the pressure to produce cars in a short ramp-up production time. The paper 
will uncover some of the major aspects of the two different cultures in the same industrial sector and will show the different threads of the social context. The semi-structured interview method used in qualitative research will help the ethical issue to remain anonymous, as interview partners discover in-depth information that will support the researcher in making recommendations for middle managers.

In the following the author identifies the principle methods of obtaining data, as well as the type of data. She will select the most suitable method for this study and will present and analyse the data, including a theoretical framework. 